
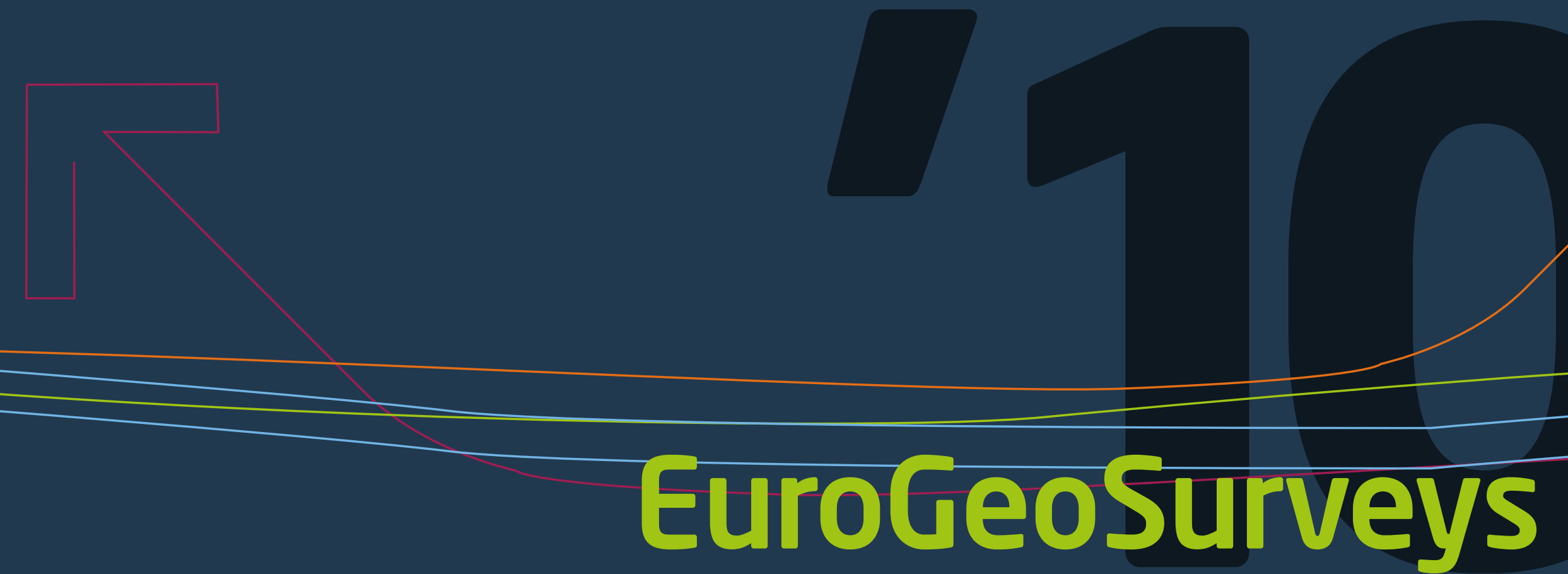
\title{
ANNUAL REPORT \\ EuroGeosurveys
}

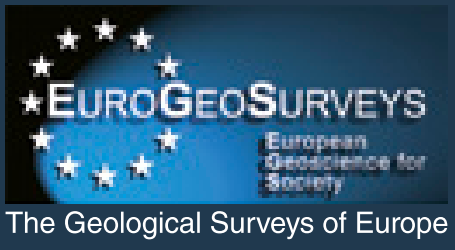




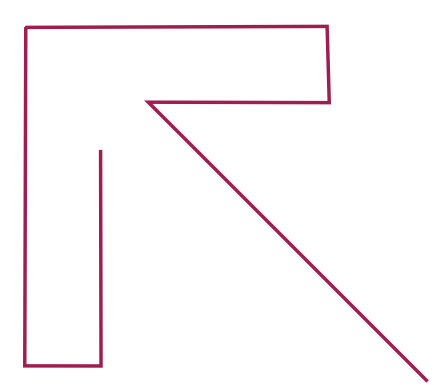

\section{EGS in Brief}

EuroGeoSurveys is a non-profit making organisation of the Geological Surveys of Europe, the national institutions responsible for geological inventory, monitoring, knowledge and research. Our principal purpose is to provide geoscientific knowledge that underpins European policies and regulations for the security, health and prosperity of society. In our day-to-day activities, we contribute to the merging of economic, environmental and social agendas.

We also facilitate networking among our members and promote their specific activities and projects.

\section{Geological Survey organisations from across Europe}

WE ARE ACTIVE IN

Marine Geology

Earth Observation

Geochemistry

GeoEnergy

Water Resources

Mineral Resources

Spatial Information - INSPIRE

Carbon Capture and Storage
A workforce that includes thousands of geoscientists at the service of European citizens

\section{Pioneering research} for Society's benefit since 1971 


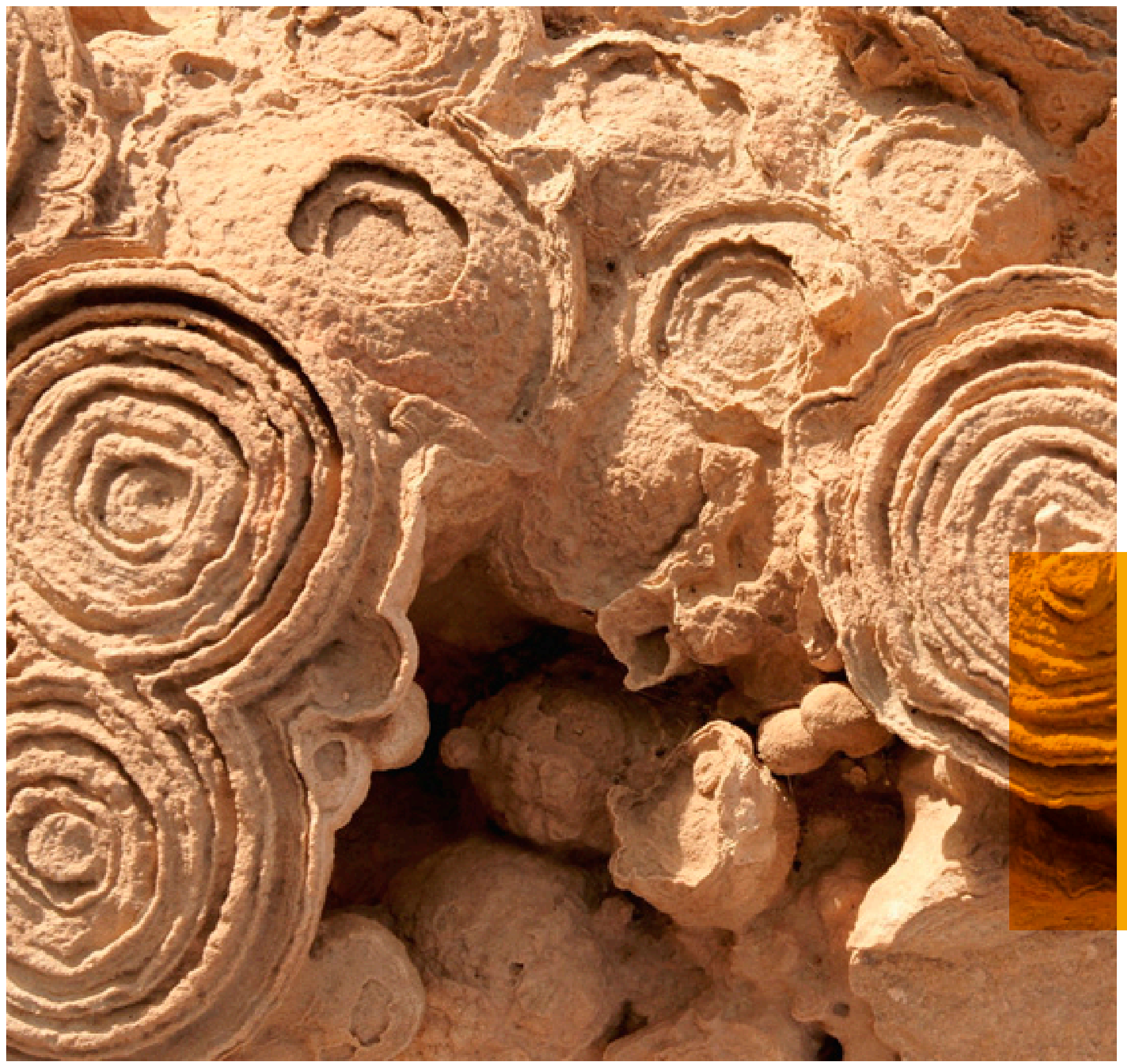




\title{
Л Conversation with Marko Komac
}

\author{
DIRECTOR OF GEOLOGICAL SURVEY OF SLOVENIA - EUROGEOSURVEYS PRESIDENT 2011-2012
}

Respected reader,

With the variety of fields that EuroGeoSurveys covers through its members, the national Geological Surveys of 32 European countries, it is hard to encompass all of them in just one page and write an absolutely unbiased overview of activities we have undertaken in 2010. It is even harder to address all societal issues related to Earth sciences or vice versa, address all Earth-related issues that have shaped 2010. Hence I will focus on the most obvious area that appeals to the wider public geohazards.

On the contrary to the general public's perception geohazards are more than just a short list of few natural processes. Geologists have listed more than twenty of them. Despite the fact that I am a geologist myself, I will, for the purpose of this introductory text to the EGS Annual Report 2010, stick to only the most infamous ones - earthquakes, volcanic eruptions, floods and landslides. These events have noticeably disrupted our daily routines in 2010, not only in Europe but globally. Last year will undoubtedly be remembered by the eruption of Eyjafjallajökull, the Icelandic volcano that paralysed almost all air traffic in the Northern hemisphere for more than a week.

Roughly 10 million travellers were affected, more than 100,000 flights cancelled and the economic loss of airlines summed up to more than 1.7 billion Euros. Luckily the eruption claimed no casualties. Less fortunate were 386 people that were killed by the eruption of Mount Merapi in Indonesia. In addition to these eruption casualties, 370 more were killed by tsunami waves which were initiated by the earthquake that preceded the volcano's eruption. Earthquakes such as those in Haiti, Chile, Sumatra and China claimed approximately 230,000 lives. Landslides took less in comparison, but the toll of roughly 2160 lives was still significant. The deadliest geohazard in Europe in 2010 were floods that caused at least 140 deaths, while globally the number of casualties due to floods reached several thousands. These events have pointed out that humans are powerless against the awesome force of Nature. Overall, natural disasters and catastrophes in 2010 have caused more than 260,000 casualties and, according to re-insurance agencies, financial losses worldwide of 170 billion Euros.

The question concerning whether these events, or at least some of them, could be forecasted and hence avoided always lurks somewhere in the human imagination. While for earthquakes only potential locations can be pre-defined, for floods and landslides the general location and the time frame of occurrence can be forecasted, up to several days in advance. In the case of volcanoes a good monitoring system helps to predict almost the exact time of eruption. It is still obvious that the most effective counter-measure to geohazards is prevention - either with engineering solutions or even better, with the avoidance of inhabiting areas exposed to geohazards. While it is not that simple for existing populated areas, it is the most useful tool for planning future settlements.

It is a matter of debate whether the number of geohazard events has increased in recent years. It is most probably true that the number of disastrous events has increased, but one should always be careful how to interpret this trend as the term "disastrous event" is of a highly subjective nature. This increase could be the cause of population growth and hence denser population in some exposed areas, recent colonisation of more exposed areas, better global media coverage of events, loss of a connection to the land due to the modern way of life and hence a lack of judgement as to whether an event is a normal geological process or one of extreme proportions, rise of property values and hence rise of damage costs etc., or a combination of several of them. One thing is certain - society needs to do more to lower its exposure level. This could be achieved by better education and public awareness, by imposing legislation constraints, by introducing innovative insurance schemes, and maybe even by listening to the Earth's heartbeat.

Geohazards are events with their origins in the Earth's dynamics that bring the most devastation to the contemporary civilisation. Yet, we - geologists - consider them as natura processes that have, are and will shape societies for epochs to come. Our society needs to be reminded again and again by geologists that we live in a dynamic, lively planet that gives and takes, creates and destroys. Since their beginnings the evolutions of civilisations have been governed by Earth's dynamic. This is an inevitable fact which we need to respect into the future. And who is more competent than geologists to help society understand, adapt to, and live with geohazards? You will find out in the following pages, although I'm sure you already know the answer.

I wish you an exciting and thought-provoking read of the EuroGeoSurveys Annual Report 2010

Marko Komac

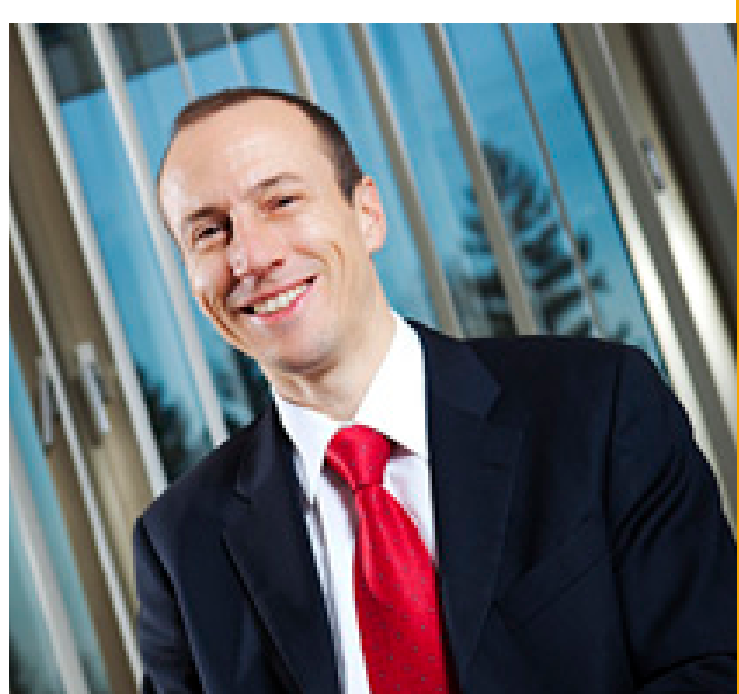




\section{Л Key People}

WORKING TOGETHER TO REACH OUR GOALS

Expert knowledge at the disposal of all European citizens, institutions, companies, media, universities,

THE EXECUTIVE COMMITTEE is the primary decision-making body. It implements the strategy formulated by the General Assembly of Members and makes proposals for future actions.

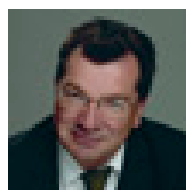

President

John Ludden

British Geological Survey

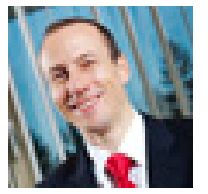

Vice-President

Marko Komac

Geological Survey of Slovenia

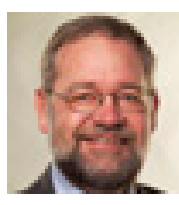

Treasurer

Johnny Fredericia

Geological Survey of Denmark

and Greenland

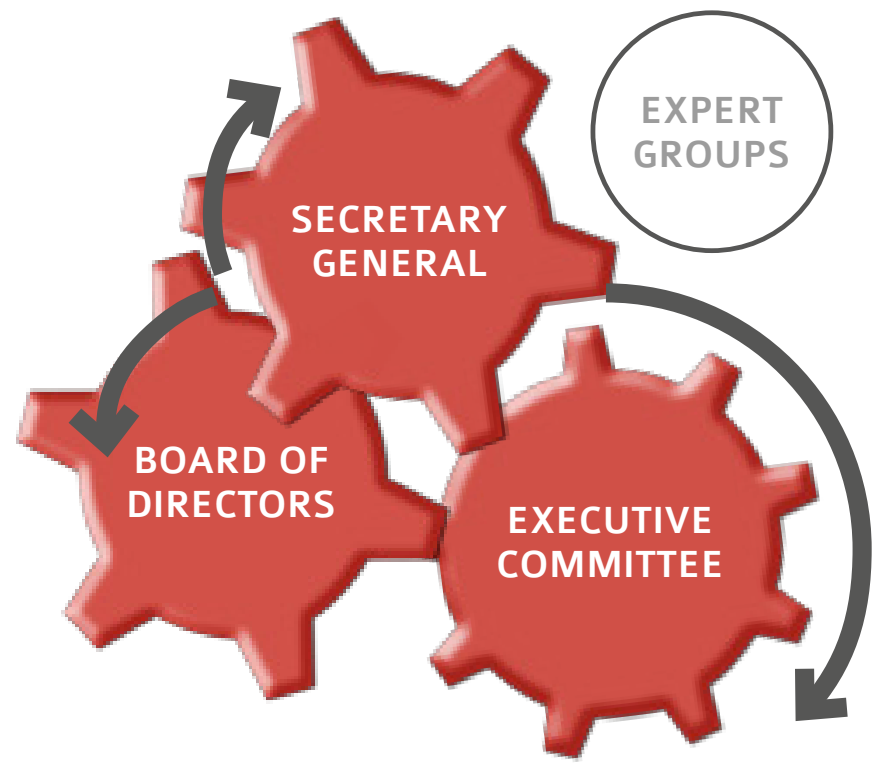

THE SECRETARY GENERAL

is responsible for the day-to-day operational

management and administration of EGS, contacts

with the European Commission and other third

parties, managing the budget and carrying out

the activities agreed by all Members.

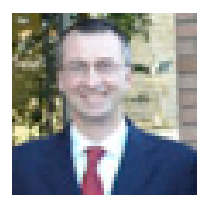

Secretary General

Luca Demicheli

Geological Survey of Italy

ISPRA
BOARD OF DIRECTORS

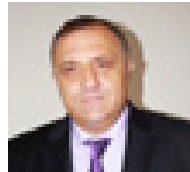

Adil Neziraj

Albanian Geological

Survey-AGS
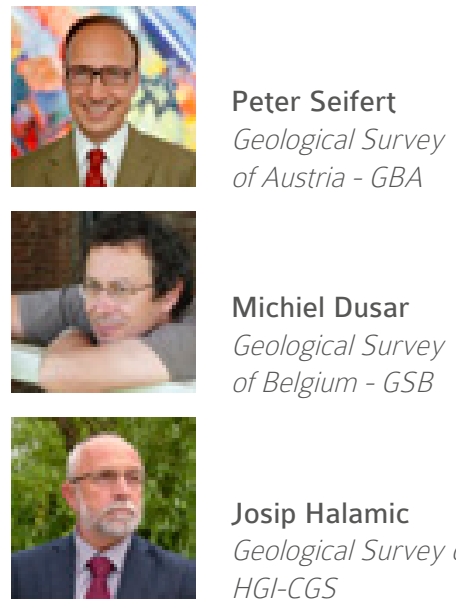

of Belgium - GSB

\section{Josip Halamic}

Geological Survey of Croatia HGI-CGS

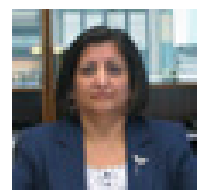

Eleni Georgiu-Morrisseau

Ministry of Agriculture.

Natural Resources and Environments

Geological Survey Department- GSD

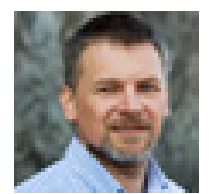

Zdenek Venera

Czech Geological Survey - CGS 


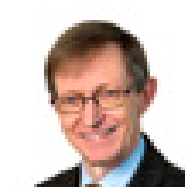

Olafur Florenz

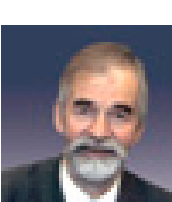

Geological Survey

of Estonia-EGK

Elias Ekdahl

Geological Survey

of Finland - GTK

Jean-Francois Rocchi

Bureau De Recherches

Géologiques et Miniéres

BRGM

\section{Hans-Joachim Kümpel}

Bundesanstalt Für Geowissenshaften

und Rohstoffe - BGR

Kostas Papavasileiou

Institute of Geology and

Mineral Exploration - IGME

Panagiotis Mitropoulos

Institute of Geology and

Mineral Exploration - IGME

László Kordos

Geological Institute

of Hungary - MAFI

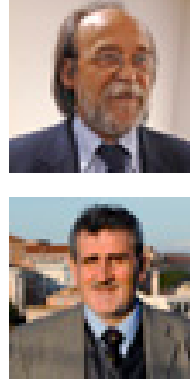

Bernardo De Bernardinis

Institute for Environmenta

Protection and Research - ISPRA

Leonello Serva

Geological Survey of Italy - ISPRA

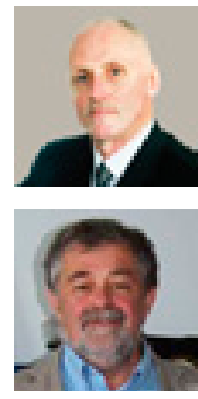

Jouzas Mockevicius

Geological Institute

of Lithuania - LGT

Robert Maquil

Service Geologique

Du Luxembourg - SGL

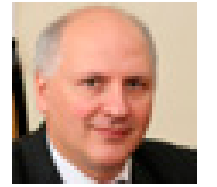

Stefan Marincea

Geological Institute

of Romania - GIR

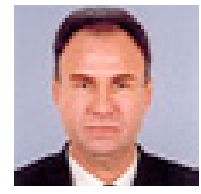

Todor Dimitrov

MOEW
Peadar Mc Ardle

Geological Survey

of Ireland - GSI

Oleg Petrov

A.P. Karpinsky all Russia

Geological Research Institute

VSEGEI

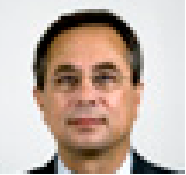

Branislav Zec

State Geological Institute

of Dionyz Stur - SGUDS

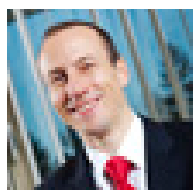

Marko Komac

Geological Survey

of Slovenia-GeozS

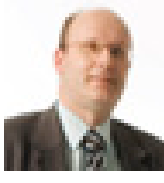

Mart van Bracht

Built Environment and

Geosciences National

Geological Survey - TNO

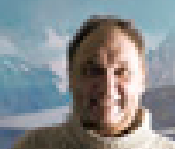

Morten Smelror

Geological Survey

of Norway - NGU

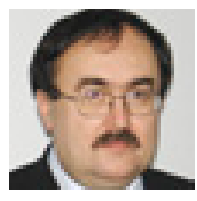

Jerzy Nawrocki

Polish Geological Institute -

National Research Institute -

PGI-NRI

Bulgarian Geological Survey-

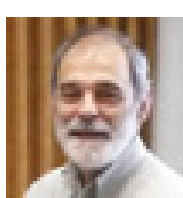

Mário Rui Machado Leite

Laboratorio Nacional

de Energia e Geologia - LNEG

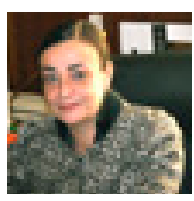

Rosa de Vidania

Instituto Geologico

Y Minero de Espana - IGME

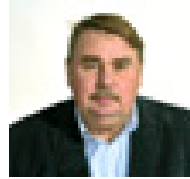

Jan Magnusson

Sveriges Geologiska

Undersokning - SGU

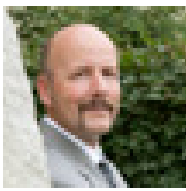

Christoph Beer

Bundsamt Für Landestopografie Landesgeologie - SWISSTOPO

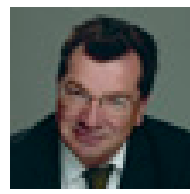

John Ludden

British Geological Survey - BGS

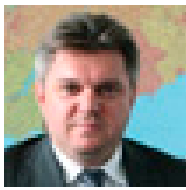

Eduard Sravytskiy

Ukranian Geological Survey

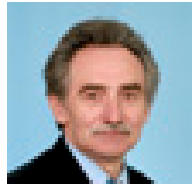




\section{EXPERT GROUPS CHAIRS}

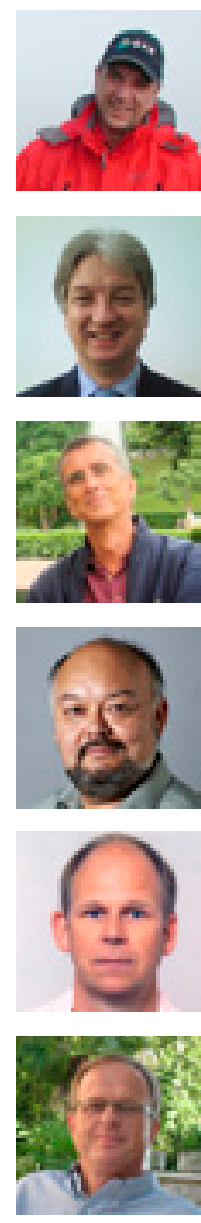

Marine Geology:

Henry Vallius

Geological Survey of Finland - GTK

Earth Observation:

Stuart Marsh

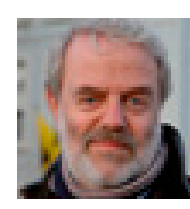

Spatial Information (INSPIRE):

Francois Robida

Francois Robida
Bureau de Recherches

Bureau de Recherches
Géologiques et Minières - BRGM

British Geological Survey - BGS

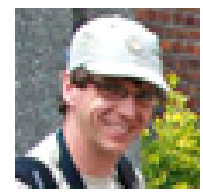

Carbon Capture and Storage -

EGS.CO

Kris Piessens

Geological Survey of Belgium - GSB

Geochemistry:

Clemens Reimann

Geological Survey of Norway - NGU

GeoEnergy:

Peter Britze

Geological Survey

of Denmark and Greenland - GEUS

Water Resources:

Hans Peter Broers

Built Environment and Geosciences

National Geological Survey - TNO

Mineral Resources:

Slavko V. Šolar

Geological Survey of Slovenia - GeoZS 
(19) GBA MOEW HGI-CGS

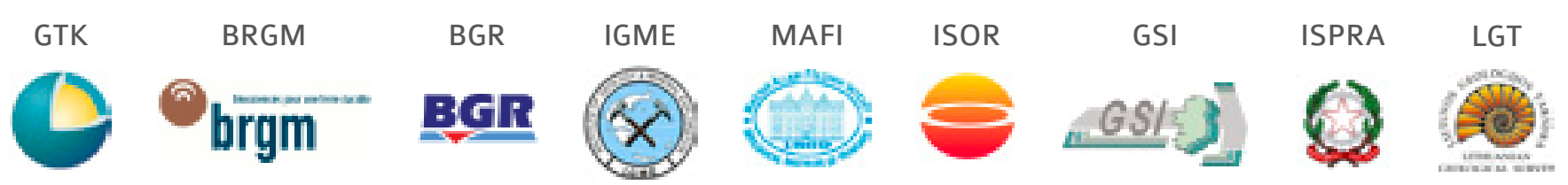

SGL

$\begin{array}{ccccc}\text { SGU } & \text { Swisstopo SGSU UkrSGRI } \\ \begin{array}{c}\text { Instituto Geológico } \\ \text { y Minero de España }\end{array} & \mathrm{SGU} & { }_{+} \text {swisstopo } & \text { EGS }\end{array}$




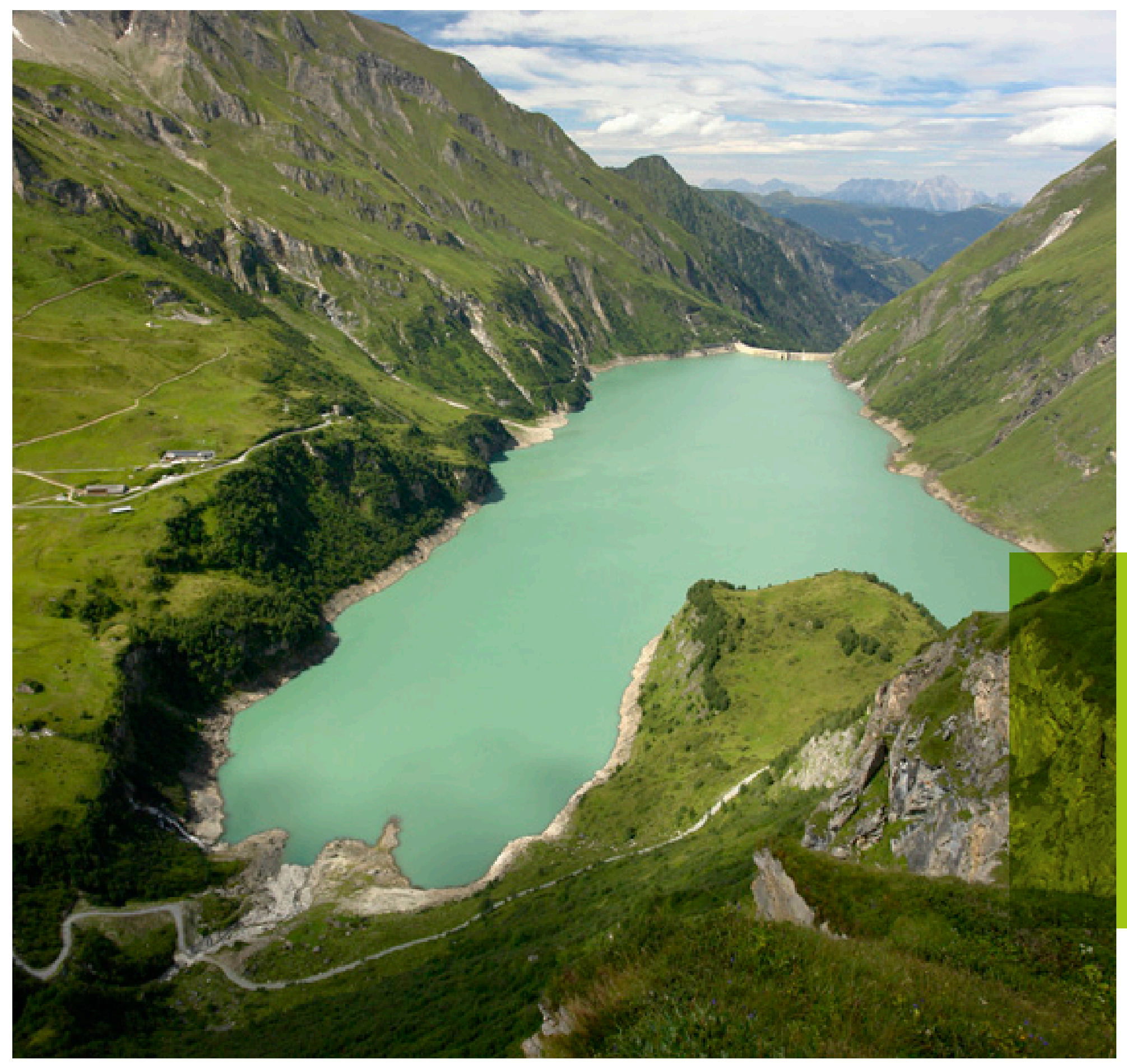




\section{Л EGS around the world}

Public relations were a focus of attention throughout 2010. Over the course of the year, we participated in over around 50 meetings. We also reached out to more than 12,000 scientists around the world particularly in Europe, through our booth displays and participation in international projects.

\section{EVENTS CALENDAR 2010}

During 2010 the EuroGeoSurveys Secretariat participated in over 50 meetings and events. Some of them have been remarkable for the EU geoscientific community, such as the launch of the Carbon Capture and Storage Task Force in February and of the Fossil Fuels Task Force in April. Due to the results achieved and to the increasing importance of these topics in the European geopolitics, the two Task Forces were, later in the year, upgraded to the rank of Expert Group, the latter with an enlarged mandate to cover also other energy sources, such as geothermal energy

The intense networking activity culminated in the signature of two important agreements with the European Environment Agency and with the United States Geological Survey.
Remarkable celebrations commemorated important achievements by the Geological Surveys of Europe, such as the $175^{\text {th }}$ Anniversary of the British Geological Survey and the $70^{\text {th }}$ Anniversary of the State Geological Institute of Dionyz Stur SGUDS, Slovakia.

In September EGS published the first ever European Atlas of mineral bottled waters, showing the geochemical composition of 1785 bottled water samples, divided on 1247 different sources at 848 locations, from 38 European countries altogether

In October OneGeology-Europe, the digital geologica map of Europe, was successfully released in Paris. The project brings a huge progress on data sharing making geological map data freely available on the internet, thanks to a ground-breaking one click licensing agreement by all participating European nations with relevant media interest. The success of the project helped Europe to confirm its leading role in OneGeology, as 72\% of the 2010 global project's web portal visits came from Europe.

In November, at the GEO Ministerial Summit, EGS was accepted as the only organisation co-chairing the GEO Science and Technology Committee.
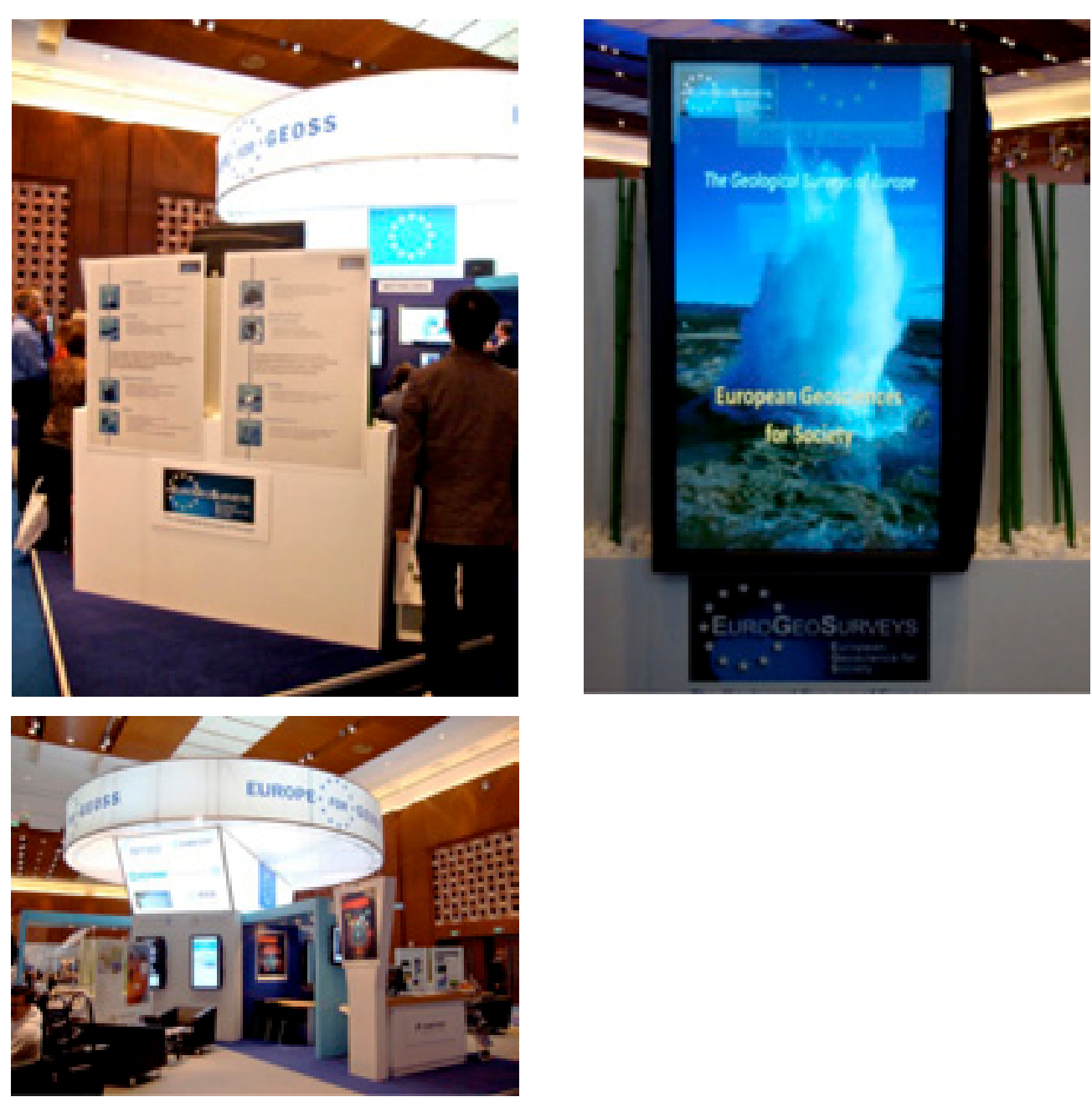


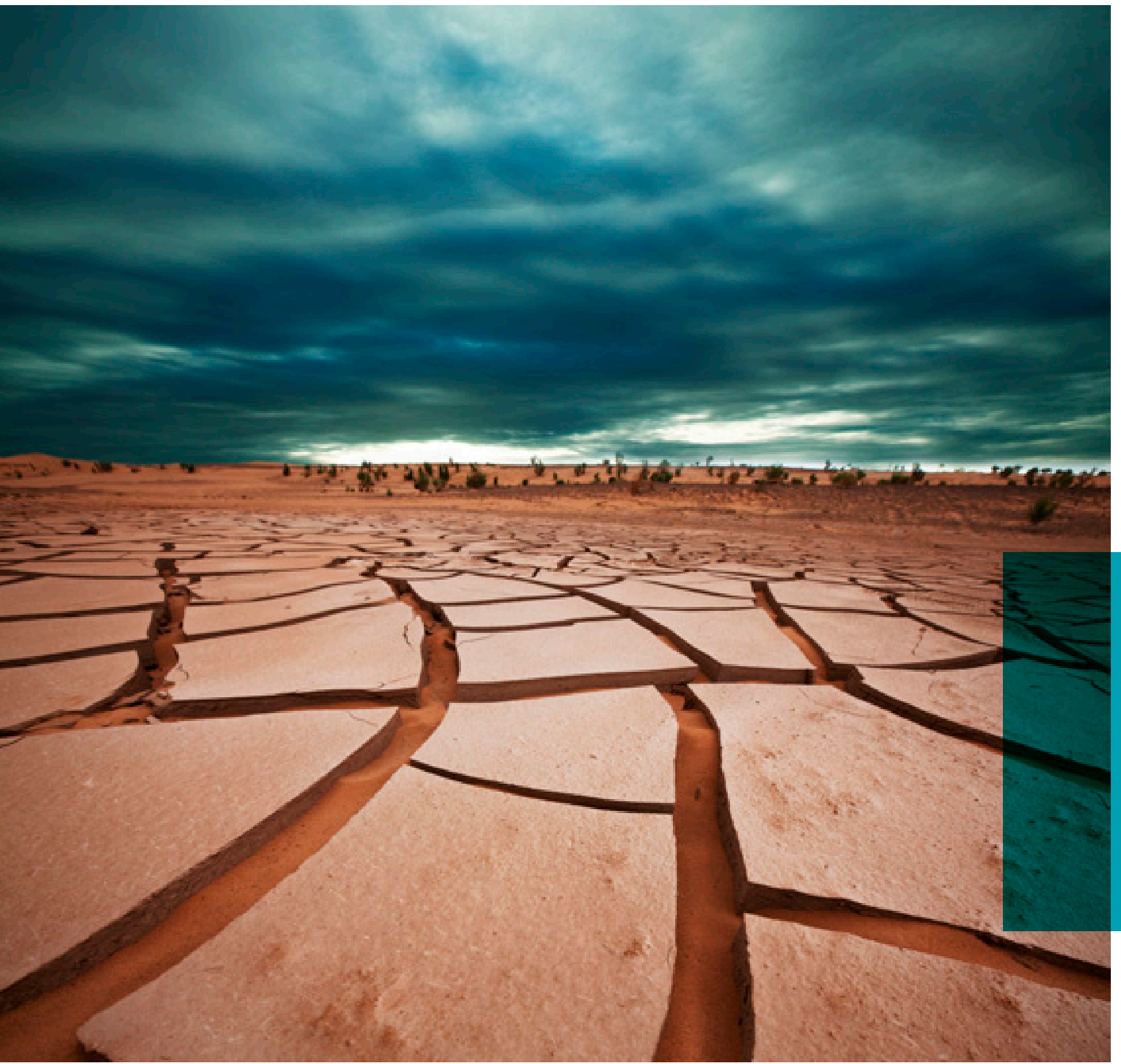




\title{
Л Earth moving
}

\author{
MAIN GEOLOGICAL EVENTS IN THE WORLD
}

Solid Earth's dynamics were a major talking point in 2010. Unfortunately much of the conversation revolved around the Gulf of Mexico oil spill and the near unprecedented amount of destruction caused by natural disasters. In the United States of America alone, there was a record of 247 natural disaster events documented (source: NOAA)

As for those of geological origin around the world, earthquakes caused the majority of both human loss and economic damage, after strong seismic activity hit Haiti, Chile, New Zealand and China.

Other major natural disasters included devastating floods in Pakistan which affected over 15 million people. However there were also some important positive news stories, such as the discovery of huge mineral deposits in Afghanistan, including iron.

copper, cobalt and gold. In particular, the discovery of apparently the world's largest deposit of lithium, a critical industrial metal, is hoped to substantially boost the Afghan economy in the long term. Some of the major European geological events are discussed below by members of EuroGeoSurveys, beginning with what caused the biggest disruption to European air traffic since World War II -

the eruption of Iceland's Eyjafjallajökull volcano.

\section{ICELAND}

The eruption of Eyjafjallajökull volcano

The Fimmvörðuháls eruption 20.03.2010 > 12.04.2010 The Eyjafjallajökull eruption 14.04.2010 > end of may 2010
Two adjoined, glacier-capped volcanoes, Katla and Eyjafjallajökull, are among the most conspicuous features of the south coast of Iceland. In historical time, Katla has been one the most active Icelandic volcanoes, and has repeatedly produced large eruptions coupled with fearsome glacier bursts threatening the farms in the region, the latest eruption occurring in 1918. The activity of Eyjafjallajökull has been on a much smaller scale with an eruption close to the year 920 and again in 1612 or 1613 and 1821-1823. Interestingly, in each case, Katla also erupted around the same time. As an eruption has been expected in Katla during the last few decades, the area around Katla and Eyjafjallajökull has been closely monitored with a variety of geophysical and geochemical methods. It was Eyjafjallajökull, however, that was the first to wake up from inactivity.

After a long dormant period, unrest was noticed in Eyjafjallajökull in the nineties with intrusive events in 1994 and 1999. Then in the middle of 2009, a new intrusive event took place and with renewed deformation of the volcano noticed in January 2010. When an eruption started in the evening of 20 March 2010, the beginning phase was so calm that geoscientists did not notice this from seismograms. In fact, it was a farmer in the region who picked out the glow from the new eruption site through the clouds and alerted the authorities. Geoscientists were soon on the scene to find out that a short volcanic fissure had opened up at the glacier-free Fimmvörðuháls pass between Eyjafjallajökull and Katla at an elevation of about
$1000 \mathrm{~m}$. Evidence indicates that magma migrating up beneath the summit of Eyjafjallajökull formed a dike that had reached the surface almost $10 \mathrm{~km}$ east of the summit caldera. Until April 12, for over three weeks, rather gentle basaltic eruption

continued, forming a few scoria cones and a small field of aa lava.

Mayhem ensued as tourists flocked to the eruption site with trucks and skidoos on the ground and planes and helicopters overhead. At one point a new fissure formed with onlookers standing nearby, and there were spectacular examples of "lava falls" as the lava fell off the steep cliffs to the north of the eruption site. The eruption had no direct effect on the farms around the volcano. The estimated volume of the volcanic products is relatively small at about $25 \times 106$ m3. However, this part of the eruption was merely a prelude to a more sinister phase.

A two-day break in eruptive activity ended in the morning of April 14. This time around the eruption site was in the summit area under the glacier cap and melt water immediately started gushing down to the plains around the volcano. Evacuations of farms started immediately and everybody was brought to safety unharmed. The eruption quickly melted through the glacier and it soon became evident that the eruption products were considerably more siliceous than in the flank eruption. Initial products had about 58\% $\mathrm{SiO} 2$ and are of trachyandesite composition. Analyses of the products indicate complex interactions between

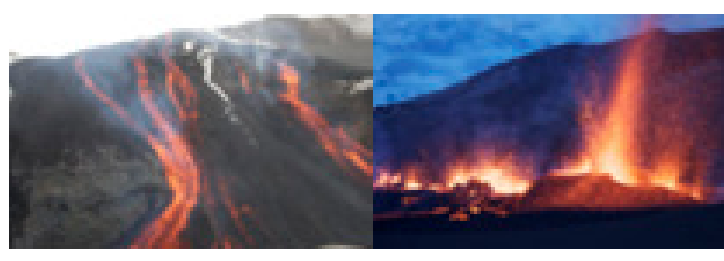

Photo: Sigvaldi Thordarson - isOR

Photo : Sigvaldi Thordarson - ÍSOR

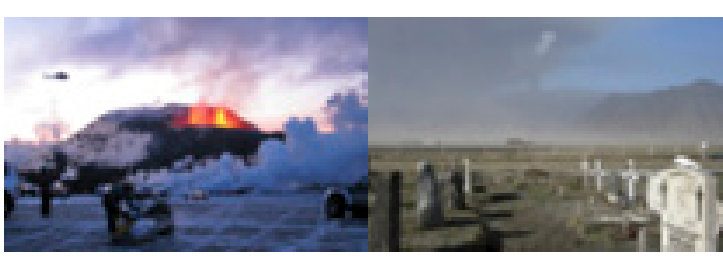

Photo: Gunnar Skúlason Kaldal

Photo : Ingibjörg Kaldal - íSOR

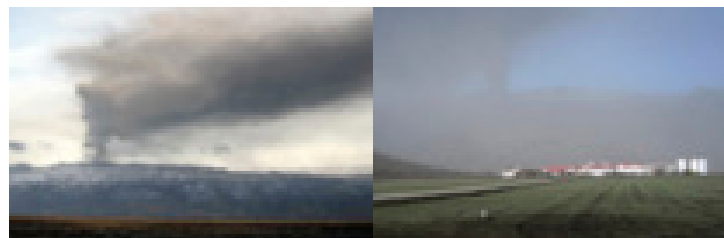

Photo : Ingibjörg Kaldal - ÍsOR

Photo : Ingibjörg Kaldal - íso 
basaltic magma, probably coming from below, and silicic magma that is likely to have been present in the feeder dike for the summit caldera. Because of the high viscosity of the magma and water interaction, the summit eruption was highly explosive most of the time, but a thick, short lava flow was also seen issuing from the summit crater. The explosiveness of the eruption meant that the plume reached $9 \mathrm{~km}$ height and large amounts of fine-grained ash then moved with the Westerlies toward Europe, resulting in the shut-down of the air space of many European countries for days and subsequent chaos and disruption on the ground.

Obviously, most of the ash fell around the volcano and many farms where severely affected as grazing land was covered with thick ash, visibility was next to nothing at times and breathing was difficult. In the village of Vík, south of Katla, children had to stay inside day after day while the village was inundated with a cloud of ash. Floods cut the main road between the south and east of Iceland and closed off the rout e to the popular tourist destination of Thórmörk, northeast of Eyjafjallajökull. By May 20 the eruption activity had subsided considerably and was over before the end of the month. The estimated volume of the erupted tephra was $250 \times 106$ m3, a relatively modes amount, but because of the explosivity, the impact of the eruption was widespread.

In the weeks and months following the eruption, large amounts of volcanic ash kept coming down from the glacier and the slopes around the glacier carried by rivers, especially during heavy rain.
The finer fractions of the ash were transported with wind during dry weather, sometimes greatly reducing visibility in South Iceland. Car owners as far away as Reykjavik frequently noticed a dusting of brownish, fine ash covering their vehicles. The feared detrimental effects of the ash on livestock seem to have been minor, and generally vegetation appears to recover quickly. In fact, the ash may have acted as a fertilizer. Eyjafjallajökull has been quiet in the last few months and no signs of continued activity have been noticed. Katla has also been restful, not showing signs of an imminent eruption.

Text: Guðmundur H. Guðfinnsson - Geologist Iceland GeoSurvey ISOR

\section{POLAND}

Catastrophic floodings in Wisła and Odra rive basins in May - June 2010 after a series of extreme rainfalls.

Damages caused by this flood in Poland were very serious. The rainfalls have sent rivers rising to record levels and flooding an area of $5540 \mathrm{~km}^{2}$

About 23,000 people were evacuated and economic losses are estimated at 2.5 milliard euros.

The floods were one of the worst natural disasters in the nation's history, turning to be unprecedented flood disasters for the last 160 years.

Polish Geological Institute participated in the operations by assessing the risk of failure of flood embankments through the use of electroresistance tomography and georadar and other engineeringgeological methods.

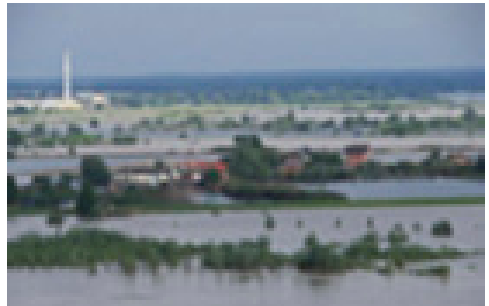

Flooding in Wisła river in June 2010 Photo by M. Ścibisz

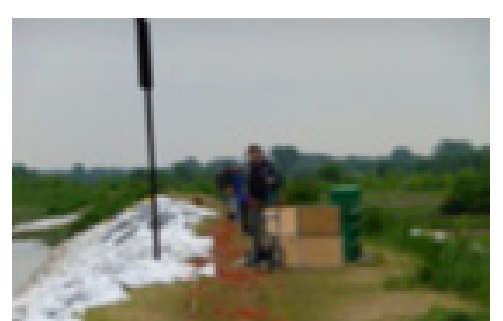

Polish Geological Institute participated in the operations by assessing the risk of failure of flood embankments through the use of electroresistance tomography and georadar and other engineering-
Reactivation of mass movements in the Polish

Carpathians after extremely heavy rainfalls and floods in May-June and August 2010.

This is the region where about 95\% of landslides

hitherto identified in Poland are located (over 50,000).

The reactivation showed the value and effectiveness

of the SOPO Landslide Counteracting System,

an early warning system for identifying and

recording mass movement and mitigation of

potential damage. That system is implemented

and supervised by the Polish Geological Institute.

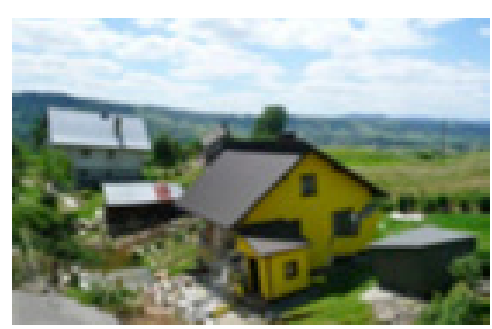

ildings destroyed by landslide in the Polish Carpathians. In that region, landslide generation sandstone by bedrock geology (alternations sandstone and shale) and śa
Photo by M. Konieczyńska 
The oldest in the world footprints of tetrapods. Sensational discovery of the oldest in the world footprints of tetrapods that dared to step onto dry land in Zachełmno quarry in the Holly Cross Mts (central Poland).

This information was published in the January $7^{t}$ 2010 edition of the journal Nature by discoverers of these footprints, Grzegorz Niedźwiedzki of Warsaw University and Piotr Szrek of Polish Geological Institute - National Research Institute (PGI-NRI) and their co-authors: Katarzyna Narkiewicz and Marek Narkiewicz of PGI-NRI and Per Erik Ahlberg of the Uppsala University. Their article has the title 'Tetrapod trackways from the early Middle Devonian of Poland'.

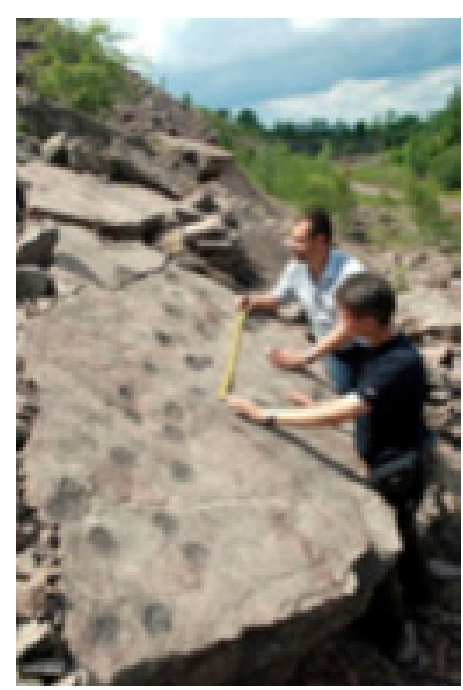

in the world. Piotr Szrek and Grzegorz Devonia
Discovery of paleo-permafrost in NE Poland (area of the Suwalki thermal anomaly). Temperature of only $0.07^{\circ} \mathrm{C}$ has been measured at the depth of $360 \mathrm{~m}$ in the exploratory borehole Udryń PIG-1, designed by the Polish Geological Institute and drilled in 2010. Survival of fossil permafrost in that area give scientists a possibility to carry out quantitative reconstruction of paleoclimate of the last glaciation period and to verify the geothermal conditions in the north-eastern Poland. That discovery is also important for implementation of the CCS and gas shales exploration programs.

Polish Geological Institute - National Research Institute
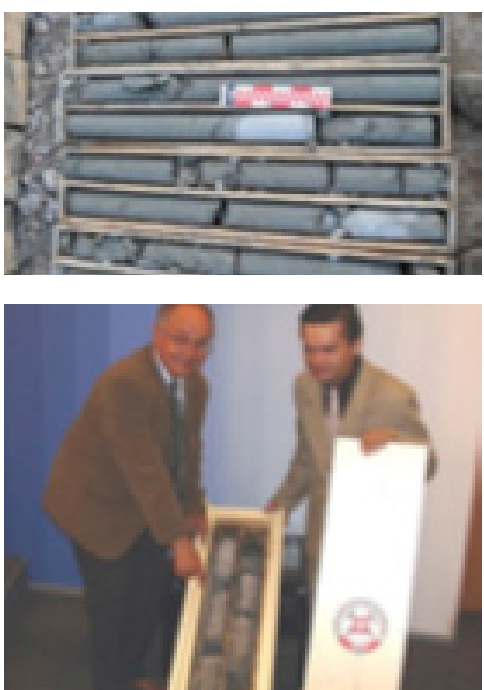

Buildings destroyed by landside in the Polish Carpathians. In that region, landslide generation is facilitated by bedrock geology (atternations of sandstone and shate) and steep slopes.

\section{ITALY}

Catastrophic floods in Northern Italy

(October - November 2010)

Since 30th October intense rainfall have affected Northern Italy caused widespread flooding phenomena in several regions.

The most catastrophic effects were recorded in Veneto, where three people died and economic damages were estimated in the order of 100 millions EURO. In particular in the Vicenza province the Bacchiglione and Retrone rivers flooded over thousands of hectares (about 30\% of the province was submerged) including large sectors of the Vicenza urban area. Moreover, near Verona the A4 highway was closed for a few hours, in the Padova and Treviso provinces hundreds of people were evacuated, and at Venice the high level water reached $101 \mathrm{~cm}$

Furthermore, in Piedmont the Bormida and Tanaro rivers inundated large areas in the Biella, Cuneo, Asti and Novara provinces (max daily rainfall value equal to $234 \mathrm{~mm}$ near Biella on 1st November). In Liguria, rain was particularly intense in the

Savona and Imperia provinces, causing widespread inundation and triggering landslides even at Genoa. In Tuscany, flooding occurred mostly in the Massa and Carrara provinces due to the extreme rainfall in a short period (220 $\mathrm{mm}$ in about 10 hours)
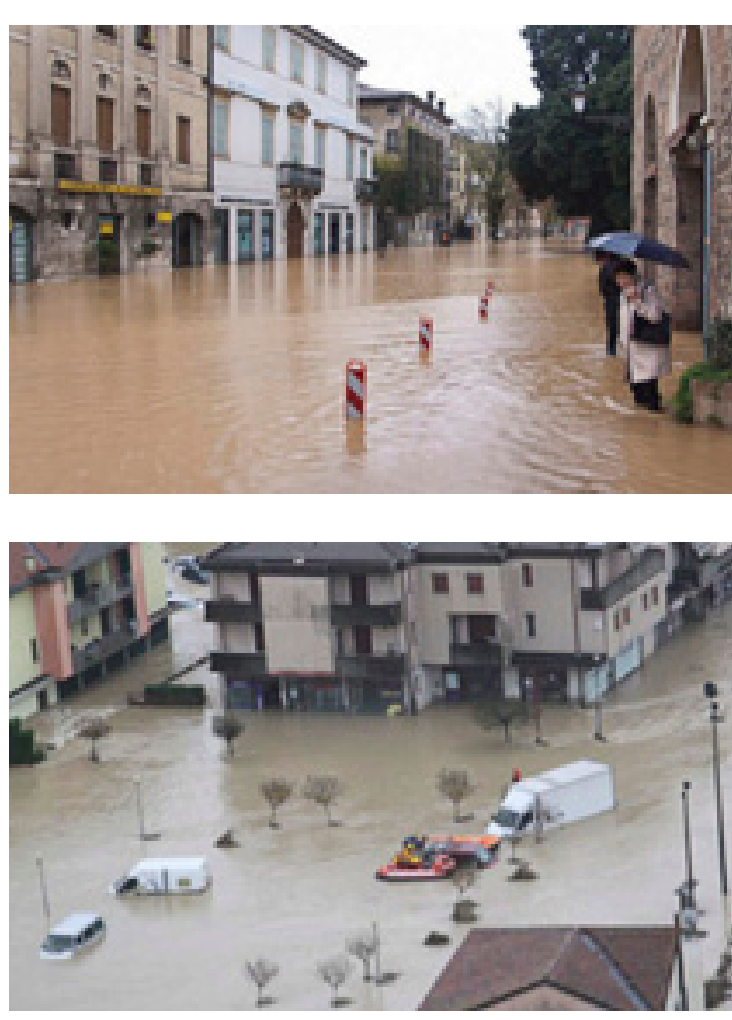

On 1st November 2010 Vicenza was flooded by the Bacchiglione and of rainfall in 48 hours). Source: Regione Veneto 
Huge landslides in Sicily and Calabria

(February 2010)

In Sicily, on 14th February 2010 a large landslide has affected the eastern portion of the San Fratello village (Messina province), causing relevant damages at several buildings including a church and the evacuation of about 1,500 people. The landslide affected mainly silt-clay deposits. Its extent was about $1 \mathrm{~km}$ large and $2.5 \mathrm{~km}$ long. Largest movements have been estimated in the order of 10-20 m.

The slope movement was triggered by the intense rainfall occurred in the eight days before the event (more than $100 \mathrm{~mm}$ ) but was also fostered by the culvert channels spilling directly into the landslide main body. The San Fratello village was already affected by relevant landslide phenomena in 1745 1922, 1623 and 1977. The Geological Survey of Italy has surveyed the landslide and evaluated the presence of residual risk.

In Calabria, on 15th February 2010, a huge landslide (about 1-2 millions m3) has affected the sector immediately at West of the Maierato village (Vibo Valentia province). The landslide was classified by the Geological Survey of Italy as translational slide evolved as a flow in the valley sector. A enormous quantity of material deposited at the bottom of the valley causing the drainage inversion of the Scuotrapiti stream and the formation of small lakes. Although the extremely large size of the landslides damages were very limited (just one building).
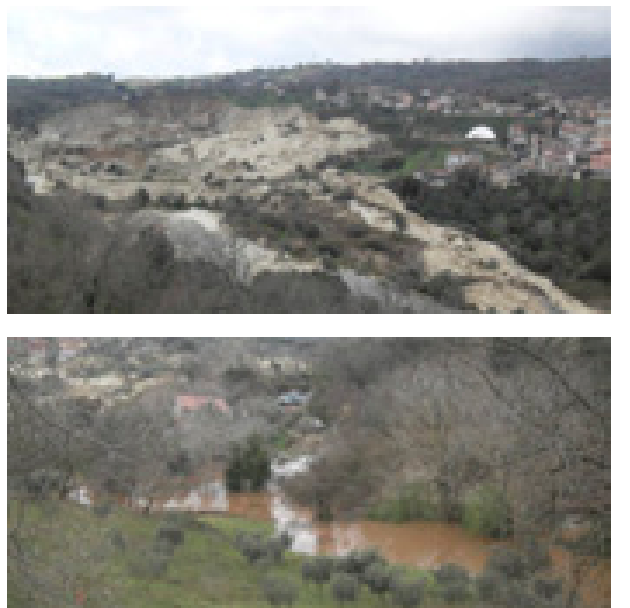

Maierato landslide: a panoramic view (left) and small lakes formed at the base of the landslided body (right). Source

of Italy
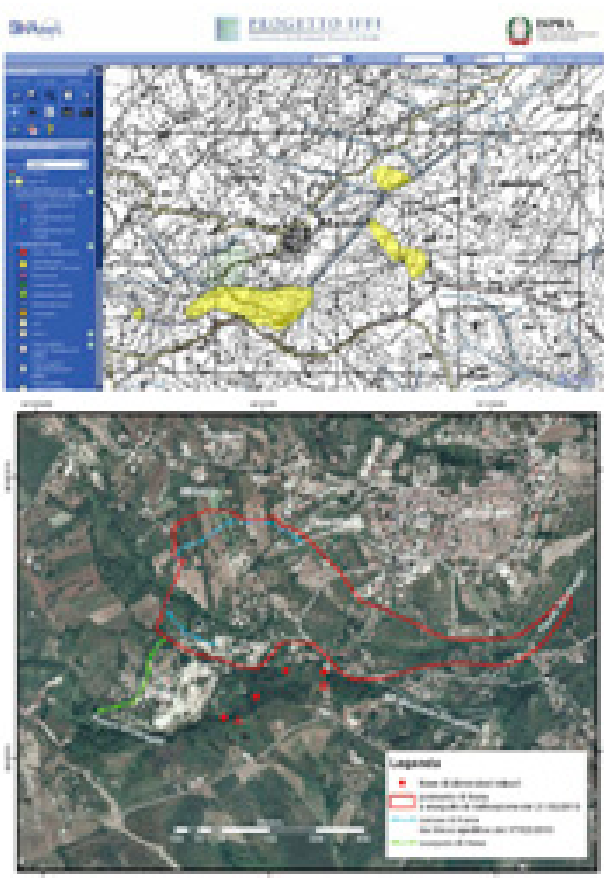

The Maierato landside was already mapped in IFFI Inventario de Fenomeni Franosi in Italia), which is the Italian landslides inventor
Tragic minor landslides in Trentino and Pontian Islands (April 2010)

In Trentino, on $12^{\text {th }}$ April a very modest surficial landslide (volume was about $400 \mathrm{~m} 3$ ) has affected the railway Malles - Merano causing the derailment of a train. As a consequence, 9 people died and 28 were injuried. The landslide was probably caused by the water spilled out from an irrigation system located at the top of the slope.

At Ventotene, one of the Pontian Islands, on 20th April a single rock fall (about 4-5 m3) killed two young students. The blocks were detached from a vertical cliff progressively eroded at the base by the action of sea waves.

Rock falls induced by a modest earthquake in the Eolian Islands (August 2010)

On $16^{\text {th }}$ August, a modest earthquake $(\mathrm{Ml}=4.5)$ was recorded in the Eolian Islands.

The event did not cause any damage to buildings or people. Nevertheless, in Lipari the seismic shaking induced the occurrence of several rock falls from the instable cliffs directly on the beaches. Although a large number of tourists was on the beach during the earthquake (which occurred early in the afternoon), fortunately nobody was hit by the falling blocks
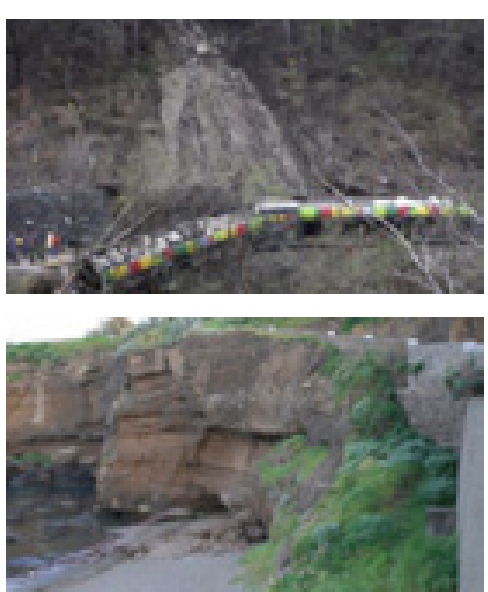

Two minor landslides in Trentino (left) and Pontian Islands (right) had a dramatic effect in terms of dead
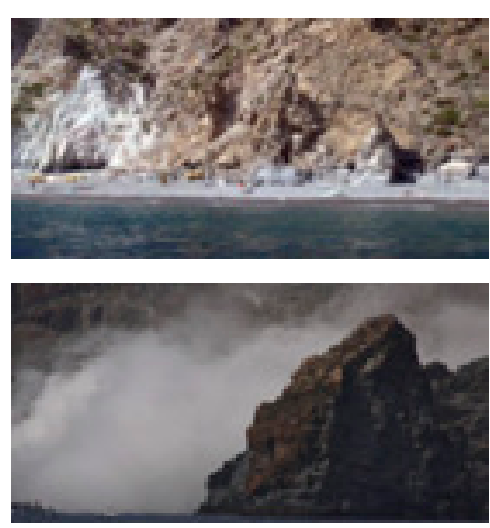

Lipari (Eolian Islands): rock falls on the beach induced by the earthquake occurred on 16 th Augus Although no injuries have been recorded, this event had clearly shown the high vulnerability of coastal
cliffs even to a very modest seismic event. 


\section{UNITED KINGDOM}

Cornwall: November 2010

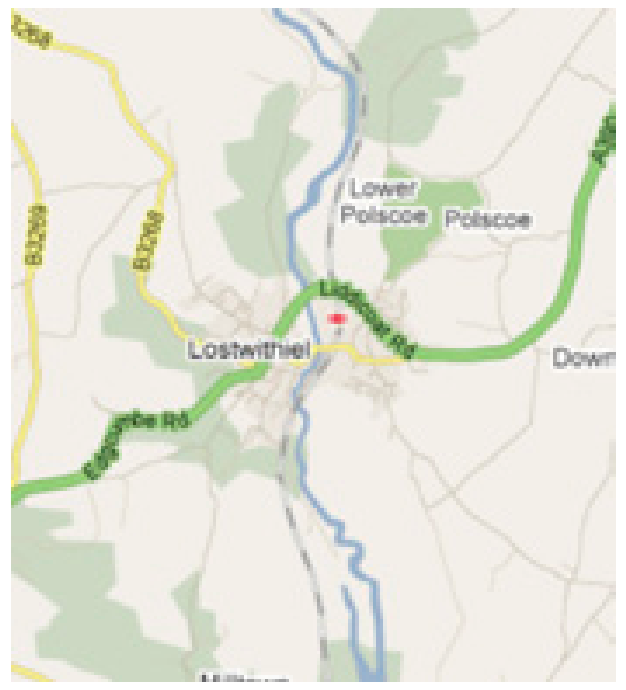

Geology changes from 625000 to 50000 scale at zoom level 13. Geology changes

A section of the BGS 1:50 000 scale geological map showing superficial deposits. The yellow areas are the alluvium deposits (clay, silt, sand and gravel); the area was last surveyed in 1982 (see Bodmin)

A BGS response team flew over the St Austell area on 17 November 2010 during the flooding to find out how modern flooding compares to ancient flood areas.

BGS geologist, Elaine Burt, observed flooding from $300 \mathrm{~m}$ (1000 ft) from a helicopter; flying over one of the worst affected areas travelling south from Bodmin to Lostwithiel along the River Fowey.
The floodwater and several minor 'landslides' have caused widespread disruption to travel and people have been evacuated from their homes

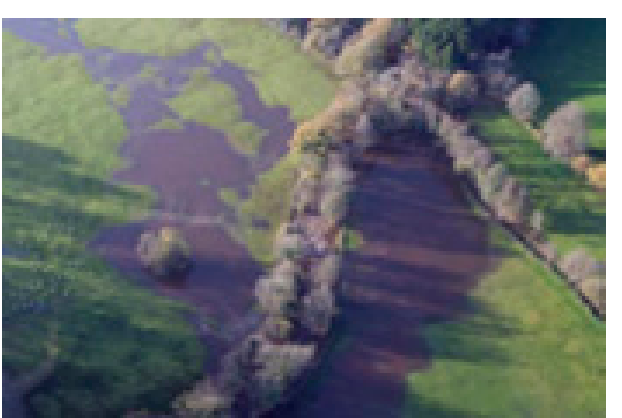

Landslide at Blubberhouses, North Yorkshire

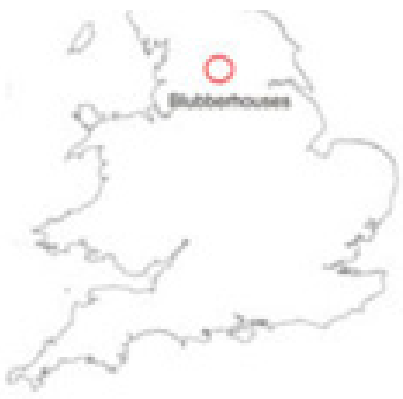

The most recent landslides, September 2010, are located to the west of Blubberhouses in North Yorkshire along the A59 road.

Although the landslides did not encroach on the road surface, the A59 was closed between

Blubberhouses and Raven's Peak while remediation work took place.
The BGS Landslide Response Team made a visit to the landslide on 30 September 2010 to investigate the failures. Information was collected for the BGS National Landslide Database and geological maps.

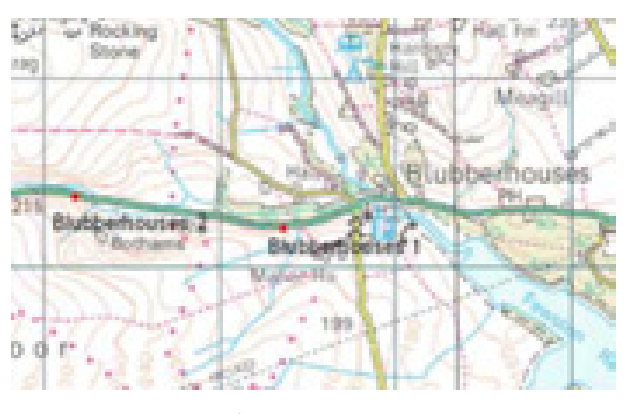

$$
\text { Approximate locations of the landslides. }
$$

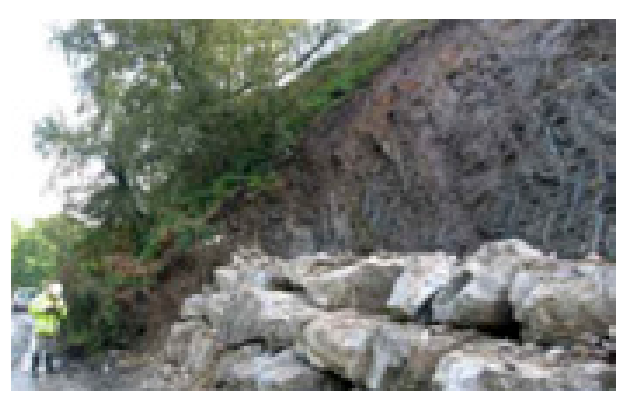

The completed remediation work at the landslide site at map location 2 west of Blubberhouses.

\section{News reports}

The landslides at Blubberhouses have been

reported in the local and national news:

- A59 closure extended after discovery of second landslip

North Yorkshire Council, 29/09/2010

- Landslip causes A59 road closure in North

Yorkshire - BBC News, 28/09/2010

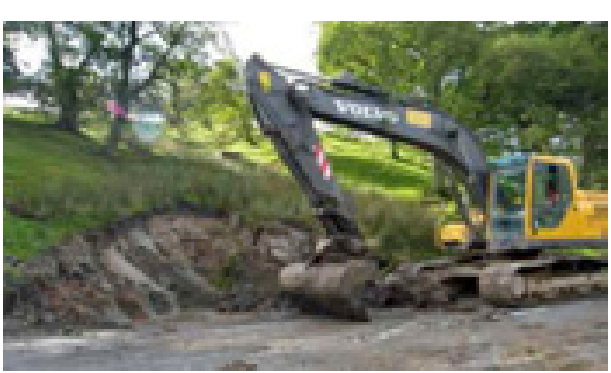
Remediation work taking place at the landslide site at map
location 1 west of Blubberhouses. 
- Road still closed after landslide

Craven Herald, 28/09/2010

\section{Geology}

The underlying bedrock geology of the area is part of the Carboniferous (Namurian) Millstone Grit

Group and comprises fine- to very coarse-grained feldspathic sandstones, interbedded with grey siltstones and mudstones, with subordinate marine shaly mudstone, claystone, coals and seatearths. Although no superficial deposits are mapped at this site it is likely that the landslide involved colluvium and weathered bedrock.

\section{The landslides}

The Blubberhouses 1 landslide has the characteristics of a flow. A spring 20 metres up the slope is likely to have contributed to the instability at this site. The fence by the side of the road prevented the flow from moving on to the A59 road.

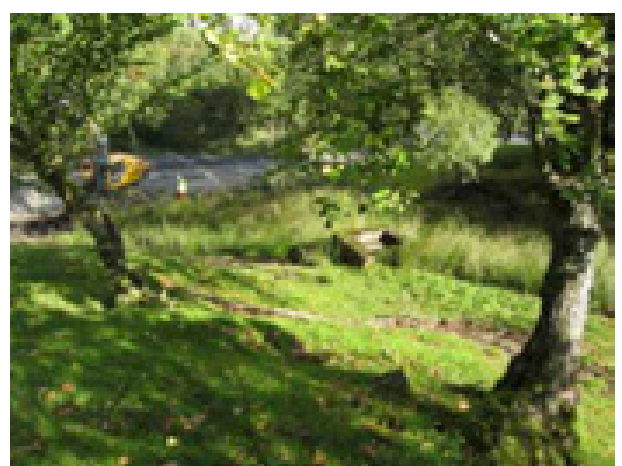

Blubberhouses 1. Looking downslope, the flow is highlighted

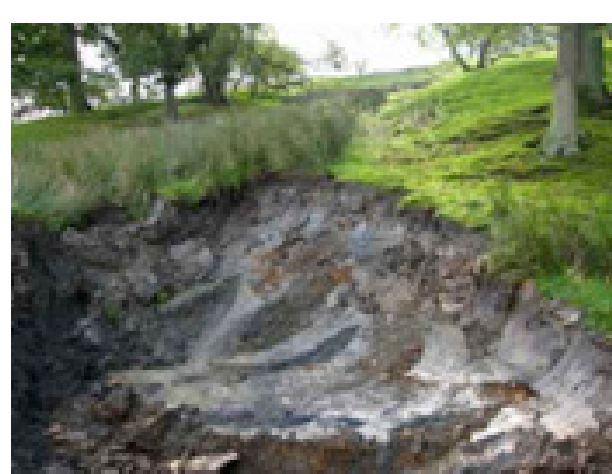

Blubberhouses 2. Looking upslope, water is flowing out of the saturated ground.

The Blubberhouses 2 landslide was an Earth Slide, the failed material had been removed when the visit took place but the area which had failed was clearly visible. Workers at the site suggested that trees uprooted upslope caused the superficial deposits and bracken that overlay the bedrock to become unstable and slide downslope.

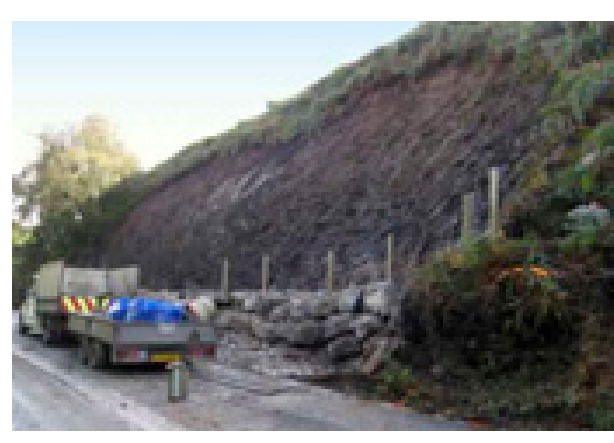

Blubberhouses 2. All the slide material has been removed and

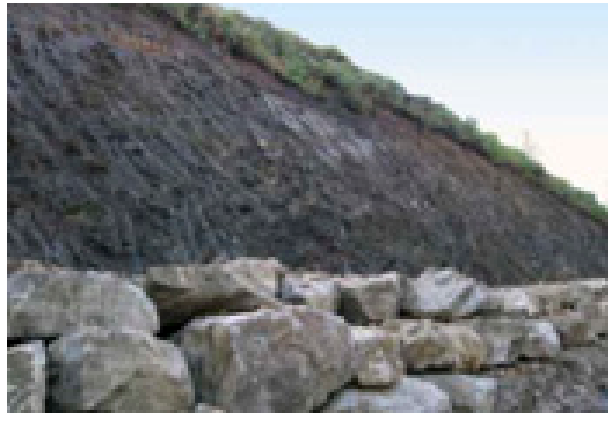

Blubberhouses 2. Thin layer of superficial deposit and bracken overlying the bedrock

This stretch of the A59 has been prone to landslides in the past; a car was reported to have been

covered by earth and rubble by a landslide in 2007.

- Flood havoc as downpour swamps Yorkshire Yorkshire Post, 15/06/2007

The Landslide Response Team recorded two remediated landslides west of the two recent slides which are likely to have been the site of this previous incident.

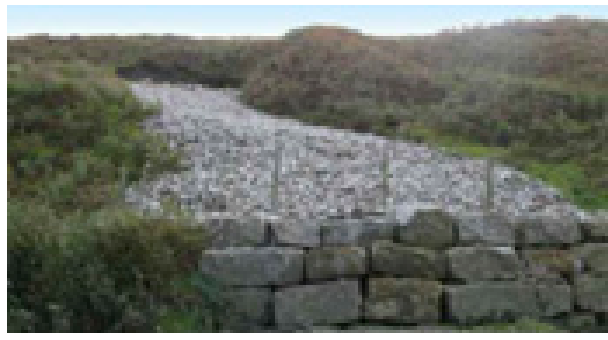

Possible site of 2007 slide.

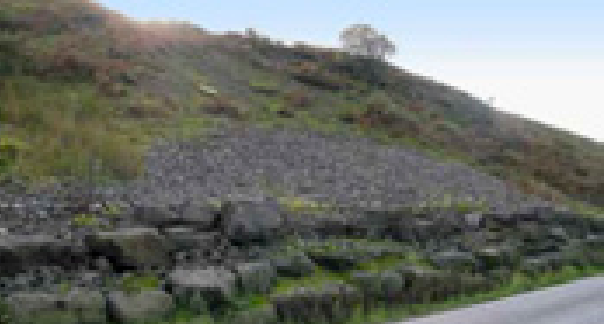

Another remediated landslide along the A59.

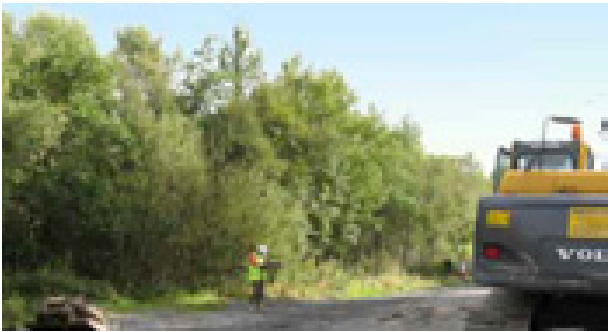

Landslide information being recorded using SIGMA.mobile.

All the information about the landslide was collected by the Landslide Response Team, using BGS •SIGMAmobile technology. 


\section{SPAIN}

Compiled the first map of active faults of the Iberian Peninsula

More than 70 national and international earthquake experts met in Siguenza (Guadalajara) to compile all available information on geological structures that might be responsible of destructive earthquakes in the Iberian Peninsula. Their findings will be published as a map of active faults and an on-line database already available from the Geological Survey's web site The first Iberian Congress on Active Faults (IBERFAULT. www.berfault.org) brought together all the experts groups working in the Iberian Peninsula and some of the most renowned experts in these matters such as North American James McCalpin or Neo-zelander Kelvin Berryman.

The current seismic catalogue of Spain only includes historical earthquakes or those detected by the national seismic network during the last 100 years. But in Iberia, deformation speeds responsible of those earthquakes are slower that in plate limits zones such as those in Chile or Japan, so, destructive earthquakes are so scarce that they might not be reflected in the historical or registered records. Seismic crisis from 5000, 10000 or 20000 years ago are nonetheless reflected in the geological record, thus paleo-seismology is very important in this region.

The meeting has designed a protocol which might be used to develop emergency programs and to be included in civil engineering models for big infrastructures and singular buildings, thermal plants, nuclear waste storages, dams, etc.
The debate of the unified criteria which included geologists, geophysics, engineers, civil servants and private companies, was audited by 3 international evaluators: Ivan Wong (Seismic Hazards Group, URS Corporation, USA), Kuvvet Atakan (Bergen University, Norway) and Pilar Villamor (New Zealand GNS), included in the $7^{\text {th }}$ European Framework Program project SHARE (Seismic Hazard Harmonization in Europe).

The database is already operative from IGME's web site and is fully compliant with the World Active Faults database (GEM, Global Earthquake Model, www.globalquakemodel.org), and meets the objectives of the INSPIRE directive in transference and interoperability The conference was organized by IGME (Dr.Miguel Ángel RodríguezPascua) the University Complutense of Madrid (UCM. Prof. José Martínez Díaz) and Barcelona University (UB Prof Eulalia Masana)

Web site of the Quaternary Active Faults Database of Iberia:

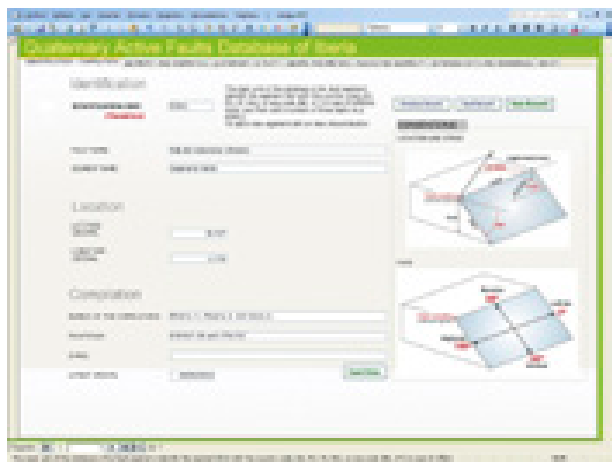

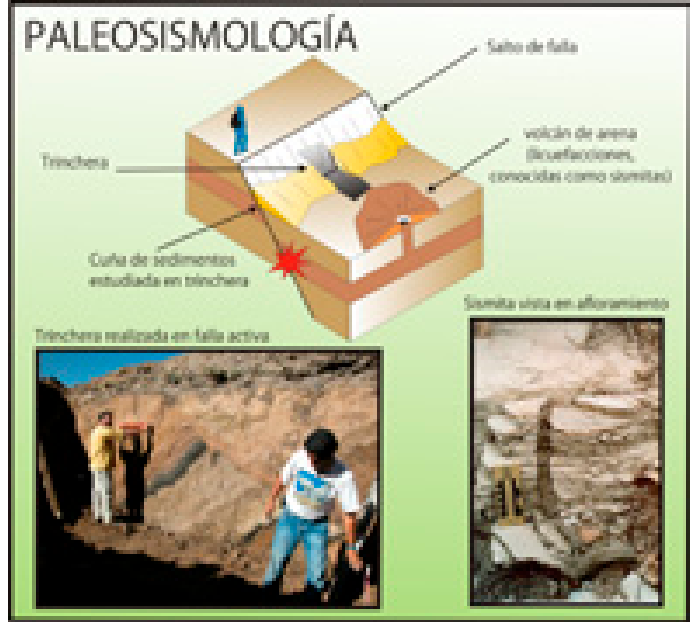

How paleoseismology is studied 
IGME investigates for the first time the rocks beneath the island of Tenerife

A $200 \mathrm{~m}$ deep borehole has been drilled in the submarine substrate to investigate the reasons for the mega landslides which originated the Güimar and La Orotava valleys.

The extracted rocks are over 12 million years old, the age in which the emerged part of the island started forming.

The project financed by the National R+D+I Plan of the Ministry of Science and Innovation, pretends to study the stability of the island volcanic edifices and the causes that originated the mega landslides that produced the Güimar valley one million years ago and La Orotava valley between 300000 and 500000 years ago.

The borehole was drilled in Igueste de San Andres and the materials drilled are fragmentary submarine materials and pillow lavas of the late submarine phases of the growth of the island.

"The nature and mechanical properties of the submarine material son which the island lies and the weight and height of the volcanic edifice are the main factors controlling the existence of landslides" comments Dr Mercedes Ferrer Gijon, IGME's specialist and director of the project.

She thinks that the probability of such events happening at a human scale is very small. Inside the borehole geomechanical and geophysical tests have been carried out to characterize the properties and behavior of the investigated materials.

IGME leads a group of researchers from the Complutense University of Madrid (UCM) La Laguna University (ULL), the Autonomous University of Madrid (UAM), the Tenerife Island Water Council, the Government of the Canary Islands, the University of Las Palmas of Gran Canary (ULPGC), and the University of Lisbon.
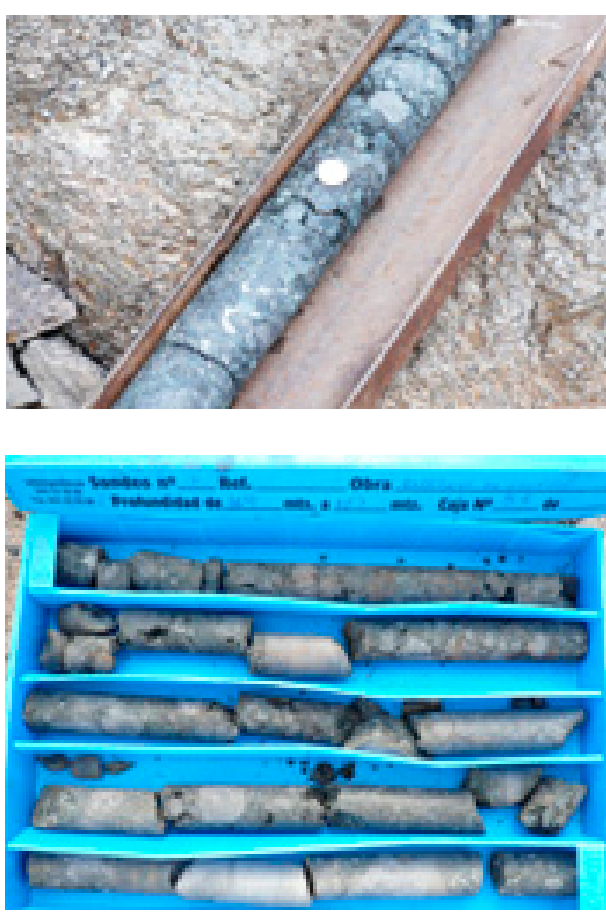

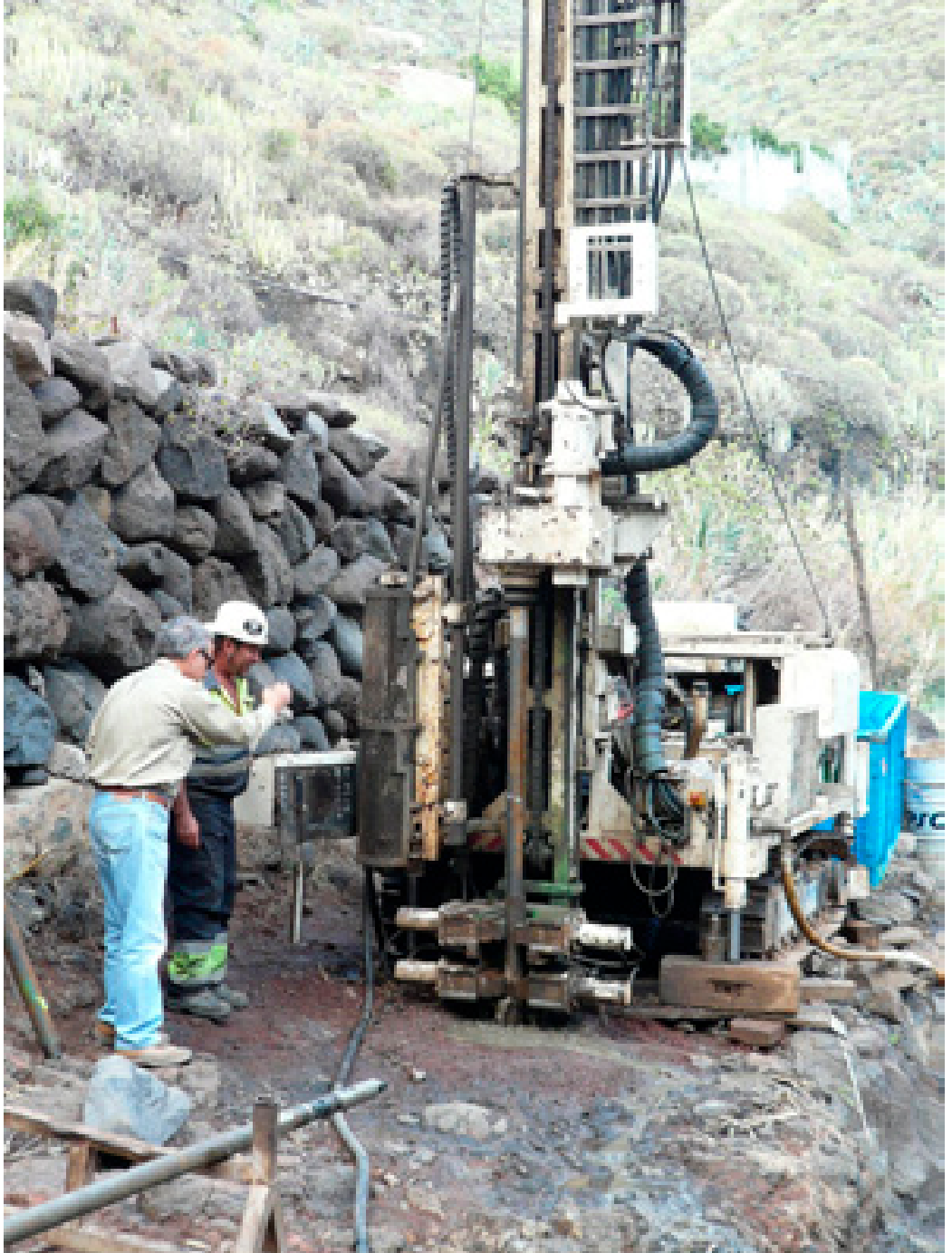


Discovered in Valencia a new fish species that lived 10 million years ago

IGME fossil insect specialist Enrique Peñalver, together with Jean Gaudant, fossil fish specialist of the National Natural History Museum of Paris, published in "Palaeogeography, Palaeoclimatology, Palaeoecology" their findings about this new 2 to $2.5 \mathrm{~cm}$ species found in the rocks of a paleolake located in Bicorb (Valencia).

The fossilized faecal deposits of this animal have revealed its feeding habits based in foraminifera and mosquito larvae, proving that the fish was an active predator. The paleolake was saline as demonstrated by the combined study of fossil animals and vegetables found in the rocks of the lake. The name adopted for this new species, Aphanius bicorbensis, reflects the location were the paleolake has been found, while the genera name Aphanius means invisible, as the living species of this genera, Aphanius iberus, found today in the region, is hard to find and is currently facing extinction. Both species have a common ancestor.
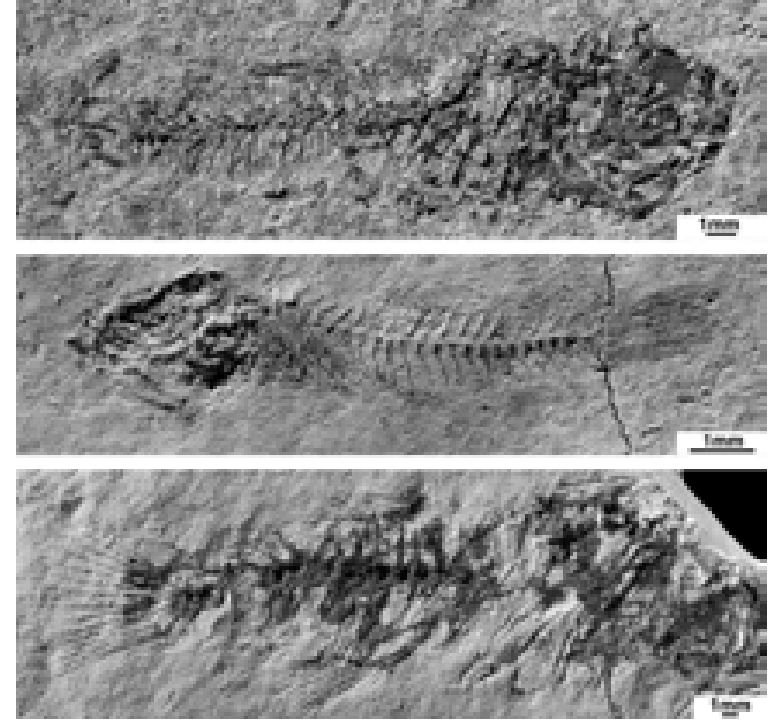

Aphanius bicorbensis
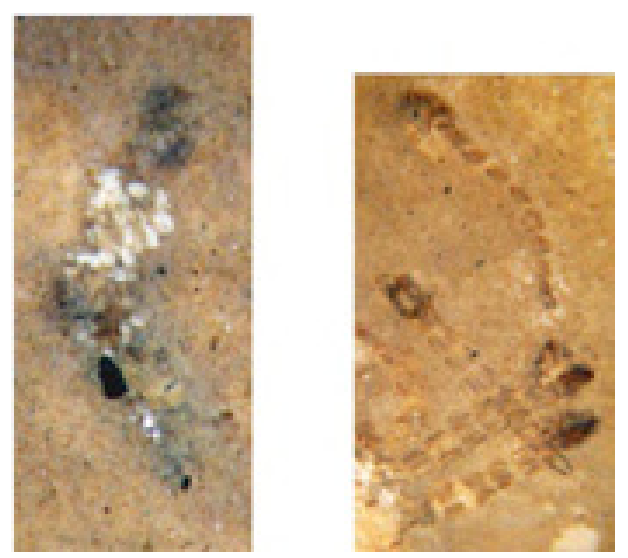

Fossil faecal deposits containing fossilized foraminifera and mosquito larvae's 
IGME will coordinate in Galicia (NW Spain) the European Project "Atlanterra" to valorize the mining heritage of this region Atlanterra is a biannual project (2010-2012) organized among European Atlantic regions and financed with FEDER funds. It groups ten European partners, geological surveys (Spain, Ireland and Portugal), local administrations and organizations related to the mining heritage of Ireland, Wales, France and Portugal.

It intends to contribute to the socioeconomic development of the regional involved by promoting cultural tourism and geotourism in regions degraded by the mining activity

Galicia shares with other Atlantic regional and rich mining past. During centuries from these territories a great variety of mineral resources have been extracted both in open cast operations and in underground mines. Mining remnants in Galicia are frequent although badly known, and this does not facilitate its touristic use. Some of them are very significant for history, whilst other are sole testimonies of the way miners worked. All of which has left a historical and cultural legacy which once inventoried and valorized could contribute to the local developments.

The work is coordinated in Spain by Dr Enrique Diaz Martínez and Angel Ferrero Arias (in Galicia)
The general objective of this international project is to valorize the abandoned mining sites located in the European Atlantic Space to contribute to its socioeconomical development. The project plans three specific objectives: cultural and nature tourism promotion, outreach of the culture and traditions associated to the mining activities and the sustainable management of this historical cultural and natural heritage.

Activities include the digital filing of documents, design of geological gardens (open air museums), promotion of geoparks, visual documenting mining landscapes, promotion of ecological studies in mining areas, research on the mining commerce routes, publication of documents and guides in pdf, mp3 and mp4 format, mining heritage maps, panels for itineraries and exhibitions, geocaches, design of itineraries to visit the geological and mining heritage, etc.

The diffusion and touristic promotion of the mining heritage of Galicia pretends to enlarge the knowledge of this type of arqueo-industrial heritage, improve the society perception of its value, and promote its reclamation, preservation and valorization. It is also envisaged a transnational network of mining heritage sites in the Atlantic Space of the EU and to establish the criteria and methodologies to develop valorization strategies to promote socioeconomic and cultural development of these areas.

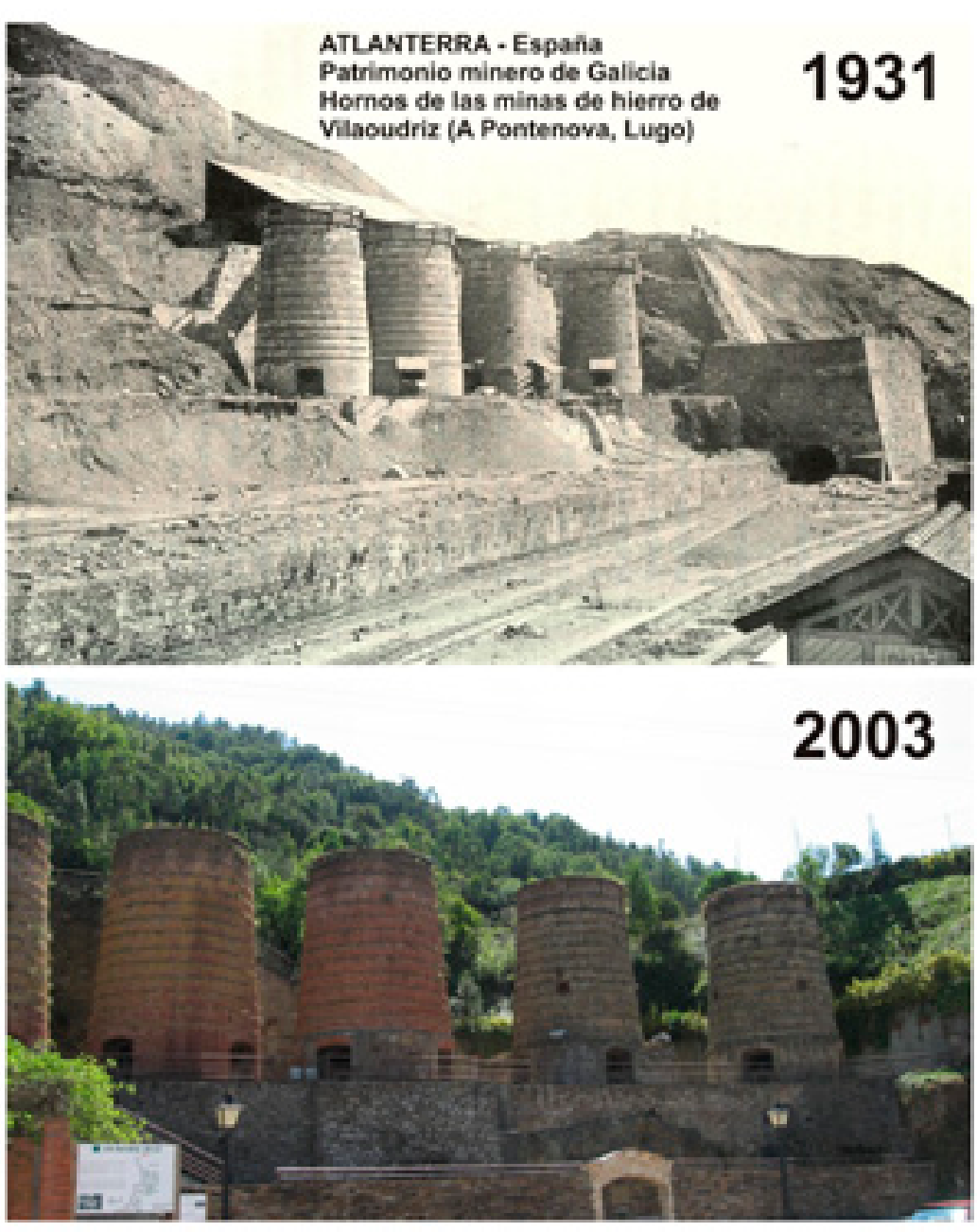


Found in Cantabria world class fossilized bacteria, that lived one million year ago inside the El Soplao cave

These fossil bacteria formed a new unknown type of stromatolite formed by manganese oxides instead of calcium carbonate, the normal

stromatolite composition. Similar living organisms appear in the fossil record since 3500 Million years and represent the oldest living forms appearing on Earth.

A team of researchers leaded by Rafael Lozano from the Geological Survey of Spain, have found inside the El Soplao cave (Cantabria, North Spain) a new type of stromatolite completely unknown on Earth. The findings have been recently been published in the international magazine Geology.

The discovered bacteria did not built the stromatolite structure as a result of photosynthesis, as is the case in normal stromatolites, since they were formed inside the cave, in absolute darkness. They are formed by manganese oxide, which gives them a black colour, contrasting sharply with the rest of the cave formations. Researchers think that the stromatolites formed in an underground river around one million years ago. The manganese dissolved in the water was used by a special type of microbia, bacteria able to oxide manganese and live in a hostile environment where nutrients were scarce. These quimiosynthetic organisms used a chemical reaction (manganese oxidation) instead of light, to synthesize their organic material.
The unusual and excellent conservation state of the fossil bacteria has allowed researchers to justify the biologic origin of these materials as normally bacteria cells degrade rapidly and are 100 times smaller than the thickness of a hair. The discover is a huge step forward in the research of

extremophille organisms specialized in oxidizing manganese and provide new clues to understand iron and manganese stromatolites found in rocks

2000 million years old
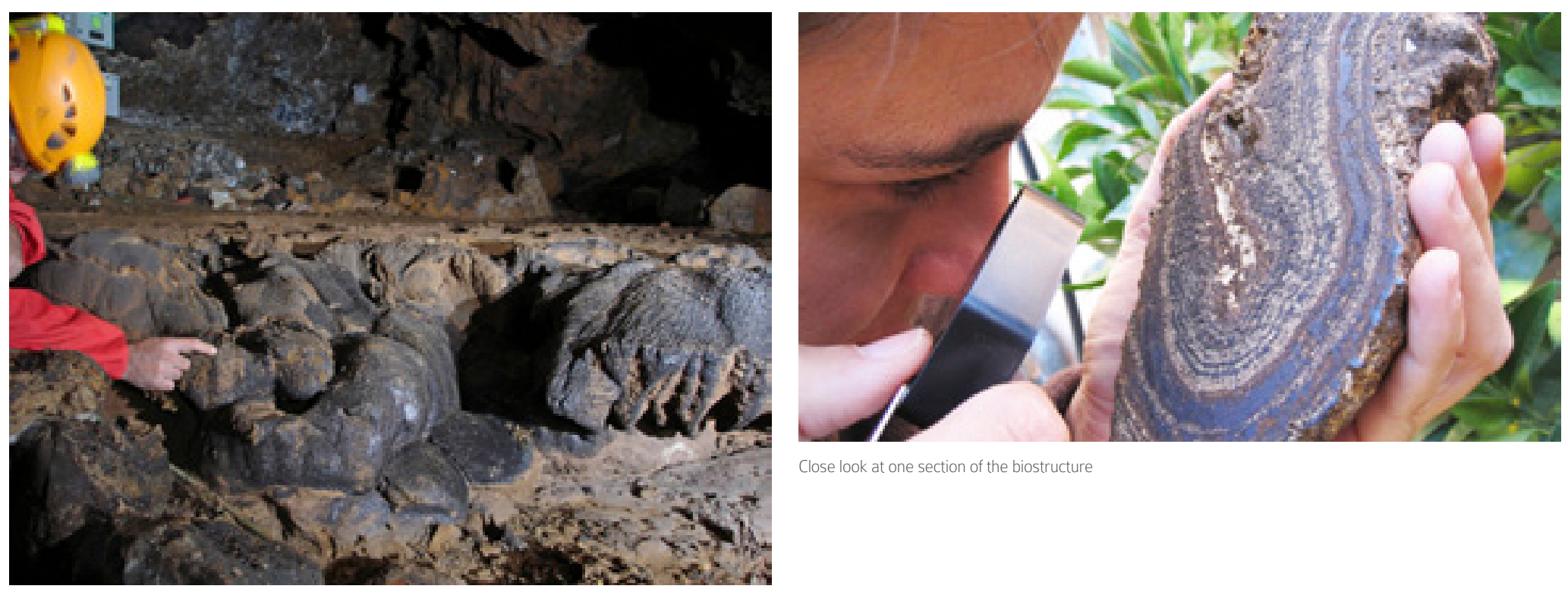

Stromatolites inside the cave
Close look at one section of the biostructure 
5 satellites of different space agencies will study ground movements in the Tramuntana range of the Mallorca island

The European Project DORIS, is a three years

project based in the collection and analysis of the

information obtained by radar sensors transported

in the satellites and installed in situ. The analysis of the images captured in 300 different dates will

allow detecting and quantifying ground movements

in "active" zones. The objective is to obtain

knowledge to mitigate the effects of ground

movements by a sustainable and safer land

planning Mallorca is an island prone to frequent

landslides due to intense rains that caused the

collapse of several roads and left without

communication several villages in the Mallorca

range. Here landslides are active processes which

happen repeatedly in time, causing high economic

losses. The knowledge of such processes is basic

for a sustainable land use planning, as is almost

impossible to forecast the exact moment when

they will happen.

Doris will have the information supplied by five

satellites of several space agencies and to obtain it,

it has been requested the reorientation of the

German satellite Terrasar X

IGME has already an ample experience in similar projects (GALAHAD in the Tena Valley in the

Pyrenees and TERRAFIRMA in the city of Murcia) in which the technologies and methodologies have already been tested, and the project is handled in Spain by Dr Gerardo Herrera.
Reviewing the radar images by three satellites of ESA (ERS-1, ERS-2 and Envisat) active during the $90^{\prime}$ will provide information about the sensible zones. Then the Japanese Alos Palsar (every 45 days) and German Terrasar X (every 11 days) satellites images will be added. A total of 300 images

will be studied which will allow to detect and quantify ground movements in active zones.

Since satellite images cannot detect slow movements (15-30 cm/year) a network of terrestrial radars will be also installed in the mountains.und It is expected that the information obtained by the combination of satellite and ground radars will provide information about the most sensible zones before a landslide happens which will permit to establish prevention measures to reduce or mitigate the effects of this natural processes. 


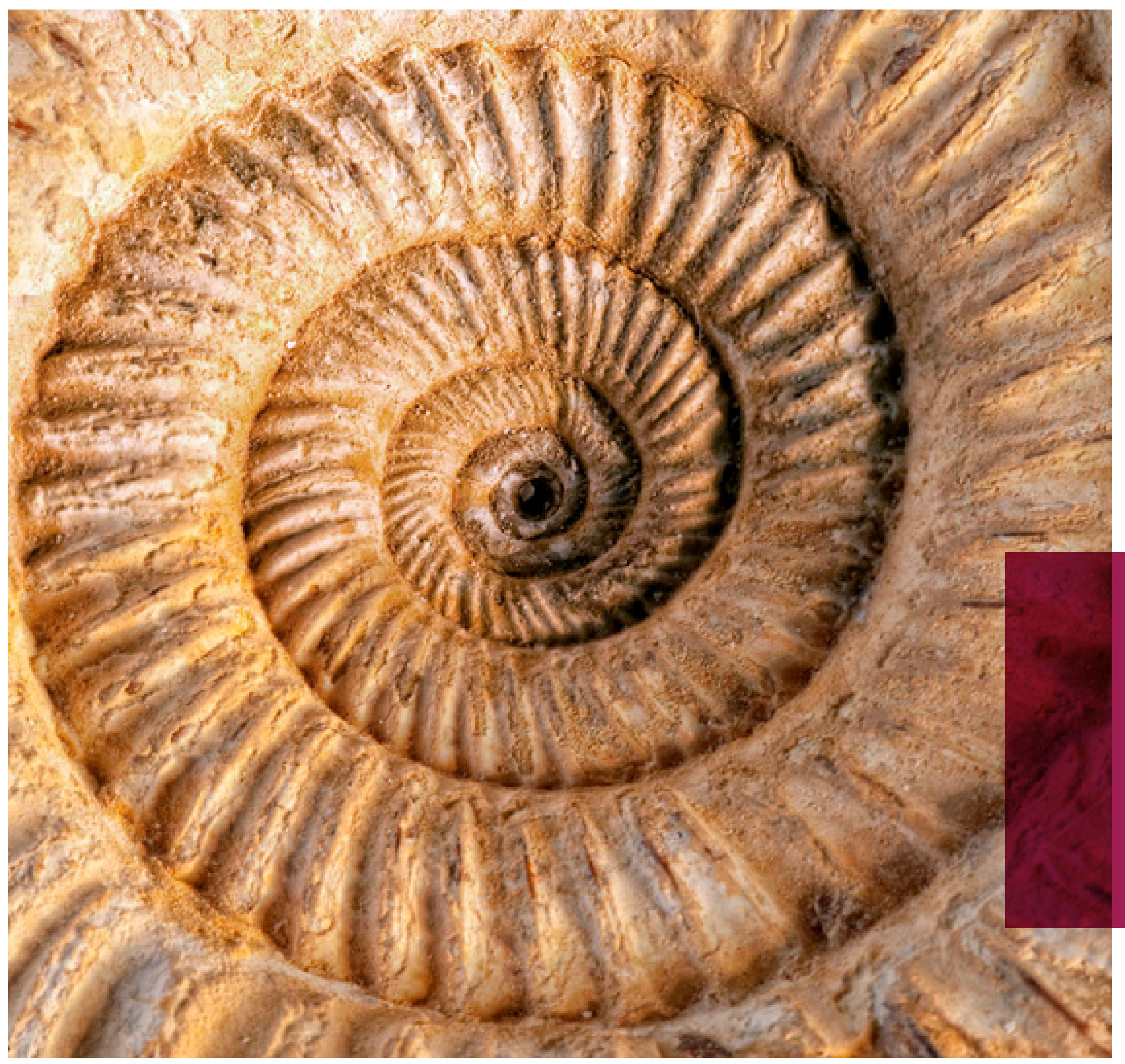




\section{$\lambda$ The shape of our business}

We are organised into Expert Groups integrating information, knowledge and expertise deriving from our member surveys in fields such as natural hazards, water, soils, energy, mineral resources, marine geology, spatial data, carbon capture and storage, geochemistry and Earth observation.

\section{EXPERT GROUP ON CO STORAGE}

\section{Mission and vision}

$\mathrm{CO}_{2}$ Capture and Storage (CCS) can be a vital technology in the mitigation of climate change over the next few decades and a rapid implementation is required to reduce $\mathrm{CO}_{2}$ emissions in time. The acceptance and technical success of CCS relies largely on the safe and permanent geological storage of $\mathrm{CO}_{2}$. To achieve this objective, proper legislation, objective evaluation of projects, and expertise and quality data on the deeper subsurface are required. The Geological Surveys have the relevant data, expertise and objectivity, facilitating their meaningful contribution to a successfu implementation of the emerging technology.

The expert group EGS.CO directly groups the expertise of 16 Geological Surveys and is the official voice of the Geological Surveys of Europe on $\mathrm{CO}_{2}$ Capture and Storage. Its mission is to engage in a dialogue with the relevant European institutes, and use its own expertise to interface between European and national policy levels. As such its agenda is closely linked to the transposition, evolution and interpretation of the CCS directive. EGS.CO offers a unique platform to monitor national and European activities at first hand and to take up the challenge to play a very significant role in the future development, evolution and deployment of CCS in Europe and beyond.

\section{Scope and focus}

Historically, Geological Surveys have fuelled the thriving European economies by providing knowledge about coal, oil and natural gas resources in the continent and further afield. In the process the Surveys have built up a profound understanding of the Earth's subsurface and have become the caretakers of huge amounts of geological information. EGS. $\mathrm{CO}_{2}$ wishes to ensure that this expertise is applied to the correct, reliable and flawless implementation of CCS, and on storage projects in particular.

Societies throughout the world are engaged in a largely cooperative race to decarbonise the global economy. Europe stimulates this process and it is demonstrating that a continent can successfully set and meet emission and renewable technology targets. $\mathrm{CO}_{2}$ Capture and geological Storage (CCS) is projected to become an essential part of this process in the near future. It has the potential to reduce the overall cost of climate measures in very low emission scenarios and offers the potential to achieve even deeper and earlier $\mathrm{CO}_{2}$ reduction targets. Decarbonisation of the power sector is often cited, but CCS is also the only solution for drastic emission cuts in sectors such as iron and steel, cement, petrochemistry, etc. for which in contrast to the power sector, no 'renewable' alternatives exist.
Geological storage of $\mathrm{CO}_{2}$ forms the key element in the CCS scheme. $\mathrm{CO}_{2}$ needs to be stored permanently in geological formations in order to turn CCS into a technological success. In spite of the complexity and uniqueness of each storage project, society is not likely to accept failure of the projects that seek to demonstrate the viability, and safety and security of this technology

EGS.CO recognises the ambitious climate goals that society is faced with, and the benefits that CCS offers in this respect. As such, CCS should be considered as a necessary mid-term portfolio option because of the way it facilitates meeting substantial climate change targets. At the same time it is sufficiently expensive to result in a reduced use of fossil fuels in the long-term thus facilitating a transition towards other less carbon intense energy resources, including renewable, sources.

However, EGS.CO is very well placed to see that CCS is currently at a tipping point. A successful demonstration of CCS projects in Europe, especially of the geological aspects, will lead to wide-scale deployment of this technology driven only by the ETS price of $\mathrm{CO}_{2}$ when this attains the expected and commercially viable levels. We envisage that there will be a commensurate rapid increase in demand for private, project related expertise, but equally for governmental competence because nationa Competent Authorities will become responsible for approving, follow-up and aftercare of storage sites, especially for safety control and verification. The Geological Surveys need to play their role to prevent a potential vacuum in expertise vital to servicing all of these requirements. 
There is also the risk that the situation may tip in the opposite ditrection. Geological Storage of $\mathrm{CO}_{2}$ holds very little direct risks to man or nature. Nevertheless, the perception is such that even a minor geotechnical failure may be perceived as sufficient proof that the technique should not be deployed on a large scale. The geological community, lead by the Geological Surveys, therefore carries the responsibility to ascertain the highest possible level of quality of the projects. Geological Surveys may also use their environmental expertise to implement the monitoring plans that need to detect potential leakage at the earliest possible stage. EGS.CO, therefore promotes, depending on the national context, the active participation of national Surveys in such projects, or alternatively encourages them to assume the role of the attentive and objective observer. EGS.CO takes upon itself the role of watchdog and communicator with open channels to European and National policy levels.

\section{The European dimension}

The CCS Directive (Directive 2009/31/EC) was approved in April 2009 by the European Parliament and forms the legal basis for deploying CCS activities across Europe. This directive needs to be transposed by the EU member states by 25 June 2011. In spite of its name, this directive focuses principally on storage issues. Four Guidance Documents were prepared in 2010 for the European Commission by the consultant group ICF International, a consortium of consultants with experts from Europe, the US and Australia. The content of successive draft versions were discussed with representatives of the member states during Information Exchange Group (IEG) meetings in the spring of 2010, The draft documents were opened for public consultation in the summer, the results of which were again presented to the IEG group in the autumn of 2010

\section{Activity report}

The activities of EGS.CO2 in 2010 were focussed on assisting DG Environment/Climate Action in the preparation of a set of "Guidance Documents" intended to assist Member States transpose the CCS Directive into national legislation.

Following an introductory meeting between DG Climate and EuroGeoSurveys, EGS.CO2 was invited to attend the IEG meetings where the draft Guidance Documents were discussed; and to input into their revision in parallel with that of the member states, and ahead of the public consultation process. EGS.CO2 was involved in the drafting of these documents from the initial outline texts through to the final draft and it provided oral and written comments at the IEG meetings. An overview of these meetings and the different notes that were prepared is listed in table 3.2. $\rightarrow$ questions

Venue: Geological Survey of Belgium, Brussels.

EGS.CO2, 2010, EGS.CO2 reply (29-03-

2010) on sharing of databases on geological

storage capacity in Europe that were

created during FP projects. $2 \mathrm{p}$.

\section{2/04/2010}

EG Meeting

IEG-meeting on the skeleton text for the Guidance Documents in relation to the CCS-directive (Brussels).

$30 / 04 / 2010$

Review remarks

IEG-meeting on the first drafts of the Guidance Documents (Brussels).

EGS.CO2, 2010, Introduction to the review

of the draft Guidance Documents on the

Implementation of the European Directive

on the Geological Storage of Carbon

Dioxide. 6 p.

$11 / 05 / 2010$

Public presentation

Presentation on the Open Venice Forum in the activities of EGS.CO2:

\section{EGS.CO2, 2010, Role of the}

EuroGeoSurveys' Expert Group on $\mathrm{CO} 2$

storage. CO2GeoNet open forum, Venice,

10-11/05/2010.

$\begin{array}{ll}\text { 20/05/2010 } & \text { Note to ad-hoc } \\ \text { question }\end{array}$

After specific remarks from EGS.CO2 that reflected specific concerns among our members, we were asked to provide our vision on how concession boundaries should be defined. This was done in the following note:

EGS.CO2, 2010, The vision of EGS.CO2 on

the issue of concession boundaries for $\mathrm{CO} 2$

storage sites. $4 \mathrm{p}$.

19/06/2010

Presentation

EGS.CO2, 2010, EuroGeoSurveys' Expert Group on CO2 storage. 25th National Delegates Forum

$14 / 09 / 2010$

IEG Meeting of EuroGeoSurveys (Budapest, 29-30/06/2010).

$14 / 09 / 2010$ Review remarks EG-Meeting on the fin

09/10/2010 Documents (Brussels).

EGS.CO2, 2010, Final review of the draft

Guidance Documents on the

Implementation of the European Directive

on the Geological Storage of Carbon

Dioxide. 6 p. 
The c. 120 page "Guidance Documents" are expected to be released publically during the first half of 2011 . The time frame for reviewing these highly technical documents was short and an efficient review procedure was needed. This was done by assigning the main chapters to topic leaders, a role generally assumed by one or other of the larger Geological Surveys (TNO, BGR, BRGM, BGS, and GSB as back-up). These were expected to have the flexibility to do a quick, but thorough review of the chapters corresponding to their topic, which formed phase 1 of the review process. During phase 2, the other partners were invited to add their comments to the documents already reviewed by the topic leaders. Phase 3

consisted of summarizing and discussing the different comments. This three stage review process allowed the completion of in-depth revisions that combine the remarks of reviewers from 16 institutes in a time span of only 3 weeks, as is demonstrated in figure 3.1 .

During 2010 EGS.CO 2 worked as an ad-hoc group without the direct need to advertise itself outside of the IEG review group. Our activities nevertheless did not remain unnoticed, and the group was invited to present their current work to the "Open Venice Forum", a well known event in the CCS community organised on a yearly basis by $\mathrm{CO}^{\mathrm{G}} \mathrm{GeoNet}$

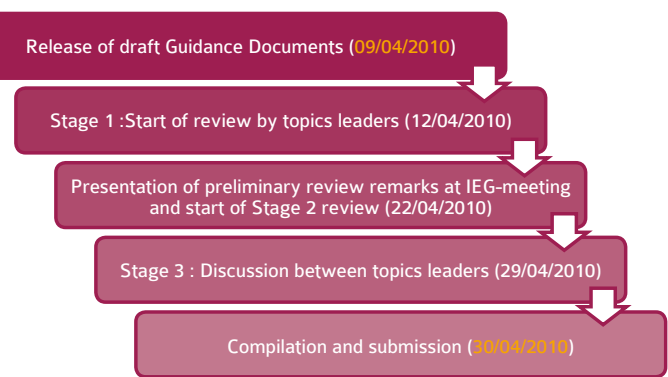

\section{Results and impacts}

The national representatives of the IEG group are mainly legislative experts, and EGS.CO quickly profiled itself as the technical reviewer of the Guidance Documents. Larger parts of the Guidance Documents were severely edited with minor and major revision marks. This led to direct discussions between the authors of the report and EGS.CO, a process which facilitated both a significant improvement in their content as well as adherence to the very strict timeline imposed for preparation of the documents.

The influence of $\mathrm{EGS}_{\mathrm{CO}} \mathrm{CO}_{2}$ is clearly noticeable throughout the document when the final version is compared to the contributions we made during its preparation. One of the more obvious improvements is the clear and explicit reference that is made to the role and expertise of the national Competent Authorities. This was lacking from the initial versions, but was adopted after $\mathrm{EGS}$. $\mathrm{CO}_{2}$ stated that a detailed discussion on the role of Competent Authorities was compulsory.

\section{Future perspectives}

In 2010, EGS.CO 2 worked through the official channel of the Information Exchange Group in close contact with DG Climate Action. This situation will change in 2011 when a Scientific Panel of independent experts will be convened by DG Climate Action as a more official advisory board.
The momentum of the successful outcome of its efforts in its inaugural year,2010 provides EGS.CO with the impetus to develop and evolve new CCS activities. It will be given the foundations that reflect the different tasks, responsibilities and activities of the Geological Surveys regarding $\mathrm{CO}_{2}$ Geological Storage. This different approach is visualised in Figure 5.1. In 2010, EGS.CO mainly functioned as a relay between the European level and the national Geological Surveys that are members of EGS.CO This was an efficient system for gathering answers to questions from the EU, or the review of European documents, which were the main tasks in 2010

This vertically orientated flow of information will be replaced by horizontal information exchange to generate a network between the Geological Surveys through which questions, expertise and other information on CCS can be distributed. This exchange is important for uniform competence building across the European surveys, but will especially allow the identification of perspectives, problems or queries that transcend beyond the national level. These will be communicated to the European level, which will be facilitated through the contacts established in 2010

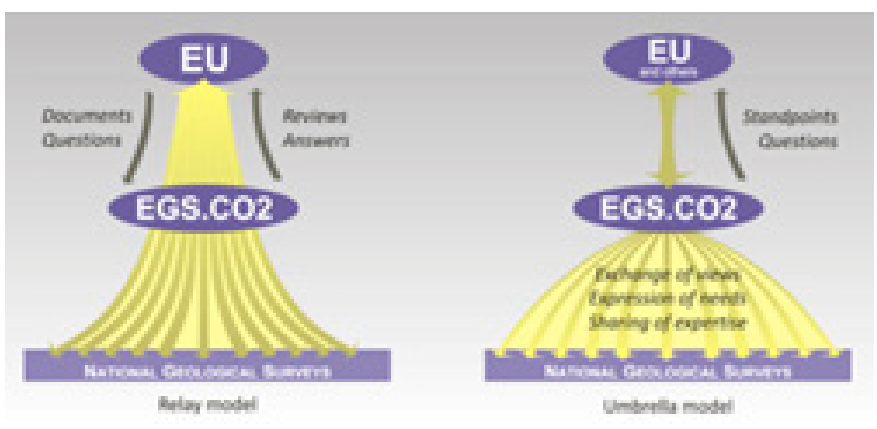


5.1 Visualisation of the organisation of EGS.CO in 2010 ('relay' model) and 2011 ('umbrella' model). The activities in 2010 were very much focussed on interacting with the European Commission, resulting in mainly vertical exchange of information. In 2011, focus will more be on the horizontal interaction between the Geological Surveys, with separate information exchanges with the central authorities.

\section{Members list}

\begin{tabular}{|lll|}
\hline Country & Survey & Name \\
\hline Belgium & GSB & Kris Piessens (Chair) \\
Czech Republic & CGS & Vit Hladik \\
Denmark & GEUS & Karen Lyng Anthonsen \\
Finland & GTK & Runar Blomqvist \\
\hline France & BGRM & Isabelle Czernichowski \\
Germany & BGR & Peter Gerling \\
Greece & IGME & Yiorgos Chatziyiannis \\
Hungary & MAFI & Anna Maria Nador \\
Ireland & GSI & John Morris \\
Italy & ISPRA & Fernando Ferri \\
Poland & PGI & Marek Jarosiński \\
Slovak Republic & SGUDS & Ludovit Kucharic \\
Spain & IGME & Roberto Martinez Orio \\
Sweden & SGU & Linda Wickström \\
The Netherlands & TNO & Henk Pagnier \\
United Kingdom & BGS & Nick Riley (Deputy chair) \\
\hline
\end{tabular}

\section{EXPERT GROUP ON WATER} RESOURCES

\section{Mission and Vision}

The focus of the Expert Group on Water Resources is on groundwater management and protection in general, and more specifically related to the groundwater aspects of the Water Framework Directive (WFD), the Groundwater Directive (GWD 2006) and the Common Implementation Strategy (CIS) of both directives.

The main activities are:

- Support and advise to DG-ENV on technical and policy-related issues

- Indentify knowledge gaps for the EU research

agenda

- Sharing experiences between member organizations in WFD and GWD implementation. A complete list of EGWR members appears as Annex I.

\section{Scope and focus}

The scope of the expert group on water resources (egwr) has been related to the groundwater aspects of the water framework directive (wfd, 2000) and on the negotiations of the groundwater directive (2006) and its subsequent implementation through the

common implementation strategy (cis).

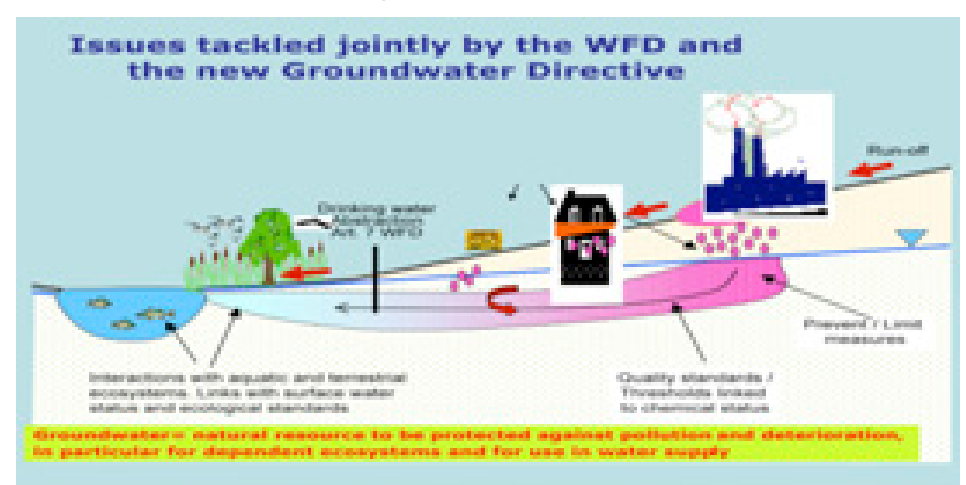

Between 2003 and 2006 EuroGeoSurveys actively contributed to discussions on the definition of the draft Groundwater Directive and the implementation of the Water Framework Directive (WFD).

EuroGeoSurveys representatives were involved in support and advise to DG-ENV on technical and policy-related issues in the Expert Advisor Forum and the EU Working Group C, which is part of the Common Implementation Strategy of the WFD.

1.2 The GWD and WFD involve an new paradigm in protection of groundwater, with increased emphasis on aquatic and terrestrial ecosystems and on the mutual influence of groundwater on surface waters.

Since 2006, after the GWD was enacted, EuroGeoSurveys has played an active role in the overall discussions within Working Group C and in the implementation process by leading and participating in drafting groups for Guidances. Moreover, the Expert group took initiatives in order to influence the EU research agenda in order to close knowledge gaps that were identified.

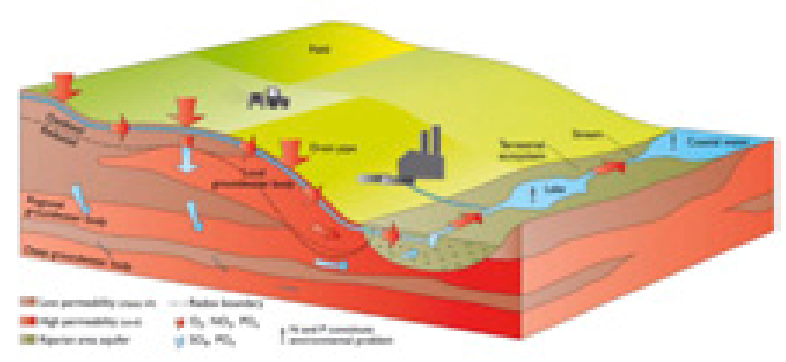

1.2 The GWD and WFD involve an new paradigm in protection of groundwater, with increased emphasis on aquatic
and terrestrial ecosystems and on the mutual influence of groundwater on surface waters.
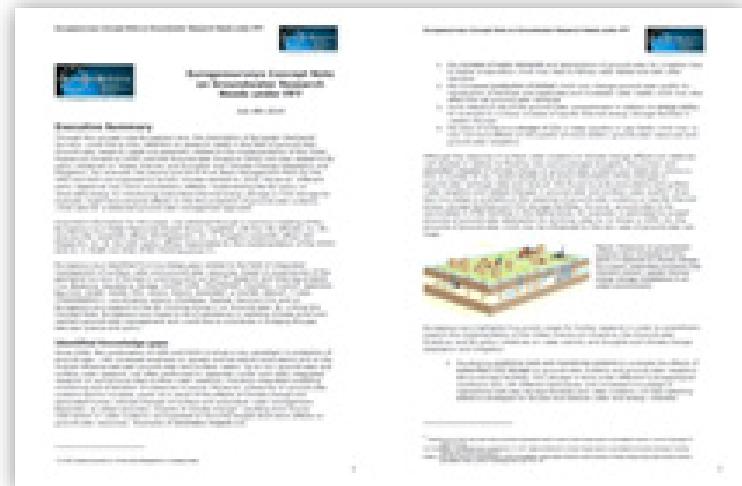
This resulted in two concept notes on Groundwater research needs under FP7, one in 2007 and one in 2010, which were discussed intensively with EU policy and scientific officers. In 2008 this lead to to a dedicated Groundwater Systems topic in the second call of FPVII. The 2010 concept note is attached in Annex II to this Annual Report.

Members of the Expert Group contributed to a large number of conferences on Groundwater Aspects in European policy and have contributed to two books which bring together science and policy aspects of Groundwater. EuroGeoSurveys contributed to 12 of the chapters of the Royal Society of Chemistry book 'Groundwater Science and Policy' (2008) and to 13 chapters of Wiley book 'Groundwater Quality Assessment and Monitoring' (2009), booth edited by EU policy officer Mr. Ph. Quevauviller.

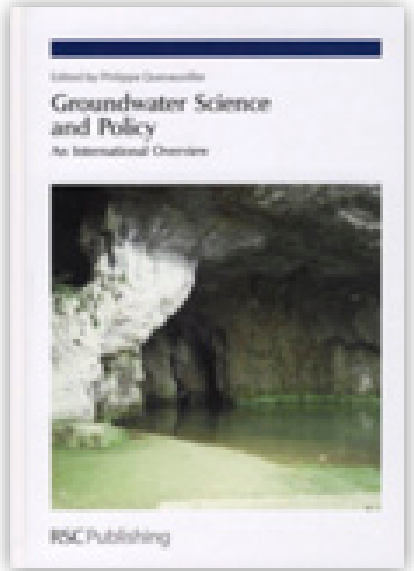

\section{The European dimension}

Between 2003 and 2006 EuroGeoSurveys actively contributed to discussions on the definition of the draft Groundwater Directive and the implementation of the Water Framework Directive (WFD).

EuroGeoSurveys representatives were involved in support and advice to DG-ENV on technical and policy-related issues in the Expert Advisor Forum and the EU Working Group C, which is part of the Common Implementation Strategy of the WFD.

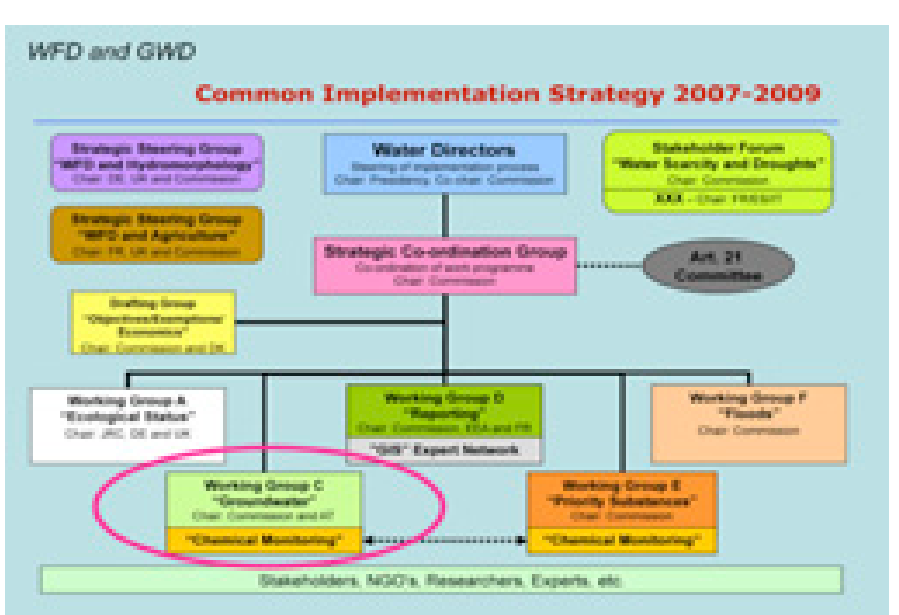

1.3 Overview of the position of EU Working Group C in the Common Implementation Strategy for the WFD and GWD.

Since 2006, when the GWD was enacted EuroGeoSurveys has played an active role in leading drafting groups, writing Guidances for the implementation of the GWD, contributing and chairing and co-chairing drafting groups on
- Guidance on Groundwater Status and Trend Assessment No. 18 (chair/co-chair, 6 EGS

members contibuting, Guidance endorsed 2009)

- Guidance on Groundwater Monitoring (4 EGS

members, endorsed 2007)

- Guidance on Groundwater Aspects of Protected Areas (4 EGS members, endorsed 2008)

- Guidance on Direct and Indirect Inputs to

Groundwater (2 EGS members, endorsed 2008).

These four Guidances form the heart of the Common Implementation Strategy of the Groundwater Directive.

The period 2009-2012 will be the start of a new period in the development of the WFD and GWD, with new scientific challenges and other activities than in 2007-2009. Work in the period 2003-2006 focused on the negotiation process of the GWD, in the period 2006-2009 on the drafting of the key Guidance s for implementation, and the period 2010-2012 is anticipated to focus on the preparation of the official review of the GWD in 2013. The work of the EGWR will change again adapting to these new circumstances. An important new scientific challenge will be the attention to the effects of Climate Change on Groundwater Systems, which also brings new opportunities to express EGS views and to influence the EU research agenda. EuroGeoSurveys chairs this EU activity. 


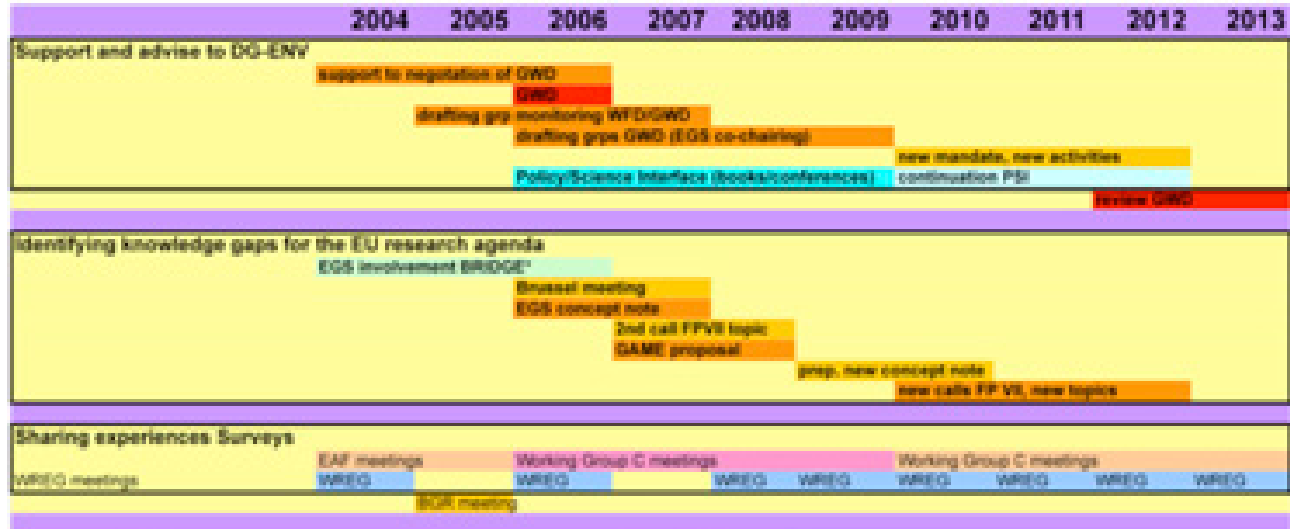

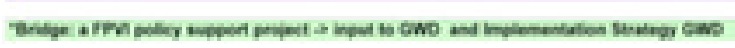

\section{Activity report}

The following specific activities have been performed in 2010 :

- Meeting of EGS secretary general and chair and co-chair of the EGWR with the new policy officer Balasz Horvath, discussing possible EGS input to the process of the 2013 GWD review and the new Working Group C activities. A total of 10

EuroGeoSurveys representatives now take part in WGC activities, chairing two of the three activities

- Preparation of a EuroGeoSurveys Concept Note on Groundwater Research Needs under FP7 which was presented to DG-ENV and DG-

Research in July 2010. The concept note identifies knowledge gaps in the field of:

- Subsurface $\mathrm{CO}_{2}$ storage and groundwater impacts

- Understanding the impacts of Climate Change on quantity and quality of groundwater resources

- Urban groundwaters: managing conflicting

demands on groundwater resources

- Groundwater Dependent Ecosystems (GDE) :

procedures for damage control

- Groundwater and Emerging Pollutants

- Organization of a one-day EGWR workshop in

Brussels (April 2010) in order to discuss the
2010-2012 EGWR activities, the role of EGWR in the support of the 2013 GWD review and to discuss the draft of the EuroGeoSurveys concept note with the following EU officials:

- Mr. Ph. Quevauviller (scientific officer DG-Research) - Mr. C. Fragakis (scientific officer DG-Research)

- Mr. B. Horvath (policy officer responsible for the implementation of the GWD)

- Mr. J. Grath (co-chair of EU Working group C).

- Meeting of Chair and senior EG member with Ph.

Quevauviller in its new role as Scientific Officer

- Attending the May 2010 Madrid and October 2010

Brugge meetings of EU Working Group C

- Preparation and presentation of a proposal for workshops on the topic of Groundwater and Climate Change Impacts as a start-up of the EU WGC ad hoc task. The task is now approved and will start in 2011. It will be chaired by EuroGeoSurveys.

\section{Results and impacts}

There is a great appreciation by the EU for the support and advice of EuroGeoSurveys, which is illustrated by the fact EG Water members chair two of the three EU activities in the WFD Common
1.4 Past, present and future activities of the Expert Group on Water Resources

Implementation Strategy in the field of Groundwater. The DG-Research officials also showed much appreciation for the EuroGeoSurveys input for future FP7 calls.

\section{Future perspectives}

Future groundwater resources management requires sound knowledge of groundwater systems and the EuroGeoSurveys Water Resources Expert Group identified a number of issues that should be addressed in future research programs. The groundwater research needs that we identified are especially related to the implementation of the Water Framework Directive (WFD) and the Groundwater Directive (GWD) but also related to EU policy initiatives on

'Water Scarcity and Droughts' and 'Climate Change Adaptation and Mitigation'. For example, the second and third River Basin Management Plans for the WFD and GWD are supposed to be fully climate-resilient by 2015. Moreover, different policy objectives may have contradictory effects; implementing the EU policy on renewable energy by introducing subsurface thermal energy storage, the storage of $\mathrm{CO} 2$ for example or the increased exploration of unconventional fossil fuel reservoirs, might have adverse effects on the protection of groundwater systems, which asks for a balanced groundwater management approach.

In its 2010concept note, EuroGeoSurveys highlighted five priority areas for further research in order to scientifically support the implementation of the Water Framework Directive, the Groundwater Directive: and EU policy initiatives on water scarcity and droughts and climate change adaptation and mitigation. 
These include:

- Developing predictive tools and monitoring

systems to evaluate the effects of subsurface $\mathrm{CO}_{2}$ storage on groundwater systems and

groundwater receptors above storage facilities

- Develop methodologies to understand, evaluate and predict the impacts of climate change on groundwater resources and interlinked surface waters and ecosystems in order to eventually

define climate-robust set of measures

- Developing tools to facilitate management

strategies for multiple uses of groundwater in

urban areas. Predictive tools and monitoring

systems

- Developing tools for relating response of Groundwater Dependent Ecosystems to the condition of groundwater systems, and to improve assessment of climate change and restoration/ protection measures

- Developing strategies to deal with the impacts of emerging pollutants in groundwater management and protection

- In supporting the European Commission in these fields, EuroGeoSurveys now chairs an ad hoc activity for EU Working Group C on Groundwater and Climate Change and organizes a workshop which is used to share information and exchange views between member states and stakeholders and could identify what the needs are for future work in Climate Change and Groundwater, both from policy and scientific perspective.

\section{Members list}

The EG Water is chaired by Hans Peter Broers (TNO) and Ariane Blum (BRGM). The group has a total of 51 members on the information list and about 38 active, full members from most of the Member States.

Annex I: Members of the Water Resources Expert Group

\begin{tabular}{|lll|}
\hline Country & Survey & Name \\
\hline THENETHERLANDS & TNO & Hans Peter Broers - CHAIR \\
FRANCE & BRGM & Ariane Blum - co-Chair \\
\hline ALBANIA & AGS & Arben Pambuku \\
AUSTRIA & GBA & Walter Kollmann \\
& GBA & Gerhard Schubert \\
CROATIA & HGI_CGS & Željka Brkić \\
\hline CYPRUS & GSD & Costas Constantinou \\
CZECH REPUBLIC & CZS & Renata Kadlecova \\
\hline DENMARK & GEUS & Per Rosenberg \\
& GEUS & Klaus Hinsby \\
& GEUS & Heidi Christiansen Barlebo \\
& GEUS & Lærke Thorling \\
\hline FINLAND & GEUS & Birgitte Hansen \\
\hline FRANCE & GTK & Jarkko Okkonen \\
GERMANY & BRGM & Didier Pennequin \\
\hline GREECE & BGR & Wilhelm Struckmeier \\
\hline HUNGARY & IGME & George Zacharioudakis \\
\hline IRELAND & MAFI & Teodora Szocs \\
\hline ITALY & GSI & Monica Lee \\
\hline & ISPRA & Michele Fratini \\
& ISPRA & Lucio Martarelli \\
\hline & ISPRA & Fabio Pascarella \\
\hline
\end{tabular}

\begin{tabular}{|c|c|c|}
\hline LITHUANIA & LGT & KESTUTIS KADUNAS \\
\hline \multirow[t]{2}{*}{ NORWAY } & NGU & Atle Dagestad \\
\hline & NGU & Jan Høst \\
\hline \multirow[t]{3}{*}{ POLAND } & PGI & Leslaw Skrzypczyk \\
\hline & PGI & Lech Smietanski \\
\hline & PGI & Anna Kuczynska \\
\hline PORTUGAL & LNEG & Augusto Marques da Costa \\
\hline SLOVAK REPUBLIC & SGUDS & Peter Malik \\
\hline SLOVENIA & GEOZS & Janko Urbanc \\
\hline \multirow[t]{3}{*}{ SPAIN } & IGME & Juan de Dios Gómez Gómez \\
\hline & IGME & Juan Antonio de la Orden Gomez \\
\hline & IGME & Miguel Mejias Moreno \\
\hline SWEDEN & SGU & Magnus Åsman \\
\hline SWITZERLAND & FOEN & Ronald Kozel \\
\hline \multirow[t]{3}{*}{ UK } & BGS & Robert Ward \\
\hline & BGS & Denis Peach \\
\hline & BGS & John Chilton \\
\hline \multirow[t]{4}{*}{ BELGIUM } & GSB & Eric Goemaere \\
\hline & GSB & Michiel Dusar \\
\hline & GSB & Marleen de Ceukelaire \\
\hline & GSB & Walter de Vos \\
\hline DENMARK & GEUS & Jens Christian Refsgaard \\
\hline ESTONIA & EGK & Rein Perens \\
\hline FINLAND & GTK & Olli Breilin \\
\hline GERMANY & BGR & Birgit Kuhns \\
\hline HUNGARY & MAFI & Gyorgy Tòth \\
\hline \multirow[t]{3}{*}{ POLAND } & PGI & Jan Mitrega \\
\hline & PGI & Andrzej Sadurski \\
\hline & PGI & Maciej Klonowkski \\
\hline SWEDEN & SGU & Lisbeth Hildebrand \\
\hline
\end{tabular}




\section{EXPERT GROUP ON MARINE}

\section{GEOLOGY}

The Marine Geology Expert Group includes representatives from 22 of the EuroGeoSurveys member organisations. In addition, associate members from non-EGS member organisations make a valuable contribution to the group's objectives (see section 9). During 2010 members of the Marine Geology Expert Group (MGEG) have continued to be active in several EC-funded projects, both as groups of EGS members and as individual participants. MGEG members are also involved in discussions to develop new EC proposals and ventures.

The main EC-funded project activity has been the EMODNET-Geology Project. Several MGEG members also participated in the Geo-Seas Project. During 2010, the Southern Permian Basin Atlas was published (June 2010) a project that involved marine scientists and petroleum geologists from six of the EuroGeoSurveys members.

\section{Mission and vision}

The Marine Geology Expert Group (MGEG) aims to deliver high-quality information and advice to inform decision-makers responsible for the European seas, and to lead in issues of global importance.

The group established a long-term strategy in 2004 when a document was submitted to

EuroGeoSurveys titled 'Geoscience for European Ocean Management - Outlook for the Next Decade' in which emphasis was placed on cross-cutting issues such as sustainable use of natural resources, climate change, habitat mapping natural hazards and long-term maintenance of databases.

The underpinning factor of this strategy was the need to establish a system that provides the European Community with the geological knowledg required to inform decisions that affect the marine environment The group promotes the view that marine geological information and interpretations are a fundamental requirement for all activities that take place in the European seas. For example, the definition of marine habitats as required by the EU Habitats and Birds Directives requires a basic framework in which to assess the importance of any habitat.

Although the group focuses on work carried out within the national geological survey organisations, it is essential that we continue to look outwards to develop collaboration between marine geologists and the marine biological, oceanographic/ hydrographic and chemistry communities, who ogether form the main providers of scientific

information for the European marine community. We also consider that it is essential for the group to expand its geographical scope whenever possible, as the issues that affect the European seas are not constrained by national boundaries.

The need to maintain collaboration between the marine departments of the surveys has never been greater. At national level, most, if not all, EU Member States are introducing policies that ensure better integration of marine science. The drivers towards these policies are mainly EU Action Plans and Directives (see section 3), and it is important that EU Member State Governments develop strategies in the marine environment that are underpinned by cross-border collaboration. In order to respond to the $E C^{\prime}$ 's demands for geological information in the marine environment, it is important that a high-level of marine geology expertise and information is visible within EuroGeoSurveys, based on full support at nationa level and active collaboration with other scientific disciplines.

\section{Scope and focus}

Marine geology has been a common theme within the geological surveys of Europe for many years.

The Expert Group therefore has a long track-record of co-operation in both science and integration of information. In the last decade, the group has led projects that have brought more than 8.5 million of EC funds to help deliver integrated databases (EUMARSIN, EUROSEISMIC and GeoSeas projects) and interpreted geological maps (EMODNETGeology).

The focus of the group is to continue to look for ways to collaborate in order to make marine geological information and advice available at a pan-European level. To meet this objective, the group has focused on responding to $E C$-funding calls and tender actions. The MGEG also recognises the importance of participating in marine policy-making at the EU level, which is done for example through the Marine Observation and Data Expert Group (see MODEG) established by the EC to provide them with the scientific, technical and operational expertise it 
needs to ensure that the European Marine

Observation and Data Network (see EMODNET)

best meets the needs of its future users. The MGEG

currently provides three members to MODEG.

The group also recognises the need to establish a long-term strategy that does not depend solely on EC funding, but which fits with the overarching EC strategy towards the use of the marine environment. The group is therefore active in initiatives such as the EuroGeoSurveys North Atlantic Group (see Geo-Seas).

\section{The European dimension}

In 2007 the Commission presented its vision for the Integrated Maritime Policy for the EU, accompanied by an Action Plan1 in which it set out the delivery of a new vision for Europe's oceans and seas based on the consultation process that resulted from the Green Paper on a Future Maritime Policy for the Union. In this Action Plan, the Commission described a new integrated governance framework for maritime affairs that requires cross-cutting tools to help policy makers and economic and environmental actors to join up their policies, interlink their activities and optimise the use of the marine and coastal space in an environmentally sustainable manner. These tools, as set out in the Integrated Maritime Policy Communication were to comprise: the development of a more integrated network of surveillance systems for European waters, the development of maritime spatial planning, assisted by a road map drawn up by Commission, and an EU Marine Observation and Data Network (EMODNET) to optimise and bring coherence to the current fragmented initiatives that gather data on oceans and seas.

Following an overwhelmingly positive response from stakeholders to its proposal, the European Commission, in its EU's Maritime Policy Blue Book, adopted in October 2007 and welcomed by the European Council in December 2007, undertook to take steps towards EMODNET in order to improve availability of high quality data. The Commission undertook to prepare by 2009 an EU action plan to make progress in this area on the basis of a road map.

It was proposed that the "proof of concept» of EMODNET be tested through preparatory actions that established portals for a number of maritime basins for hydrographic, geological, biological and chemical data as well as functional habitat maps. As well as providing access to marine data of a standard format and known quality and identify gaps in coverage, the projects would identify the main challenges in moving from a preparatory urEMODNET programme to an operational EMODNET. As a result of a tender action, a group of surveys from the MGEG bid for and won the contract to provide the geological information for the EMODNET programme.

An impact assessment will assess options for moving towards a definitive EMODNET, both in the intermediate period 2011-2013 and in the long term after 2014. At the same time efforts will begin to integrate other funding mechanisms. Given that EMODNET is very much focused on a sea-basin scale and given the impetus accorded to territorial cohesion by the new Green Paper, discussions will begin to determine whether cohesion funding could support the initiative. Moves will begin to integrate EMODNET with initiatives under the EU's Research Infrastructure actions and the Common Fisheries Policy Data Collection Regulation.

The ur-EMODNET will be operational throughout 2010 and 2011, collecting feedback from users on fitness for purpose and indicating how the definitive EMODNET might be set up. Should these prototypes prove to be successful, efforts will be made to extend their geographic range in order to cover all of the waters of EU Member States for one or more sets of parameters through Community instruments for territorial cooperation. Preparatory actions are designed to prepare proposals with a view to the adoption of future actions. Based on the knowledge gathered during this exploratory ur-EMODNET a strategy will be developed for moving ahead.

Underpinning the EC's integrated maritime policies are a number of directives that require input of geological information and knowledge. These directives steer the work carried out at national level within the marine departments of the European geological surveys, and help the MGEG members to align their work such that they are well-placed to respond to EC strategy.

These include:

- Environmental Impact Assessment Directive (June 1985), Directive 85/337/EEC

- Habitats Directive (May 1992), Directive 92/43/EEC

- Water Framework Directive (October 2000)

Directive 2000/60/EC 
- Strategic Environmental Assessment Directive

(June 2001), Directive 2001/42/EC

- Roadmap for Maritime Spatial Planning

(November 2006), COM(2008) 791

- Marine Strategy Framework Directive

(Adopted June 2008), Directive 2008/56/EC

- Marine Knowledge 2020 Initiative

(September 2010) COM(2010) 461

- Marine Spatial Planning in the EU, COM(2010) 771

- Common Fisheries Policy of the European Union

1 (http://ec.europa.eu/maritimeaffairs/pdf/

ActionPaper/action_plan_en.pdf)

\section{Activity report}

\section{EC-funded Projects}

\section{EMODNET-Geology}

In response to the EU Green Paper on Future Maritime Policy, the European Commission initiated the European Marine Observation and Data Network (EMODNET). The overall objective is to create pilot studies that assemble fragmented and inaccessible marine data into interoperable, contiguous and publicly available datasets for whole maritime basins.

The EMODNET-Geology project is one of four preparatory action projects that, in addition to marine geology, bring together information on marine chemistry, marine biology and hydrography. Each project will define the processes, technologies and approximate costs of implementing a fully functioning European Marine Observation and Data Network. For the EMODNET-Geology project the project partners are compiling data layers for the Baltic Sea, Greater North Sea and Celtic Sea.

The delivery of the EMODNET-Geology data layers

is being achieved through the adoption and adaption of technologies developed by the OneGeologyEurope (1G-E) project (Figure 4.1). The maritime map lavers are being delivered using the IG-E porta to allow the delivery of both onshore and offshore geological information via a single portal.

The geology data available includes:

- sea-bed sediments (Figure 4.2)

- sea-floor geology (see Gigure 4.1)

- boundaries and faults

- rates of coastal erosion or accumulation

- geological events (submarine slides,

earthquakes etc.)

- minerals

The project started in July 2009 and will end in July 2012, after which the group will deliver not only the final GIS data layers, but also recommendations to the Commission for the 'real' EMODNET project which will start in 2013-14. The next phase of the project is expected to expand into the regional seas nor presently included in the EMODNET-Geology project such as the Atlantic and Mediterranean seas. www.bgs.ac.uk/emodnet

Please note that this is a temporary url. The project has purchased the address www.emodnet- geology.eu, which will be made live during February 2010.)

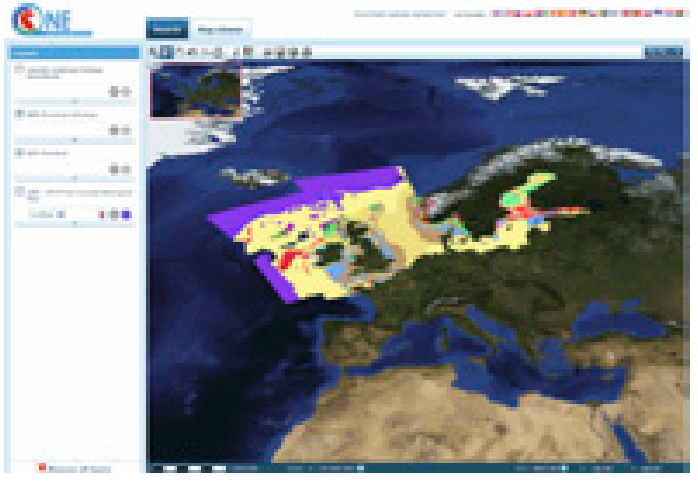

Fig. 4.1. The EMODNET-Geology sea-bed geology layer in the On

\section{Geo-Seas}

Geo-Seas is implementing an e-infrastructure of 26 marine geological and geophysical data centres located in 17 European maritime countries (14 of which are EGS Members). Users are enabled to identify, locate and access pan-European, harmonised and federated marine geological and geophysical datasets and derived data products held by the data centres through a single common data portal.

The aims of Geo-Seas are aligned with European directives and recent large-scale framework programmes on global and European scales, such as GEOSS and GMES, EMODNET and INSPIRE. Geo-Seas is expanding the existing SeaDataNet marine and ocean data management infrastructure to handle marine geological and geophysical data, data products and services, creating a joint infrastructure covering both oceanographic and marine geoscientific data.

www.geo-seas.eu 
Members of the MGEG participate in a range of

EC-funded projects. These include:

- MARSUNO-Maritime Surveillance in the Northern European Sea Basins 2010-2011. SGU (Sweden). www.marsuno.eul

- BLAST - Bringing Land and Sea Together. BGS (UK). www.blast-project.eul

- PERGAMON. IGME (Spain), GEUS (Denmark), BGR (Germany)

www.cost-pergamon.eu/index.html

- FINMARINET. GTK (Finland). http://en.gtk.fi research2/program/seafloor/finmarinet.html

- INFLOW. GTK (Finland), VSEGEI (Russia), GEUS (Denmark) www.bonusportal.org

- EMODNET-Hydrography. LNEG (Portugal), GSI (Ireland). www.emodnet-hydrography.eu - WRECK Protect. GEUS (Denmark).

http://wreckprotect.eu/home/

\section{Industry/survey partnerships}

\section{// Southern Permian Basin Atla}

The Southern Permian Basin Atlas (SPBA) project was a joint project between the Geological Surveys of the United Kingdom, Belgium, Denmark,

the Netherlands, Germany and Poland and a wide range of Petroleum Exploration \& Production

companies, licensing authorities, research institutes and universities. The project started in 2005 and was published in June 2010 in both paper and digital (GIS format. The Atlas follows the successful collaboration between geological surveys and the oil and gas industry that resulted in the publication of the 'Millennium Atlas: petroleum geology of the central and northern North Sea' in 2003. Although principally a description of the stratigraphy and hydrocarbon geology of the land area of Europe, the Atlas includes the southern North Sea and parts of the Baltic. Several of the surveys marine geologists were involved in its production including the Chief Editor

\section{// North African Petroleum Geological Atlas} (NAPGA)

Members of the SPBA Project, led by TNO, are currently working on a new Atlas project, the North African Petroleum Geological Atlas (NAPGA). If the funds can be raised from the hydrocarbons industry, the project proposes to provide easy and inexpensive access to the accumulated knowledge held by severa organisations on the basins of the area and to help gaining a better understanding of the geology of North Africa. The aim is to publish a comprehensive and systematic overview of the results of over 100 years of petroleum exploration and research in the North African region, including Morocco, Algeria, Tunisia, Libya and Egypt, in both paper and digital (GIS) format.

\section{// NAG-TEC (Tectonic Development of the}

North-east Atlantic)

EGS members from Denmark (Project Co-ordinator the UK, Norway, Germany, the Netherlands, Iceland and Ireland in collaboration with Jarðfeingi (formed by the merger of the Faroese Geological Survey and the Petroleum Administration in 2005) are working on a proposal to produce a geological Atlas and GIS of the North-East Atlantic conjugate margins. The project will be co-funded by the industry and survey partners.

// National Marine Geology Programmes Each of the MGEG members' marine geology departments continue to pursue a wide range of activities. Some of these are highlighted in the following section. A more comprehensive list of
MGEG partners' activities is included in the minutes and reports of the MGEG annual meeting, which are available from the group's Secretary (agst@bgs.ac.uk).

\section{// Denmark}

GEUS have participated in research projects including SEDIMICE (linking sediments with ice-sheet response and glacier retreat in Greenland) CLIMICE, which is a project under the Marie Curie Action programme, which aims to reconstruct late Holocene changes in sea ice variability and regional sea surface temperatures (SST) in the Labrador Sea and the Pergamon Project (Permafrost and Gas hydrate related methane release in the Arctic and impact on climate change). Habitat mapping has been undertaken in the Danish North Sea for the Nature Agency. GEUS also participate in a number of EC-funded projects (see above).

\section{I/ Estonia}

GSE have participated in research into the geology around the possible nuclear power plant area on Suur-Pakri Island (Gulf of Finland, NW Estonia) and the Neugrund impact structure area, and have participated in the investigation of the impact of the gas pipeline (Nord Stream) in the Gulf of Finland.

Work continued on the coastal monitoring

sub-programme that was established in 1994 for observing, measuring and predicting possible

environmental changes in the Estonian coastline.

\section{// Finland}

Surface sediment samples were collected in the Gulf of Finland, the Kvarken, the Archipelago Sea and in the Bothnian Sea for the environmental geochemistry/ECOBARS subproject. 
The GTK Marine Geology group also participated in the Finnish Inventory Programme for the Underwater Marine Environment (VELMU) to study the diversity of underwater marine biotopes and species. VELMU is a collaboration between ministries and lead by the Finnish Environment Institute.

\section{// France}

Four mapping projects were completed; three from the French Atlantic coast and one from the Mediterranean. The Marine Geology team of BRGM also took part in the GHEMOD project offshore western Guadeloupe to produce a 3D model of the geothermal system; the VASCO Project offshore Marseille to help the evaluation of the $\mathrm{CO}_{2}$ storage potential of the area and the BSS (BSS-Mer) project to upgrade and update the national marine geology database "BGM"

\section{// Germany}

Geoscientific Potential of the German North Sea (GPDN): Exploration and development of the German North Sea (EEZ) aiming to a sustainable development of the North Sea maritime economic and natural area - a joint project of BGR together with LBEG (State Authority for Mining, Energy and Geology), and BSH (Federal Maritime and Hydrographic Agency) with additional partners from industry, research institutes, and universities.

\section{// Ireland}

The INFOMAR programme is a joint venture between the Geological Survey of Ireland and the Marine Institute and is the successor to the Irish National Seabed Survey. Covering some 125,000 $\mathrm{km}^{2}$ of Ireland's most productive and commercially valuable inshore waters, INFOMAR will produce integrated mapping products covering the physical, chemical and biological features of the seabed. www.infomar.ie

\section{// Italy}

The Italian geological mapping project (CARG) has published 16 maps at 1:50 000 scale, including the offshore area. A further 49 map areas have been surveyed and are about to be printed. Offshore data include depositional environments and sediment texture; wherever possible, they are correlated with land information to show the continuity of the Quaternary deposits. 6 sheets at 1:250,000 scale describing the Italian sector of the Adriatic Sea are to be published soon.

www.isprambiente.gov.it/Media/carg/index.html

\section{// Netherlands}

3D seismic mapping of the North Sea. The mapping program was focused on the southern part of the Dutch shelf (cores and 2D seismics) and the northern part of the Dutch shelf (3D seismics). It included the development of a digital geological model for the upper 30 metres of the seabed, an associated resource analysis for aggregates, and an inventory of 3D seismic time slices for the shallow subsurface.

\section{// Norway}

MAREANO: An integrated large-scale programme for shelf and slope investigations around Lofoten and in the southern Barents Sea (www.mareano.no) conducted by NGU and partners (including the Institute of Marine Research (IMR) and the Norwegian Hydrographic Service (SKSK)
Portugal. The LNEG-UGM are currently involved in a number of projects, 12 of which are funded by the National Science Foundation (FCT): FREEZE, SCARPS, SWIMGLO, HOLOCLIMA, MELT KP-5, INTER-TRACE, CALIBERIA, MONA, CLIMHOL, DEEPFORAM, TAGUSDELTA, PANOCEAN. TwO projects are funded by the FCT through the ESF EUROCORES programmes EUROMARC \& TOPO-EUROPE (AMOCINT; TOPOMED), one EU Portugal-Galiza Cooperation (NATURA MIÑO$\mathrm{MINHO}$ ), and one funded by the programme for national development QREN (PORLISBOA). In addition 3 cruise proposals were approved inside the European program EUROFLEET.

\section{// Spain}

CONTOURIBER project. The aim is to study the contourite depositional systems generated by the Mediterranean water masses along the continental slope of Iberia, which contain a valuable record of the Iberian continental margin evolution. The project also supports activities related to the IODP proposal in the Gulf of Cadiz (IODP, Proposal -644 "GUCADRILL").

\section{// Sweden}

The Swedish Marine Geological Mapping

Programme. During 2010, fieldwork was carried out along the Blekinge Coast, the Uppland Coast, the Västernorrland Coast, the Kalmar Sound and the northern Bohus Coast of the Skagerrak. The aim of the programme is to produce 1:100 000 maps showing sea-bed sediment distribution and shallow stratigraphy. 


\section{// United Kingdom}

MAREMAP (Marine Environmental Mapping Programme). BGS, with partners at the National Oceanography Centre (NOC) and Scottish Association for Marine Science (SAMS) have initiated the MAREMAP project to combine their expertise and provide a multidisciplinary approach to improve understanding of the seabed, shallow geology, habitats and heritage.

\section{Results and impacts}

\section{EMODNET}

At the European strategic level, the main results and impacts of the MGEG partners' work has been achieved within the EMODNET-Geology Project, which has seen excellent co-operation between some of the MGEG surveys. This is now a wellestablished network that has all the tools for future work in European marine spatial planning and integrated maritime policy of the European Union. The EMODNET-Geology Project was recognised during the opening remarks by Maria Damanaki, the European Commissioner for Maritime Affairs and Fisheries, at the EurOcean 2010 Conference in Ostend, Belgium in October 2010. Speaking about the need to better integrate marine information, Commissioner Damanaki said:

"Making data easy to find, easy to access and easy to process was therefore our first aim. Preparatory actions under the integrated maritime policy have therefore been exploring how consortia of laboratories could set up thematic assembly groups that would gather the data collected within one sea basin, process them and make them available for all stakeholders. For instance European national geological surveys have joined together to produce the first continuous seamless data layers of seafloor sediments in the Baltic, North Sea and Celtic Seas. Another consortium is using this information to set up the first consolidated coherent European map of sea-bed habitats."

\section{MODEG}

Three staff from the marine geology expert group members were recently appointed to the European Commission's (DG MARE) Marine Observation and Data Expert Group (MODEG) as mandated by EuroGeoSurveys. Henry Vallius (GTK) and Robert Gatliff (BGS) are serving their second term on MODEG, while Terje Thorsnes (NGU) is a new MODEG member. MODEG's mission is to provide the Commission with the scientific, technical and operational expertise it needs to ensure that the European Marine Observation and Data Network (EMODNET) best meets the needs of its future users. This is an influential group that will help provide direct advice to the EC on their requirements for geological information and knowledge.

\section{Other European and National Committee}

\section{membership}

Henry Vallius represents Finland on the European Commission DG MARE Member State Expert Group on Integrated Marine Policy (subgroup on Marine Knowledge).

\section{Future perspectives}

As stated above, the EMODNET-Geology members will deliver not only the final GIS data layers, but also recommendations to the Commission for the 'real' EMODNET project which will start in 2013-14. There will, however, be an interim period between 2011 and 2013 when some new actions will take place. The next phase of the project is expected to expand into the regional seas not presently included in the EMODNET lots, which for the EMODNETGeology project would mean such areas as the Atlantic and Mediterranean seas. The future work is likely to focus also geological parameters and features that are not dealt with in the ur-EMODNET lots.

An expansion of the EMODNET into areas not presently included in the project will involve geological surveys from those areas, which the expert group will promote through the final report of the EMODNET-Geology project and through the MODEG of DG MARE of the European Commission.

\section{Other activities}

\section{Annual meeting 2010}

- The annual meeting of the MGEG was held in Berlin on January 28th 2011, following an EMODNET-Geology meeting. The meeting was hosted by German colleagues and the venue was the Federal Ministry of Traffic, Building, and Urban development, Krausenstraße 17-20, 10117 Berlin. The meeting was attended by 22 members from 14 countries.

- Meetings and presentations by the MGEG Chair

- Oceanology International '10, London, 8-11 March

- EuroGeoSurveys, 25th National Delegates Forum, MAFI, Budapest, June 29th

- Presentation; Vallius: Annual report 2009 
- EuroGeoSurveys, 29th General Assembly, GEUS, Copenhagen, September 15th

- Presentation; Vallius, H., and Stevenson, A. :

Future Marine Management - from a geologists point of view.

\section{Bibliography}

H. Doornenbal \& A.G. Stevenson (editors), 2010.

Petroleum geological atlas of the southern Permian Basin area. EAGE Publications, Houten (order through www.eage.org/bookshop). Hardbound, 342 pp. Price EUR 175.00. ISBN 978-90-73781-61-0. Also available as DVD (pdf format); price EUR 160.00. Atlas + DVD: price EUR 225.00 (all prices exclusive handling and shipping). SPBA GIS maps and database: EUR 10,000 for single-site license; EUR 25,000 multi-site licence (excl. VAT).

\section{Members list}

The Chair and Secretary of the MGEG would like to thank all of the group members for their participation in the compilation of this report.

The following list includes current nominated representatives* and member organisations of the MGEG; additional contributors to the Annual Report are also shown for some organisations:

- Henry Vallius* (GTK, Finland) MGEG Chair

- Alan Stevenson* (BGS, UK) MGEG Secretary

- Arben Pambuku* (AGS, Albania)

- Vera Van Lancker* (MUMM/GSB, Belgium)

- Emanuil Kozhuharov* (MOEW, Bulgaria)

- Slobodan Miko* (HGI_CGS, Croatia)

- Jørgen Leth* (GEUS, Denmark)

- Sten Suuroja* (GSE, Estonia)

- Aarno Kotilainen* (GTK, Finland)
- Pol Guennoc* and Fabien Paquet (BRGM, France)

- Lutz Reinhardt* (BGR, Germany)

- Andreas Andrinopoulos* (IGME, Greece)

- Koen Verbruggen* (GSI, Ireland)

- Andrea Fiorentino* and Silvana D'Angelo* (ISPRA, Italy)

- Albertas Bitinas* (LGT, Lithuania)

- Reidulv Bøe* and Terje Thorsnes (NGU, Norway)

- Szymon Uscinowic* and Regina Kramarska

(PGI, Poland)

- Fátima Abrantes and Gabriela Carrara

(LNEG, Portugal)

- Constantin Costea* (GIR, Romania)

- Daria Ryabchuk* (VSEGEl, Russian Federation)

- Teresa Medialdea Cela* (IGME, Spain)

- Johan Nyberg* and Ingemar Cato (SGU, Sweden)

- Sytze van Heteren* (TNO, The Netherlands)

- Robert Gatliff* (BGS, UK)

Non-EGS associated organisations (EMODNET-

Geology participants)

- Manfred Zeiler (BSH, Germany)

- Inara Nulle, Tatjana Sadrina and Baiba Brikmane and (LEGMC, Latvia)

- Algimantas Grigelis and Leonora Zivile

Gelumbauskaite (NRC-IGG, Lithuania).

\section{TASK FORCE ON FOSSIL FUELS}

This has been the first year with the EuroGeoSurveys Fossil Fuel Task Force (EGS FF TF). This task force was generated under the encouragement of the EU DG ENER and was first thought only to be engaged with fossil fuels. Later in 2010 it was decided that the task force also should cover geothermal energy. The Task Force consists of 19 representatives from
12 of the EuroGeoSurveys member organisations. The EGS FF TF had its first meeting in February 2011 where the main focus was to discuss and agree on the Task Force Mission and Vision statements.

\section{Vision}

The EuroGeoSurveys Fossil Fuels \& Geothermal Energy Task Force wishes to develop into a GeoEnergy Expert Group and become a leading partner within a European Fossil Fuel and Geothermal information network that will provide expertise to support the GeoEnergy supply for Europe.

GeoEnergy information provided by EGS FF TF is based on public available and accessible information and data, which are of globally comparable

standards of excellence for science and expertise. The EGS GeoEnergy expertise will be provided for the European Society.

The vision will be carried out collaboratively with other organizations that have GeoEnergy information and expertise, and with consumers of that information.

\section{Mission}

The EuroGeoSurveys Fossil Fuels \& Geothermal Energy Task Force shall provide impartial, scientifically robust information to advance the understanding of fossil fuel energy and geothermal energy (GeoEnergy) resources in Europe, to contribute to plans for a secure energy future, to facilitate evaluation and responsible use of energy resources, and to analyse future GeoEnergy resources of Europe and possibilities of their sustainable use. 
The EuroGeoSurveys Fossil Fuels \& Geothermal Energy Task Force research portfolio is responsive to the EU Commission policies and priorities, either established through legislative forms or not, internal strategic planning, important and unanticipated global events, customer surveys and needs, and the guiding principles of objective and impartial science.

\section{The European dimension}

The EGS FF TF was generated as a response to a request from EU DG ENER. The request was originally formed as a demand for an impartial mapping and resource evaluation of the EU coal. EuroGeoSurveys decided that this request had merit for the generation of a new Task Force - The EuroGeoSurveys Fossil Fuels \& Geothermal Energy Task Force.

As stated in the vision the Task Force research portfolio will be responsive to the EU Commission policies and priorities, which will follow the guiding principles of objective and impartial science.

\section{Activity report}

Since May 2010 EGS FF TF has become a Member of the Berlin Forum Indigenous Fossil Fuels Working Group under DG ENER. In September the Task Force gave a presentation of the newly published Petroleum Geology Atlas of the Southern Permian Basin Atlas (SPBA).

The Southern Permian Basin Atlas project was a joint project between the Geological Surveys of the United Kingdom, Belgium, Denmark, Netherland, Germany and Poland together with a wide range of Petroleum companies, licensing authorities, research institutes and universities.

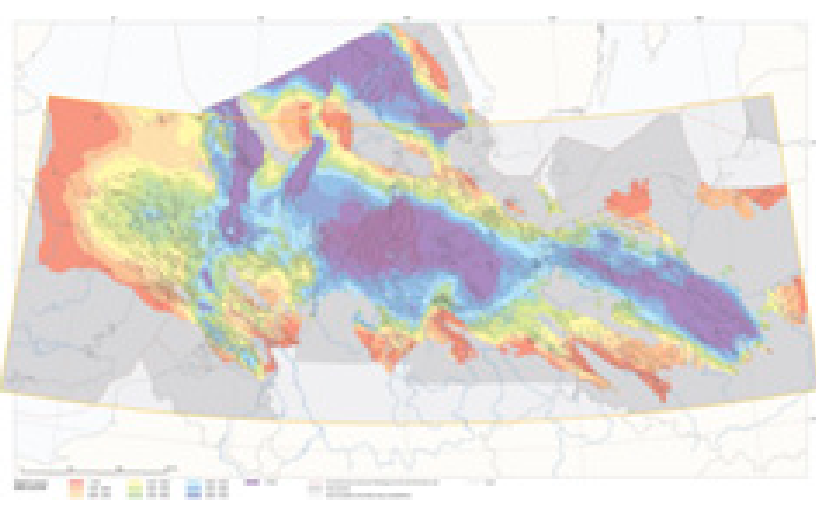

Fig. 1: Base Zechstein from the SPBA Atlas (Doornenbal 8 Stevenson (eds.), 2010)

\section{Results and impacts}

Due to the work carried out in the Berlin Forum Indigenous Fossil Fuels Working Group the EGS Fossil Fuel Task Force is by the DG ENER considered as their independent experts and advisors on geological matters with regards to GeoEnergy.

The task force has been involved with two EU public consultations:

- Responds to the draft of the IGD-TP Strategic Agenda (SRA). The draft had no points on site characterization and site selection, the most geological part of the identification of a deep geological disposal, as these matters have been treated before. Thus the EGS FF TF did not send further remarks to the SRA Working Group about

the IGD-TP Strategic Agenda draft.

-THE EXTERNAL DIMENSION OF THE EU ENERGY POLICY. Again this policy is not directed to geoscience. A statement on share of scientific knowledge will benefit the mutua understanding between the neighboring countries and EU is currently being worked on

\section{Future perspectives}

\section{EU Unconventional Plays}

The task force will try starting a pilot study on a study of Gas potential of the Lower Paleozoic Shales in the Baltic Basin together with USGS. It includes on- and offshore areas in the following countries: Norway, Sweden, Denmark, Finland, Estonia, Latvia, Lithuania, Kaliningrad (Russian enclave), Poland and Germany. The main reason for such a corporation is that while the European Geological Surveys has the data and knowledge on the specific shale stratigraphy, sedimentology, petrography etc., USGS has built up, through their work in the US, a vast experience in assessing the shale gas potential.

The overall goal with this pilot study is to develop the pilot into a study that covers the entire Europe, financed by the FP8.

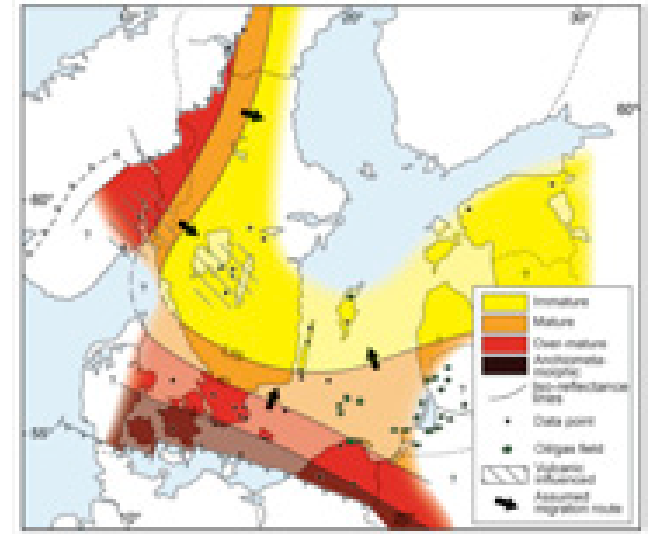

Fig. 2: In Baltic Sea: Alum Shale in Oil (Buchardt, Nielsen Schovsbo 1997) 


\section{EU Coal Mapping}

The task force will also bid on an expected DG ENER tender for mapping the EU coal resources.

This tender was proposed last year, but with insufficient funds.

EXPERT GROUP ON GEOCHEMISTRY

\section{Members lis}

\begin{tabular}{|c|c|c|}
\hline Country & Survey & Name \\
\hline Austria & GBA & Gerhard Letouze \\
\hline C.Republic & CGS & $\begin{array}{l}\text { Josef Godany } \\
\text { Karel Martinek }\end{array}$ \\
\hline Cyprus & GSD & Loannis Panayides \\
\hline Denmark & GEUS & Peter Britze \\
\hline France & BRGM & $\begin{array}{l}\text { Didier Bonijoly } \\
\text { Aurélien Leynet } \\
\text { Philippe Calcagno }\end{array}$ \\
\hline Germany & BGR & $\begin{array}{l}\text { Bernhard Cramer } \\
\text { Dr. Peter Gerling }\end{array}$ \\
\hline Greece & IGME & $\begin{array}{l}\text { DimitriosKarageorgiou } \\
\text { Antonios Metaxas }\end{array}$ \\
\hline \multirow[t]{2}{*}{ Poland } & PGI & $\begin{array}{l}\text { Marek Jarosinski } \\
\text { Jacek Kasinski }\end{array}$ \\
\hline & & Pawel Poprawa \\
\hline Romania & IGR & Mircea Ticleanu \\
\hline Slovenia & GeozS & Milos Markic \\
\hline The Netherlands & TNO & Drs. Henk Pagnier \\
\hline United Kingdom & BGS & Michael Stephenson \\
\hline
\end{tabular}

\section{GEOCHEMISTRY EXPERT GROUP}

The Geochemistry Expert Group has 53 official members from European Geological Surveys and associated institutions. Because of the diverse activities of the Group, there is additional

participation of scientists coming from European Surveys, universities and other institutions in the projects. For example, in the project on European Ground Water Geochemistry, using bottled water as a sampling medium, which ended in August 2010, there were 45 outside participants, and in the current GEMAS project there are 43 outside participants.

The Geochemistry Expert Group has a Chairperson, and a three member Executive Committee, consisting of the Chairperson and two Group members, and for the management of the GEMAS project there is an additional member from Eurometaux.

\section{Mission}

The mission of the EuroGeoSurveys Geochemistry Expert Group is to provide high quality geochemical data of near-surface materials, to develop

harmonised databases for multi-purpose use, and to provide independent expert advice to the European Commission, to decision makers, but also to supply sound background data to scientists for their research, and to the public, in general, for education and other purposes.

To achieve this mission, systematic geochemical data for the whole of Europe are generated by harmonised methods of sampling of near-surface materials (soil, stream or floodplain sediment, water), sample preparation, chemical analysis, quality control, data processing, and presentation. The systematic geochemical information is published in the form of geochemical atlases, which are freely available, and can be used for (a) state of the environment reports, (b) mineral exploration (c) agriculture, (d) forestry, (e) animal husbandry, (f) geomedicine or medical geology, (g) determination of natural background values for environmental risk assessment, etc.

Why are Geochemical Atlases important? The answer is given by Darnley et al. (1995, p.X: www.globalgeochemicalbaselines.eu/files/Blue Book_GGD_IGCP259.pdf)

Everything in and on the earth - mineral, animal and vegetable - is made from one, or generally some combination of, the 86 naturally occurring chemical elements. Everything that is grown, or made, depends upon the availability of the appropriate elements.

The existence, quality, and survival of life depend upon the availability of elements in the correct proportions and combinations. Because natural processes and human activities are continuously modifying the chemical composition of our environment, it is important to determine the present abundance and spatial distribution of the elements across the Earth's surface in a much more systematic manner than has been attempted hitherto.

Systematic geochemical mapping is considered, therefore, as the best available method to document changes in the levels of chemical elements in

materials occurring at or below the Earth's surface. 


\section{The European dimension}

Table 3.1 summarises European Commission (EC) Directives that require European wide harmonised geochemical data. In the sections of the different on-going projects during 2010, the relevant EC Directives are given. It is noted that all projects are INSPIRE compliant (EC, 2007).
Table 3.1 Summary of some European Commission (EC) Directives driving the demand for harmonised geochemical background data across political borders (modified from Johnson and Demetriades, 2011, Table 2.3, p.22)

\section{DIRECTIVE}

EC Water Framework Directive

(WFD) (2000/60/EC)

\section{SUMMARY}

This requires Member States to meet a good ecological status for water quality objectives (except where deviations from the standard are justified): and to identify basic and supplementary measures to deal with point source and diffuse pollution. The directive will be managed on the basis of River Basin Districts (one or more drainage catchments).

It has been formulated to implement the EC Integrated Pollution Prevention and Control Directive (96/61/EC). Its objective is to control pollution from industry.

This directive seeks to encourage the use of sewage sludge in agriculture, but regulates its use in order to protect the environment from its harmful effects.

(86/278/EEC)

Directive under consideration. The European Union included in the 6th Environmental Action Programme the 'Thematic

in the 6th Environmental Action Programme the 'Thematic soil protection Directive.

This proposed directive is seen as a supplementary measure to the WFD to minimise the adverse

EC Mine Waste Directive

(2006/21/EC)

EC Habitats Directive (92/43/EEC)

This directive is concerned with the conservation of natural habitats and of wild fauna and flora.

EC Landfill Directive (1999/31/EC)
The Landfill (England and Wales) Regulations of 2002, implement the EC Landfill Directive, which aims to prevent or reduce the negative environmental effects of landfil.

\section{APPLICATION GEOCHEMICAL DATA}

Geochemical background data for low order streams produced by the European Geochemical Atlas project can provide information about surface water quality for farmers and those who manage land. In addition the data produced by the project on Ground water Geochemistry using bottled water as 'proxy' can be used to assess the quality of ground water but also bottled water with respect to inorganic constituents. Regulatory bodies and administrators can use these data to determine guideline levels for elemental concentrations.

Geochemical background data can be used by both industry and regulators to assess the impact of polluting industries on the environment. The geochemical background data provide a reference point against which changes can be measured.

Geochemical background data can be used to monitor and model the impact on the environment of sewage sludge.

Geological Surveys have over 50 years of experience with producing geochemical maps from soil samples at all scales - from local to continental. Geological Surveys are the only organisations systematically sampling soil from urban areas, and can establish the urban geochemical background in order to assess the impact of human induced pollution.

Geochemical background data can be used to monitor and model the impact on the environment of mine waste.

Climatic or anthropogenic changes to the geochemistry of the surface environment that may impact on fauna and flora can be monitored using geochemical background data of the surface environment.

Geochemical data can be used to monitor and model the impact on the environment of landfills. 


\begin{tabular}{|c|c|c|}
\hline INSPIRE Directive (2007/2/EC) & $\begin{array}{l}\text { Establishing an Infrastructure for Spatial Information in the } \\
\text { European Union for making available relevant, harmonised, } \\
\text { and quality geographic information to support formulation, } \\
\text { implementation, monitoring, and evaluation of policies and } \\
\text { activities that have a direct or indirect impact on } \\
\text { the environment. }\end{array}$ & $\begin{array}{l}\text { Harmonised geochemical background data for the whole of Europe are } \\
\text { needed in order to assess impacts on the environment. }\end{array}$ \\
\hline $\begin{array}{l}\text { REACH Directive (EC 1907/2006) } \\
\text { [Registration, Evaluation, } \\
\text { Authorisation and Restriction of } \\
\text { CHemical substances] - } \\
\text { The new law entered into force on } \\
1 \text { June } 2007\end{array}$ & $\begin{array}{l}\text { The aim of REACH is to improve the protection of human health } \\
\text { and the environment through the better and earlier identification } \\
\text { of the intrinsic properties of chemical substances. There is a } \\
\text { need to fill information gaps to ensure that industry is able to } \\
\text { assess hazards and risks of the substances, and to identify and } \\
\text { implement the risk management measures to protect humans } \\
\text { and the environment. }\end{array}$ & $\begin{array}{l}\text { Geochemical background data are needed to establish the variable } \\
\text { geochemical background across Europe, and the local maximum threshold } \\
\text { values, against which any future changes can be monitored. For REACH } \\
\text { additional data on soil properties determining the availability of metals in } \\
\text { soil are required. The GEMAS project will provide for the first time a fully } \\
\text { harmonised data set for soil properties and metals at the European scale. }\end{array}$ \\
\hline
\end{tabular}

\section{Agricultural and grazing land soil geochemistry}

The Agricultural and Grazing land soil geochemistry project (GEMAS) fulfils requirements of the following EU Directives, regulations, and communications: 1// Regulation (EC) No 1907/2006 of the European Parliament and of the Council of 18 December 2006 concerning the Registration, Evaluation, Authorisation and Restriction of Chemicals (REACH), establishing a European Chemicals Agency, amending Directive 1999/45/EC and repealing Council Regulation (EEC) No 793/93 and Commission Regulation (EC) No 1488/94 as well as Council Directive 76/769/EEC and Commission Directives 91/155/EEC, 93/67/EEC, 93/105/EC and 2000/21/EC (EC, 2006a, 2007);

2// Directive 2004/35/CE of the European Parliament and of the Council of 21 April 2004 on environmental liability with regard to the prevention and remedying of environmental damage (EC, 2004):
3// European Regulation (EC) No 1272/2008 on Classification, Labelling and Packaging of Substances and Mixtures (CLP Regulation), adopting in the EU the Globally Harmonised System (GHS) (EC, 2008a), and

4// Communication from the Commission to the Council, the European Parliament, the European Economic and Social Committee, and the Committee of the Regions: Thematic Strategy for Soil Protection (EC, 2006b).

The administration of REACH (Registration, Evaluation and Authorisation of (hemicals), the new European Chemicals Regulation adopted in December 2006 (EC, 2006a, 2009), and the pending EU Soil Protection Directive (Van Camp et al., 2004: EC, 2006b), require additional knowledge about

"soil quality" at the European scale. REACH specifies that industry must prove that it can produce and use its substances safely. Risks, due to the exposure to a substance during production and use at the local, regional, and European scale, all need to be assessed. In contrast, to human-made organic substances that do not occur naturally in the environment, all industries dealing with natura resources will face in the near future a number of specific questions:

Most of the metal industries' "products" occur also naturally - the natural background variation needs to be established, in addition to a methodology to differentiate the industrial impact from the natural geogenic background. What is the "bioavailability" of metals and other chemical elements in soil? What is the long-term fate of metals and other chemical elements added to soil?

Besides fulfilling the conditions of EC policy documents, it satisfies other EU international commitments, such as (i) the United Nations Strategic Approach to International Chemicals Management (SAICM) (UNEP, 2006), and (ii) the OECD Work on Investigation of High Production Volume Chemicals (OECD, 2009). 


\section{European Groundwater Geochemistry (EGG-Project)}

The Ground water Geochemistry Project, using bottled water as "proxy", fulfils conditions of the EC Directive 2000/60/EC (EC, 2000), and its results

should assist the European Commission in its legislative work on bottled waters with respect to

inorganic constituents, e.g.

- Directive 65/65/EEC of 26 January 1965 on the approximation of provisions laid down by law. regulation or administrative action relating to medicinal products (EC, 1965)

- Directive 80/777/EEC of 15 July 1980 on the approximation of the laws of the Member States relating to the exploitation and marketing of natural mineral waters (EC, 1980a)

- Directive 80/778/EEC. Council Directive of 15 July 1980 relating to the quality of water intended for human consumption (EC, 1980b)

- Directive 96/70/EC of the European Parliament and of the Council of 28 October 1996 amending Council Directive 80/777/EEC on the approximation of the laws of the Member States relating to the exploitation and marketing of natural mineral waters (EC, 1996)

- Directive 98/83/EC of 3rd November 1998 on the quality of water intended for human consumption (EC, 1998)

- Directive 2003/40/EC/16-5-2003/ establishing the list, concentration limits and labelling requirements for the constituents of natural mineral waters and the conditions for using ozone-enriched air for the treatment of natural mineral waters and spring waters (EC, 2003).
- Directive 2008/32/EC of the European Parliament and of the Council of 11 March 2008 amending Directive 2000/60/EC establishing a framework for Community action in the field of water policy, as regards the implementing powers conferred on the Commission (EC, 2008b).

Further, the information produced can also be used in the national legislative procedure of European

Union member countries.

\section{Urban geochemistry}

Communication from the Commission to the Council, the European Parliament, the European Economic and Social Committee, and the Committee of the Regions: Thematic Strategy for Soil Protection (EC, 2006b). EC Integrated Pollution Prevention and Control Directive (IPPC) (2008/1/EC) (EC, 2008c).

\section{ACTIVITY REPORT}

\section{Continued work with the FOREGS} samples/data

Perchlorate analylytical results have been received for a number of the old FOREGS Topsoil samples from the USGS. Analysis was much more difficult than foreseen and the USGS is not able to deliver results for the whole sample set. There are, however, enough results available to plot a map. Alecos Demetriades (Hellas) is still working on an electronic popular version of the Atlas. In addition, a number of publications based on the Chinese data are in the process of being written and these are outlined below together with the leading person:
- Alecos Demetriades, Hellas : regional distribution of $\mathrm{Au}$;

- Benedetto de Vivo (Italy): effects of low density sampling (submitted);

- Maria Joao Batista (Portugal) : regional distribution of Sn, and

- Reijo Salminen (Finland) : regional distribution of F, $\mathrm{Cl}$ and $\mathrm{B}$.

All remaining FOREGS samples are now stored at BGS.

There were a number of international publications during 2010, using single FOREGS maps and/or data (see Publications)

\section{Geochemistry of Agricultural and} Grazing Land Soil (GEMAS)

The GEMAS project is running according to plan. The majority of analytical results have been received, and passed quality control. The results for $\mathrm{Pb}$-isotopes (NGU) are expected to be ready in May/ June 2011.
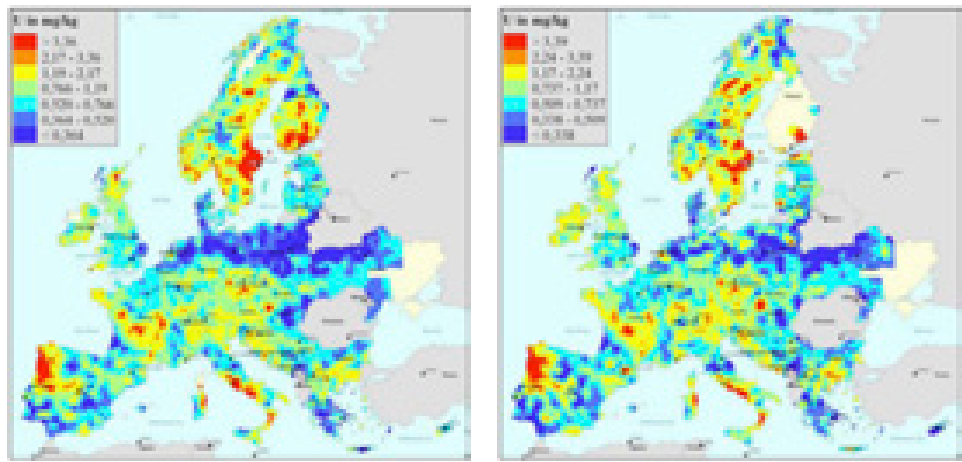

ig. 6.1 Aqua regla extractable Uranium (U) distribution in (a) Agricultura soil $(0-20 \mathrm{~cm},<2 \mathrm{~mm}, \mathrm{n}=2132)$, and $($ b) $\mathrm{Grazing}$ 
Eurometaux organised a very successful metals workshop, based on the GEMAS data, at ECHA (European Chemical Agency) in Helsinki at the beginning of July 2010. Further, GEMAS presentations were undertaken at a number of national and international conferences.

\section{Urban Geochemistry}

\section{Part 1 - The Book}

Chris Johnson, Alecos Demetriades, Juan Locutura and Rolf Tore Ottesen have edited a book on "Urban Geochemistry", which will be published by Wiley-Blackwell in April 2011. The full reference is: Johnson, C.C., Demetriades, A., Locutura, J. \& Ottesen, R.T. (Editors), 2011. Mapping the Chemical Environment of Urban Areas. Wiley-Blackwell, Oxford, UK, 618 pp. (http://eu.wiley.com/WileyCDA/ WileyTitle/productCd-0470747242,descCddescription.html). A full report will be given in next year's annual report, but an outline of the book structure is given below.

The book presents a comprehensive overview of the methods currently being employed to map and interpret the distribution of chemical elements and organic compounds in our towns and cities.

Clearly structured throughout, the book is divided into two distinct sections. The first part, consisting of twelve chapters, covers more general aspects of urban chemical mapping with an overview of current practice, and reviews of different features of the component methodologies (chemical analysis,

quality control, data interpretation, and presentation, risk assessment, etc.). The second part, comprising twenty chapters, includes a number of case studies from different urban areas, principally from Europe, but with some contributions from North America, Africa, and Asia, authored by those national or academic institutions tasked with investigating the chemical environment of their major urban centres. An informative list of abbreviations and acronyms, used in the text, is included and many of the chapters define terms frequently employed in geochemical mapping that will help researchers give more clarity to the way in which such work will be described in the future.

Chapters include strategies that can be employed to map urban environments, along with sampling procedures, which are used for a variety of sample media. Analytical methodologies for determining chemical elements and compounds are covered and their relative merits and disadvantages presented. Methods for defining element associations and what areas can be considered contaminated are documented, as are techniques for distinguishing between the natural chemical background and chemicals and compounds introduced by human activity. Many of the chapters discuss the potential impact on human health and describe the multidisciplinary effort, usually supported by legislation, required to deal with the legacy of contamination found in many urban areas.

A review paper was presented at the $12^{t}$ International Congress of the Geological Society of Greece: Planet Earth - Geological processes and sustainable development, Patras University, Hellas (May 2010):
// Demetriades, A., Birke, M., Locutura, J., Bel-lan, A.B., Duris, M. and the EuroGeoSurveys Geochemistry Expert Group, 2010. Urban geochemical studies in Europe. In: G. Koukis, A. Zelilidis, I. Koukouvelas, G. Papatheodorou M. Geraga and V. Zygouri (Editors), Proceedings of the $12^{\text {th }}$ International Congress of the Geological Society of Greece: Planet Earth - Geological processes and sustainable development. Bulletin of the Geological Society of Greece, XLIII(5), 2338-2349.

\section{Part 2 - The Urban Geochemistry project} (URGE)

The URGE project's objective is to compare the urban geochemistry of several European cities using the same sampling protocol and analytical procedures. It has already started and is led by Rolf Tore Ottesen of NGU. Interest from within the surveys represented in the Geochemistry Group is very large, originally, more than 25 members of the group volunteered to sample a city for the project. The main problem for the project was financing the analyses. It was agreed to use a commercial laboratory for the analytical work and that each participating city/survey must cover the analytical costs. Up to date Acerra-Marigliano (Napoli), Aschersleben, Dublin, Kristiansand, Hämeenlinna, and Sisak are sampled; Karlstad, Maribor, and Athens will follow in 2011.

This is an important project, because it is dealing with the chemical environment of urban areas, where most of us live and work. Geological Surveys are the only institutions that can map systematically urban areas, and in a harmonised manner to 
produce comparable data sets across Europe, and have the know how to distinguish between the natural and urban (anthropogenically modified) geochemical background. Furthermore, legislatively driven demand for geochemical data from the urban environment is now an important requirement in the challenge to produce healthier and cleaner towns and cities. It is, therefore, important that in 2011 further cities are added to the project.

\section{Annual meeting}

The annual meeting of the Geochemistry Expert Group (GEG) was held from the 6th-8th October 2010 at Divani Palace Acropolis Hotel in Athens (Hellas), and it was hosted by the Institute of Geology and Mineral Exploration. Twenty-eight people attended the meeting. The group received a very warm welcome to Athens from Associate Professor Kostas T. Papavasileiou, the I.G.M.E. General Director, who congratulated the group on its excellent activities and noted that the group is distinguished by its publications. He offered the group further praise for the relevance of both urban geochemistry activities and the GEMAS project. The first two days were devoted to group activities, including the URGE project. The third day was totally devoted to national presentations of GEMAS results.

\section{Participation in international projects}

Members of the working group are collaborating in a number of EU-funded research projects:

// Maria Joao Batista (Portugal), Alecos Demetriades (Hellas) and Juan Locutura (Spain) are participating in the ProMine project (Nano-particle products from new mineral resources in Europe -

http://promine.gtk.fi), which is financed by the $7^{t h}$ Framework programme (2009-2013).

// Alecos Demetriades (Hellas) is participating in the GS Soil project (Assessment and strategic development of INSPIRE compliant Geodata-

Services for European Soil Data - www.gssoil.eu) which is a financed by the eContentplus programme (2009-2012).

// Clemens Reimann (Norway) has a "Norwegian Financial Mechanism" project (Biogeochemistry of the Czech Republic) with the Institute for Landscape and Ornamental Gardening in Pruhonice.

\section{GEMAS project calendar}

Peter Hayoz (Switzerland) has produced a very attractive "GEMAS Project Calendar" for 2011 based on field photographs from the project. The calendar is available for download from the internet for all project partners, and we plan to have it available on the EGS server as well. Eurometaux was very impressed by the product and considers sponsoring the printing of a number of calendars.

Geochemistry Expert Group website and Google Earth GEMAS photo database

Paolo Valera (Italy) is working on a Geochemistry Expert Group web-site, with sub-sites for all the projects and products. Edith Haslinger (Austria) works on a "GEMAS Google Earth photograph database", where it will be possible to click on the sample sites and be able to download the field photographs (Picture 8.1). Both the website and GEMAS photo database will be hosted on the EuroGeoSurveys server

\section{Annual meeting}

The next meeting of the geochemistry group is scheduled for early October 2011 in Helsinki. It is considered to invite ECHA to participate for a one day meeting with presentations from the GEMAS project.

\section{Main conferences attended}

Geochemistry Expert Group members participated with presentations in the following conferences:

- ICA (Symposium of the International Copper Association), Phoenix, Arizona, USA - invited presentation, 23.7.2010: Reimann, C., et al., 2010. The geochemical mapping of agricultural soils project - do you know your background?

- SEGH (Society of Environmental Geochemistry and Health), Galway, Ireland: Reimann, C. Demetriades, A., Birke, M. and the EuroGeoSurveys Geochemistry Expert Group, 2010. Geochemica mapping of agricultural and grazing land soils at the European Scale. SEGH 2010 International Conference and Workshops: Environmental Quality and Human Health, Galway, Ireland, 27 June - 2 July 2010. SEGH 2010 Book of Abstracts, 65. Available online at: www.nuigalway. ie/segh2010/download/SEGH2010\%20Book_of_ Abstracts.pdf

- IUSS 19th World Congress of Soil Science,

Brisbane, Australia: Ernstsen, V., Cicchella, D., Demetriades, A., De Vivo, B., Dinelli, E.,
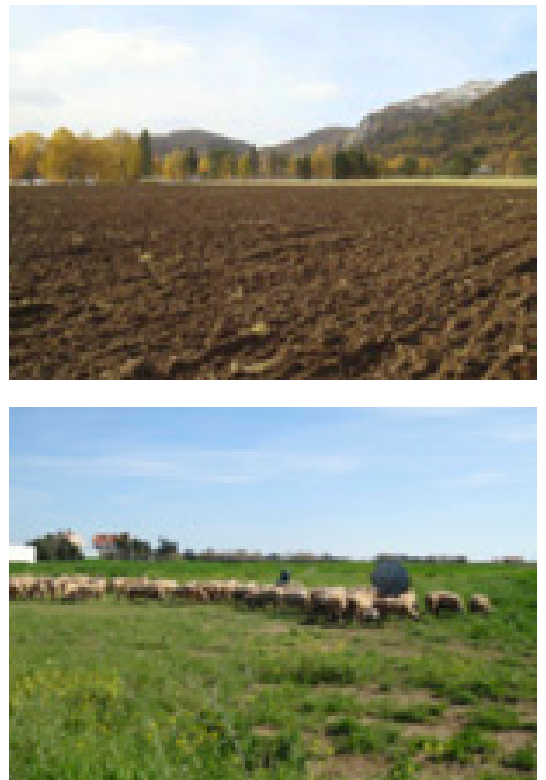

Picture 8.1 (a) Agricultural soil, Norway, and (b) Grazing land soil (Cyprus). 
von Platen, F., Reimann, C., Tarvainen,

T. \& the EuroGeoSurveys Geochemistry Expert Group, 2010. Organic carbon in topsoil from arable land and grazing land of Europe. 19th World Congress of Soil Science, Soil Solutions for a Changing World, 1-6 August 2010, Brisbane.

Australia. Published on DVD, 139-141.

- Croatian Geological Congress, Šibenik, Croatia: Husnjak, S., Halamić, J., Šorša, A. \& Rubinić, V. 2010. Pedological, geological and geochemical characteristics of GEMAS project samples in

Croatia. Croatian Geological Congress, Šibenik, Book of abstracts, 342-343.

- Croatian Pedological Congress, Plitvice, Croatia: Šorša, A., Halamić, J. \& Husnjak, S., 2010 Geochemical Mapping of Agricultural Soils and Grazing Lands in Croatia - a part of

EuroGeoSurveys project. Croatian Pedological Congress, Plitvice, Book of abstracts, 154-155.

- 20th SETAC Europe Annual Meeting, Seville, Spain: Reimann, C., Birke, M., Demetriades,

A. \& the EuroGeoSurveys Geochemistry Expert Group, 2010. GEMAS: Geochemical mapping of agricultural and grazing land soil at the European scale. Poster presentation, 20th SETAC Europe Annual Meeting, 23-27 May 2010, Science and Technology for Environmental Protection, Seville, Spain. Available online at: www.eventure-online.com/eventure/publicSearch. do ?action=saveacongressld=3358

- 12th International Congress of the Geological Society of Greece: Planet Earth - Geological processes and sustainable development, Patras University, Hellas (May, 2010): See Demetriades et al. (2010) in publications.

\section{Results and impacts}

In 2010 the Group published the results of the European ground water geochemistry project using bottled water as the sampling medium. These results generated wide interest among the scientific community, and also industry, because for the first time a total of 72 parameters were determined on water samples at the scale of a whole continent. The European Federation of Bottled Waters, after studying the published results, is of the opinion that the EuroGeoSurveys atlas entitled "Geochemistry of European Bottled Water" is the best hitherto publication on the inorganic chemistry of bottled water. These results, together with those produced in the EuroGeoSurveys "Geochemical Atlas of Europe" project are of interest to, and are used by, scientists, decision makers and the public alike throughout the world, since they are the only truly harmonised data sets in Europe.

The Bottled Water book received quite a number of positive reviews in International Scientific Journals, and is already used for teaching hydrogeochemistry classes at several universities.

\section{Future perspectives}

The Group is very active, and some of the planned activities are outlined below

- The book "Mapping the Chemical Environment of Urban Areas", bearing the EuroGeoSurveys logo, is planned to be published in April 2011.

- New analytical results of the GEMAS project will be released to each participating country, following their quality control, and writing of the relevant report. All the national GEMAS results will be

processed during 2011, and national reports written.

- The GEMAS atlas and results are expected to be released in late 2013.

- The participation of more countries in the URGE

(Urban Geochemistry) project is expected.

- A Google Earth application with all the GEMAS

photographs is being prepared.

- A Group website is being prepared and will reside on the EuroGeoSurveys server.

- Finally, new results on the samples of the

"Geochemical Atlas of Europe" project, received from China, are being processed and a number of publications are planned.

\section{Partnership}

Most of the work that is being carried out by the EuroGeoSurveys Geochemistry Expert Group is essentially sponsored by the member Geological Surveys and associated institutions. The GEMAS (Geochemical mapping of agricultural and grazing land soils) project, because it is of interest to industry for compliance to the REACH directive, is co-funded with more than 600.000 Euro by Eurometaux and the associated European metal producers. The project received also some direct funds from EGS.

The analytical work for the GEMAS project is partly financed by the following organisations: Eurometaux (www.eurometaux.org), Cobalt Development Institute (CDI), European Copper Institute (ECI),

Nickel Institute, Europe, European Precious Metals Federation (EPMF), International Antimony

Association (i2a), International Manganese Institute (IMnI), International Molybdenum Association 
(IMOA), ITRI Ltd. (on behalf of the REACH Tin Metal Consortium), International Zinc Association (IZA) International Lead Association-Europe (ILA-Europe) European Borates Association (EBA), the (REACH) Vanadium Consortium (VC) and the (REACH) Selenium and Tellurium Consortium.

Apart from the sponsors, the EuroGeoSurveys Geochemistry Expert Group is collaborating in the GEMAS project with a number of organisations, such as Alterra in The Netherlands, the Norwegian Forest and Landscape Institute, several Ministries of the Environment and University Departments of Geosciences in a number of European countries, and CSIRO Land and Water in Adelaide, Australia.

Finally, all GEMAS samples were analysed at BGR by $\mathrm{XRF}$, and NGU determined $\mathrm{pH}$, total carbon and sulphur and the lead isotopes (isotopes: Ap samples only). The University of East Anglia determines the Sr isotopes on the Gr samples.

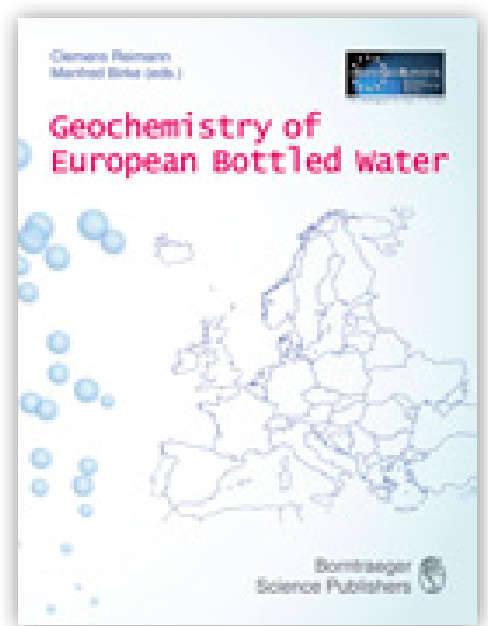

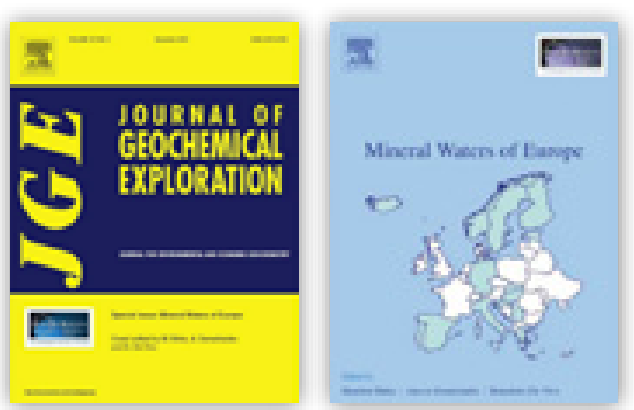

Fig. 5.2 Covers of the Special issue of the Journal of Geochemical Exploration on "Mineral Waters of Europe" 1. soft bound cover edition, and 2. hard bound cover edition.

\section{Members list}

\begin{tabular}{|c|c|c|}
\hline Country & Survey & Name \\
\hline NORWAY & NGU & $\begin{array}{l}\text { Clemens Reimann } \\
\text { (Chairperson) }\end{array}$ \\
\hline ALBANIA & AGS & Agim Mazreku \\
\hline AUSTRIA & GBA & $\begin{array}{l}\text { Sebastian Pfleiderer } \\
\text { Gerhard Hobier } \\
\text { Albert Schedl }\end{array}$ \\
\hline BELGIUM & GSB & Walter De Vos \\
\hline BULGARIA & MOEW & Valeri Trendafilov \\
\hline CROATIA & HGI-CGS & $\begin{array}{l}\text { Josip Halamić } \\
\text { Ajka Šorša }\end{array}$ \\
\hline CYPRUS & GSD & Andreas Zissimos \\
\hline $\begin{array}{l}\text { CZECH } \\
\text { REPUBLIC }\end{array}$ & CZS & Michal Poñavič \\
\hline DENMARK & GEUS & Vibeke Ernstsen \\
\hline ESTONIA & EGK & $\begin{array}{l}\text { Jaan Kivisilla } \\
\text { Valter Petersell }\end{array}$ \\
\hline
\end{tabular}

\begin{tabular}{|c|c|c|}
\hline FINLAND & GTK & $\begin{array}{l}\text { Tommi Kauppila } \\
\text { Timo Tarvainen }\end{array}$ \\
\hline FRANCE & BRGM & $\begin{array}{l}\text { Ignace Salpeteur } \\
\text { Philippe Negrel }\end{array}$ \\
\hline GERMANY & BGR & Manfred Birke \\
\hline HELLAS & IGME & Alecos Demetriades \\
\hline HUNGARY & MAFI & Gyozo Jordan \\
\hline IRELAND & GSI & Patrick O'Connor \\
\hline ITALY & ISPRA & $\begin{array}{l}\text { Marco Falconi } \\
\text { Nicoletta Calace } \\
\text { Maurizio Guerra }\end{array}$ \\
\hline LITHUANIA & LGT & Virgilija Gregorauskiene \\
\hline LUXEMBURG & SGL & Robert Maquil \\
\hline NORWAY & NGU & $\begin{array}{l}\text { Jan Høst } \\
\text { Rolf Tore Ottesen }\end{array}$ \\
\hline POLAND & PGI & $\begin{array}{l}\text { Anna Pasieczna } \\
\text { Aleksander Biel } \\
\text { Aleksandra Dusza-Dobek }\end{array}$ \\
\hline PORTUGAL & LNEG & $\begin{array}{l}\text { Maria Joao Batista } \\
\text { Rita Caldeira } \\
\text { Joao Matos }\end{array}$ \\
\hline ROMANIA & GIR & Adriana Ion - office \\
\hline ROMANIA & GIR & Adriana Ion - personal \\
\hline $\begin{array}{l}\text { SLOVAK } \\
\text { REPUBLIC }\end{array}$ & SGUDS & Dusan Bodis \\
\hline SLOVENIA & GEOZS & Mateja Gosar \\
\hline SPAIN & IGME & $\begin{array}{l}\text { Juan Locutura } \\
\text { Alejandro Bel-Lan }\end{array}$ \\
\hline SWEDEN & SGU & $\begin{array}{l}\text { Madelen Andersson } \\
\text { Kaj Lax }\end{array}$ \\
\hline SWITZERLAND & SWISTTOPO & Peter Hayoz \\
\hline THE NETHERLANDS & TNO & Jasper Griffionen \\
\hline UK & BGS & $\begin{array}{l}\text { Shaun Reeder } \\
\text { Dee Flight } \\
\text { Andreas Scheib } \\
\text { Chris Johnson }\end{array}$ \\
\hline UKRAINE & UkrSGRI & $\begin{array}{l}\text { Boris Maliuk } \\
\text { Volodymyr Klos } \\
\text { Maryna Vladymyrova }\end{array}$ \\
\hline
\end{tabular}


List of additional GEMAS participants

\begin{tabular}{|c|c|c|}
\hline Country & Survey & Name \\
\hline \multirow[t]{3}{*}{ AUSTRIA } & GBA & Heinz Reitner \\
\hline & AIT & Edith Haslinger \\
\hline & TU Wien & Peter Filzmoser \\
\hline \multirow[t]{3}{*}{ BELGIUM } & $\begin{array}{l}\text { Rio Tinto } \\
\text { Minerals }\end{array}$ & Ilse Schoeters \\
\hline & $\begin{array}{l}\text { Euro- } \\
\text { metaux }\end{array}$ & Violaine Verougstraete \\
\hline & ARCHE & Koen Oorts \\
\hline $\begin{array}{l}\text { BOSNIA\& } \\
\text { HERZEGOVINA }\end{array}$ & GSBH & Hazim Hrvatovic \\
\hline CROATIA & $\begin{array}{l}\text { University } \\
\text { of Zagreb }\end{array}$ & Stjepan Husnjak \\
\hline CYPRUS & GSD & Zomenia Zomeni \\
\hline $\begin{array}{l}\text { CZECH } \\
\text { REPUBLIC }\end{array}$ & CZS & Miloslav Duris \\
\hline FINLAND & GTK & Mikael Eklund \\
\hline F.Y.R.O.M. & $\begin{array}{l}\text { Institute } \\
\text { Chemistry, } \\
\text { Sts. Cyril } \\
\& \\
\text { Methodius } \\
\text { University }\end{array}$ & Trajce Stafilov \\
\hline \multirow[t]{3}{*}{ GERMANY } & BGR & Rainer Hoffmann \\
\hline & & Jens Utermann \\
\hline & & Uwe Rauch \\
\hline HELLAS & IGME & $\begin{array}{l}\text { Maria Kaminari } \\
\text { Marianthi Stefouli }\end{array}$ \\
\hline HUNGARY & MAFI & $\begin{array}{l}\text { Ubul Fügedi } \\
\text { László Kuti }\end{array}$ \\
\hline IRELAND & GSI & Vincent Gallagher \\
\hline
\end{tabular}

\begin{tabular}{|c|c|c|}
\hline \multirow[t]{6}{*}{ ITALY } & $\begin{array}{l}\text { Univ. } \\
\text { Napoli }\end{array}$ & Benedetto De Vivo \\
\hline & $\begin{array}{l}\text { Univ. } \\
\text { Napoli }\end{array}$ & Annamaria Lima \\
\hline & $\begin{array}{l}\text { Univ. } \\
\text { Napoli }\end{array}$ & Stefano Albanese \\
\hline & $\begin{array}{l}\text { Univ. } \\
\text { Bologna }\end{array}$ & Enrico Dinelli \\
\hline & $\begin{array}{l}\text { Univ. } \\
\text { Sannio }\end{array}$ & Domenico Cicchella \\
\hline & $\begin{array}{l}\text { Univ. } \\
\text { Cagliari }\end{array}$ & Paolo Valera \\
\hline LATVIA & $\begin{array}{l}\text { LEGM } \\
\text { Agency }\end{array}$ & Aivars Gilucis \\
\hline MONTENEGRO & GSM & Ranko Srvkota \\
\hline NORWAY & NGU & Ola A. Eggen \\
\hline POLAND & PGI & Pawel Kwecko \\
\hline PORTUGAL & LNEG & Cátia Prazeres \\
\hline \multirow[t]{2}{*}{ SERBIA } & GIS & Aleksandra Gulan \\
\hline & SEPA & Dragana Vidojević \\
\hline \multirow{3}{*}{$\begin{array}{l}\text { SLOVAK } \\
\text { REPUBLIC }\end{array}$} & \multirow[t]{3}{*}{ SGUDS } & Igor Slaninka \\
\hline & & Peter Sefcik \\
\hline & & Silvester Pramuka \\
\hline SWITZERLAND & ART & Reto Giulio Meuli \\
\hline THE NETHERLANDS & Alterra & Gerben Mol \\
\hline \multirow{3}{*}{$\begin{array}{l}\text { UNITED } \\
\text { KINGDOM }\end{array}$} & BGS & Mick Strutt \\
\hline & BGS & Paul McDonnell \\
\hline & $\begin{array}{l}\text { Univ. East } \\
\text { Anglia }\end{array}$ & Jurian Hoogewerff \\
\hline \multirow{4}{*}{$\begin{array}{l}\text { INTERNATIONAL } \\
\text { AUSTRALIA }\end{array}$} & \multirow{4}{*}{$\begin{array}{l}\text { CSIRO } \\
\text { Land \& } \\
\text { Water }\end{array}$} & Mike McLaughlin \\
\hline & & Jason Kirby \\
\hline & & Sean Forrester \\
\hline & & Les Janik \\
\hline
\end{tabular}

\section{EXPERT GROUP ON MINERAL}

RESOURCES

\section{Introduction}

Since the last National Delegate Meeting in

Budapest at the end of June 2010, Mineral Resource Expert Group (MREG) stayed active on the EU level within the same structures (DG Enterprise, DR Research, ETP SMR...) as before. Main activities were related to the expertise of MREG on the EU level, especially within European Commission (EC) (particularly related minerals policy development and minerals projects funded by EC). Activities of pat year are described in this MREG Annual Report.

\section{Mission and vision}

Main ideas of MREG were developed in the first half of 2010. These ideas help the MREG to express its position very clearly, especially during the interaction with European Commission.

The mission of the EuroGeoSurveys Mineral Resources Expert group (EGS MREG) is to provide the best available mineral expertise and information based on the knowledge base of member geological surveys, for policy, industry, communication and education purposes on European level.

EuroGeoSurveys Mineral Resources Expert group (EGS MREG) wishes to become the leading partner within a European mineral information network, or other form of cooperation, that will be provide tools and expertise to support sustainable minerals supply for Europe. Mineral information provided by EGS 
MREG is based on globally comparable standards of excellence for science and expertise and these standards will be maintained. Vision will be carried out collaboratively with other organizations that have mineral information and expertise, and with consumers of that information

\section{Scope and focus}

In recent years (since 2007) minerals related topics returned on the political and research agenda on European level by Communication "Raw Materials Initiative (RMI)" and several calls for the minerals projects. This trend is to continue (with new Communication in February 2011 and drafting document on Innovation Partnership). Therefore is a need for more synergy among minerals teams of EGS members. The RMI communications created a historic opportunity to establish the European Mineral Intelligence Network (eMINEnt) on European Union level. eMINEnt would be built on existing national /member states capacities and other international ones.

The emphasis of MREG is on two main areas: - Establishing European Mineral Intelligence

Network or other form within the EGS members in the core,

- Information about and coordination of EU projects related to minerals among all members of EGS

- Main features that are supporting the main activity areas of MREG program are:

1// To strengthen the EGS MR EG group and relations with other relevant bodies or

institutions by improved communication and coordination
2// To focus on priorities:

- Communication on Raw Materials Initiative

- RMI and supporting actions (such as

Innovation Partnership)

- EU minerals projects (past \& ongoing)

- European Technological Platform - Sustainable

Mineral Resources (ETP-SMR)

\section{The European dimension}

MREG activities are all EU level focused in order to increase EU level visibility of EGS MREG members, their work and expertise on national and internationa level. This increase likelihood that EGS members will get involved in minerals related activities on the EU level.

\section{DG ENTERPRISE - Raw Materials Initiative /}

\section{Policy development}

Report of Working Groups

In the summer of 2010 the Commission published a report on (1) critical raw materials and (2) on the exchange of best practices in the area of land use planning and administrative conditions for exploration and extraction. Both reports had been developed by two ad hoc groups of the Raw Materials Supply Group. Within both groups members of MREG were represented. In the report on exchange ... MREG proposal on European Mineral Network was add as report's annex.

Reports can be found at:

- http://ec.europa.eu/enterprise/policies/rawmaterials/critical/index en htm

- http://ec.europa.eu/enterprise/policies/rawmaterials/sustainable-supply/index_en.htm
Public Consultation

Reports were discussed and commented within a public consultation that took place in summer and early fall 2010. Many EGS members sent stand alone replies on questionnaire. MREG as group made joint reply that was sent in by EGS Secretary General Luca Demicheli. EGS reply is an Annex 6.2.

Innovation Partnership

In autumn 2010 DG Enterprise stared to draft a document entitled Innovation Partnership (IP).

Occasionally MREG members were asked for advice or response. In the beginning of December 2010 IP draft was presented at the workshop organized by EC. Within the document geological knowledge expertise, surveys and EGS have an important role. Document envisages five Working Groups, one of them should be devoted to "Knowledge and Infrastructure Base" that is very closely related to MREG activities.

MREG was asked by EU Commission to provide a list of experts for all potential Working groups. List was delivered in January 2011. Next workshop is to be at the end of February 2011

\section{DG RESEARCH - Research projects}

EU Minerals Projects with EGS members

Due to the increased activities on minerals policy level, EC started to fund more extensively minerals related projects. There are several ongoing projects with strong EGS member surveys involvement; many of them are coordinated by EGS members. 
At the beginning of the 2011 following EU minerals projects with EGS members are (alphabetically)

- AEGOS - African-European Georesources Observation System; Project coordinator:

BRGM - www.aegos-project.org

- EO-MINERS - Earth Observation for Monitoring and Observing Environmental and Societal Impacts of Mineral Resources Exploration and Exploitation; Project Coordinator: BRGM -

www.eo-miners.eu

- EUROGEOSOURCE - IT portal ; Project

Coordinator TNO - www.eurogeosource.eu

- POLNARES - EU Policy on Natural Resources; Project Coordinator: CEPMLP) at the University

of Dundee - www.polinares.eu/project.html

- PROMINE - Nano-particle products from new

mineral resources in Europe; Project Coordinator:

GTK - http://promine.gtk.fi

- SARMa - Sustainable Aggregate Resource Management; Project Coordinator: GeoZS www.sarmaproject.eu

MREG in Advisory Board of Mineral Projects MREG / Chair of the MREG is currently a member of the Advisory Group of two EU mineral projects: (1) AEGOS and (2) EUROGEOSOURCE.

\section{ETP-SMR}

MREG and few national surveys are members of European Technological Platform Sustainable Mineral Resources (ETP-MR) that was established in 2005, and officially recognized by EU Commission in 2008
MREG is not only the member of High Level Group (assembly of ETP SMR members), but also member of Steering Committee a small group that is actively involved in preparation of ETP SMR documents

(such as Strategic Research Agenda,

Communication plan, ...)

\section{Proposal to host ETP-SMR Secretariat}

In the second half of 2010 EGS / MREG got proposal to host ETP-SMR Secretariat. EGS office and MREG started negotiations with ETP-SMR. Decision on hosting ETP SMR Secretariat will be taken in med March 2011

\section{Future perspectives}

The first half of the year 2011 MREG will be very busy due to the fact that program for Innovation Partnership (IP) on raw materials will created and discussed. MREG already did precede a list of experts for different Working packages. Beside that EGS proposed to EC MREG's willingness to take a lead of Working Package "Knowledge and Infrastructure Base". Decision on IP implementation will be taken in the second half of 2011. Beside work on Innovation Partnership other activities are planned, such as regular (1) communication among MREG members, (2) coordination among ongoing EU projects, especially between EuroGeoSource and Promine with regard to INSPIRE directive, and also on ongoing and future calls for projects on minerals. There will be (3) active involvement in ETP SMR and in (4) other organizations (cooperation with USGS?) and activities (Raw Materials Group, EU minerals related conferences, etc...).

\section{Members list}

\begin{tabular}{|c|c|c|c|}
\hline Country & Survey & Name & E-mail \\
\hline ALBANIA & AGS & & \\
\hline \multirow[t]{3}{*}{ AUSTRIA } & GBA & Maria Heinrich & Maria.Heinrich@geologie.ac.at \\
\hline & GBA & Albert Schedl & Albert.Sched|@geologie.ac.at \\
\hline & GBA & Sebastian Pfleider & Sebastian.Pfleiderer@geologie.ac.at \\
\hline BELGIUM & GSB & & \\
\hline CROATIA & HGI_CGS & Miko Slobodan & slobodan.miko@hgi-cgs.hr \\
\hline CYPRUS & GSD & Christodoulos Hadjigeorgiou & chadjigeorgiou@gsd.moa.gov.cy \\
\hline CZECH REPUBLIC & CZS & Petr Rambousek & petr.rambousek@geology.cz \\
\hline \multirow[t]{2}{*}{ DENMARK } & GEUS & Leif Thorning & Ith@geus.dk \\
\hline & & Christian Knudsen & ckn@geus.dk \\
\hline ESTONIA & EGK & Mare Kukk & m.kukk@egk.ee \\
\hline \multirow[t]{2}{*}{ FINLAND } & GTK & Raimo LAHTINEN & raimo.lahtinen@gtk.fi \\
\hline & & Saku VUORI & saku.vuori@gtk.fi \\
\hline FRANCE & BGRM & Patrice Christmann & p.christmann@brgm.fr \\
\hline \multirow[t]{3}{*}{ GERMANY } & BGR & Peter Buchholz & peter.buchholz@bgr.de \\
\hline & & Henrike Sievers & henrike.sievers@bgr.de \\
\hline & & Thomas Oberthür & thomas.oberthuer@bgr.de \\
\hline GREECE & IGME & Nikolaos Arvanitidis & narvanitidis@thes.igme.gr \\
\hline HUNGARY & MAFI & János Halmai & halmai@mafi.hu \\
\hline ICELAND & ISOR & & \\
\hline IRELAND & GSI & Gerry Stanley & gerry.stanley@gsi.ie \\
\hline ITALY & ISPRA & & \\
\hline LATVIA & LEGMA & & \\
\hline LITHUANIA & LGT & Juozas Mockevicius & juozas.mockevicius@|gt.It \\
\hline LUXEMBOURG & SGL & & \\
\hline \multirow[t]{2}{*}{ NORWAY } & NGU & Jan Høst & Jan.Host@NGU.NO \\
\hline & & Rognvald Boyd & rognvald.boyd@ngu.no \\
\hline \multirow[t]{2}{*}{ POLAND } & PGI & Stanislaw MIKULSKI & stanislaw.mikulski@pgi.gov.pl \\
\hline & & Tadeusz SMAKOWSKI & tadeusz.smakowski@pgi.gov.pl \\
\hline
\end{tabular}




\begin{tabular}{|c|c|c|c|}
\hline PORTUGAL & LNEG & Helena Santana & helena.santana@ineti.pt \\
\hline ROMANIA & GIR & & \\
\hline RUSSIAN & $\begin{array}{l}\text { FEDERATION } \\
\text { VSEGEI }\end{array}$ & & \\
\hline \multirow[t]{2}{*}{ SLOVAK REPUBLIC } & SGUDS & Peter Balaz & peter.balaz@geology.sk \\
\hline & & Zoltan Nemeth & zoltan.nemeth@geology.sk \\
\hline SLOVENIA & GEOZS & Slavko Solar & slavko.solar@geo-zs.si \\
\hline \multirow[t]{2}{*}{ SPAIN } & IGME & Manuel Regueiro & m.regueiro@igme.es \\
\hline & & Juan Locutora & j.locutura@igme.es \\
\hline SWEDEN & SGU & Lisbeth Hildebrand & lisbeth.hildebrand@sgu.se \\
\hline SWITZERLAND & SWISSTOPO & Andreas Kühni & andreas.kuehni@swisstopo.ch \\
\hline THE NETHERLANDS & TNO & Michiel van der Meulen & michiel.vandermeulen@tno.nl \\
\hline UK & BGS & Andrew Bloodworth & ajbl@bgs.ac.uk \\
\hline \multirow[t]{2}{*}{ UKRAINE } & SGSU & & \\
\hline & UkrSGRI & & \\
\hline
\end{tabular}

Regional surveys

Germany, Bavaria

Italy, Emilia-Romagna

Spain, Catalunya

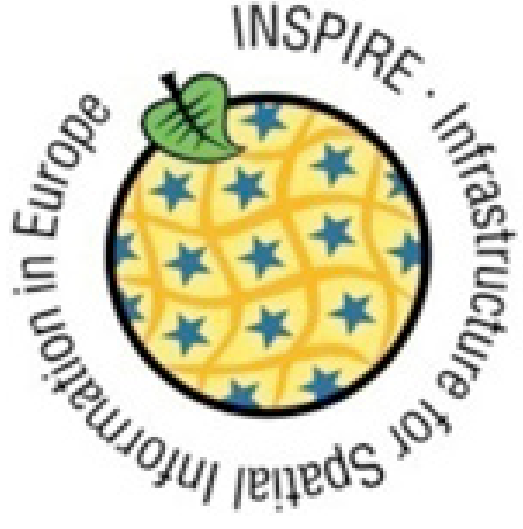

Directive is critical for the success of the initiative to build the European Spatial Data Infrastructure. EGS has been very active in the INSPIRE process since its inception in 2002, and is fully involved in the working groups created by the Commission to prepare the implementation rules.

The role of the Expert Group as a coordinating and supporting structure is therefore important to guarantee that the impact of the Directive for the surveys will be positive and to ensure that it will contribute to build the Geoscientific Spatial Data Infrastructure which is one of the main strategic objectives of EGS.

\section{Mission and vision}

\section{Mission}

The mission of the inspire and Geographic Information Expert Group is to coordinate the efforts of the

European Geological Surveys to build the Geoscientific Spatial Data Infrastructure, as a contribution to EGS strategy. The Expert Group has a direct role to

contribute to the definition of the European policies which aim at developing the European information infrastructure (INSPIRE, SEIS, GMES). It is also a place to share expertise between EGS members. 
The current prime mission of the Spatial Information Expert Group is to coordinate the contribution of EuroGeoSurveys to the INSPIRE implementation.

In practical terms:

- to prepare the contribution of EGS to review the INSPIRE implementing rules (IR), and to co-ordinate with direct contributions from national surveys

- to propose experts for the INSPIRE TWGs

(Thematic Working Groups) to be set-up by the Commission for writing the IR

- to prepare the material to be submitted to the

TWGs (including "uses cases")

- to share expertise between EGS members about interoperability developments and implementation - to co-ordinate relation between EGS and standardization bodies (IUGS/CGI, OGC,...).

As the other Expert Groups, the INSPIRE and Geographic Information EG has also the mission to define and propose projects that could be funded by the EC, and could contribute to the global objectives of EGS. In particular, the definition of the follow-up of OneGeology-Europe to develop a common EGS infrastructure is part of the current mission of the EG.

\section{Vision}

INSPIRE sets up a framework of data, technology, policies, standards, and human resources, necessary to facilitate the sharing and using of spatial information. This broad and ambitious objective has been recognized as strategic for the Geological Surveys, giving the opportunity to provide a better visibility, access and use to the subsurface data, information and knowledge.
The development of the INSPIRE rules is therefore very important to consider, as it will condition the success and the efficiency of the implementation of the European Spatial Data Infrastructure.

EGS has been involved in the design of the Directive from 2003, and has been identified as a very supportive and contributive community. European projects, such as OneGeology-Europe have demonstrated the capacity of EGS members to develop and implement prototypes of INSPIRE compliant infrastructures.

On a longer perspective, it is important to notice the strong connection of INSPIRE with GMES and with SEIS (Shared Environmental Information System). SEIS aims at developing a comprehensive European network of information services based on the INSPIRE principles that could be used in particular for reporting on environmental directives. The Commission will prepare in 2011 an implementation plan for SEIS that will develop the relationships and between three major European initiatives.

\section{The European dimension}

The INSPIRE process is divided into three phases (the detailed roadmap is given in Annex):

- Preparatory phase (2004-2006)

// Co-decision procedure

// Start of preparation of Implementing Rules

- Transposition phase (2007-2009)

// Directive entered into force 15 May 2007

// INSPIRE Committee starts its activities

26 June 2007
// Continuation of preparation of Implementing Rules

// Transposition into national legislation

// Adoption of Implementing Rules by Comitology

- Implementation phase (2009-2013)

// Implementation and monitoring of measures // Continuation of preparation of Implementing

Rules

// Adoption of Implementing Rules by Comitology

Since 2007, EGS experts have contributed to the initial drafting teams covering network services, metadata, data sharing, and data specifications.

The thematic communities are now involved in the definition of the 25 themes of the Annex II and III. This work is done by TWGs (Thematic Working

Groups) through a very precise and strict process developed by the data specification drafting theme during the last years.

The quality of this work will be critical for:

- the evaluation of the cost of implementation for

the data providers (such as the Geological Surveys),

- the usefulness of the information for end users,

- the capacity to merged data coming from different themes to address complex environmental issues.

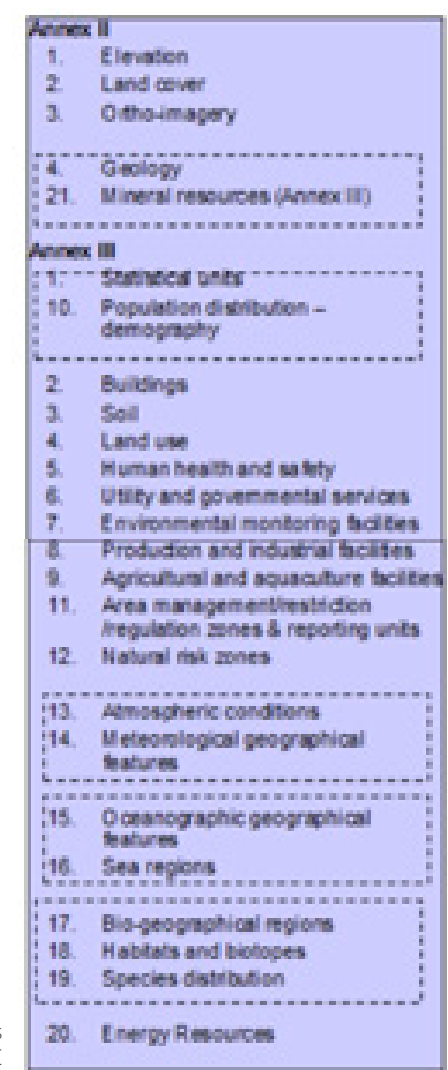


The global process, the methodology and the

contribution of the stakeholders for defining the data

specifications is very precisely defined and can be

illustrated as follows:
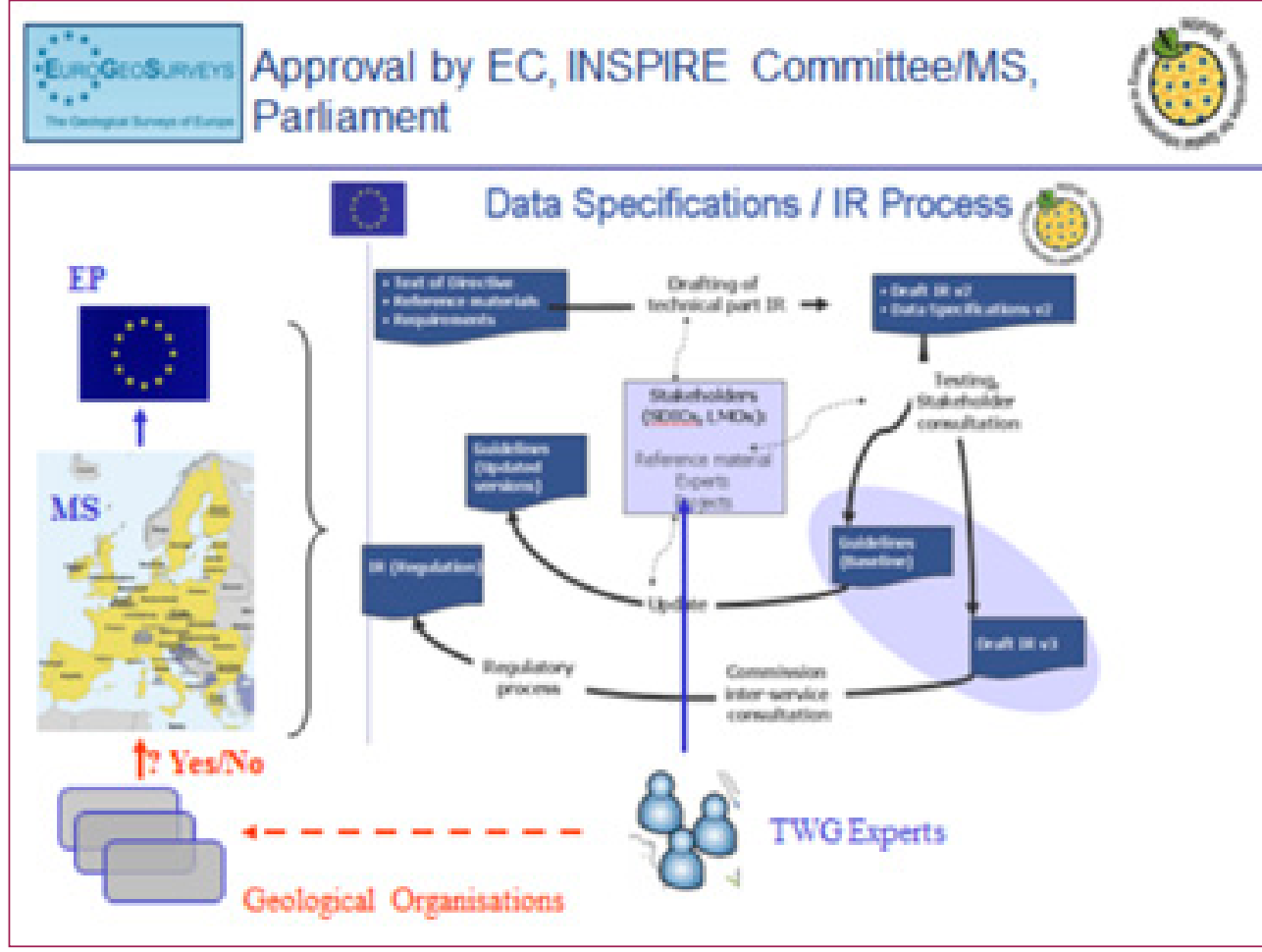

Data specification process: from the work of

Approval by the Parliament to
One of the key issues when defining the data

specifications is to define the appropriate degree of

complexity of the data (difficult to implement if too

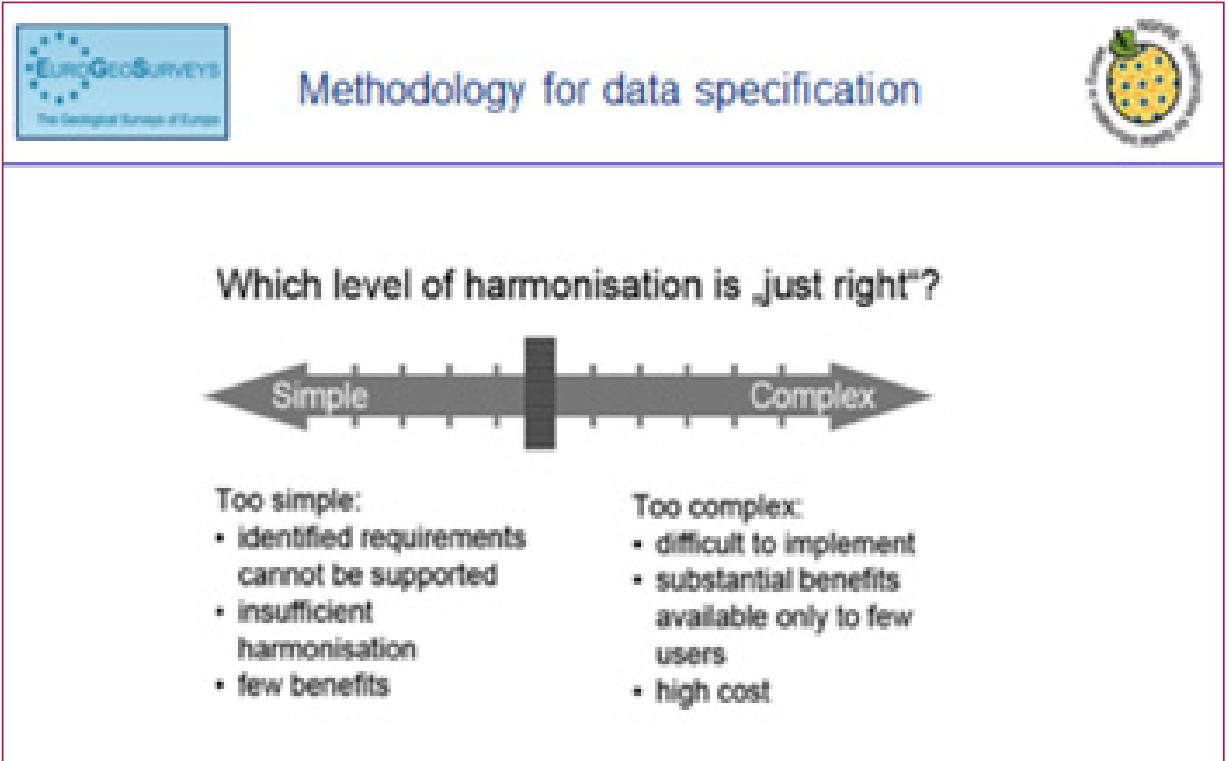




\section{Activities on EU level}

Contribution to INSPIRE implementing rules EGS decided in 2009 to have a pro-active strategy for the contribution to INSPIRE

"...We are now entering a phase that presents a great opportunity for EGS to gain a greater visibility within the EU and in particular the INSPIRE arena, to demonstrate how geoscience information can address the environmental and societal needs that are the goals of INSPIRE. But we have also to consider some challenges and threats if we EGS does not take the leadership on some upcoming actions..

The scope and quality of these data specifications will greatly influence our capability to deliver the data expected by INSPIRE at reasonable costs, derived from our existing systems, and addressing the real needs of our customers. It is therefore imperative that EGS plays a leading role in the specification work. To be passive at this time would leave the initiative with the Commission, creating a potential for unwelcome and unintended consequences.

After an internal call for candidates managed by the Expert Group, EGS has proposed 14 experts to the Commission to participate to the TWGs. All of them have been selected by the JRC (in charge of the technical coordination of INSPIRE). They contribute and facilitate the work of 3 themes: geology, mineral resources and natural risk zones. Other themes are also relevant for EGS : energy, soils, restriction/regulation zones, environmenta monitoring facilities, but no expert has been proposed by EGS. Altogether, the Commission received 318 proposals of experts, from 101 organizations, and 54 candidates for the Geology and Mineral Resources TWGS (only 2 non EGS members have been retained in these TWGs).

The EG is supporting the TWGs experts, and provides the connection with all the EGS members.

\begin{tabular}{|clll}
\hline Role & Expert name & Survey & Thematic working group \\
\hline \multirow{6}{*}{ Facilitator } & BGR & Geology and Mineral Resources \\
& Kristine ASCH & SGU & Geology and Mineral Resources \\
& Stefan BERGMAN & BGR & Soil \\
& Einar EBERHARDT & NGU & Geology and Mineral Resources \\
& Bjern FOLLESTAD & BGS & Natural Risk Zones \\
& Andrew HARRISON & BGS & Geology and Mineral Resources \\
& Dominique JANJOU & BRGM & Geology and Mineral Resources \\
\hline \multirow{2}{*}{ Editor } & Uffe LARSEN & GEUS & Geology and Mineral Resources \\
& John LAXTON & BGS & Geology and Mineral Resources \\
& Miguel LLORENTE ISIDRO & IGME & Natural Risk Zones \\
& Tomasz NALECZ & PGI & Geology and Mineral Resources \\
\hline \multirow{2}{*}{ Facilitator } & Simon PEN & TNO & Geology and Mineral Resources \\
& Jean-Jacques SERRANO & BRGM & Geology and Mineral Resources \\
& Jouni VUOLLO & GTK & Geology and Mineral Resources \\
\hline
\end{tabular}

List of the EGS experts selected in the TWGs.

The TWGs started to work in May 2010.

The TWGs are currently working on a version 2.0 of the data specifications, which will be made available end of June 2011 for review by stakeholders for review, comments and testing.

In May 2010, the EG has submitted to the JRC a that will be conducted by the EG, in coordination with the contributing projects.

According to the current planning, the fina specifications for the Annexes II and III will be

adopted mid-2012, and will have to be implemented from December 2014 for the new datasets, and in

May 2019 for the existing datasets.

Related projects

Some projects are contributing to the INSPIRE

implementation and have or will deliver practical tests that will be provided to the Commission.

- OneGeology-Europe: this project is probably the most complete and advanced test of INSPIRE implementation by a thematic community (geological surveys from 20 members states). proposal to coordinate a testing of specifications 
It addresses all the topics of INSPIRE (metadata, data, network services, data sharing, monitoring). Some of the highlights of the project are:

- development of an harmonized geological map at the 1:1M scale based on distributed services - setup of WMS and WFS harmonized and

multilingual services, multilingual client, unique

license for data use and downloading,..

The portal and the catalog services will be maintained (by BGRM and CZS) with a financial

support of EGS, the data services will be maintained by the surveys.

The EG is working on a road map and project proposals for the development of the OneGeologyEurope platform.

- Promine, AEgOS, PANGEO, EuroGeoSource, Emodnet, GeoSeas, Thermomap, GeoRG are also contributing in the different thematic domains.

\section{Meetings}

The Spatial Information Expert Group met physically

or by teleconference at different occasions:

- Brussels - 12 November 2009

- Krakow - 22 June 2010

(during the INSPIRE Conference)

- Brussels - 30 January - 15t February 2011

(with invitation of European projects representatives)

- Teleconference - 11 May 2011

- Planned meeting : Edinburgh - 30 June 2011

(during the INSPIRE Conference);
The EG has co-organized a session dedicated to Geoscience at the Krakow 2010 Inspire Conference.

The Chair of the EG has been invited to:

- the "technical workshop of INTERREG GeORG" on 18th of November 2010 in Freiburg im Br.

"The role of EuroGeoSurveys in the development of a geoscientific data infrastructure in Europe based on INSPIRE - F. Robida"

- the "CIP ICT PSP Stakeholder Meeting regarding

Geographic Information" on 20 ${ }^{\text {th }}$ October 2010

in Luxemburg.

\section{Future perspectives}

During the next months, the EG will coordinate the testing of the version 2.0 of data specifications.

This task will involve all the EGS members that want to contribute. It will be the last occasion to have an influence on the scope and content of the specifications that will become part of the EU regulation in the coming years. The kick-off of this testing will be organised in end June 2011

The process of development of the data specifications has indicated that the specifications that will come in the legislation (with an obligation to implement) will probably be more limited than originally planned.

A large part of the specifications will therefore be published as recommendations (no obligation to implement). This will give at the same time more flexibility, and more control by the communities. This means that EGS will have a key role to play in the future to maintain and develop those "extended" specifications.
The development of the OneGeology-Europe

infrastructure through an extension of its geographic coverage, an extension to more detailed geological maps and to other geoscientific domains is now a key priority of EGS. The EG will contribute to define and propose to the Directors a long term vision,

as well as a road map of its development.

\section{Members list}

\begin{tabular}{|c|c|c|c|}
\hline Country & Survey & Name & E-mail \\
\hline ALBANIA & AGS & Lavdie Moisiu & ledimoisiu@gsa.gov.al \\
\hline \multirow[t]{2}{*}{ AUSTRIA } & \multirow[t]{2}{*}{ GBA } & Werner Stöckl & werner.stoeckl@geologie.ac.at \\
\hline & & Marcus Ebner & marcus.ebner@geologie.ac.at \\
\hline \multirow[t]{5}{*}{ BELGIUM } & \multirow[t]{5}{*}{ GSB } & Pierre-Yves Declercq & pierre-yves.declercq@naturalsciences.be \\
\hline & & Nathalie Maricq & nathalie.maricq@naturalsciences.be \\
\hline & & Laetitia Dupin & laetitia.dupin@naturalsciences.be \\
\hline & & Christian Burlet & Christian.Burlet@naturalsciences.be \\
\hline & & Kris Piessens & Kris.Piessens@naturalsciences.be \\
\hline CYPRUS & GSD & Ioannis Panayides & ipanayides@gsd.moa.gov.cy \\
\hline CZECH REPUBLIC & CZS & Dana Capova & dana.capova@geology.cz \\
\hline DENMARK & GEUS & Jorgen Tulstrup & jtu@geus.dk \\
\hline ESTONIA & EGK & Jann Kivisilla & j.kivisilla@egk.ee \\
\hline \multirow[t]{2}{*}{ FINLAND } & \multirow[t]{2}{*}{ GTK } & Jarmo Kohonen & jarmo.kohonen@gtk.fi \\
\hline & & Juoni Vuollo & jouni.vuollo@gtk.fi \\
\hline \multirow[t]{4}{*}{ FRANCE } & \multirow[t]{4}{*}{ BGRM } & François Robida & f.robida@brgm.fr \\
\hline & & Daniel Cassard & d.cassard@brgm.fr \\
\hline & & Daniel Janjou & d.janjou@brgm.fr \\
\hline & & Jean-jacques Serrano & jj.serrano@brgm.fr \\
\hline \multirow[t]{3}{*}{ GERMANY } & \multirow[t]{3}{*}{ BGR } & Kristine Asch & kristine.asch@bgr.de \\
\hline & & Einar Eberhardt & Einar.Eberhardt@bgr.de \\
\hline & & Rainer Baritz & rainer.baritz@bgr.de \\
\hline GREECE & IGME & Nikolaos Arvanitidis & narvanitidis@thes.igme.gr \\
\hline HUNGARY & MAFI & Ferenc Sikhegyi & sikhegyi@mafi.hu \\
\hline
\end{tabular}




\begin{tabular}{|c|c|c|c|}
\hline IRELAND & GSI & Mary Carter & Mary.Carter@gsi.ie \\
\hline \multirow[t]{4}{*}{ ITALY } & \multirow[t]{4}{*}{ GSI } & Valentina Campo & valentina.campo@isprambiente.it \\
\hline & & Carlo Cipolloni & carlo.cipolloni@isprambiente.it \\
\hline & & Marco Pantaloni & marco.pantaloni@isprambiente.it \\
\hline & & Maria Pia Congi & mariapia.congi@isprambiente.it \\
\hline LUXEMBOURG & NGU & Robert Colbach & robert.colbach@pch.etat.lu \\
\hline \multirow[t]{3}{*}{ NORWAY } & \multirow[t]{3}{*}{ LEGMA } & Jan Host & Jan.Host@NGU.NO \\
\hline & & Bjørn Follestad & \\
\hline & & Per Ryghaug & Per.Ryghaug@NGU.NO \\
\hline \multirow[t]{3}{*}{ POLAND } & \multirow[t]{3}{*}{ PGI } & Urszula Stepien & uste@pgi.gov.pl \\
\hline & & Tomasz Nalecz & thal@pgi.gov.pl \\
\hline & & Aleksandra Lukasiewicz & aleksandra.lukasiewicz@pgi.gov.pl \\
\hline \multirow[t]{4}{*}{ PORTUGAL } & \multirow[t]{4}{*}{ LNEG } & Teresa Cunha & teresa.cunha@ineti.pt \\
\hline & & Judite Fernandez & judite.fernandes@ineti.pt \\
\hline & & Lidia Quental & lidia.quental@ineti.pt \\
\hline & & Cristina Antunes & cristina.antunes@ineti.pt \\
\hline ROMANIA & GIR & Anca-marina Vajdea & anca.vijdea@igr.ro \\
\hline \multirow[t]{2}{*}{ SLOVENIA } & \multirow[t]{2}{*}{ GEOZS } & Matija Krivic & matija.krivic@geo-zs.si \\
\hline & & Jasna Sinigoj & jasna.sinigoj@geo-zs.si \\
\hline \multirow[t]{4}{*}{ SPAIN } & \multirow[t]{4}{*}{ IGME } & Ángel Prieto Martín & Ángel Prieto Martín a.prieto@igme.es \\
\hline & & Maria Mancebo & mj.mancebo@igme.es \\
\hline & & Miguel Llorente Isidro & \\
\hline & & Fernando Perez cerdan & f.perez@igme.es \\
\hline \multirow[t]{2}{*}{ SWEDEN } & \multirow[t]{2}{*}{ SGU } & Lars Stolen & lars.kristian.stolen@sgu.se \\
\hline & & Stefan Bergman & \\
\hline SWITZERLAND & SWISSTOPO & Nils Oesterling & nils.oesterling@swisstopo.ch. \\
\hline \multirow[t]{2}{*}{ THE NETHERLANDS } & \multirow[t]{2}{*}{ TNO } & Tirza Van Daalen & tirza.vandaalen@tno.nl \\
\hline & & Simon Pen & \\
\hline \multirow[t]{5}{*}{ UK } & \multirow[t]{5}{*}{ BGS } & Richard Hughes & rah@bgs.ac.uk \\
\hline & & Matthew Harrison & mharr@bgs.ac.uk \\
\hline & & Andrew Hughes & aghug@bgs.ac.uk \\
\hline & & John Laxton & Laxton, John L. <j|l@bgs.ac.uk> \\
\hline & & Jeremy Giles & jrag@bgs.ac.uk \\
\hline
\end{tabular}

Regional Surveys

\begin{tabular}{|lll|}
\hline ITALY Emilia-Romagna & Michela Grandi & mgrandi@regione.emilia-romagna.it \\
\hline
\end{tabular}

(formal GS representative in bold).

\section{Annexes}

\section{Detailed Roadmap of INSPIRE}

\section{Last Updated :18/02/2011}

\begin{tabular}{|c|c|c|}
\hline \multicolumn{3}{|l|}{ Adoption } \\
\hline Milestone date & Article & Description \\
\hline 15-May-2007 & - & Entry into force of INSPIRE Directive \\
\hline 15-Aug-2007 & $22 \$ 2$ & Establishment of the INSPIRE Committee \\
\hline 14-May-2008 & $5 \S 4$ & $\begin{array}{l}\text { Submission for opinion of the INSPIRE committee of IR for the creation } \\
\text { and updating of metadata }\end{array}$ \\
\hline 03-Dec-2008 & $5 \S 4$ & Adoption of INSPIRE Metadata Regulation \\
\hline 19-Dec-2008 & $21(4)$ & $\begin{array}{l}\text { Submission for opinion of the INSPIRE committee of IR for monitoring } \\
\text { and reporting }\end{array}$ \\
\hline 19-Dec-2008 & 16 & $\begin{array}{l}\text { Submission for opinion of the INSPIRE committee of IR for discovery } \\
\text { and view services }\end{array}$ \\
\hline 15-May-2009 & $24 \S 1$ & Provisions of Directive are brought into force in MS \\
\hline 05-Jun-2009 & 17(8) & $\begin{array}{l}\text { Submission for opinion of the INSPIRE committee of IR governing the access } \\
\text { rights of use to spatial data sets and services for Community institutions } \\
\text { and bodies }\end{array}$ \\
\hline 05-Jun-2009 & $21(4)$ & $\begin{array}{l}\text { Adoption of COMMISSION DECISION regarding INSPIRE monitoring } \\
\text { and reporting }\end{array}$ \\
\hline 19-Oct-2009 & 16 & Adoption of INSPIRE Regulation on Network Services (Discovery and View) \\
\hline 14-Dec-2009 & 9(a) & $\begin{array}{l}\text { Submission for opinion of the INSPIRE committee of Irs for the } \\
\text { interoperability of spatial data sets and services for Annex I spatial } \\
\text { data themes }\end{array}$ \\
\hline 14-Dec-2009 & 16 & Submission for opinion of the INSPIRE committee of IR for download services \\
\hline 14-Dec-2009 & 16 & $\begin{array}{l}\text { Submission for opinion of the INSPIRE committee of IR for transformation } \\
\text { services }\end{array}$ \\
\hline 29-Mar-2010 & $17(8)$ & $\begin{array}{l}\text { Adoption of Regulation as regards the access to spatial data sets and services } \\
\text { of the Member States by Community institutions and bodies under } \\
\text { harmonised conditions }\end{array}$ \\
\hline 17-Jun-2010 & 9(a) & $\begin{array}{l}\text { Submission for opinion of the INSPIRE committee of amendment to } \\
\text { Regulation for the interoperability of spatial data sets and services for Annex I } \\
\text { spatial data themes on code lists }\end{array}$ \\
\hline 23-Nov-2010 & 16 & $\begin{array}{l}\text { Adoption of amendment of Regulation (EC) No } 976 / 2009 \text { as regards } \\
\text { download services and transformation services }\end{array}$ \\
\hline 23-Nov-2010 & 9(a) & $\begin{array}{l}\text { Adoption INSPIRE regulation for the interoperability of spatial data sets } \\
\text { and services for Annex I spatial data themes }\end{array}$ \\
\hline
\end{tabular}




\begin{tabular}{|c|c|c|}
\hline 04-Feb-2011 & 9(a) & $\begin{array}{l}\text { Adoption INSPIRE amendment to Regulation for the interoperability of spatial } \\
\text { data sets and services for Annex I spatial data themes on code lists }\end{array}$ \\
\hline June 20121 & 16 & $\begin{array}{l}\text { Submission for opinion of the INSPIRE committee of IR for the services } \\
\text { allowing spatial data services to be invoked }\end{array}$ \\
\hline October 20121 & 9(b) & $\begin{array}{l}\text { Submission for opinion of the INSPIRE committee of IRs for the } \\
\text { interoperability of spatial data sets and services for Annex II and III spatial } \\
\text { data themes }\end{array}$ \\
\hline \multicolumn{3}{|l|}{ Implementation } \\
\hline Milestone date & Article & Description \\
\hline 15-May-2010 & $21 \S 121 \S 2$ & Implementation of provisions for monitoring and reporting \\
\hline 03-Dec-2010 & 6(a) & $\begin{array}{l}\text { Metadata available for spatial data sets and services corresponding } \\
\text { to Annex I and II }\end{array}$ \\
\hline 30-Jun-2011 & 15 & The EC establishes and runs a geo-portal at Community level \\
\hline 19-Oct-2011 & $17(8)$ & $\begin{array}{l}\text { Implementation of Regulation as regards the access to spatial data sets } \\
\text { and services of the Member States by Community institutions and bodies } \\
\text { under harmonised conditions for new arrangements }\end{array}$ \\
\hline 09-Nov-2011 & 16 & Discovery and view services operational \\
\hline 23-Nov-2012 & $7 \S 3,9(\mathrm{a})$ & $\begin{array}{l}\text { Implementation of Commission Regulation (EU) No 1089/2010 of } \\
23 \text { November } 2010 \text { implementing Directive 2007/2/EC of the European } \\
\text { Parliament and of the Council as regards interoperability of spatial data } \\
\text { sets and services for Newly collected and extensively restructured Annex } \\
\text { I spatial data sets available }\end{array}$ \\
\hline December 20121 & 16 & Transformation services operational \\
\hline December 20121 & 16 & Download services operational \\
\hline 04-Feb-2013 & $7 \S 3,9(\mathrm{a})$ & $\begin{array}{l}\text { Implementation of Commission Regulation (EU) No 102/2011 of } \\
4 \text { February } 2011 \text { amending Regulation (EU) No } 1089 / 2010 \text { implementing } \\
\text { Directive 2007/2/EC of the European Parliament and of the Council as } \\
\text { regards interoperability of spatial data sets and services for newly } \\
\text { collected and extensively restructured spatial data sets }\end{array}$ \\
\hline 19-Apr-2013 & $17(8)$ & $\begin{array}{l}\text { Implementation of Regulation as regards the access to spatial data sets } \\
\text { and services of the Member States by Community institutions and bodies } \\
\text { under harmonised conditions for existing arrangements }\end{array}$ \\
\hline 03-Dec-2013 & 6(b) & Metadata available for spatial data corresponding to Annex III \\
\hline December 20143 & $7 \S 3,9(\mathrm{~b})$ & $\begin{array}{l}\text { Newly collected and extensively restructured Annex II and III spatial data } \\
\text { sets available }\end{array}$ \\
\hline
\end{tabular}

\begin{tabular}{|c|c|c|}
\hline 23-Nov-2017 & $7 \$ 3,9(a)$ & $\begin{array}{l}\text { Implementation of Commission Regulation (EU) No } 1089 / 2010 \text { of } \\
23 \text { November } 2010 \text { implementing Directive } 2007 / 2 / E C \text { of the European } \\
\text { Parliament and of the Council as regards interoperability of spatial } \\
\text { data sets and services for other spatial data sets still in use at the date } \\
\text { of adoption }\end{array}$ \\
\hline 04-Feb-2018 & $7 \S 3,9(\mathrm{a})$ & $\begin{array}{l}\text { Implementation of Commission Regulation (EU) No } 102 / 2011 \text { of } 4 \\
\text { February } 2011 \text { amending Regulation (EU) No } 1089 / 2010 \text { implementing } \\
\text { Directive 2007/2/EC of the European Parliament and of the Council as } \\
\text { regards interoperability of spatial data sets and services for other spatial } \\
\text { data sets still in use at the date of adoption }\end{array}$ \\
\hline October 20191 & $7 \S 3,9(\mathrm{~b})$ & $\begin{array}{l}\text { Other Annex II and III spatial data sets available in accordance with IRs } \\
\text { for Annex II and III }\end{array}$ \\
\hline 23-Nov-2010 & 16 & $\begin{array}{l}\text { Adoption of amendment of Regulation (EC) No } 976 / 2009 \text { as regards } \\
\text { download services and transformation services }\end{array}$ \\
\hline 23-Nov-2010 & 9(a) & $\begin{array}{l}\text { Adoption INSPIRE regulation for the interoperability of spatial data sets } \\
\text { and services for Annex I spatial data themes }\end{array}$ \\
\hline
\end{tabular}

1 Date proposed by the commission

3 Date depending on entry into force of measure 


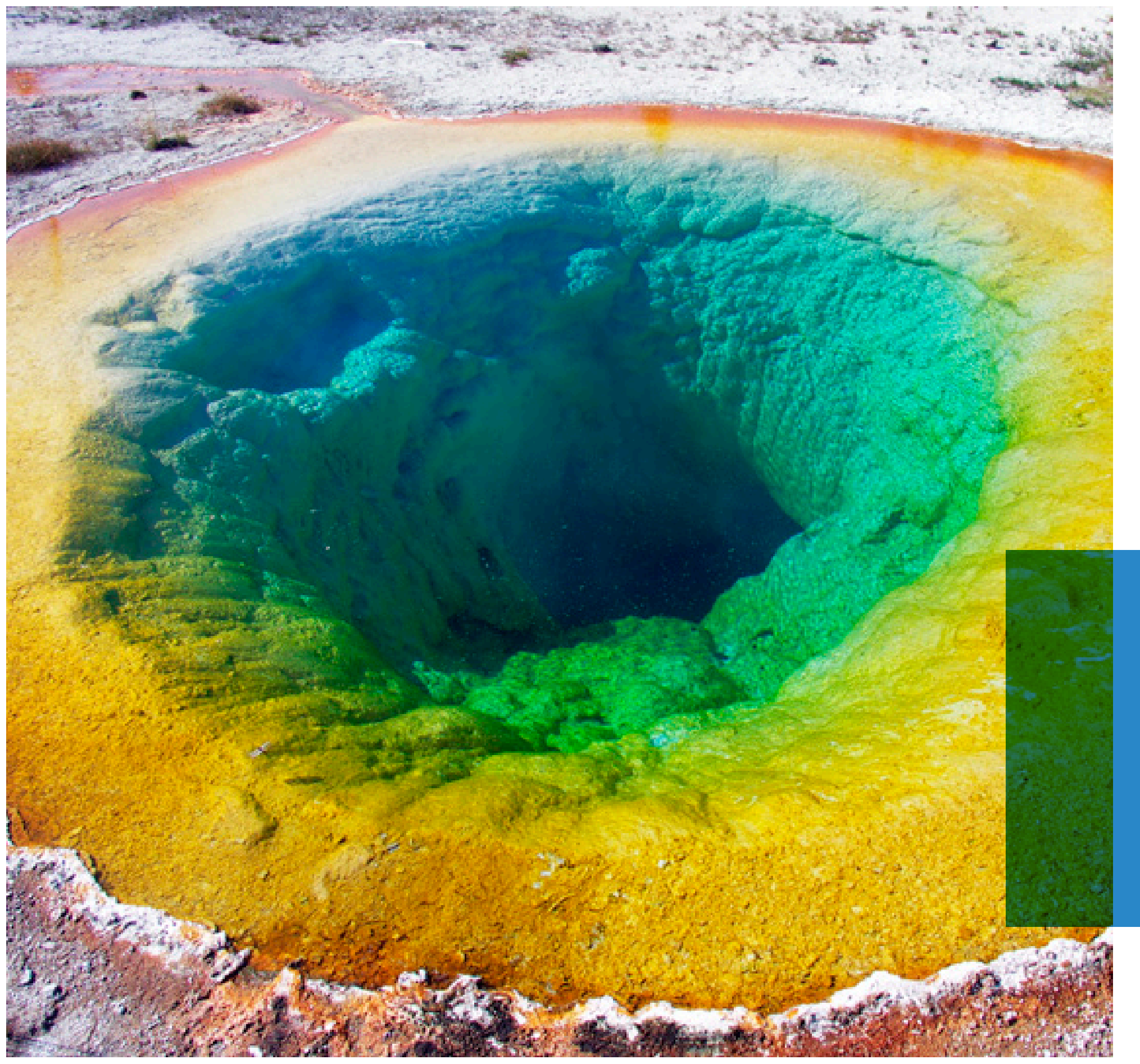




\section{$\nearrow$ An integrated "business" model}

\section{EGS 2010 Statistics}

In this section you will find some interesting statistical information on EuroGeoSurveys member organisations, such as staff numbers and budget data, showing past trends as well as specific details from 2010

\section{Staffing}

EuroGeoSurveys represented a combined total of about 18,000 staff in 2010. Chart 1 shows the fluctuations of staff numbers within our members over the past 10 years.

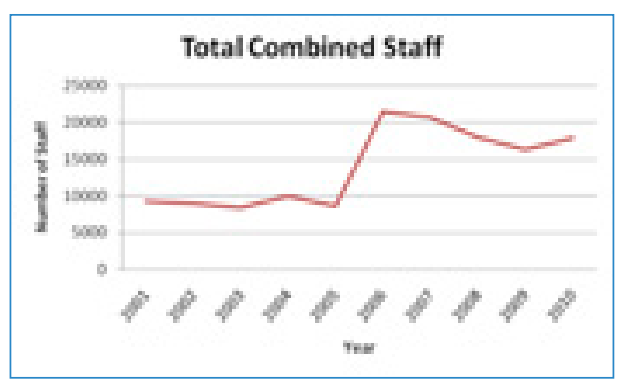

Chart 1 Total combined staff of all EGS Member organisations over the last 10 years. Albania, Bulgaria and Romania's data was not available.

In the early stages of the 2000s our membership consisted of a steady number of staff at around 9000 people. The large increase in numbers between 2005 and 2006 can be attributed to the incorporation of Ukraine's State Geological Survey and the National Academy of Sciences of Ukraine (Department of Geosciences) as members. Since then there has been a steady decline, most likely due to the economic downturn in Europe, up until a small recovery of numbers in 2010.

For 2010, the total staff numbers of each mem ber survey can be seen in Chart 2. The number of scientific staff within each survey is also shown.

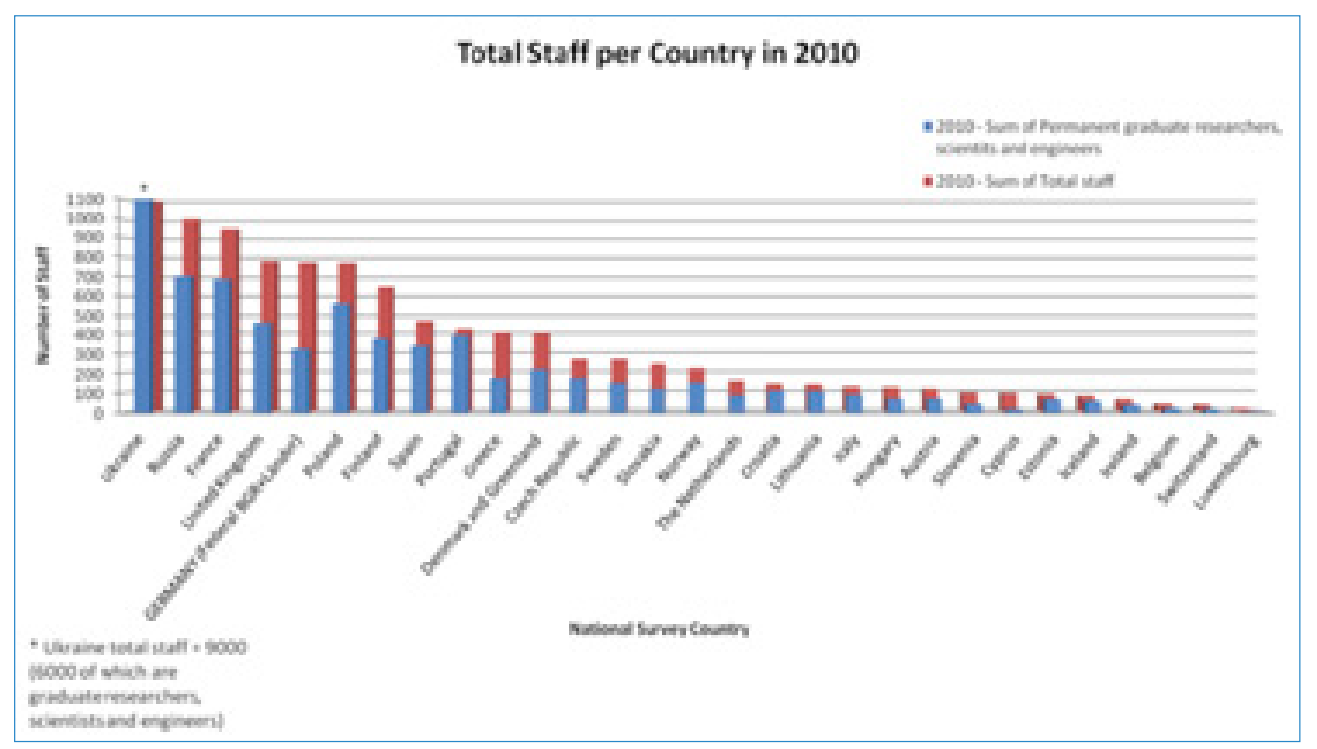

Chart 2 Total staff for each EGS Member (in red), showing he propor (in not available. 


\section{Budgets / Funding}

In 2010, the combined budgets of EGS Members totalled over $€ 800$ million. As seen in Chart 3 , a peak of over $€ 1$ billion was reached in 2009 but there followed a significant decrease to below 2006 levels that could most likely be attributed to recent public spending cuts throughout Europe.

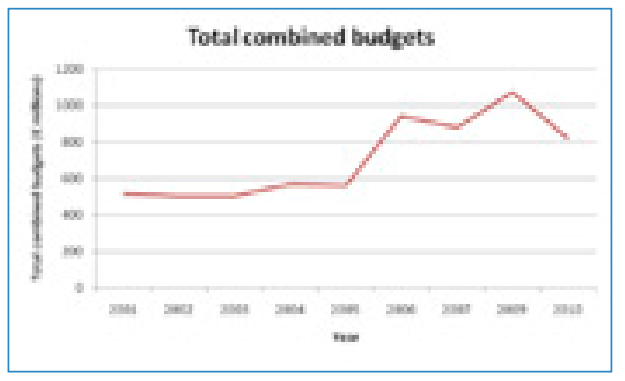
Chart 3 Total combined budgets of all EGS Member
organisations over the last 10 years. Albania, Bulgaria, Italy and Romania's data was not available.

The national geological surveys throughout Europe receive funding from a number of different sources, for example from government funding or EU research funding. A breakdown of funding sources for each

EGS Member in 2010 can be seen in Chart 4

On one end of the scale, Cyprus and Luxembourg rely wholly on governmental funding for their operations whereas Estonia, Poland and Iceland are more dependent on other sources of income.

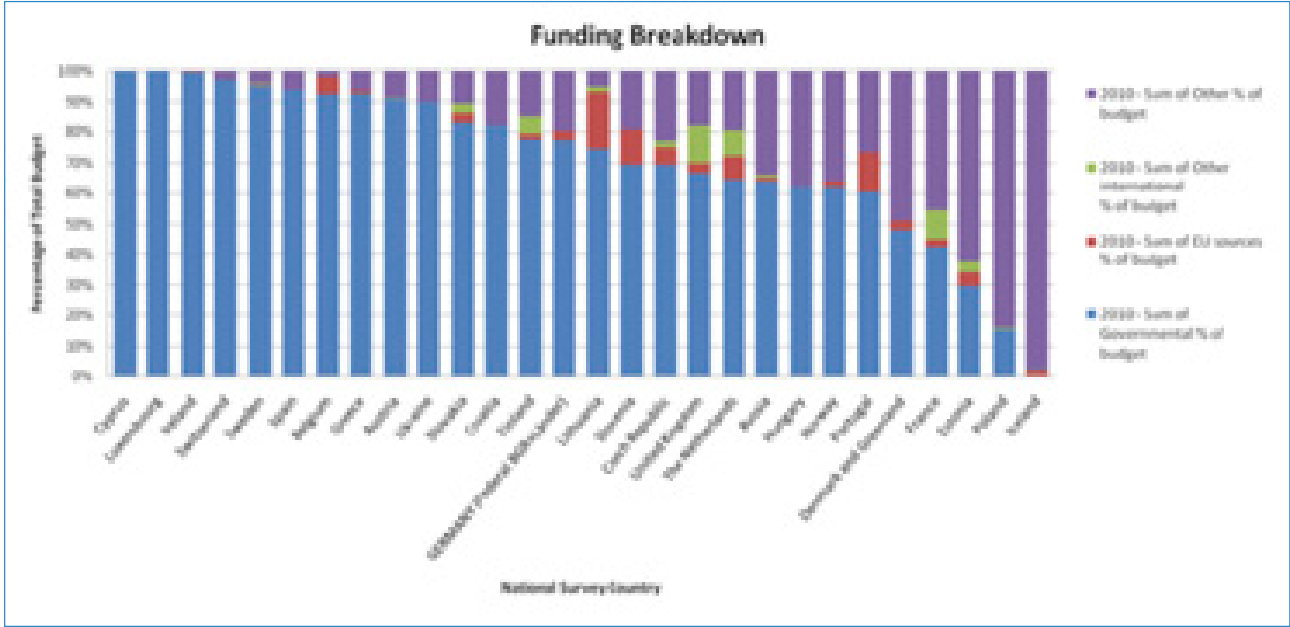

Chart 4 Breakdown of funding sources for each EGS Member.

Albania Bugaria, Italy and Romania's data was not available. 


\section{Geological Activities}

Geological expertise can be called upon to address

a broad range of topics, from the more common

geological issues like geohazards to seemingly

unrelated areas such as how to deal with

radioactive waste or even tourism. Chart 5 shows

the variety of activities that EGS members are

involved in.

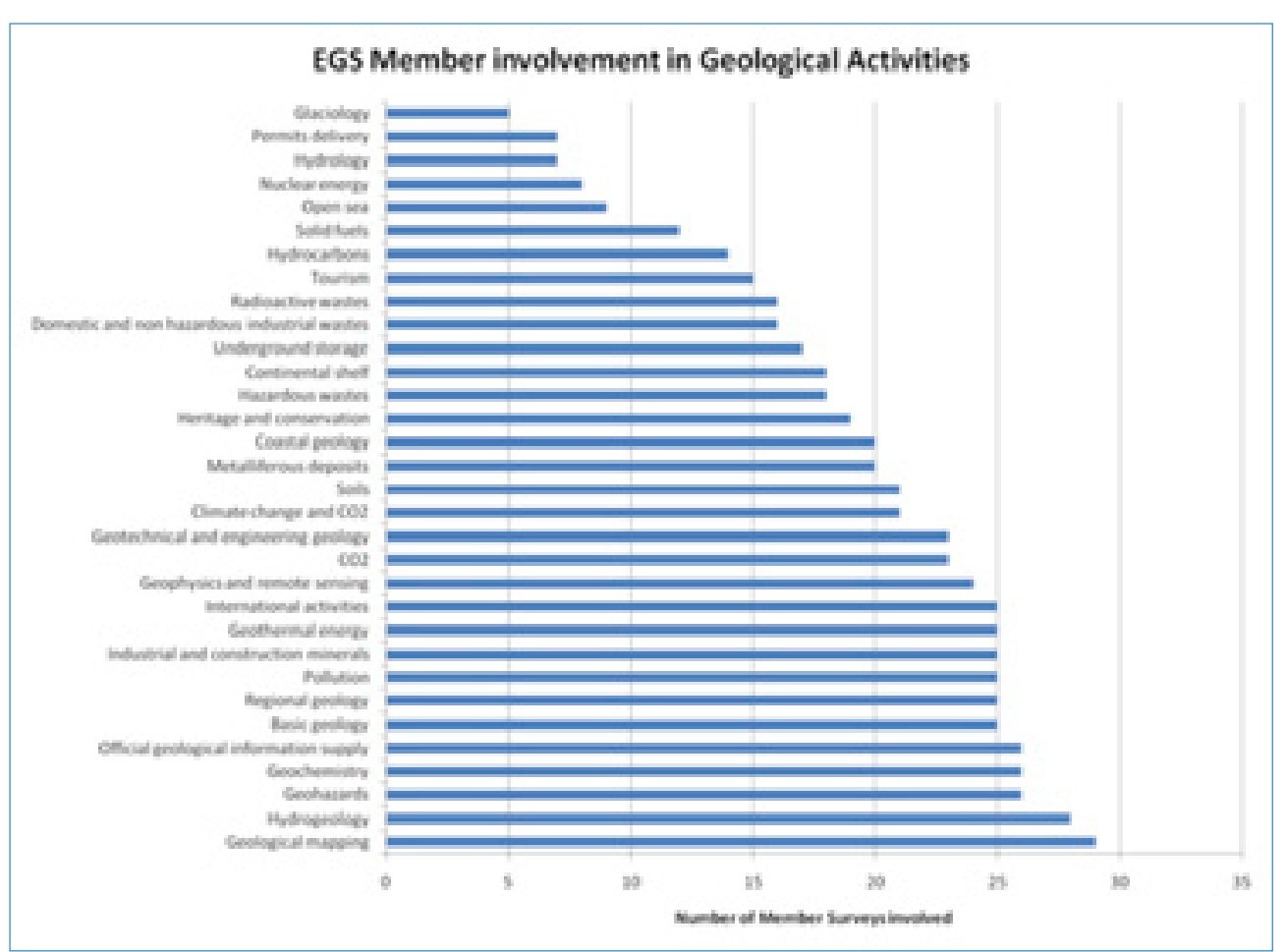

Chart 5 Number of EGS members involved in

various geological activities in 2010. Albania, Bulgaria

\section{Survey Status and Governance}

The national geological surveys that make up EGS are all public bodies that are under the jurisdiction of various government ministries. Charts 6 and 7 show the distribution of EGS members as different

institutional bodies and under the supervision of

different ministries within their respective countries.

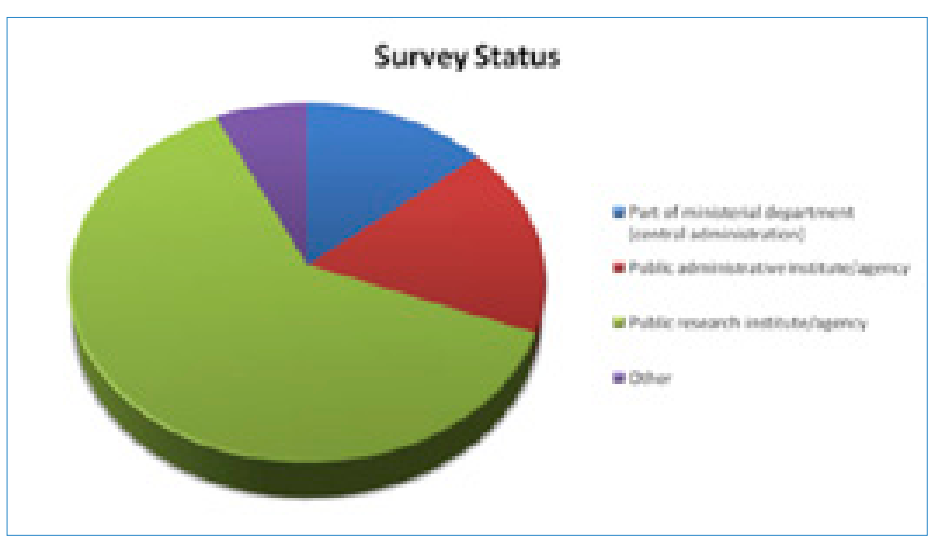

Chart 6 Institutional status of EGS members.

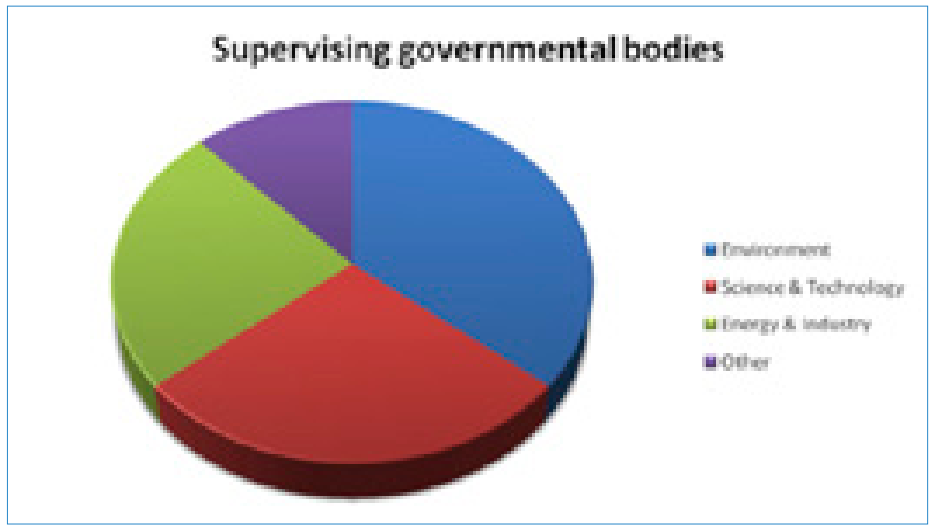




\section{Promine}

ProMine

Nano-particle products from new mineral resources in Europe http://promine.gtk.fi

- Total budget: € 17.39 million

- EU contribution $€ 11$ million

- Project duration: 2009 - 2013

- Coordinator: Geological Survey of Finland

- Sponsor: European Commission FP7-NMP-2008-

LARGE-2

- Number of persons/Members involved: 28 partners from 11 European countries, 161 person-years

\section{Context}

The non-energy extractive industry (NEEI) is a significant contributor to the economy of the EU providing metalliferous and non-metalliferous mineral resources to the society as well as creating direct and indirect employment. Many industries rely directly on the availability of mineral raw materials. These industries provide direct employment for almost 30 million people, which means that the availability of raw materials plays key role for the economy of the EU. Nevertheless, current demand exceeds production therefore the
EU is heavily dependent on mineral and metal imports leading to an annual trade deficit of about $€ 11$ billion. Metallic minerals accounted for $90 \%$ o this deficit, while there were also net trade deficits in construction minerals (€456 million) and industrial minerals (€798 million).

Another major issue is that the EU is totally dependent on imports for some strategic metals. Important strategic high-tech metals for the European industry include cobalt, niobium, rhenium rare earth elements, platinum and titanium. In the development of state-of-the-art technology and advanced products they are of crucial significance.

\section{Objectives}

The main objective of ProMine is to develop innovative concepts and processes for strategic mineral supply and for new high added value mineral-based products. Consequently, ProMine has a strong industrial involvement. Its consortium covers the entire supply chain from extraction and raw materials manufacturing to mineral products manufacturing and by-product materials utilization. It includes metal mining industry producing about $70 \%$ of metals mined within EU.

ProMine focuses on two parts of the production chain by targeting extractive and end-user industries. Upstream, the first ever Pan-EU GIS based mineral resource and advanced modeling system for the extractive industry will be created, showing known and predicted, metallic and non-metallic mineral occurrences across the EU. Detailed 4D computer models will be produced for four metalliferous regions. Upstream work will also include demonstrating the reliability of new (Bio) technologies for an eco-efficient production of strategic metals, driven by the creation of on-site added value and the identification of specific needs of potential end-users. Downstream, a new strategy will be developed for the European extractive industry which looks not only at increasing production but also at delivering high value, tailored nano-products which will form the new raw materials for the manufacturing industry.

ProMine research focuses on metal products partly in nano-scale: Conductive metal fibres,

rhenium and rhenium alloy powders, nano-silica, iron oxyhydroxysulphate and new nano-particle based coatings for printing paper. These products will have a major impact on the economic viability of the extractive industry. They will be tested at bench scale, and a number selected for development to pilot scale where larger samples can be provided for characterisation and testing by end-user industries.

Central to the themes of ProMine, and in accordance with the cradle to cradle approach, is the holistic concept that all solid and liquid materials at an exploitation site are potential useful resources, even those traditionally considered as waste. This means that the way a site is exploited becomes environmentally more sustainable, new uses and products can be found for minerals
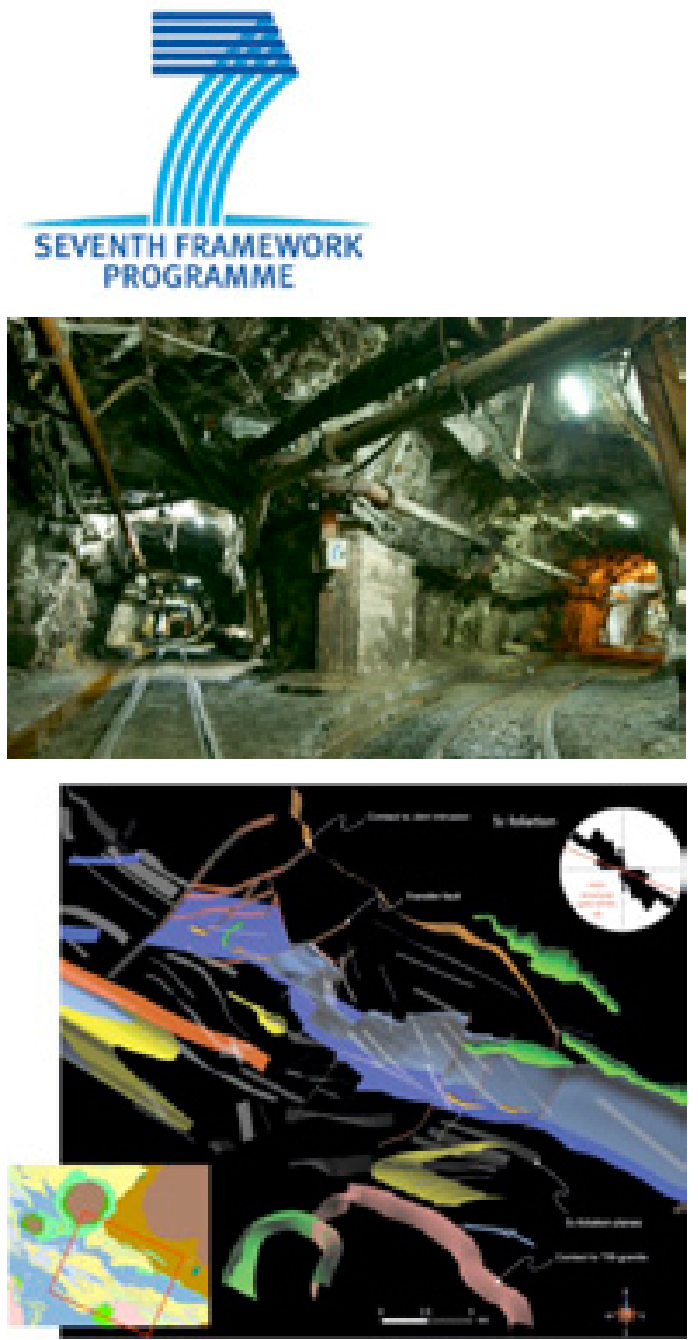
leading to increased profitability, and the dissolved metal emissions and final waste burden will be reduced.

ProMine responds to a number of initiatives of the EC's Raw Materials Initiative which launched measures:

- Initiative 7 "Encourage better networking between national geological surveys with the aim of increasing the EU's knowledge base"

- Initiative 8: "Promote skills and focused research on innovative exploration and extraction technologies, recycling, materials substitution and resource efficiency", and

- Initiative 9: "Increase resource efficiency and foster substitution of raw materials".

Expectations of industry from ProMine include: - Improving the diversity and volume of European "metallic" resources to be exploited in the future (new resources + mining wastes).

- Upgrading mining waste to secure and good raw materials.

- Making the society understand the new environmental friendly approach of mining due to advanced technology.

- Making the EU and its individual countries understand the importance of mining for further economic development.

- Active co-operation/knowledge transfer between geological surveys, industry, other research organizations, universities and SME's.

- Rational pan-European management of metallic minerals production and supply including re-use of by-products and wastes.
- Active networking with relevant national and international research activities and programs. - Finding additives from the mining industry that can give added value characteristics to the products that respond market expectations. - Lowering production costs. Lowering energy consumption ( $\mathrm{CO}_{2}$ load)

- Increase the profits, reduce the metal grades in the wastes minimizing the environmental impact.

\section{Project Structure}

ProMine consists of the following work packages (in parentheses WP Leader/Industrial Technical Advisor):

-WP1: Geological mineral resource potential modelling across Europe (BRGM/PMO) -WP2: 4D Modelling of mineralised belts (LTU/BOLIDEN)

- WP3: New nano-products from mineral exploitation (IMN/ECOREN)

- WP4: Eco-efficient metal production methods and utilization of secondary materials (BRGM/KGHM CUPRUM)

- WP5: Assessment of sustainability and

environmental impact (KEMAKTA/Hellas Gold)

-WP6: Knowledge management and exploitation (IRMCo)

-WP7: Project management (GTK)

\section{Participation in major conferences}

1// ProMine Information Day,

Brussels 25 $5^{\text {th }}$ February 2010.

2// First "China-EU Workshop on Clean Production
Technologies" Beijing, China - 17-18 March 2010. 3// Third International Symposium:

Mineral resources and mine development. Aachen, Germany, 26-27 May 2010.

4// Freiberger Forschungsforum Research Conference, Freiberg, 9-11 June.

5// gOcad Meeting. Nancy, France, 12-13 June 2010

6// "NANOFUTURES" European Initiative -

The European Technology Integration and

Innovation Platform (ETIP) in Nanotechnology, Gijon, Spain 15.6.-16.6. 2010

7// EU-Australia Joint Science and Technology Committee (JSTCC) reviewing progress of cooperation between the two regions - thematic workshops dealing with the main S\&T areas. Australia, June 2010.

8// $4^{\text {th }}$ INSPIRE Conference. Krakow, 22-25 June 2010 9// Conference of the International Association of Mathematical Geosciences. Budapest, Hungary, 28 August -2 September 2010

10// Seismix 2010 Symposium. Cairns, Australia, 29 August - 3 September 2010

11// International Mine Water Association (IMWA) Symposium. Cape Breton, Nova Scotia, 5-12 September 2010.

12// European Industrial Technologies 2010 - Integrating nano materials and production Brussels, Belgium, 7-9 September.2010

13// XIX Congress of the Carpathian Balkan Geological Association, CBGA 2010 Thessaloniki, 23-26 September 2010 14// 2010 TAPPI International Conference on Nanotechnology for the Forest Product Industry. Espoo, Finland, 2729 September 2010
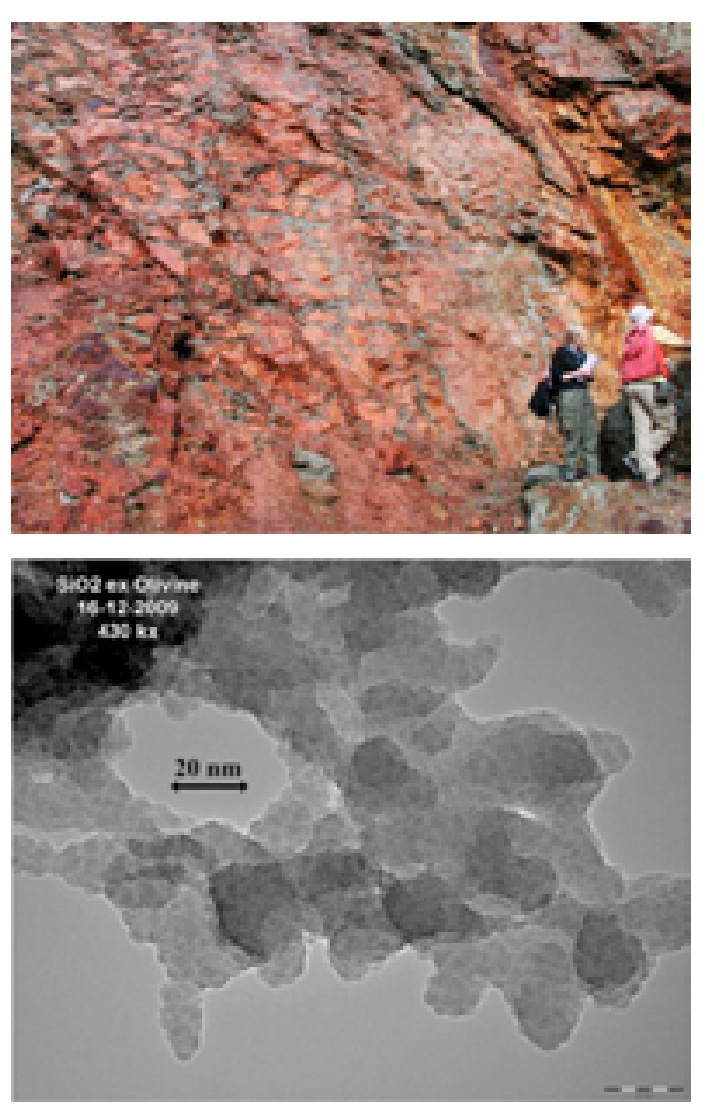
15// GeoDarmstadt2010 Conference. Darmstadt, Germany, 8-9 October 2010

16// LITHOSPHERE 2010 Symposium. Helsinki, Finland, 27-28 October 2010

$17 / / 2^{\text {nd }}$ International Conference: By-Product Metals in Non-Ferrous Metals Industry. Wroclaw, Poland, 13-15 $5^{\text {th }}$ October 2010 $18 / / 5^{\text {th }} 3 \mathrm{D}$ Geolnfo Conference. Berlin, Germany, 3-4 November 2010

$19 / / 5^{\text {th }}$ International Symposium on Bio-8 Hydrometallurgy - BioHydromet'10,

Cape Town, South Africa, 8-9 November 2010 20// Metal Kokkola 2010 Conference on 16-17.11.2010, Kokkola, Finland

21// Seminar of the Polish Technological Platform of Non-Ferrous Metals. Gliwice, Poland, 17 November 2010

22// Workshop on "Standards and standardisation as a tool for the dissemination and

implementation of research results" Brussels, Belgium, 14 th December 2010
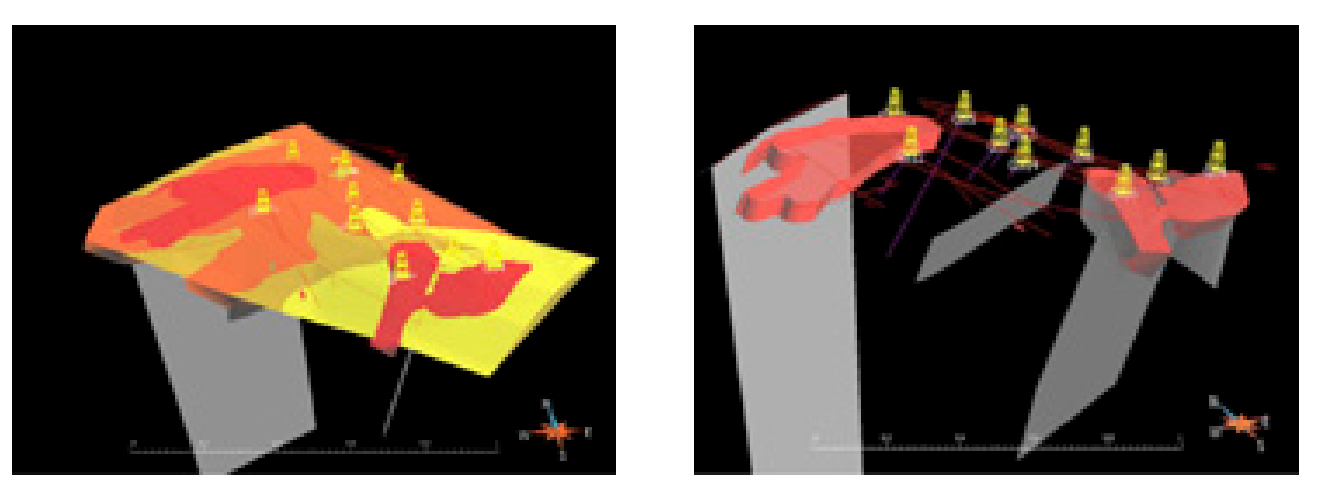

3D models of the Konos gold epithermal deposit in Thrace region, Northern Greece
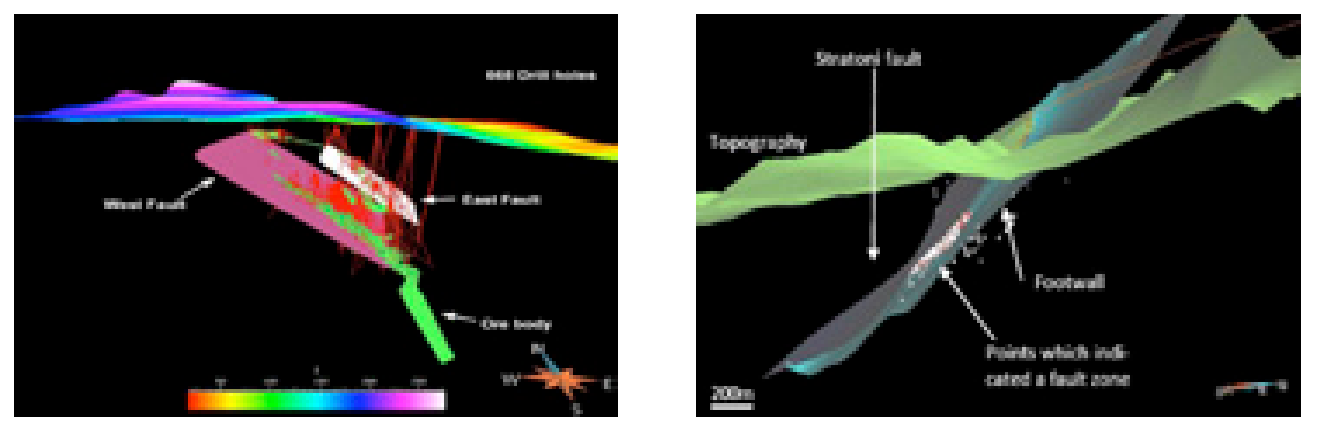

3D model of the Olympias polymetallic deposit in northern Greece 3D geology of the mineralized Stratoni fault in northern Greece 


\section{(10) EMODnet it}

\section{EMODNET-Geology Project}

Introduction

In December 2007 the European Parliament and Council adopted a common text for the Marine Strategy Framework Directive which aims to achieve environmentally healthy marine waters by 2020. This Directive includes a requirement for an overarching European Marine Observation and Data Network (EMODNET). Consequently, the EU Green Paper on Future Maritime Policy outlined plans to create EMODNET pilot studies that assemble fragmented and inaccessible marine data into interoperable, contiguous and publicly available datasets for whole maritime basins.

The EMODNET-Geology project is one of five preparatory action projects that, in addition to marine geology, bring together information on marine chemistry, marine biology, hydrography and physical parameters. Each project will define the processes, technologies and approximate costs of implementing a fully functioning European Marine Observation and Data Network. For the EMODNET-Geology project, the project partners are compiling data layers for the Baltic Sea, Greater North Sea and Celtic Sea (Figure 1).

The EMODNET-Geology partners consist of the national geological survey organisations of the UK, Ireland, France, Belgium, The Netherlands, Germany, Denmark, Norway, Sweden, Finland, Estonia, Latvia, Lithuania and Poland, who are working together to deliver the requirements of
EC Tender MARE/2008/03. The geological surveys of Europe provide an existing network (through the Association of European Geological Surveys EuroGeoSurveys) that aims to deliver marine geological information solutions to decision makers in European government and industry, as well as providing baseline information for academic research. The contract between the EC and the EMODNET-Geology project partners was signed on 16 July 2009; the project will run until July 2012 The project has a total budget of $€ 925,000$ provided by the European Commission.

\section{Project objectives}

The EMODNET-Geology project is compiling information held by the project partners and additional datasets that are publicly available. The EMODNET-Geology website (www.emodnetgeology.eu) provides access to the outputs, which are delivered through the 'OneGeology-Europe (1G-E)' portal (www.onegeology-europe.org).

Existing metadata will continue to be stored on the EU-SEASED website, currently being developed and upgraded under the EC-funded GeoSeas project (www.geo-seas.eu). The consortium is bringing together datasets of all available sea-bed sediments including rate of accumulation or sedimentation; sea-floor geology (including age, lithology and origin); geological boundaries and faults; rate of coastal erosion and sedimentation; geological events and event probabilities (to include information on submarine landslides, volcanic activity, earthquake epicentres); seismic profiles and minerals (including aggregates, oil and gas).

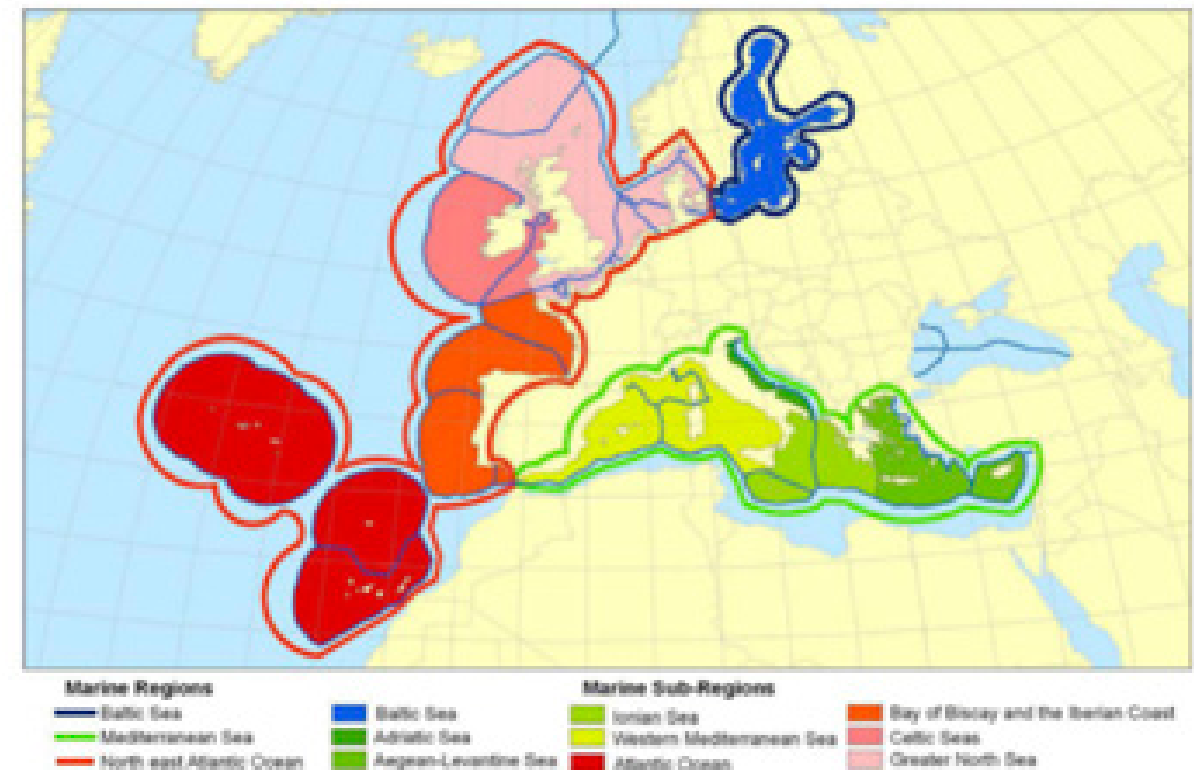

Project details

Fig 1. Marine Regions and Sub-Regions as defined by the Marine Strategy Framework Directive.

The project is being implemented in four phases.

Phases 1-3 are the Development phases and

Phase 4 is the Maintenance phase.

Phase 1. Development of the data layers and portal (months 1-12; July 2009-July 2010); Phase 2.

Testing and monitoring of the information layers (months 13-18; August 2010- January 2011):

Phase 3. Upgrade of the system following testing (months 19-24; January 2011-July 2011); Phase 4. Maintenance of the system (months 25-36; August 2011-July 2012). 
The project is implemented through 11

workpackages, each led by organisations with

experience in the specific fields. These are:

-WP1. Project Management (British Geologica

Survey)

-WP2. 1:1 million marine geological data

specification and sourcing (British Geological

Survey)

-WP3. Sea-bed sediment information compilation and harmonisation (Geological Survey of Finland)

-WP4. Sea floor geology compilation and

harmonisation (Bundesandstalt für

Geowissenschaften und Rohstoffe (BGR) -

Federal Institute for Geosciences and Natural

Resources, Germany)

-WP5. Coastal erosion or sedimentation

(TNO- Geological Survey of the Netherlands)

-WP6. Geological events and probabilities

(Geological Survey of Norway)

-WP7. Minerals (Geological Survey of Ireland)

- WP8. Integration with OneGeology-Europe

(including portal development) (British Geological Survey)

-WP9. Dissemination (British Geological Survey)

- WP10. Liaison with EMODNET lots (British

Geological Survey)

-WP11. Project analysis and sustainability (British Geological Survey).

Each of the data workpackages (WPs 3-7) consists of a development phase (October 2009 to July

2010), upgrade phase (July 2010 to July 2011) and a maintenance phase (August 2011 to July 2012).

\section{Examples of information products}

The EMODNET-Geology Workpackage 3 has compiled and harmonised all available sea-bed sediment information at a scale of 1:1 million for the pilot study area. The harmonised information includes an evaluation of the different classification schemes used in each country and the maps have been compiled according to the most appropriate scheme for integration with the hydrographic chemical and biological lots, and in particular the EUSeaMap project, a broadscale habitat mapping project which is also an integral part of EMODNET (http://jncc. defra.gov.uk/page-5020). The most up-to-date version of the map is given in Figure 2.

One of the aims of the EMODNET-Geology project is to highlight data gaps and deficiencies, for example the low-resolution data on which many of the national geological interpretations are based. This is being achieved through the development if an Index Map (see Figure 3) and a GIS layer showing confidence in the interpretations (based on the data sources used to make the geological maps). These types of information are essential to allow users (and in particular decision-makers) to understand the limitations of the maps.

\section{Integration with OneGeology-} Europe

As described above, one of the prime objectives of the EMODNET-Geology pro ject is to integrate marine geology data layers in the OneGeologyEurope (1G-E) portal to provide where possible

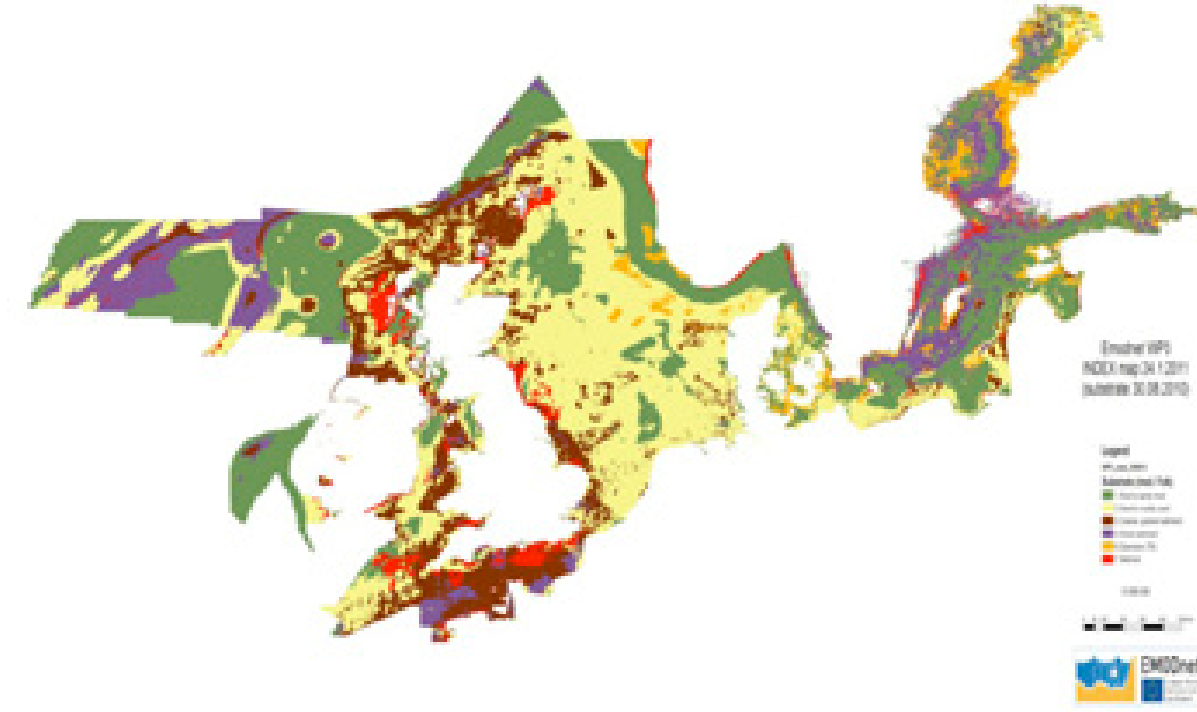

interoperable geological spatial datasets for both the onshore and offshore area of Europe.

2. Sea-bed substrate map of the EMODNETGeology Project study area.

The advantages of sharing the 1G-E portal is the provision @of 1) public access to all interoperable geological spatial datasets 2) scientific and

informatics specification for the harmonisation of geological data at 1:1 million resolution and

progress towards a harmonised onshore-offshore geological dataset for the European Community 3 multilingual discovery metadata 4) a robust data model, schema and mark-up language for the geosciences, which is OGC compliant and documented and deployed across the EU 5) a web portal providing easy access to marine geological data 6) guidance on re-use of geological data 7) exchange of science, technology, informatics and communications skills across the EU. These

deliverables will allow substantial progress towards 
INSPIRE goals - users will be able to discover, view and download geoscience data across the EU, which will also provide a template for other environmental data themes. The system will also provide a reference base on which other valuable data products and services can be built.

An example of an integrated onshore-offshore map in the $1 \mathrm{G}-\mathrm{E}$ portal is the stratigraphic map compiled under Work package 4 (Figure 3).

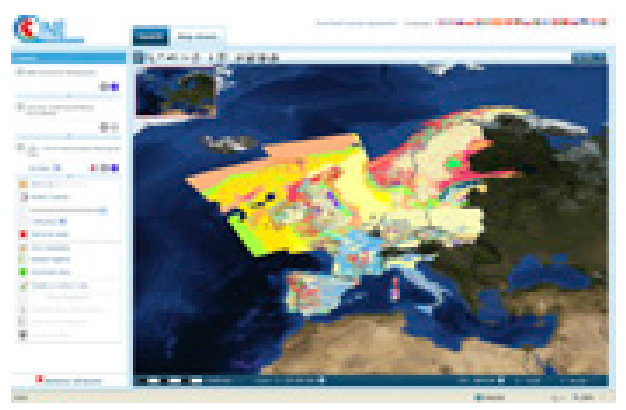

Fig 3. One-Geology Europe and EMODNET-Geology stratigraphy information.

The EMODNET-Geology project at international conferences

The EMODNET-Geology project was included in three separate presentations and a poster at the 'Geoscience 2010' meeting in Dublin, Ireland (November 3-4, 2010). The EMODNET-Geology project was mentioned in the opening remarks by Maria Damanaki, the Commissioner for Maritime Affairs and Fisheries, during the EurOcean 2010 Conference in Ostend, Belgium on October 122010
EMODNET-Geology was also included in a presentation at the GEO (Group on Earth Observations) Ministerial Summit in Beijing, China from 3-5 November. The project was part of the EuroGeosurveys contribution to an exhibit organised by the EC, which also included ESA and Eumetsat. A book entitled 'Crafting Geoinformation' included the OneGeology project and the offshore information being provided by EMODNET-Geology. The book can be downloaded at:

www.earthobservations.org/documents/geo_vii geo7 crafting geoinformation.pdf

The EMODNET-Geology project was presented at the Baltic Sea Geology Conference in St Petersbur by Anu Kaskela of the Finnish Geological Survey.

\section{C) NE}

\section{OneGeology-Europe}

\section{Introduction and Objectives}

Seeking answers to the challenges of natural and man-made disasters (landslides, earthquakes, flooding, pollution and erosion), securing natural resources (minerals, mining, energy and wate supply), and not least, adapting to climate change is driving the need to provide multidisciplinary knowledge for both the public and decision makers. Finding solutions to these challenges depends absolutely on spatial geological data, being easily accessible. Like most things environmental, few of these challenges respect national frontiers or boundaries and if we want to assess and address these environmental challenges at a European scale we need access to coherent European geological data too

Rich geological data does exist in each European national geological survey, but it was exceptionally difficult to discover, and it existed in different formats and was made available via different services, with different access conditions.

\section{Project outcomes}

The OneGeology-Europe project (1G-E) has made geological spatial data held by the Geological 
Surveys of Europe more easily discoverable, accessible and shareable. It has also ensured that geology plays a leading role in European spatia data development (ie INSPIRE) and that Europe plays a leading role in the global OneGeology initiative.

OneGeology-Europe has worked as a large multinational team and has delivered its contractual products and services but most importantly some key outcomes:

- An interoperable geology spatial dataset at in 1:1 million scale has been made available from distributed data from more than 20 European nations on a state-of-the-art web multilingual map portal.

- A major multinational deployment of geosciences specifications and OGC standards enabling the viewing and downloading of environment spatial data.

- OneGeology-Europe has addressed the legal aspects of data access and the outcome is a single harmonised licence agreed by all data providers allowing free access for all and a harmonised Code of Practice.

- A multilingual discovery metadata portal has been developed to facilitate access to the data in the portal and much more data residing in geological surveys.

- Europe is now leading the world in the development of a multinational geoscience spatial data infrastructure (SDI) and the project is making substantial contribution to the implementation of INSPIRE (metadata, data specifications, services, datasharing, monitoring).
- The project has accelerated the development and deployment of an international interchange standard for geology, GeoSciML.

- $1 \mathrm{G}-\mathrm{E}$ has progressed the harmonisation of geoscientific language in Europe and globally. These achievements are enabling the sharing of data both within and outside of the geological community, within Europe and globally.

\section{Project details}

OneGeology-Europe was supported by the European Commission's eContentplus programme for Best Practice Networks, operated by the Directorate General for the Information Society and Media.

OneGeology -Europe project has 28 partners in its consortium from 21 Member States. There are 20 geological surveys (data providers) and 6 representatives of the user community, an expert on legal aspects of spatial data access and a representative of the umbrella organisation for all geological surveys of Europe (EuroGeoSurveys). Six other geological survey organisations also kindly contributed to the work of the project.

OneGeology-Europe is making a pivotal contribution to the global project OneGeology, a partnership of 116 nations. Through its simple mission to make data more accessible and shareable, and to transfer expertise to do that OneGeology has made a significant impact in geoscience and spatial data and their application.
The OneGeology-Europe project began in September 2008 and was successfully concluded in October 2010

The total project budget was $€ 3.25$ million, with $€ 2.6$ million being provided by the eContentplus programme.

\section{Significant conferences attended}

- Paris, 22-23 February 2010: IUGS Executive Committee Meeting

- Brussels, 23 March 2010: Directors' Workshop:

The voice of European geosciences

- Athens, 29-30 April 2010: 4th GEO European

Projects Workshop

- Vienna, 3-7 May 2010: European Geosciences Union General Assembly / International Atomic Energy Agency / Geological Survey of Austria / International Year of Planet Earth National

Committees meeting

- Algiers, 10-12 May 2010: General Meeting of the Organisation of African Geological Surveys

- Rome, 25 May 2010: Launch of the Italian geoportal

- Krakow, 22-25 June 2010: INSPIRE Conference 2010

- Berlin, 24-25 June 2010: OneGeology and IUGS-CGI global meeting

- Calgary, 10-14 May 2010: GeoCanada 2010

- Copenhagen, 13-15 September 2010: European Environment Agency - EuroGeoSurveys joint workshop

- Beijing, 3-5 November 2010: VII GEO Plenary Session and Ministerial Summit 

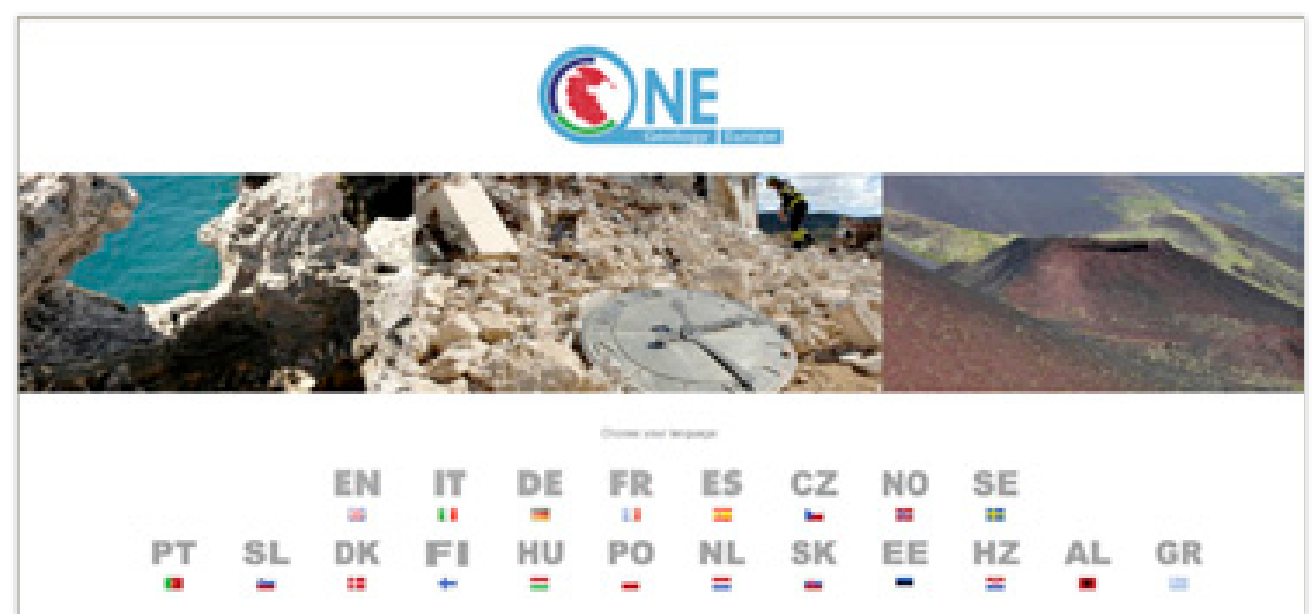

OneGeology-Europe website - multilingualism

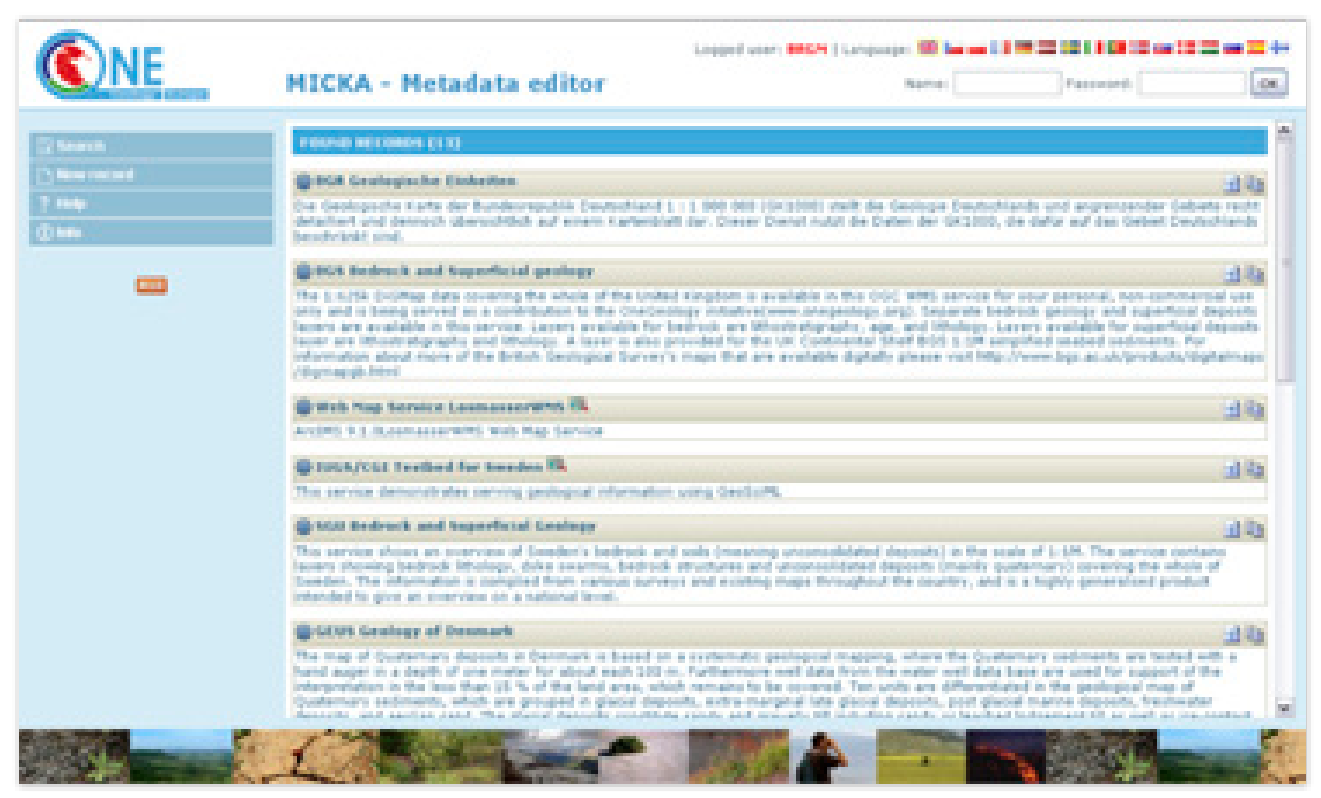

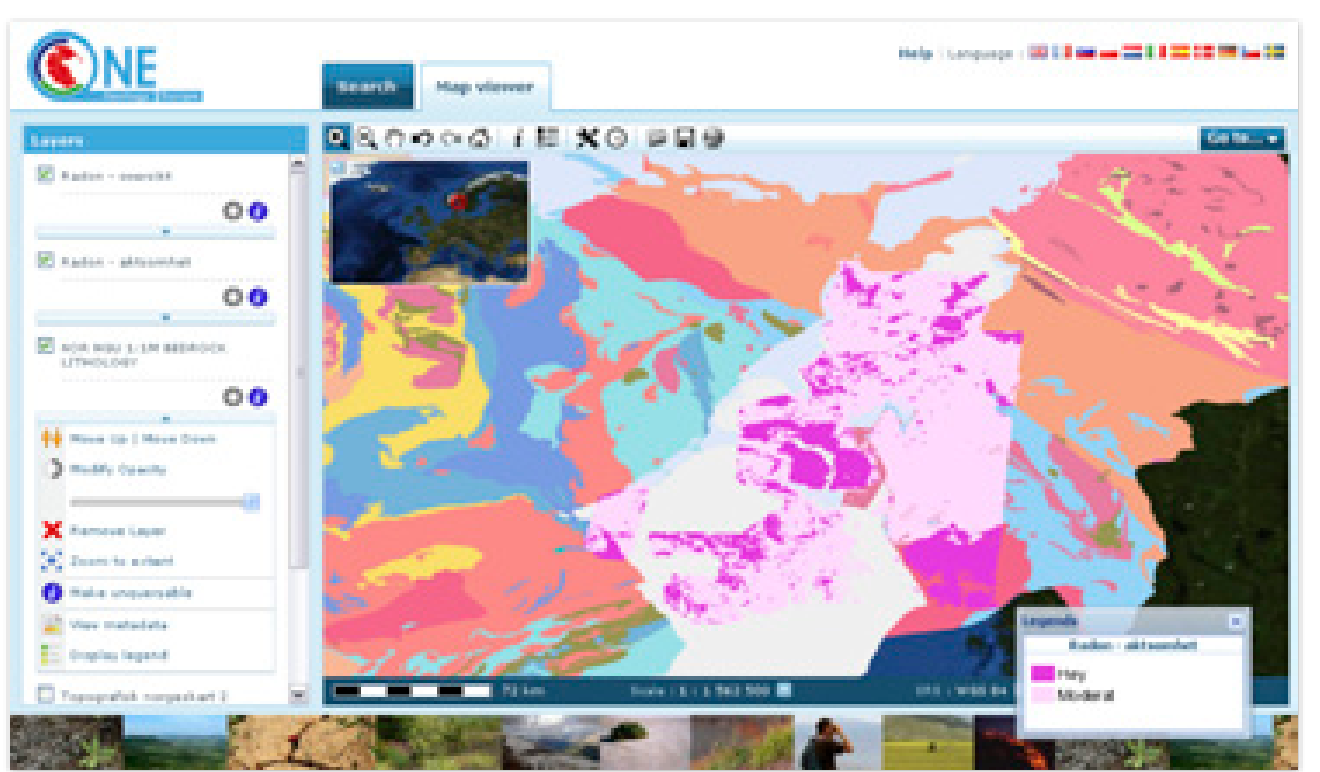

Portal: Applied geological dataset (Radon) shown over bedrock - Norway 


\section{Geo-Seas}

\section{Introduction}

Despite the fact that there is a large volume of geological and geophysical data available for the marine environment it is currently very difficult for users to locate and access these datasets or use them in an integrated way. This is due to the use of different nomenclatures, formats, scales and coordinate systems not only between individual countries but also within the same country between different organisations.

In an attempt to overcome some of these barriers the Geo-Seas project is developing an

e-infrastructure for the delivery and exchange of marine geological and geophysical data.

This infrastructure is made up of 26 data centre in 17 European coastal countries and includes research and academic institutes as well as a number of national geological surveys.

The Geo-Seas infrastructure allows a range of users including researchers, academics and policy makers to directly access harmonised marine geological and geophysical data sets via a single portal which is available on the project website www.geo-seas.eu. In addition a number of complex data products are being developed in consultation with end users.

The project is currently in the population and delivery phase with the data centres now engaged in delivering metadata for their datasets using common standards (based on the ISO19115 metadata standard) and making the associated datasets available in the agreed delivery formats. A number of datasets are now available via the portal and the volume of available data is continuing to increase as the component data centres come on-line.

\section{Objectives}

The main objective of the Geo-Seas project is to provide direct user access to harmonised marin geological and geophysical metadata and datasets which are ready for use through the development and use of common standards, vocabularies and methodologies. The project also aims to enhance interoperability with other data types and infrastructures such as those used in the wider earth science community. Geo-Seas is also underpinning key European directives such as INSPIRE which is developing standards and a structure for delivering integrated spatial information services, as well as international initiatives such as the Global Monitoring for Environment and Security (GMES) and the Global Earth Observation System of Systems (GEOSS), both of which are urging the provision and exchange of environmental data and information.

\section{Project details:}

Geo-Seas started in May 2009 and will continue for 42 months until October 2012. It is funded by the EU Framework Programme 7 (FP7)Research Infrastructures initiative and has a total budget of
$€ 6.7$ million of which $€ 4.9$ million is being contributed by the $\mathrm{EC}$ with the remaining budget contributed by the project partners

The Geo-Seas project is building upon the work of the SeaDataNet project which has created an e-infrastructure for the delivery of oceanographic data throughout Europe. Geo-Seas is adopting and adapting the architecture, methodologies and technologies developed by the SeaDataNet for use with geological and geophysical data.

This has resulted in the development of a joint e-infrastructure covering both oceanographic and marine geological and geophysical data which in turn has facilitated the development of multidisciplinary science through the creation of interoperable data sets (for use in both ocean science and the wider user communities: Geo-Seas has also built upon the work done by a number of earlier EU funded projects including EUSeaSed and SEISCAN, both of which created extensive marine geoscience metadatabases. These metadata catalogues have been used as the basis for the development of the Geo-Seas metadata standards and have also been upgraded for incorporation into the Geo-Seas metadatabase.

The Geo-Seas project is made up of 11 work packages, each of which has a number of tasks and associated key deliverables which will ultimately contribute to the implementation of the Geo-Seas e-infrastructure. These work packages are broken down into three categories: 
Networking activities:

- project management

- infrastructure management and monitoring,

- training in the use of the Geo-Seas software tools

- development of standards for metadata and data

exchange/delivery,

- population of metadatabases and associated

vocabularies and directories

- communication

- dissemination

Service activities:

- access to the metadata, data and products

Joint research activities:

- development of software tools and services,

- installation and testing of these tools at each of

the data centres,

- user consultation

- development of the more complex data products

\section{Project outcomes}

The Geo-Seas project is creating a pan-European e-infrastructure which is improving the discovery, accessing and delivery of harmonised geological and geophysical data and data products to a diverse community of end users across a wide range of disciplines.

The Geo-Seas portal (Figure 1) allows users to search through the metadata catalogue, find the data they need (Figures $2 \& 3$ ), assess its suitability for their particular purpose and then either download the data directly or place an order for the data according to the access and use restrictions which have been put in place by the data supplier. The mode of delivery of the data will also depend on the volume of data requested.

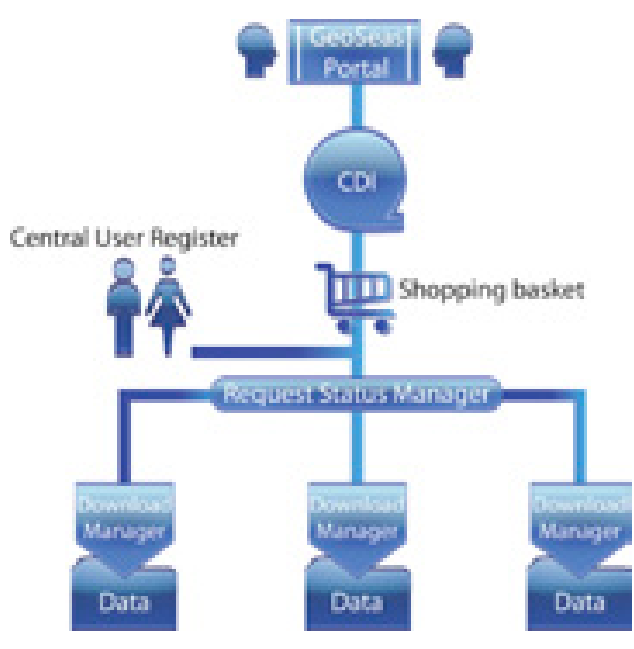

Figure 1: Geo-Seas portal data request mechanism

Geo-Seas is contributing to e-infrastructure development in a number of key areas which include scientific data (coherent management and access to data) and standards (data management, metadata, delivery and formats); and is currently seeking to encourage other organisations to adopt these common standards and methodologies. This will lead to an increased interoperability with other disciplines, organisations and between countries in Europe and beyond. As a first step towards this, Geo-Seas is currently developing collaborative links with other European initiatives such as EMODNET and One Geology as well as with key organisations involved with marine data management in

Australia and the USA

\section{Significant conferences attended}

During 2010 the Geo-Seas project has been presented at:

- 29 - 31 March 2010: Paris, France: International Conference on Marine Data and Information Systems (IMDIS)

- 3 - 10 May 2010, Vienna, Austria: European Geological Union Congress

- 12 - 13 October 2010: Ostend, Belgium:

EUrOCEAN 2010 Conference

- 22 - 25 June 2010: Cracow, Poland: INSPIRE 2010 Conference

- 13 - 17 December 2010, San Francisco, USA: American Geophysical Union Fall meeting

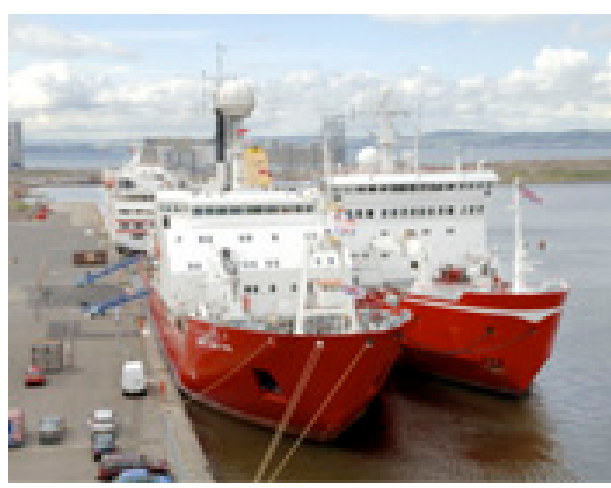

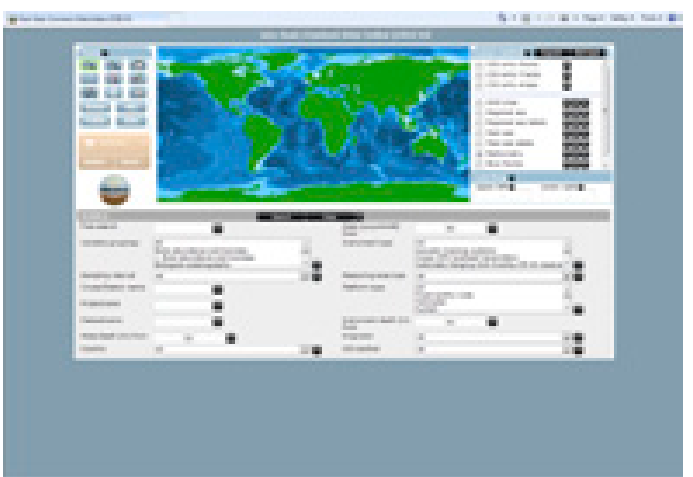

Figure 2: Geo-Seas portal metadata search
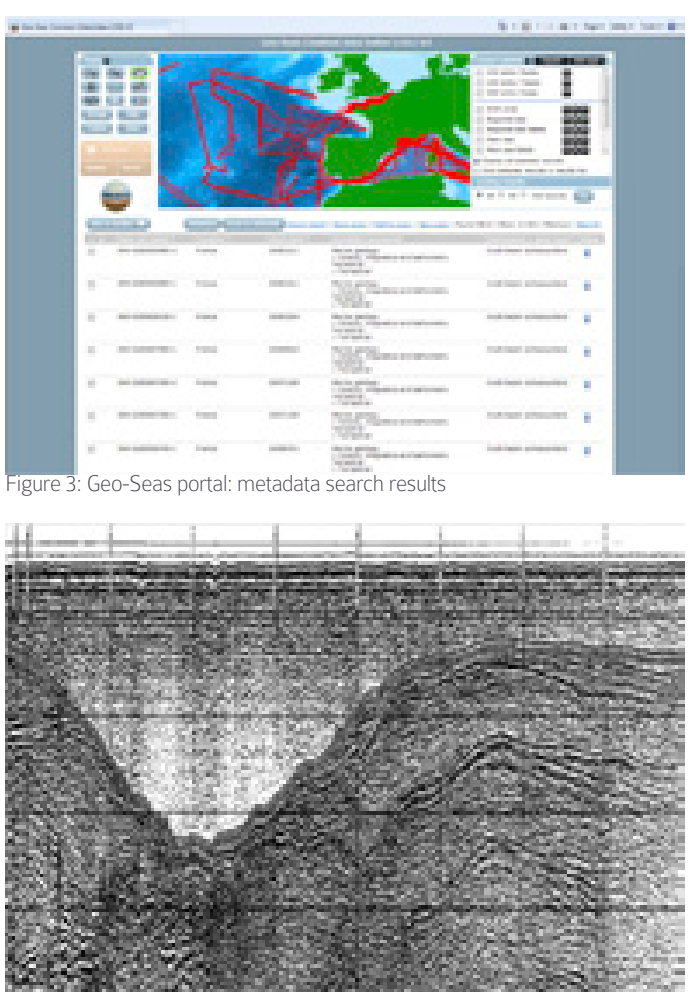


\section{¿SARMa}

\section{SARMa}

\section{Sustainable Aggregates Resource \\ Management: description of the} South East Europe project SARMa

Slavko V. Šolar, Geological Survey of Slovenia Deborah J. Shields, Colorado State University and Politecnico di Torino

\section{Introduction}

Earth scientists, particularly geologists, are involved not only in fundamental research projects, but also in applied science projects. Most applied projects are multidisciplinary and have as their goal the solution of different open and ongoing challenges that society faces. An important set of these projects deals with the provision of an adequate and secure supply of raw materials. Within such projects many questions are addressed by geologists, who are able to utilize their technical knowledge to collect relevant data, analyze those data and to compile it into comprehensive information that provides a solid base for sound decision making. Geologists can best perform these tasks when they are aware of the need for information, the potential contribution of geology and other disciplines, and prevailing societal paradigm of sustainable development. Consider, for example, the case of aggregates (crushed stone, sand and gravel), which are crucial for infrastructure and construction. Many countries are rich in aggregates, but supply is not coordinated, which is the case within South East
Europe. Among many challenges are illegal and damaging quarries, unreclaimed sites, limited recycling, and community opposition. Primary aggregates can only be extracted where they occur, but quarrying has had environmental and social impacts, including inefficient usage of water and energy, air pollution, and community disruption. These have given the industry a negative image, intensified by illegal quarrying, limited recycling of construction and demolition (C\&D) wastes, and minimal use of quarry and industrial by-products.

Project's objectives and structure

To meet the aforementioned challenges the project entitled "Sustainable Aggregates Resource Management" (SEE/A/151/2.4/X - SARMa) was approved by the EU Commission and co-funded by ERDF funds in 2009. Main objectives of the project are to develop a common approach to sustainable aggregate resource management (SARM) and sustainable supply mix (SSM) planning, at three scales, to ensure efficient and secure supply in

South East Europe. Efficient, low socioenvironmental impact, quarrying and waste management is SARM. SSM promotes the use of multiple sources of aggregates, including recycled wastes and industrial by-products (slag) that together maximize net benefits of aggregate supply across generations

The SARMa project will have duration of two and half years (2009-2011) and is designed as a series of interlinked activities structured in 5 Work
Packages (WPs). Two are general: WP1 Transnational project management and coordination, and WP2 Communication and dissemination. Because SARMa is developing solutions to problems at multiple spatial scales, the remaining WPs are thematic and scale-based, WP3 (local scale) started first, followed in month 5 by WP4 (regional/national), which is building on preceding outputs and results. WP5 (transnational scale) began in second part of the project, and builds on WP3 and in particular WP4. Each thematic WP comprises a set of activities that are conducted sequentially or in combination when there is a common purpose or location.

WP3 activities are:

- 3.1 Environmentally friendly extraction practices

- 3.2 Illegal quarrying

-3.3 Recycling

- 3.4 Manual for the site level.

WP4 activities are:

- 4.1 Sustainable aggregate resource management - 4.2 Planning for sustainable supply mix.

WP5 activities are:

- 5.1 Harmonization of legislation and policies

- 5.2 Sustainable supply across SEE and

Aggregates Intelligence System

- 5.3 Manual for the national and transnational level.

Project partners have collected data, completed case studies, filled out questionnaires, solicited input from public authorities, met with

\section{SOUTH EAST} EUROPE

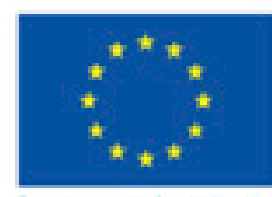

EUROPEAN UNION 
stakeholders, and reviewed relevant literature. The results of these efforts will be reported in Manuals that synthesize the collected information, report conclusions and make recommendations for actions that will improve the aggregate management and supply situation in SEE. The audience for the WP 3 Manual is local, i.e. quarry operators (industry) as well as the local community, which is usually represented by local authorities, but can also include other stakeholders. This is an important consideration since the focus would be different if it was compiled for the public authority or for any other individual stakeholder group. WP's 4 and 5 results and recommendations will be reported in a Manual aimed primarily at regional and national public authorities, but again made available to any interested party. In addition, a Manual on Life Cycle Assessment for recycling and a report on the Aggregates Intelligence (decision support) System will be distributed.

\section{Partnership and outputs}

The project partnership has the requisite expertise for implementing the project, achieving the objectives and producing the planned outputs. These include. the aforementioned manuals on SARM and SSM at the regional, national and transnational spatial scales, and methodology of life cycle assessments in the primary and secondary aggregates sectors, plus recommendations to industry and public authorities on environmentally and socially acceptable quarrying, prevention of illegal quarrying, quarry waste management and opportunities for increasing the rate of recycling of quarry waste and construction and demolition waste, implementation of relevant EU legislation, and aggregates policy and management.

Geologists form a major part of the project partnership. They are part of most partners' teams, especially within Geological surveys that are involved as partners or subcontractors (Geological Survey of Slovenia, Slovenia; Institute of Geology and Mineral Exploration, Greece; National Institute or Research-Development in domain of Geology, Geophysics, Geochemistry and Remote Sensing; Romania, Geological Survey of Albania; and Geological Survey of Croatia)

\section{Implications}

The SARMa Project has implications for raw materials supply within SEE and beyond. The EU realizes the importance of sustainable supply of raw materials and has launched several Communications (last February 2011) under the Raw Materials Initiative (RMI). SARMa directly adds to the second pillar of RMI (supply from EU sources - national minerals policies, minerals planning policies, knowledge base). SARMa also will facilitate the achievement of the Waste Directive recycling goal for Construction and Demolition Wastes. The project is also important because there is an increasing need to discuss and implement sustainable policies for both the management and extraction of

aggregates and other mineral resources, as well as the regulatory framework guiding the exploitation of mineral wealth.
SARMa is already having an impact in every Partner country. Through personal meetings with Partners, as well as public meetings, industry public authorities, and community members are becoming more aware of the challenges associated with managing aggregate resources and ensuring that a secure, sustainable supply will be available for their communities, countries and economies. Their engagement in SARMa is leading to results and recommendations that will be widely applicable in SEE and beyond the region as well.

More information: www.sarmaproject.eu
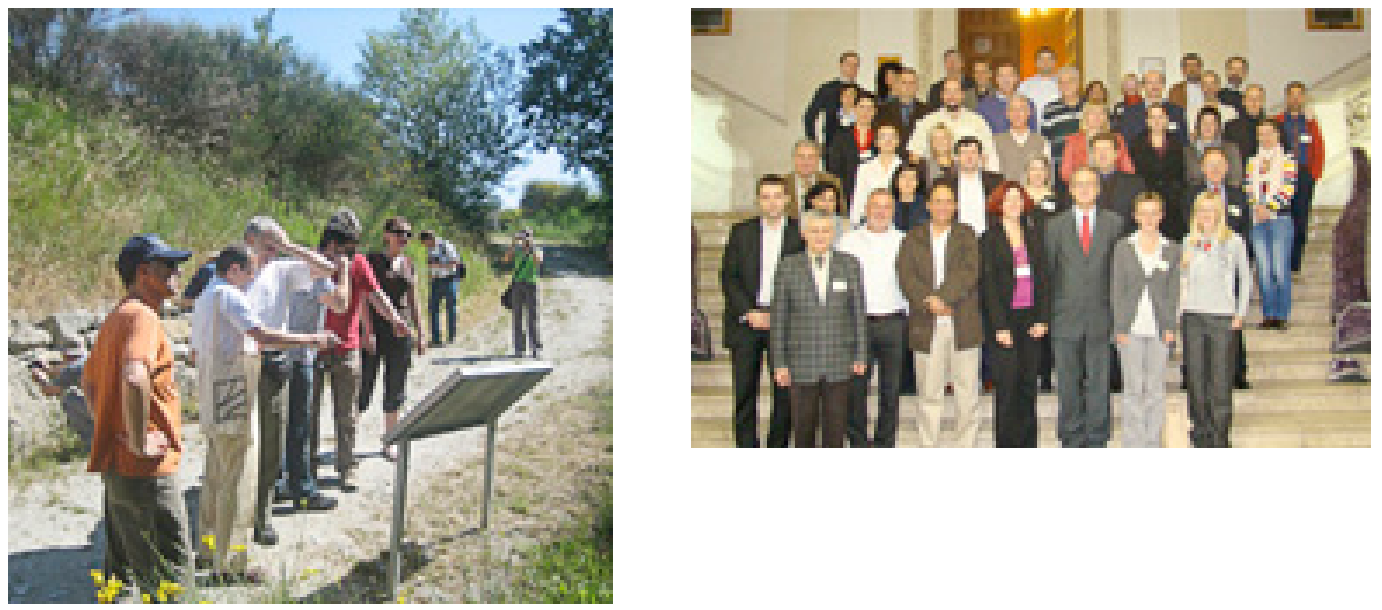

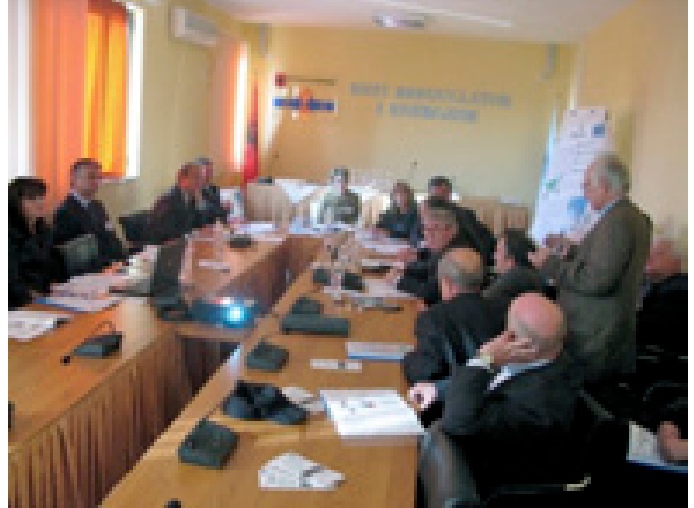




\section{Therm(Map}

\section{Project ID card}

- Funded under: The Information and

Communication Technologies Policy Support Programme (CIP-ICT-PSP)

- Area: Theme 6 - Public Sector information

- Total cost: €3.87m

- EU contribution: $€ 1.93 \mathrm{~m}$

- Project reference: 250446

- Execution: From 01/09/2010 to 31/08/2013

- Project status: Running

- Contract type: The Information and

Communication Technologies Policy Support

Programme PB Pilot Type B

\section{Description of the project objectives}

The objective of the ThermoMap project is to provide an efficient and effective estimation of the shallow geothermal potential on a large to medium scale for all nine countries which are involved in this project (Austria, Belgium, France, Germany, Greece, Hungary, Iceland, Romania and United Kingdom).

To achieve this objective ThermoMap will develop a solution to combine already existing datasets in the partner countries for an area visualisation of shallow geothermic resources by soil-.

climatological-, topographical-, geological-, administrative- and groundwater data.
In principle many research \& development activities in the field of geothermal energy have been planned resp. have been implemented on a national or international level.

Especially with regard to the actual discussions about renewable energies and the protection of resources those activities will be enhanced and the general acceptance of shallow geothermal energy will be increased in the next few years. Currently the geothermal investigations focus on the vertical systems and drilling techniques. However, regarding horizontal systems and technologies applicable for the upper $10 \mathrm{~m}$ below surface only very rare information are available within the shallow geothermal energy.

Thermomap is in a position to contribute information for this specific field of shallow geothermal energy.

The research into the shallow geothermal potentia for this project is divided into two parts:

- The first part is the appraisal within test areas in the different partner countries for the estimation on a large scale level divided in three depth ranges up to 10 meters.

- The second part is the estimation of the shallow geothermal potential for the whole partner country expressed by an outline map on a medium scale level.

Generally the project is divided into three phases: Firstly the data collection and data harmonisation, secondly the set up of the model including processing, analysis and visualisation, and finally the test of the results.

\section{Workflow since project start}

As already mentioned the project consists of three phases. Currently we are in the first project phase named data collection

In order to filter adequate data and to harmonise them on a common basis two working groups have been set up. On the one hand the parameter definition group which takes care about the data filtering, on the other hand the standardisation group which should specify the standard for the data harmonisation.

During a comprehensive clarification meeting of both working groups the frame conditions for the set up of the catalogue ("catalogue for data requirements, arithmetic instructions and derivation rules", D3.1.) and the required data thereof have been agreed upon.

Subsequently the catalogue has been developed. This catalogue highlights datasets required for the calculation of the shallow geothermal potential expressed by the heat conductivity and the heat capacity for the test areas as well as an estimation for the outline map.

The catalogue has been developed in order to inform the partners about the data, the quality requirements and to support them in the collection of these datasets.
SOUTH EAST EUROPE

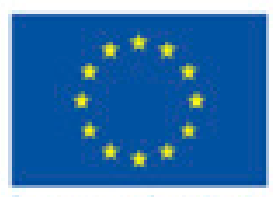
EUROPEAN UNION 


\section{Results}

During the set up of the catalogue for the test areas several parameters have been proven themselves to be essential for the calculation of the heat conductivity and the heat capacity.

Those parameters are the grain size (texture class), the bulk density and the temperature (air resp. soil temperature). For example many other important system parameters can be derived from the grain size. In this context the pore size distribution should be highlighted which delivers on the other hand percentage values of the porosities in the field capacity, the dead water content and the air capacity.

Subsequently those percentage values can be assigned to the individual bulk density classes

(low, mean, high) which are according to the three depth classes as there are shallow class 10 to $3 \mathrm{~m}$ intermediate class (3 to $6 \mathrm{~m}$ ) and deep class (6 to $10 \mathrm{~m}$ ). With regard to the use of the outline map it is targeted to establish a process of elimination which areas are suitable for shallow geothermal technologies and which are not.

The analysis of the geodata will be performed in a GIS environment (second phase of the project visualization) and is facilitated by standardized methods. The resulting geothermal potential will be mapped on a local scale in test sites (third phase of the project - testing) and on a medium scale for all partner countries and it will be integrated in

a Web Service. With special regard to the general discussion about the provision of renewable and sustainable energies and the moving away from conventional energy resources, the ThermoMap project can deliver new pulses for a decentralized, sustainable and low environmental impacting energy supply of the future.

At the end ThermoMap will provide different user-groups with an interactive information tool running in a web browser. Private users may check the potential of their local environment, community planning and administration authorities may test the geothermal potential of their entire administrative unit. Researchers participating in ThermoMap will have access to the entire geodata pool, which will be set up in Web Map Service (WMS), Web Coverage Service (WCS) and Web Feature Service (WFS).

The ThermoMap project addresses private users who for example want to build or renovate a house; it addresses community planning and administration authorities, who want to display new housing areas and want to inform about the geothermal potential at the same time.

\section{Participants}

Coordinator: FRIEDRICH-ALEXANDER-

UNIVERSITAET ERLANGEN NURNBERG,

GERMANY

\begin{tabular}{|lll|}
\hline Organisation & & Country \\
\hline FRIEDRICH-ALEXANDER-UNIVERSITAET ERLANGEN NURNBERG & FAU & GERMANY \\
\hline PARIS-LODRON-UNIVERSITAET SALZBURG & PLUS & AUSTRIA \\
\hline INSTITUT ROYAL DES SCIENCES NATURELLES DE BELGIQUE & RBINS-GSB & BELGIUM \\
\hline EUROPEAN GEOTHERMAL ENERGY COUNCIL & EGEC & BELGIUM \\
\hline BUREAU DE RECHERCHES GEOLOGIQUES ET MINIERES & BRGM & FRANCE \\
\hline REHAU AG+CO & REHAU & GERMANY \\
\hline GeSellIschaft beratender Ingenieure für BaU Und EDV mbH \& CO.KG & GBI & GERMANY \\
INSTITUTO GEOLOGIKON KAI METALLEYTIKON EREYNON & IGME & GREECE \\
MAGYAR ALLAMI FOLDTANI INTEZET & MAFI & HUNGARY \\
ISLENSKAR ORKURANNSOKNIR & ISOR & ICELAND \\
\hline INSTITUTUL GEOLOGIC AL ROMANIEI & IGR & ROMANIA \\
BRITISH GEOLOGICAL SURVEY (NATURAL ENVIRONMENT RESEARCH COUNCIL) & BGS (NERC) & UNITED KINGDOM \\
\hline
\end{tabular}

List of presentations

(duration 01/09/00 till 31/12/00)

\begin{tabular}{|llllll|}
\hline Name of the conference & $\begin{array}{l}\text { Number of } \\
\text { participant }\end{array}$ & Place & Presenter & $\begin{array}{l}\text { Kind/Title of } \\
\text { presentation }\end{array}$ & Date \\
\hline $\begin{array}{l}\text { Marktredwitzer } \\
\text { Bodenschutztage }\end{array}$ & 110 & $\begin{array}{l}\text { Marktredwitz/ } \\
\text { Germany }\end{array}$ & $\begin{array}{l}\text { David Bertermann } \\
\text { (FAU) }\end{array}$ & ThermoMap & 06/10/2010 \\
$\begin{array}{l}\text { LISA 2010 } \\
\text { Kopavogur/ }\end{array}$ & $\begin{array}{l}\text { Gunnlaugur M. } \\
\text { Einarsson (ISOR) }\end{array}$ & ThermoMap & $21 / 10 / 2010$ \\
\hline
\end{tabular}




\section{GSSoil}

\section{GS Soil}

\section{Assessment and strategic development of INSPIRE compliant Geodata-Services for European Soil Data}

- EU-Programme: eContentplus*

- Funding: 4,1 Mio $€$ (overall budget $5.1 \mathrm{Mio} €$ )

- Duration: 06/2009 - 05/2012 (3 years)

- Coordinator: Coordination Center PortalU

(German Environmental Portal)

- Consortium: 34 Partner, 18 EU member states,

24 soil data providers

\section{Introduction}

Within the European Member States comprehensive soil data assets exist. Although notable amounts of soil data have already been prepared digitally, data accessibility is still extremely limited. The inter-organizational and cross-border distribution of soil data is tremendously difficult and in many cases datasets are not interoperable, neither on a technical nor on a semantic level. For the huge community of experts and citizens within the European Union soil data therefore are difficult to obtain, to understand and to use. Soil information is essential in particular for land use planning, environmental protection and impact analysis as well as for risk analysis. Within the INSPIRE directive the theme soil is explicitly addressed as an individual theme (Annex III) and besides that soil related environmental, agricultural and forestry aspects are also addressed in Annex II and III.
According to this, the thematic focus of GS Soil is set on soil as an important parameter according to climate, land use, geology and geomorphology. At the same time soils are the basis for food production and consumer health, for the ecological and economical balance and for many other important bases of life. The outstanding meaning of the topic has recently been underlined by the EU efforts to establish a common soil directive.

\section{Project objectives}

The project GS Soil aims at establishing a European network to improve the access to spatial soil data for public sector bodies, private companies and citizens. The project will consider aspects of data organization, data harmonization as well as semantic and technical interoperability in order to produce seamless geospatial information and to improve the data access for a wide community of different user groups. The structural specification for the description and harmonization of spatial soil data within Europe as well as the operation of a corresponding spatial infrastructure are main objectives of GS Soil. The Member States, of which a majority is represented in the GS Soil consortium, will establish and operate a network of services for spatial datasets and metadata.

This network includes distributed services for data transformation, discovery, view and download. The final result of the project will be a central Soil Portal, where European soil data from heterogeneous sources will be bundled. In order to ensure cross-border usability of the portal and related services, aspects of multilingualism and data interpretation will be considered thoroughly. In this respect the harmonization of metadata will also be a key topic within the project work.

The inclusion of European stakeholders as e.g. the JRC (European Soil Centre) ensures the cooperative development of the GS Soil Portal within the existing thematic and structural

framework. Besides the establishment of the Soil Portal all strategic project results will be

documented and disseminated in order to support the future implementation of further INSPIRE themes in all 27 European Member States.

BGR and IGME-GR, the two Geological Surveys involved in the project, act as experienced users but will even provide national soil geochemical datasets and maps, also with respect to the EGS Geochemical Atlas of Europe, and to select target user specific testing scenarios. Within INSPIRE, BGR participates as Legally Mandated Organization (LMO), but also as Spatial Data Interest Community (SDIC) through EGS and the German National Data Infrastructure (GDI-DE). It is member of the drafting team "Data Specifications". IGME has a prominent role in the EGS Geochemistry Expert Group and has a good control of the European geochemical data available.

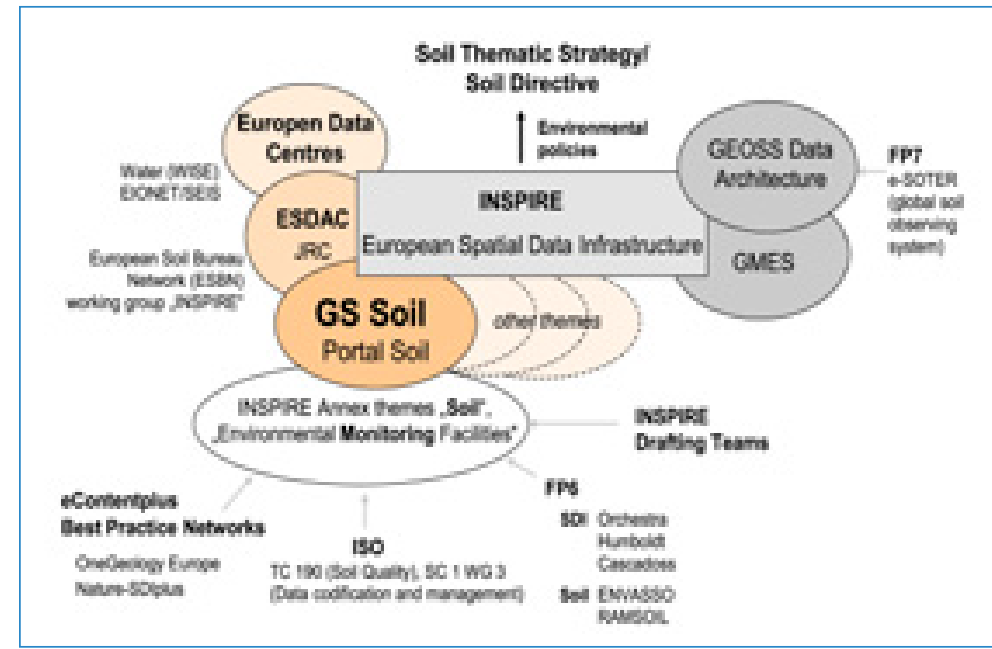




\section{Project structure}

GS Soil is a huge and ambitious project with international applicable goals. The strong and sustainable network of technical, soil and environmental experts will ensure the success of the project. GS Soil is divided into 7 work packages to achieve the objectives of the proposed project:

-WP1: Project Coordination and Networking

-WP2: Content Provision Framework

-WP3: Data Management \& Metadata

-WP4: Harmonisation \& Semantic Interoperability

-WP5: Establishment of an integrated Network \&

Soil Portal

-WP6: Evaluation \& Sustainability

-WP7: Dissemination, Awareness \& Clustering

In WP1 an effective cooperation of and

communication between the project partners will take centre stage. WP1 forms the framework for the whole project. In these WP all project information including milestones and deliverables and financial issues are bundled and communicated to the European Commission. The main part of WP1 will thereby achieved by the GS Soil

Coordinator (KST PortalU). Smaller parts of WP1 will be achieved by the quality manager and the work package leader. WP2, WP3 and WP4 will set up on each other. The soil and soil related data will be analysed, necessary metadata will be identified and provided and specific datasets will be

systematically harmonised. The improved access to the data via the GS Soil Portal is the main objective of WP5, while WP6 focuses on user

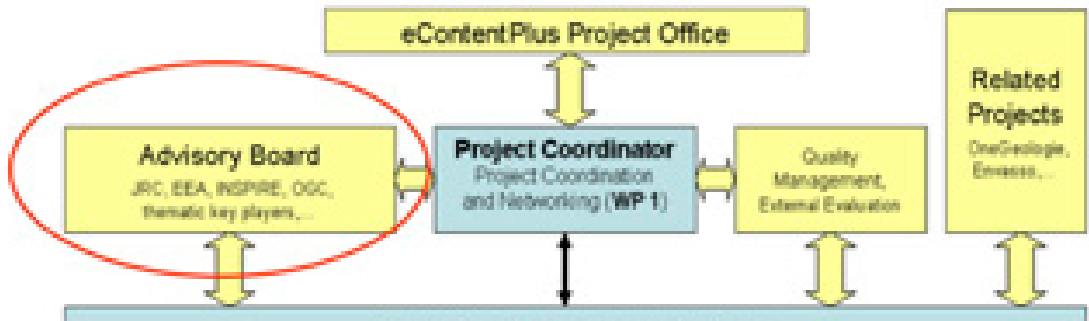

Operational Management Group

\begin{tabular}{|l|l|l|l|} 
WP 2 \\
WP 3
\end{tabular}

17

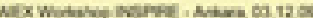

needs and long-term perspectives of the GS Soi Portal. With the dissemination of GS Soil results including best practice guidelines and technical tools in WP7 the project will be rounded off.

\section{Project outcomes}

- One-Stop-Portal-bundling of soil data \& metadata in central Soil Information Portal

$/ /$ for soil and soil related information

// for any kind of users (experts, other interested persons)

- All kinds of textual documents

- Geospatial Metadata

- Maps

- Other Data (e.g. observation data).

/ for information of different administration levels (European, national, regional)

// for different kind of information

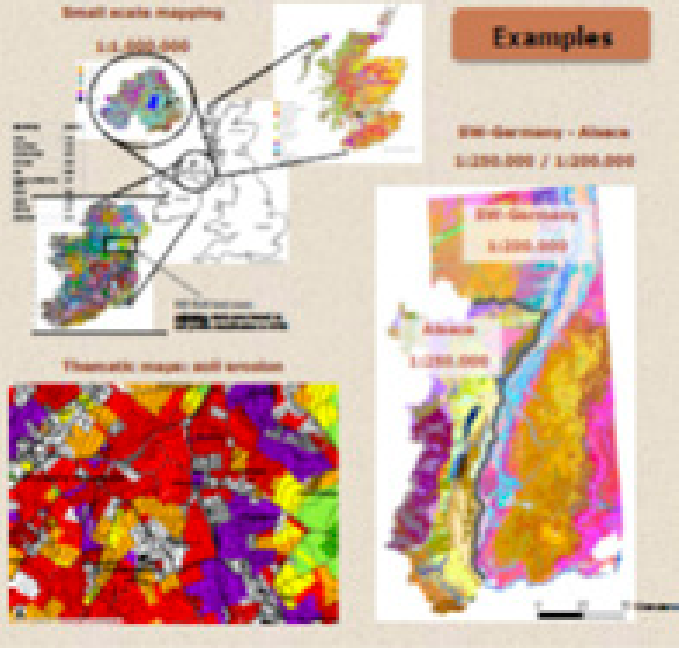




\section{The GS Soil project at international conferences}

1. K. Feiden et. al. (2010): Lessons learned (so far) and best practice from the eContentplus-project GS SOIL. INSPIRE conference 2010 (Workshop)

2. K. Feiden, F. Kruse, B. Houskova, T. Reznik,

E. Eberhardt, R. Baritz, C. Figueiredo (2010):

Progress of the transnational cooperation in

building up a SDI for European soil data

(eContentplus-project GS SOIL) INSPIRE

conference 2010

3. FEIDEN, K. (2009): Building up an INSPIRE

compliant spatial data infrastructure for

European Soil data - Introduction to the

eContentplus project GS SOIL "Assessment and

strategic development of INSPIRE compliant

Geodata-Services for European Soil Data".

Technical Assistance and Information Exchange instrument (TAIEX) of the Directorate-General Enlargement of the European Commission

INSPIRE Workshop, 2.-4. December 2009, Ankara

4. WALTNER, I., LÁNG, V., FUCHS, M., MICHÉLI, E. (2010): Application of a centroid based concept for the correlation of national soil classification with the WRB. 4th Global Workshop on Digital Soil Mapping, Rome, 24.-26.05.2010

5. VANDEKERCKHOVE, L., VANTHOURNOUT, L., VAN DEN EECKHAUT, M., POESEN, J.,

VANWESENBEECK, $\vee$., VAN DAMME, M BOEL, K., DE NIL, K., DE ROUCK, T.,

VERGAUWEN, I. (2009): Integrating landslide

information in the Flemish Subsoil Database (DOV). $6^{\text {th }}$ European Congress on Regional Geoscientific Cartography and Information Systems, Munich, 10.-12.06.2009

6. SIMOTA, C., AND M. DUMITRU. (2010): Biophysical Criteria Designating Agriculture Drought Affected Areas in the Context of

Climate Changes. Balkan Water and Observation Systems (BALWOIS), 24-29 May 2010, Ohrid FYROM

7. K. Feiden et. al. (2010): Progress of the transnational cooperation in building up a SDI for European soil data (eContentplus-project GS SOIL). INSPIRE conference 2010

8. FEIDEN, K. (2009): The eContentplus-PROJECT "GS SOIL": Assessment and strategic development of INSPIRE compliant GeodataServices for European Soil Data. Hungarian Journal of Landscape Ecology, Tájökológiai Lapok 7 (2): 485-487 (2009).

9. FIGUEIREDO, CARLOS, GONÇALVES, MARIA DE CONCEIÇÃO, REVEZ, GONÇALO; MARTINS, RUI, TILSNER, DIRK (2010):

GS SOIL: Assessment and strategic development of INSPIRE compliant GeodataServices for European Soil Data. ESIG 2010 OEIRAS (PORTUGAL), FEBRUARY 2010 4/4

10. FEIDEN K., KRUSE F., EPITROPOU V. AND KARATZAS K. (2010): The GS SOIL portal prototype and its integrated network.

Proceedings of the 24th International

Conference on Informatics for Environmental Protection (Envirolnfo2010) in press.
11. EPITROPOU V., KARATZAS K. AND BASSOUKOS A. (2010): Open tools and services for INSPIRE related environmental data and metadata: reporting on experiences gained in GS SOIL. Proceedings of the $24^{\text {th }}$ International Conference on Informatics for Environmental Protection (Envirolnfo2010) in press.

12. $19^{\text {th }}$ PanHellenic Meeting of GIS -ESRl: ArcGIS (Arc View-Arclnfo-ArcGIS Server) users. Athens, Greece, 18-20 November 2009 (NAGREF)

13. Thematic Day Technosols, the man-made soils, a challenge for urbanized societies,

02.12.2009. Soil Science Society of Belgium - National Committee for Soil Science, Brussels, Belgium (LNE)

14. Novel Methods 2010. Venue: Novel Methods for reducing agricultural nutrient loading and eutrophication, Meeting of COST 869 Working Group 2 and 3, MTT Agrifood Research Finland, 13. -16.06.2010 


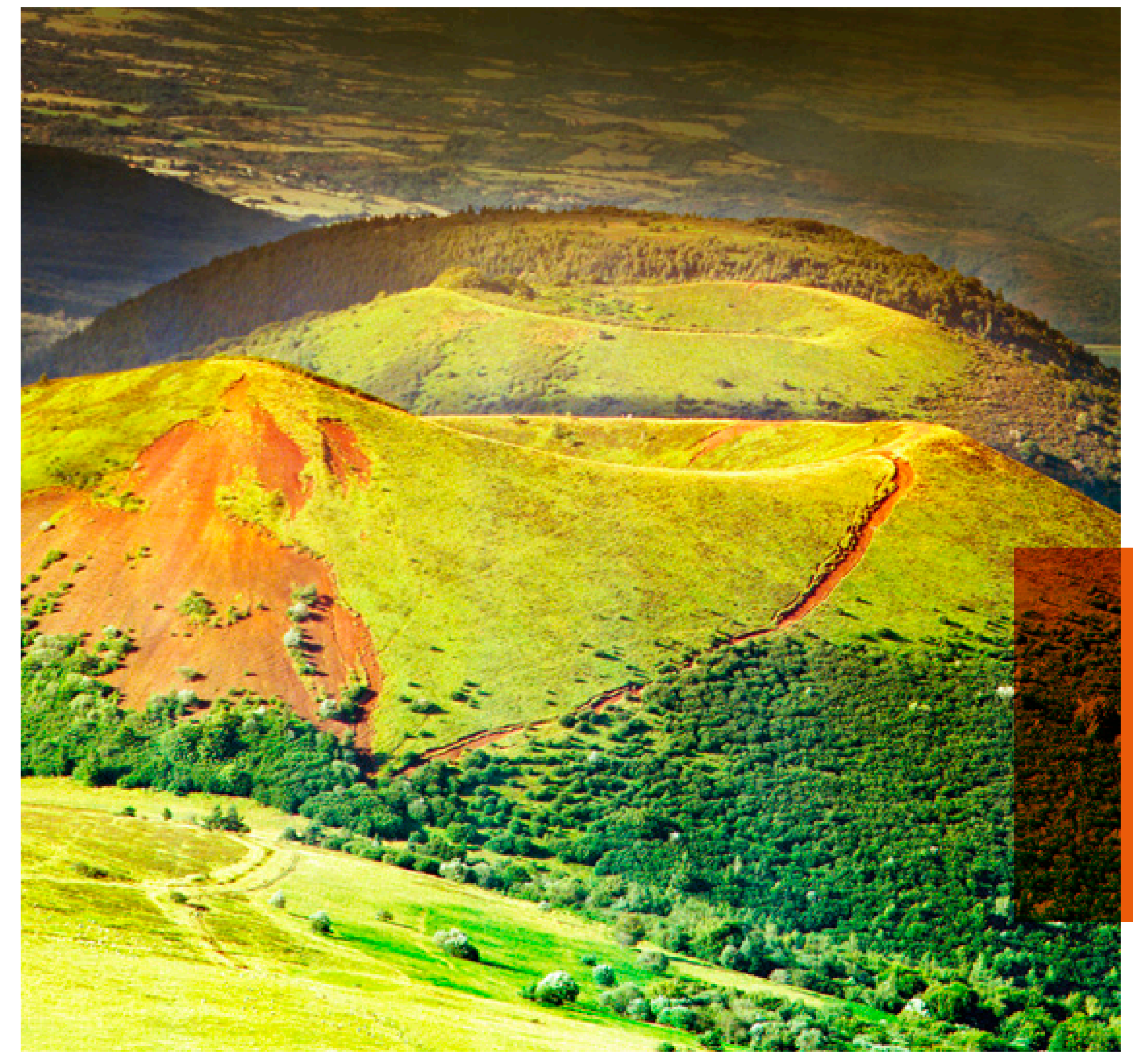




\section{オ EGS \& Media}

TALKING ABOUT US

\begin{tabular}{|c|c|c|c|c|}
\hline Titolo Articolo & Testata & Tipologia & Data & Link \\
\hline $\begin{array}{l}\text { *Libri / EuroGeoSurveys pubblica Atlante europeo } \\
\text { delle acque minerali }\end{array}$ & ॥ Velino & Press Agency & $11 / 09 / 2010$ & www.ilvelino.it/articolo.php?ld=1196132 \\
\hline $\begin{array}{l}\text { NASCE L'ATLANTE EUROPEO DELLE ACQUE } \\
\text { MINERALI }\end{array}$ & ANSA & Press Agency & 10/09/2010 & www.ansa.it/ambiente/notizie/notiziari/acqua/20100910170335141342.html \\
\hline $\begin{array}{l}\text { EuroGeoSurveys ha analizzato le acque minerali } \\
\text { europee: risultati incoraggianti }\end{array}$ & Greenreport & Website & 10/09/2010 & $\begin{array}{l}\text { www.greenreport.it__new/index.php?page=default? } \\
\text { id=\%206618 }\end{array}$ \\
\hline \multirow[t]{2}{*}{ Acque minerali e veleni } & Terra & newspaper & 15/09/2010 & www.terranews.it/news/2010/09/acque-minerali-e-veleni \\
\hline & Terra & newspaper & 15/09/2010 & www.terranews.it/news/2010/09/\%C2\%ABservono-piu-controlli\%C2\%BB \\
\hline $\begin{array}{l}\text { "Servono più controlli" - Intervista al tossicologo } \\
\text { Antonio Marfella }\end{array}$ & Terra & newspaper & 15/09/2010 & www.terranews.it/opinioni/2010/09/acque-minerali-facciamo-chiarezza-di-ettore-fortuna-presidente-di-mineracqua \\
\hline $\begin{array}{l}\text { SALUTE PUBBLICA, RISPONDE IL TOSSICOLOGO } \\
\text { di Antonio Marfella (tossicologo, oncologo, Isde } \\
\text { Campania) }\end{array}$ & Terra & newspaper & 21/09/2010 & $\begin{array}{l}\text { www.terranews.it/opinioni/2010/09/salute-pubblica-risponde-il-tossicologo-di-antonio-marfella-tossicologo-oncologo- } \\
\text { isde-campani }\end{array}$ \\
\hline Le acque minerali? buone ma non troppo & Jacktech & Website & 21/09/2010 & www.jacktech.it/news/blog/blog-lifestyle/musica-web-radio-green/acqua-le-acque-minerali-buone-ma-non-troppo \\
\hline *L'agenda di ambiente ed energia & ॥ Velino & Press Agency & 11/09/2010 & www.livelino.it/articolo.php?ld=1196208 \\
\hline Intervista a Luca Demicheli & Radio Vaticana & Radio & $12 / 09 / 2010$ & \\
\hline Nasce l'atlante geochimico delle acque minerali & Ecoradio.it & Website & 12/09/2010 & www.ecoradio. .t/lindex.php?option=com_contentatask=viewgid=10540\&/temid=9 \\
\hline Intervista a Luca Demicheli & Ecoradio & Radio & 13/09/2010 & www.ecoradio.it/index.php?option=com_content\&task=view\&id=10539\&ltemid=44 \\
\hline In Italia acque minerali di alta qualità & $\begin{array}{l}\text { lo Donna - } \\
\text { Corriere della } \\
\text { Sera }\end{array}$ & Article & 11/09/2010 & \\
\hline $\begin{array}{l}\text { SALUTE: NUOVO ATLANTE DELLE FALDE } \\
\text { ACQUIFERE EUROPEE, ACQUE BUONE }\end{array}$ & ASCA & Press Agency & 10/09/2010 & $\begin{array}{l}\text { www.asca.it/newscanale-SALUTE__NUOVO_ATLANTE_DELLE_FALDE_ACQUIFERE_EUROPEE_ACQUE } \\
\text { BUONE-947836-ATT--salute.html }\end{array}$ \\
\hline $\begin{array}{l}\text { EuroGeoSurveys publishes the European Atlas of } \\
\text { bottled water - around } 1800 \text { bottles examined }\end{array}$ & Innovated UK & Website & 24/09/2010 & $\begin{array}{l}\text { https://ktn.innovateuk.org/web/tony-hartwell/blogs//blogs/eurogeosurveys-publishes-the-european-atlas-of-bottled- } \\
\text { water-around-1800-bottles-examined;jsessionid=F85B4DC6A54958DB4D4986F5415F8E11.9OphEwv4 }\end{array}$ \\
\hline La geochimica delle acque minerali & Geologi.info & Website & 13/09/2010 & www.geologi.info/Sar\%C3\%A0-Roma-la-capitale-dei-pianeti_news_x_5414.html \\
\hline La geochimica delle acque minerali & Acqua Chimica & Blog & 13/09/2010 & http://acquachimica.blogspot.com/ \\
\hline $\begin{array}{l}\text { PUBBLICATO L'ATLANTE EUROPEO DELLE } \\
\text { ACQUE MINERALI }\end{array}$ & $\begin{array}{l}\text { Free News } \\
\text { Online }\end{array}$ & Website & 10/09/2010 & www.freenewsonline.it/2010/09/10/pubblicato-latlante-europeo-delle-acque-minerali/ \\
\hline Huge natural variation of elements in bottled water & Ngu.no & Website & 13/09/2010 & www.ngu.no/no/Aktuelt/2010/Enormous-natural-variation-of-elements-in-bottled-water-/ \\
\hline |l libro verità sulle acque minerali europee & Ad-Angelini & Blog & 21/09/2010 & http://ad-dangelini.blogspot.com/ \\
\hline
\end{tabular}




\begin{tabular}{|c|c|c|c|c|}
\hline $\begin{array}{l}\text { Acqua italiana tra le migliori d'Europa, per quella } \\
\text { slovacca alti i nitrati }\end{array}$ & $\begin{array}{l}\text { Buongiorno } \\
\text { Slovacchia }\end{array}$ & Website & 14/09/2010 & www.buongiornoslovacchia.sk/index.php/archives/6315 \\
\hline L'acqua italiana tra le migliori d'Europa & $\begin{array}{l}\text { Galileo } \\
\text { - Giornale di } \\
\text { scienza }\end{array}$ & Website & 13/09/2010 & www.galileonet.it/articles/4c8e07f772b7ab63b700004a \\
\hline $\begin{array}{l}\text { Qualità Acque Minerali: quelle italiane sopra la } \\
\text { media europea }\end{array}$ & Spesa 2.0 & Website & 15/09/2010 & www.spesaduepuntozero.it/2010/09/qualita-acque-minerali-quelle-italiane-sopra-la-media-europea/ \\
\hline Ny atlas: Geokemin i Europas flaskvatten & Sgu.se & Website & & www.sgu.se/sgu/sv/produkter-tjanster/nyheter/nyheter-2010/flaskvatten.html \\
\hline $\begin{array}{l}\text { EuroGeoSurveys trova uranio nelle acque minerali } \\
\text { in bottiglia }\end{array}$ & Ecquo & Website & 08/10/2010 & http://magazine.quotidiano.net/ecquo/lasco/2010/10/08/eurogeosurveys-trova-uranio-nelle-acque-minerali-in-bottiglia/ \\
\hline $\begin{array}{l}\text { EuroGeoSurveys } \\
\text { Playing a signifi cant role in helping to harmonise } \\
\text { Europe's geological survey information, Secretary } \\
\text { General Luca Demicheli explains how work carried } \\
\text { out by the organisation can help shape policy and } \\
\text { regulations in a broad range of areas, from water } \\
\text { safety to natural disasters }\end{array}$ & & Interview & June 2011 & \\
\hline
\end{tabular}




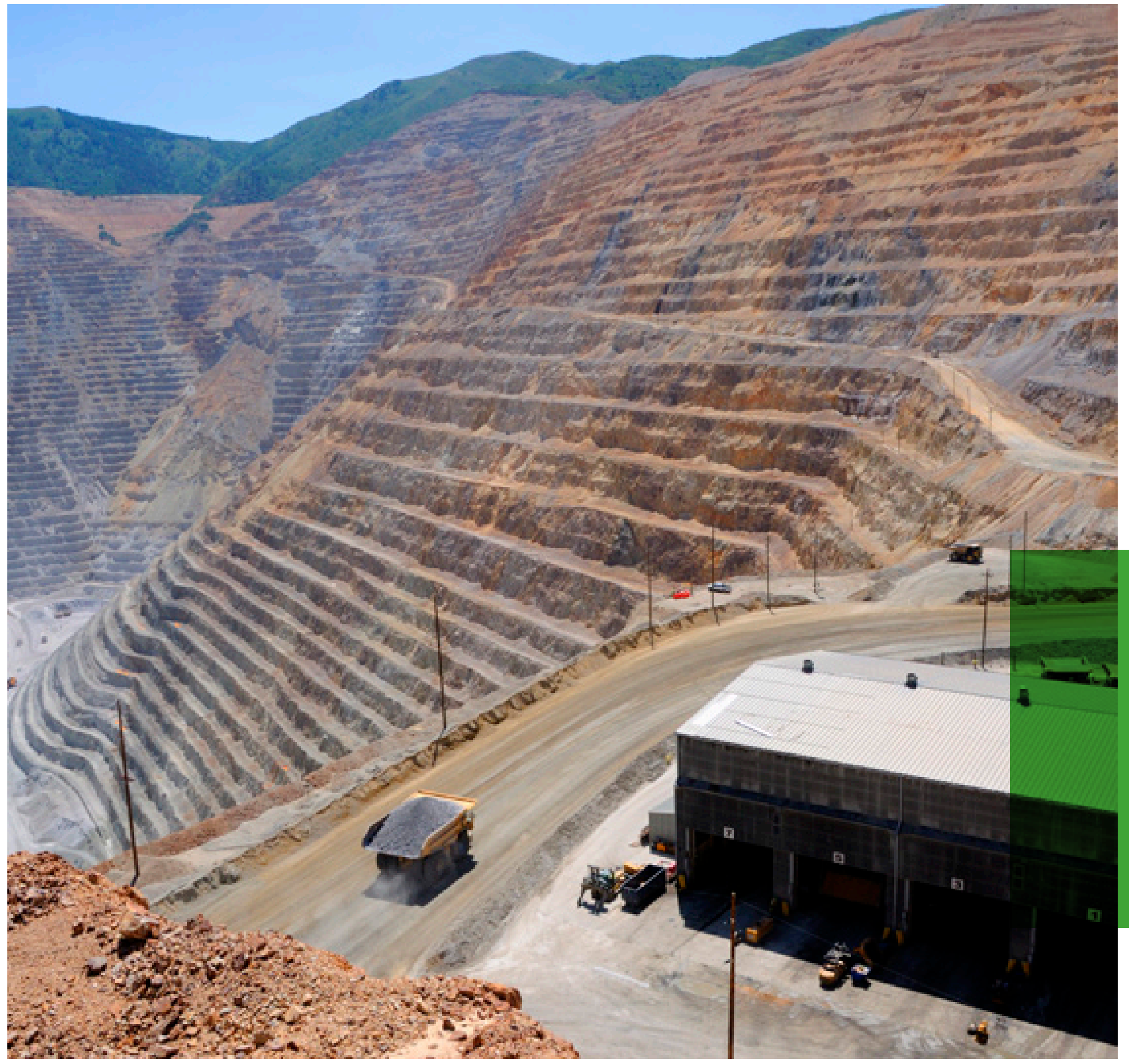




\section{オ There's more...}

\section{D=RA $\begin{aligned} & \text { Deutsche } \\ & \text { Rchssoltiogentur }\end{aligned}$}

\section{DERA}

Market transparency and potentials in the mineral

resources sector

The German Mineral Resources

Agency (DERA) founded

Since raw material imports are the base for Germany's industrial performance and growth a sustainable resources policy is an integral part of the German economic politics.

On April 23rd 2010 the German Federal Minister for Economics and Technology, Mr. Rainer Brüderle, said: "...It is important, that we increase transparency in the resource markets. For this purpose, we will expand the Federal Institute for Geosciences and Natural Resources to be the central mineral resource Agency for the German economy..".

To meet the requirements of the industry with regard to information on raw materials the German Mineral Resources Agency (Deutsche Rohstoffagentur = DERA) was founded in October 2010 by the Federal Minister of Economics and Technology Rainer Brüder

The DERA is part of the Federal Institute for Geosciences and Natural Resources (BGR) in Hannover and serves as the central German information and consultation platform for non-renewable resources (metals, minerals, aggregates, energy resources).

DERA's main topics include:

- Availability of mineral resources, supply and demand analyses

- "Critical" raw materials

- Evaluation of mining projects

- Mineral resource potentials: Domestic raw materials, resources from tailings and waste materials, marine resources

- Resource efficiency at primary production

- Resource potentials of secondary raw materials

- Certified trading chains in mineral production

One of DERA's aims is to supply the German industry, politics and society with mineral resources information and analyses. DERA also offers customized advice and assistance to companies and business associations with regard to their resource supply.

The agency will also establish governmental and industrial networks and seek national and international cooperation on mineral resources. Expert assistance will be given to the German government in setting up and implementing support programs for the German industry to secure their raw materials supply.

DEAR will play an active role in the cooperation with developing countries by supporting those with a sustainable use of their resource potential and the integration of developing countries in the international resource economy.

\section{Contact}

German Mineral Resources Agency (DERA) in the Federal Institute for Geosciences and Natura Resources (BGR)

+49 (0)511 6433200

kontaktbuero-rohstoffe@bgr.de

www. deutsche-rohstoffagentur.de

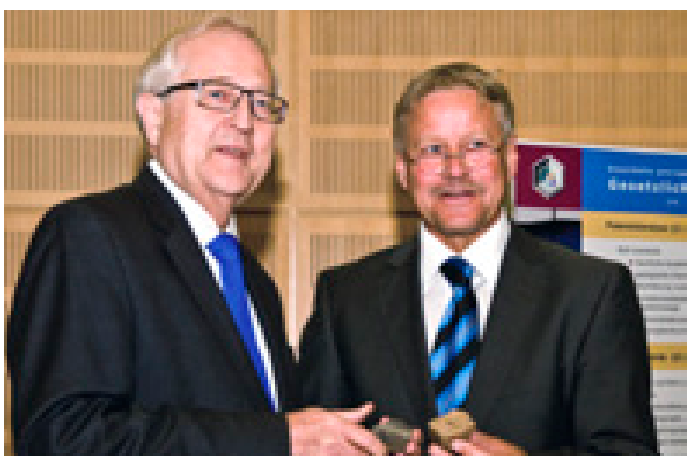

Federal Minister Brüderle and BGR president Prof. Kümpel at the aunch event of the German Mineral Resources Agency

"The new German Mineral Resources Agency (DERA) will help to further pool the existing knowledge and skills in the provision of consulting services on raw materials. I am convinced that this is an important step towards safeguarding Germany's position as an industrial location for the long term." (Federal Minister of Economics and Technology Rainer Brüderle). 


\section{Evaluation of risk exposure to natural hazards in Central America}

In the framework of a regional technical cooperation project 'Mitigation of Georisks in Central America' (2002-2010), the BGR assisted the mandated Federal agencies of the project countries El Salvador, Guatemala, Honduras and Nicaragua in the recording, assessment and monitoring of geological hazards and the realization of relevant georisk analyses. The project fostered social and political awareness rising regarding disaster risk and aimed at the integration of georisk assessments into the regional spatial planning and disaster prevention.

The national and trans-national perspective had been considered as the natural disasters affecting Central America like volcanic eruptions, destructive earthquakes or floods are regional phenomena which often affect several countries or the whole region. Therefore, these events require both national and trans-national planning tools and mitigation strategies which should be based on respective risk information.

In 2009-2010, the project performed comprehensive national and trans-national georisk exposure analyses (single and multi-hazard approach) on the administrative level of 'Municipio' for the project countries, based on a uniform methodology and comparable/harmonized datasets. The main focus was placed on the development of a practicable and reproducible standard methodology which enables the elaboration of comparable georisk information and their implementation into disaster prevention activities (e.g. in particular risk-sensitive spatial planning)

The methodological framework and the risk exposure assessment results for Central America have been published in a 'Guidebook for Assessing Risk Exposure to Natural Hazards in Central America' (Balzer et al., 2010) focusing on the Disaster Risk Management context. The guidebook is available in Spanish and English language as well.

\section{References}

Balzer, D., Jäger, S. \& D. Kuhn (2010): Guidebook for Assessing Risk Exposure to Natural Hazards in Central America - El Salvador, Guatemala, Honduras, and Nicaragua. - Project of Technical Cooperation 'Mitigation of Georisks in Central America': 121 pages; 26 figures; 44 tables; 35 maps; San Salvador, Guatemala-City, Tegucigalpa, Managua, Hannover (ISBN: 078-3-9813373-7-2; Spanish version: ISBN 978-3-9813373-8-9).

\section{Contact}

Dr. Dirk Balzer \& Dr. Dirk Kuhn

Federal Institute for Geosciences and Natural Resources (BGR), Hannover

30655 Hannover, Stille-Weg 2

e-mail: dirk.balzer@bgr.de - dirk.kuhn@bgr.de

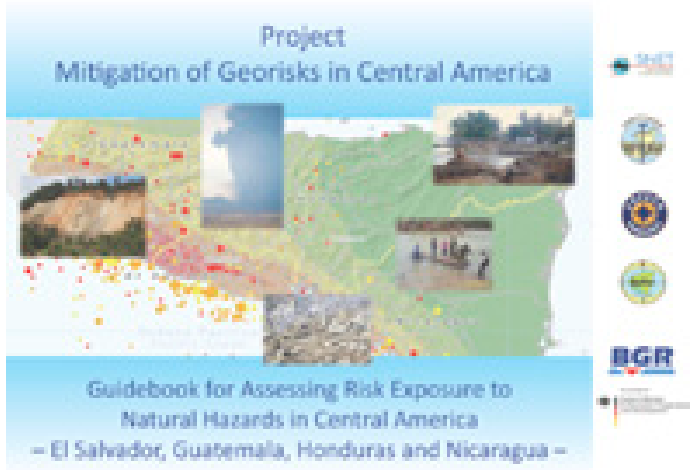

Fig. 1: Title page of the "Guidebook for Assessing Risk Exposure to Natural Hazards in Central America'.

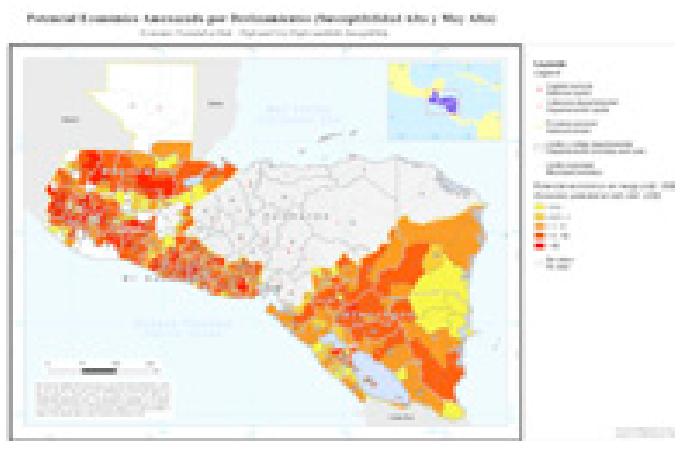

Fig. 2: Example Risk Exposure Map: Economic potential (in Mio US\$ at risk to high and very high landslide susceptibility for the countries El Salvador, Guatemala and Nicaragua. 


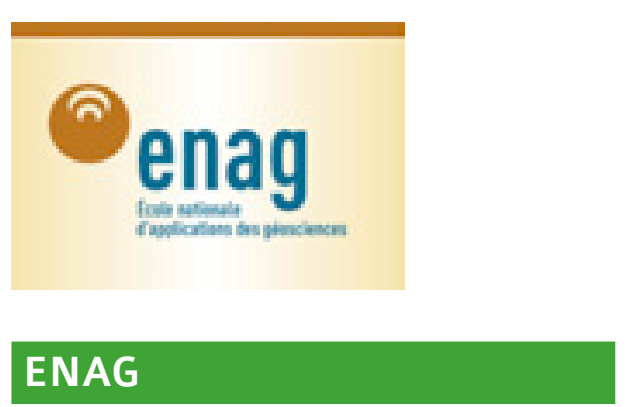

ENAG, the French National School for Applied Geoscience, opened its doors on September $15^{\text {th }} 2010$, with a first class of 12 students attending the post-graduate course entit»led "Sustainable management of mineral resources". This course trains exploration geologists with a professional edge while introducing them to the various dimensions of the extractive industry (economic, legal, risk management, sustainable development, etc.). One of ENAG's goals is to contribute to geoscience capacity-building in emerging economies, in particular in Western Africa. A consortium of mining companies operating in the region is being gathered to support the scholarship.

Potential candidates for this course are invited to visit the school's website at: www.enag-brgm.fr
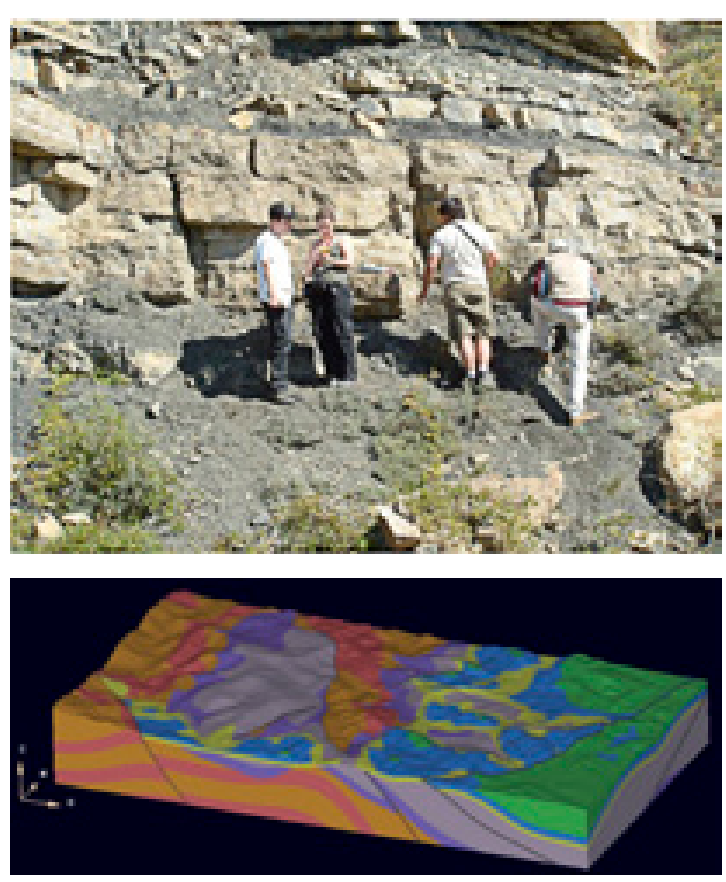

Geological mapping coupled with 3D structural modeling Cévennes area, South of France 


\section{SPAIN}

IGME deploys the new observation network Topolberia, which will help in the prediction of earthquakes in Spain

The fresh data obtained will be translated into recommendations on areas of Spain in which seismic resistant construction standards should be more o less rigorous. A similar system was used by Chilean and French geologists to predict the earthquake which occurred $27^{\text {th }}$ February but we will need at least 5 years data so that the new data can be considered representative and precise.

Topoibera (www.igme.es/internet/Topolberia/default. $h t m l)$ a consortium of 10 Spanish research institutions and $107 \mathrm{PhD}$ researchers, is probably the most important Earth Sciences project developed in Spain and is financed by the CONSOLIDER INGENIO 2010 program of the Spanish Ministry of Science and Innovation with a budget of $5.4 \mathrm{M} €$

Two combined observation networks will allow modeling earth crust structure and quantify crust deformation to predict earthquakes. Topolberia adds up the real measured stressed accumulated in a particular point and the knowledge of the crust, to the instrumental register and the historical register of earthquakes which happened in the peninsula which will allow explaining why there is an earthquake in a certain place.

The passive seismic network, which has recently been moved to the central area of the peninsula has been deployed during one and a half year in the south of the peninsula and includes the extension of the Betic Range to the Riff zone of Morocco. Researchers take advantage of the energy produced by low intensity earthquakes (2 or 3 in the Richter scale) which are happening continuously in the peninsula, to collect the information from the seismographs and model the structure of the Earth crust.

The new network of 40 precision GPS will allow measuring small millimetric scale movements produced under our feet. If in a zone there is a displacement of $10 \mathrm{~mm} / \mathrm{year}$ and there are no documented catastrophic earthquakes in 100 years, those millimeters mean an accumulated deformation of one meter, meaning that such area is prone to an earthquake of a certain level soon. The same system was used in 2009 by the Geophysical Institutes of France and Chile to predict the recent catastrophic earthquake. With the GPS network it will be possible to predict the scale and the moment in which an earthquake might happen

All data generated during the 4.5 years will be modeled by geophysical experts of the Earth Sciences Institute Jaume Almera.

The consortium partners are the Earth Sciences Institute Jaume Almera (IJA CSIC), the Geological Survey of Spain (IGME), the Royal Institute and Observatory of the Army of San Fernando (Ministry of Defense), the Complutense University (UCM), the University of Oviedo (UO), the University of Barcelona (UB), the Autonomous University of Barcelona (UAB), the University of
Granada (UGR), the University of Jaen (UJAEN) and the university of Cadiz (UCA), and another groups of the University of Salamanca and the University of Zaragoza.

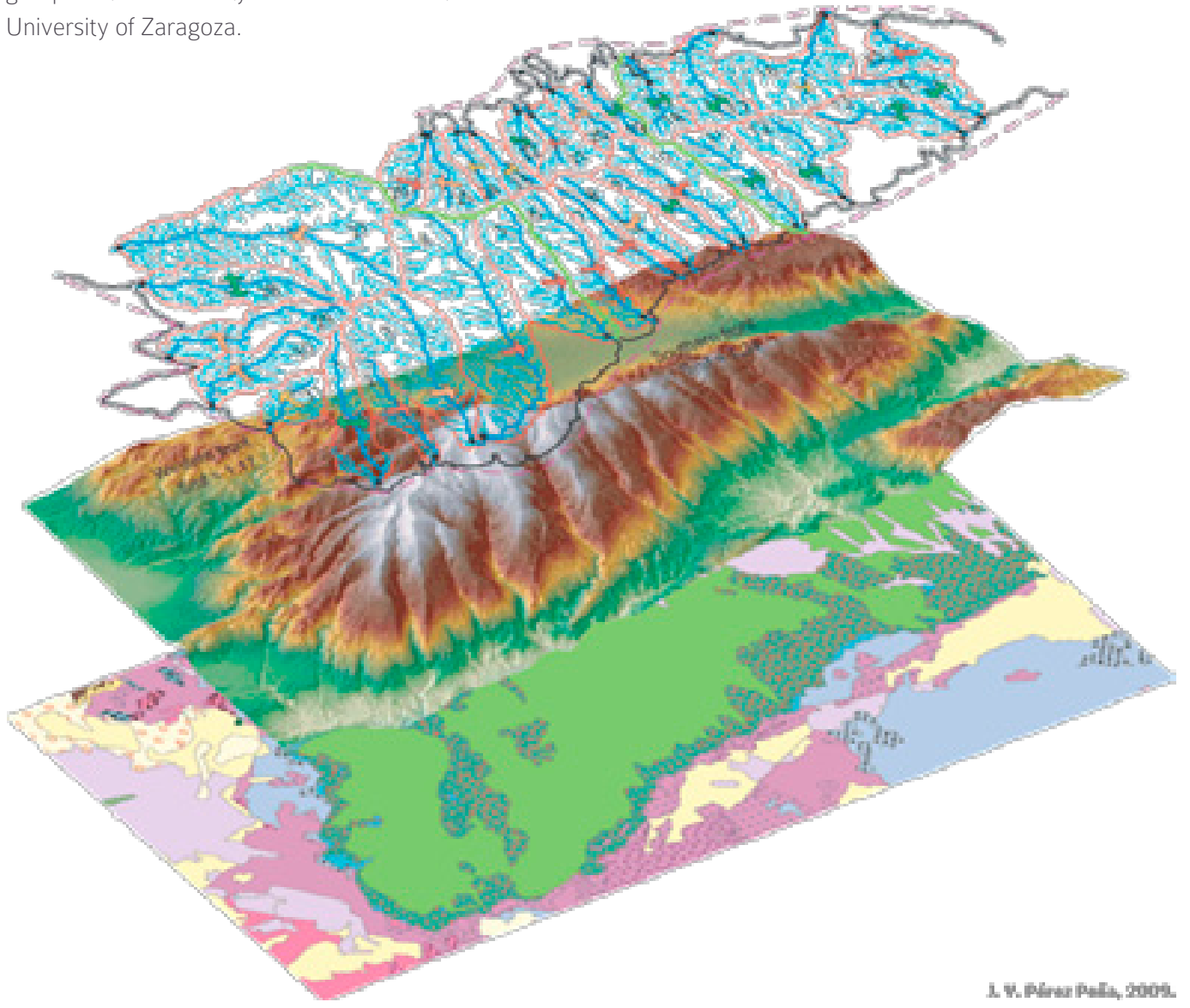

Digital topographic models (DTM) include the topography of surface land and the bathymetry marine basins, continental margins, etc. This data is integrated through a geographical information system (GIS). These are main tools to perform a detailed analysis of the surface slope maps, mandatory for assessment of taxsides. 
Re-assessing the economic value and growth opportunities of abandoned, ceased and/or unexploited state mine concessions in Greece

The EU is highly dependent on imports of strategically important raw materials which are increasingly affected by market distortions.

At the same time, a significant opportunity exists for securing material supplies by improving resource efficiency and recycling. The communication from the Commission of the European CommunitiesCOM (2008) 699 in securing reliable and undistorted access to raw materials is increasingly becoming an important factor for the EU's competitiveness and, hence, crucial to the success of the Lisbon Partnership for growth and jobs. The EU is also highly dependent on imports of "high-tech" metals such as cobalt, indium. germanium, platinum, rare earths, and titanium, and there are particular reasons why materials are considered critical. One of the three pillars towards an integrated raw materials strategy intends to boost overall resource efficiency and promote the extraction of European minerals.

In this respect the Greek Institute for Geology and Mineral Explorations (IGME) initiated in 2010 a new project, backed up by the Ministry of Environment, Energy and Climate Change, aiming to reactivate the mining industry by re-assessing the economic value and resource sustainability of abandoned and/or inaccurately evaluated state mine districts, stimulate activity and investments in those currently under exploitation and trigger the development of some to create new job opportunities through extraction of existing resources and identification of new ones. An inventory and assessment of the mineralization types, grades and volumes associated with more than 100 state mines sites properties all over the country are being identified and currently ranked to consider their re-operation possibilities. All ore exploration features are

inventoried, investigated, evaluated, digitally stored and GIS based. Each state mine concession is documented on Site Inventory Data Forms and assigned a site name specific to the area investigated. Waste stockpiled materials left over from mining or processing are also taken into account as modern extraction technologies are more efficient than historic ones and make secondary resources become potential raw materials for critical minerals extraction.

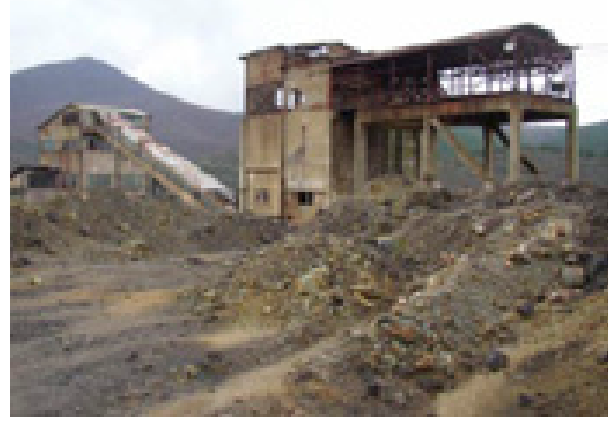

Ore stockplie and primary crusher from an abandoned base meta mine in northern Greece

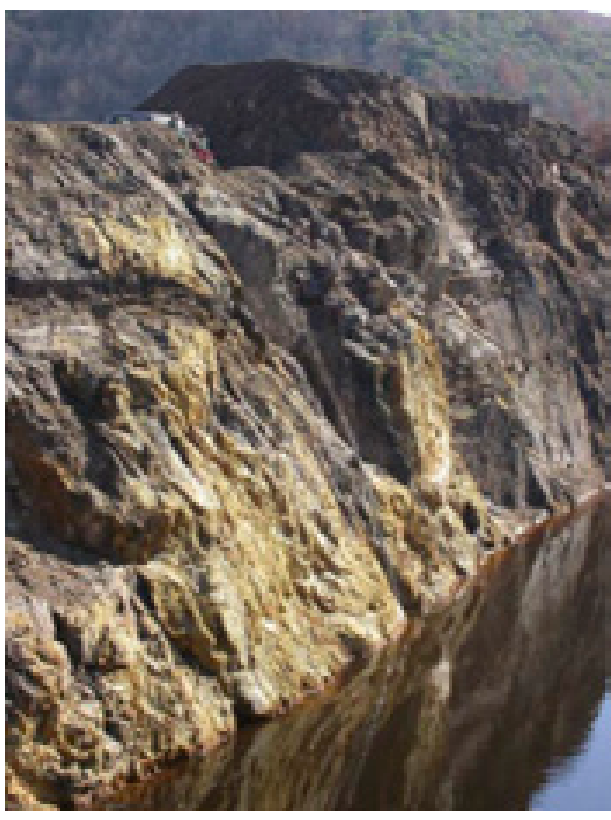

Abandoned open pit mine in northern Greece

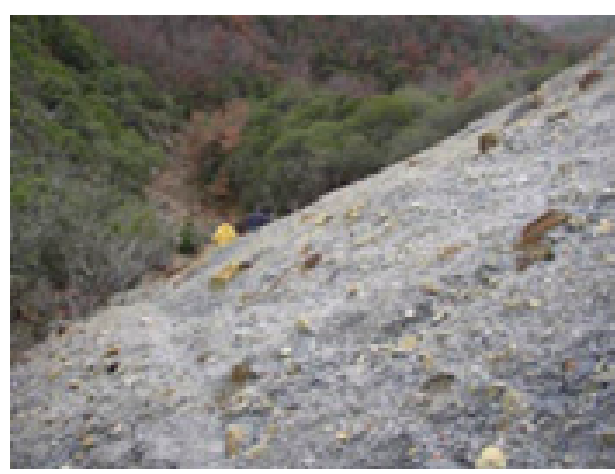

Stockpiled mine waste materia 


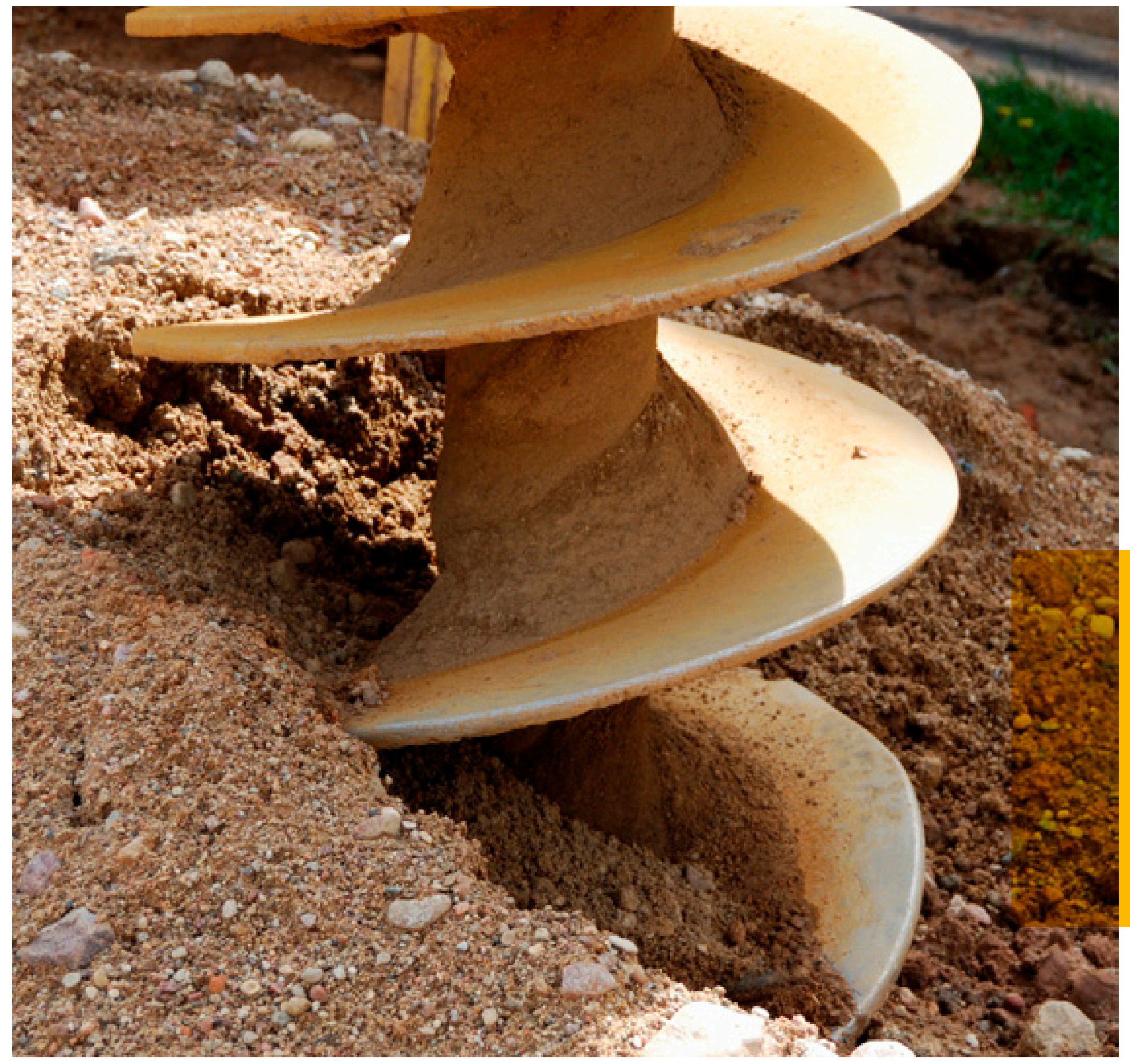




\title{
オ Perspectives 2011
}

\author{
BROADENING OUR HORIZONS
}

Large-scale project for emerging social needs

\section{Pance:t:}

Project short title: PanGeo

Long title: Enabling Access to Geological

Information in Support of GMES

Sponsor: EC's Seventh Framework Programme

Theme: [SPA.2010.1.1-01] Stimulating

Development of Downstream GMES

Services

Budget: Total project costs: €3,225,066

EU contribution: $€ 2,407,717$.

Conferences attended during 2010: None (project started $1^{\text {st }}$ Feb 2011)

Project consortium (37 partners in total)

Includes all 27 EU National Geological Surveys. The PanGeo 'Core Team' comprises: Fugro NPA Ltd (UK - Project Coordinator), British Geological Survey (UK), Landmark Information Group (UK), TNO (N), SIRS (F), Institute of Geomatics (E), BRGM (F), EuroGeoSurveys (B), AB Consulting Ltd (UK), European Federation of Geologists (B),

Tele-Rilevamento Europa (I). Altamira Information (E), Gamma Remote Sensing (S)

\section{Project context}

There are GMES services for the sea, air and land surface. There is little, however, for the sub-surface

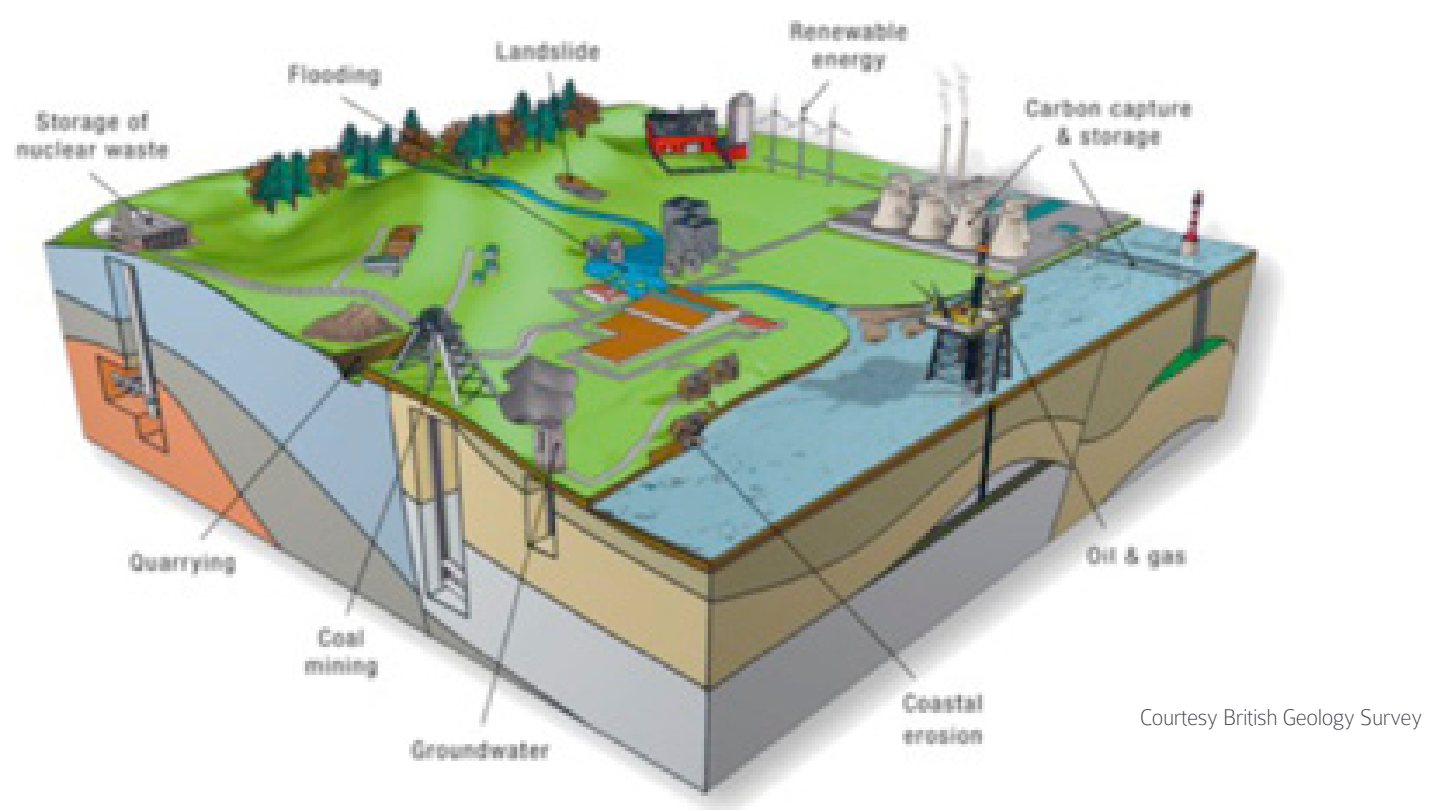

- the geology, although geology has a direct impact on the surface. To a geologist, the land surface, what happens on it, and geology cannot be separated. A key objective of PanGeo, therefore, is to introduce more geology into GMES

The advantages of this are not only for the nationa geological surveys, local authorities and decisionmakers who need to understand the geological risks across Europe, but also for the GMES Core Services of GEOLAND2, in helping to provide a more complete picture of the environmental status of the Urban Atlas towns, and also SAFER, in providing additional 'resilience' (or 'reference map') information pre and post disaster.
Currently, the various national geological surveys of Europe operate in a largely independent manner. The geological maps produced by them vary in terms of quality, scale and format. Although many geological features and hazards are common to many countries, there is little cross-country standardisation or consideration of European geology in a holistic manner. In fact OneGeology Europe is a key initiative trying to change this situation by implementing common standards.

PanGeo is aiming to take a step in developing the 'missing geological link' for GMES by initiating a pan-European geological service which will derive 
and standardise geohazard information across an initial subset of the Urban Atlas towns across Europe. It is hoped that eventually PanGeo will be fully incorporated into OneGeology Europe.

\section{Project scope}

PanGeo is a 3-year Collaborative project that started 1st February 2011 with the objective of enabling free and open access to geohazard information in support of GMES. This will be achieved by providing an INSPIRE-compliant, free, online geohazard information service for the two largest towns in each EU country (Cyprus and Luxembourg only one) -52 towns in total ( 13\% of EU population). The geohazard information will be served in a standard format by the $27 \mathrm{EU}$ nationa Geological Surveys via a modified version of the 'shared access' infrastructure as devised for the DG ISM project One-Geology Europe. The information to be served (a new Ground Stability data-layer and accompanying interpretation) will be made by each Survey, and be compiled from integrations of:

- Satellite Persistent Scatterer InSAR processing, providing measurements of terrain-motion. - Geological and geohazard information already held by national Geological Surveys.

- The landcover and landuse data contained within the GMES Land Theme's Urban Atlas.

Upon user enquiry, a PanGeo web-portal will automatically integrate the geohazard data with the Urban Atlas to highlight the landcover polygons influenced. Mousing over polygons will hyperlink to interpretative text. User input to design will be facilitated by the Surveys contracted into the project and initiation of a 'Local Authority Feedback Group'. It is trusted that sustainability of PanGeo will be achieved by attracting a proportion of the remaining 253 Urban Atlas towns to procure the PanGeo service for their towns. The service that will already be provided in their country will form the basis of the required promotional activity.

The key users of PanGeo are anticipated as: - Local Authority planners and regulators who are concerned with managing development risk - National geological surveys and geoscience institutes who collect and disseminate geohazard data for public benefit,

- Policy-makers concerned with assessing and comparing European geological risk, much as the Urban Atlas data is used to compare the landcover/use status of European towns.

Contribution to policy

implementation and development

The provision of an open-access, standardised information service on geohazards will enable policy-makers and regulators to:

- Systematically assess geohazards in each of the 52 towns involved.

- Gain understanding of the geohazards themselves.

- Know who to talk to for more information. - Statistically analyse and cross-compare geohazard phenomena across EU countries. - Gain a better understanding of the socio- economic costs involved.

- Make more informed decisions.

- Have confidence that the information provided is robust and reliable.

- Also, EU citizens will be empowered with access to knowledge previously known only to a few.

Policy areas of relevance

Local policy: Following the EU subsidiarity principle, terrain-motion and associated geohazard policy is generally enacted at the local level. Some examples of local policies suggested by the Geological Surveys include: monitoring the impacts of dissolution and sinkholes in Hamburg city centre (Germany); monitoring of nuclear power plant

stability (Lithuania): monitoring flood plain subsidence in urban areas (Luxembourg).

National policy: There are many national policies of EU member states that mandate the collection of geohazard data. Examples cited include:

Map of active faults' project (Slovenia); Monitoring of hydroelectric power plants and the burial of nuclear and hazardous waste (Latvia): Mitigation of Climate Change impacts (Estonia, Denmark national programs).

European Union policies: PanGeo is relevant to several EU strategies and Directives:

- The EC Directive on Landfill (1999) requires that Tandfill site must meet certain conditions relating to the risk of flooding, subsidence, and landslides. - The EC Flood Directive (2007) requires Member States to assess the flood risk of all wate

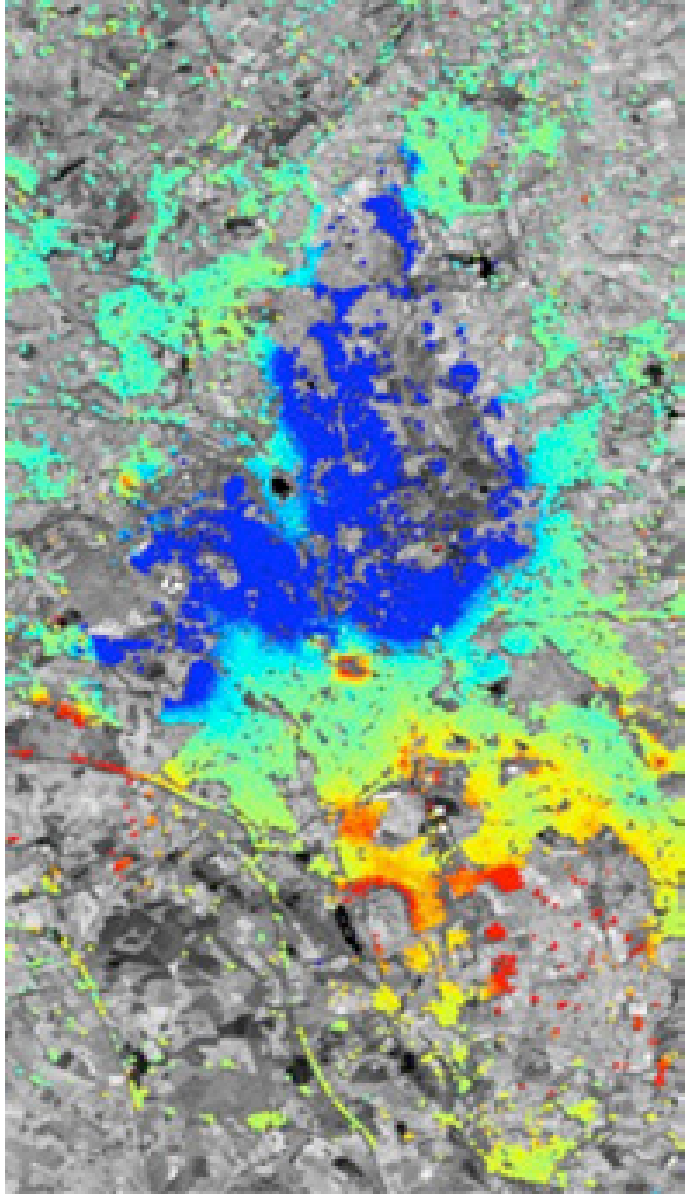

InSAR resut . 
courses and coast lines; map assets and humans at risk; and to take adequate measures to reduce this flood risk.

- The European Programme for Critical Infrastructure Protection (ECPIP, 2006) was introduced for the identification and designation of European critical infrastructure and the assessment of the need to improve thei protection. Related to this, Eurocode 8 (of the European Structural Design codes) is concerned with making buildings and civil engineering structures resistant to earthquakes.

- Future EC directives relevant to PanGeo are The Prevention of Natural and Man-Made Disasters, and The EU Strategy for Supporting Disaster Risk Reduction (DRR) in Developing Countries. Both these strategies require disaster mitigation by obtaining detailed information on areas most at risk from geohazards and their indirect impacts.

International policies and strategy: There are several international programs subscribed to by the EU and individual Member States involving social, economic and environmental considerations under the sustainable development agenda into which PanGeo could provide valuable information: - Policy for sustainable economic progress in parallel with environmental protections was highlighted in the Brundtland Report (1987), the Rio Declaration on Environment and Development (1992) and Agenda 21 (1992) programs, and the Aarhus convention (1997)

- Climate change policy has become the increasing focus of international environmental concerns as evidenced by COP15 (2009). While geohazards are not a measure of climate change per se, terrain-motion, e.g. subsidence, can increase the risk of flooding (see FP7 SubCoast project), thus the capacity to understand geohazard risk and monitor the threat imposed is increasingly important as advocated in the Stern Review (2006). - The Lisbon Strategy (2000) objective is to make Europe "the most competitive and the most dynamic knowledge-based economy in the world capable of sustainable economic growth ... and respect for the environment." PanGeo will actively contribute to the environmental and economic pillars of the strategy. By making accessible state of the art, pan-European

information on geohazard, PanGeo is enhancing public knowledge in a key area and creating an infrastructure that future project and users can continue to develop.

\section{Pance:t:}

MPA furma

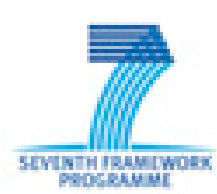

Gmes 


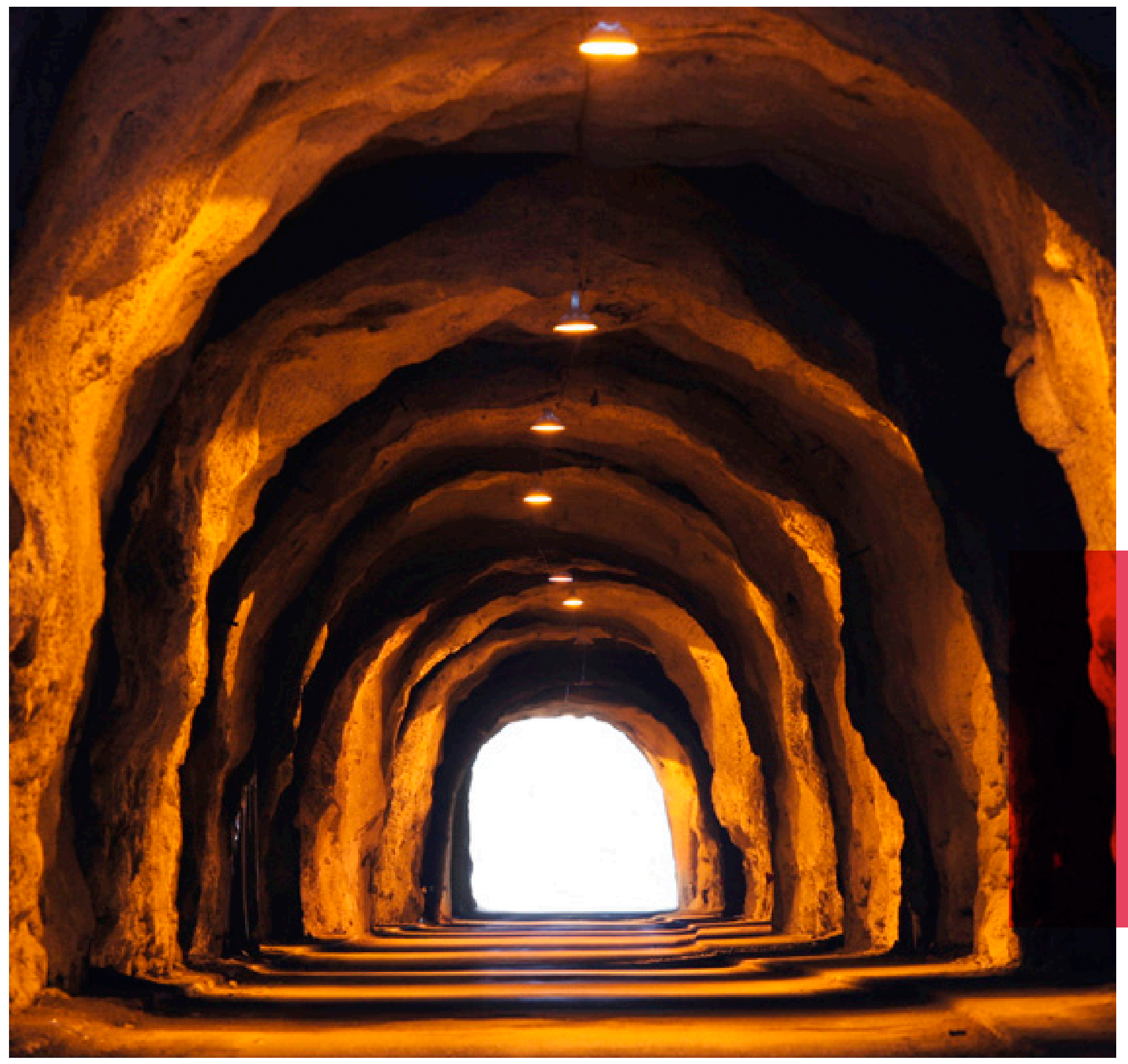




\section{オ Highlights}

\section{Agreement with the European Environment Agency (EEA)}

An agreement between EGS and EEA has been signed in Beijng on the $3^{\text {rd }}$ of November.

The Agency was represented by Prof. Jacqueline McGlade, Executive Director, while on behalf of EGS the Secretary General, Luca Demicheli, signed the paper "in the area of integrating environmental and geo-scientific data, information and knowledge".

The general objective of this agreement is to "secure a long-term cooperation in integrating environmental and geo-scientific data, information and knowledge. The specific objectives are to secure awareness and commitment to the provision and use of EGS data and capacities by EEA, promoting the appropriate use of geological data and knowledge in the whole spectrum of environmental issues".

The agreement says that EGS will provide EEA with "non-exclusive access to the OneGeologyEurope interoperable onshore geological data for all Europe at the scale of 1:1 million. Data can be downloaded for a specific area and they are free in accordance with the OneGeology-Europe Licensing Agreement, signed by EGS data providers". The other points of the agreement are about the help that EGS will give to EEA in the best exploitation of the data for environmental protection purposes, the cooperation between the parties in order to secure "broader, sustainably free and open access to geological data and information on the Internet", and thus seeking to extend the cooperation to the areas of "natural resources specifically groundwater - climate change, natural hazards and geochemistry, and they shall organise specific meetings to address this issue".

\section{A memorandum to make US} and European Geoscientists closer than ever

An agreement that gets two continents closer than ever before, at least from the geosciences point of view. It's the Memorandum of understanding signed on the 28 of December 2010 between EEA and the USGS (United States Geological Survey) about the contributions of these two organisations to the "establishment of global monitoring networks including (but not limited to) hazards monitoring, energy and non-energy mineral resources, and climate change" besides the exchange of best practices between the experts.

The tasks of the two signing institutions fits very well together, since EEA promotes the contribution of geosciences to European Union affairs and provides a permanent network between the services across the continent, while USGS aims to provide reliable scientific information to describe and understand the Earth and to manage natural resources, developing predictive tools for scenario building and decision-making about natural systems

So, the agreement focuses on the establishment of global tools for the same purposes, created by identifying, defining and implementing mutually beneficial research projects and monitoring

programs, also working together to develop and share expertise, data, information, tools,

technology, and provide guidance and support for the data providers and users. The Memorandum also aims to encourage the interaction among the appropriate offices of the two institutions, including also (but not only) the EGS Expert Groups on Earth Observation and on Mineral Resources, and the EGS Task Force on Fossil Fuels, with the idea of a total cooperation, well represented by the signatures on the MOU by John N. Ludden, EGS President, and Suzette M. Kimball, Deputy Director for USGS.

\section{EGS reinforces its role in Beijing}

A very important outcome, for $E G S$, from the attendance at the 2010 GEO Beijing Ministerial Summit that has been celebrated at the beginning of November in the Chinese capital. Apart from the signature of the agreement with the EEA about the OneGeology-Europe project data, EGS has managed its own booth, inside the European Union area, where The Secretary General, Luca Demicheli, met diplomats, scientists, and EU executives, like the Director of the European Environment Agency (EEA), Prof. Jacqueline McGlade, and the Vice President of the European Commission, Mr. Antonio Tajani, Commissioner for Industry and Entrepreneurship. 


\section{オ Highlights}

People from EGS attended to the booth during the entire event, showing the visitors video slides

about EuroGeoSurveys main activities. In the final

day of the summit, during the plenary,

EuroGeoSurveys was assigned a very important

task which reaffirms the importance of the

organization role: in fact, EGS was accepted as

co-chair for the GEO Science and Technology (S\&T)

Committee, that engages the scientific and

technological communities in the development

implementation and use of a sustained GEOSS in

order to ensure that GEO has access to sound

scientific and technological advice.

In fact, the Group on Earth Observations is

coordinating efforts to build a Global Earth

Observation System of Systems, or GEOSS.

GEO was launched in response to calls for action

by the 2002 World Summit on Sustainable

Development and by the G8 (Group of Eight)

leading industrialized countries. These high-level

meetings recognized that international

collaboration is essential for exploiting the growing

potential of Earth observations to support decision

making in an increasingly complex and

environmentally stressed world. GEO is a voluntary

partnership of governments and international

organizations. At the moment, GEO's Members

include 85 Governments and the European

Commission. In addition, 61 intergovernmental,

international, and regional organizations with a

mandate in Earth observation or related issues

have been recognized as Participating

Organizations 


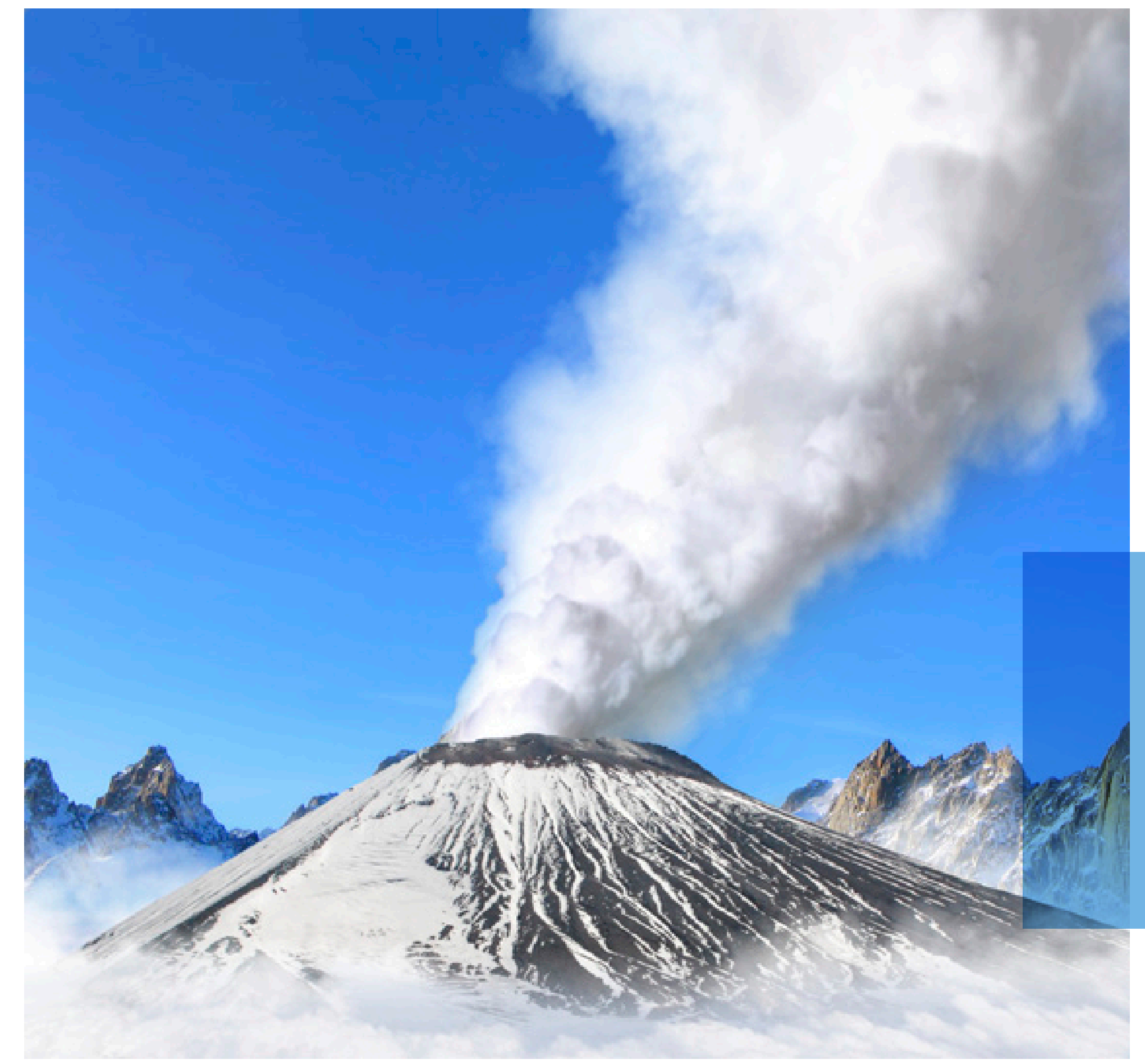




\title{
オ Geological Surveys: a prospective view
}

\author{
JACOUES VARET - BRGM
}

Geological Surveys in Europe are expected to face in the coming years a faster changing world implying a stronger involvement in most of their fields of competences. Moreover new or renewed areas of work also emerge as supplementary solicitors. As entities of the public sector, major challenges will hence have to be faced in a general context of restriction of state's budgets with a risk of lack of proper skills available in highly demanding areas of strong economic interest. With sound strategic view and indefectible engagement, we will make it!

\section{Major drivers for future}

development

Seven major drivers can be identified at global (planet Earth) level, implying strong science driven public policies, of direct interest for Geological Surveys:

1. Climate change: need to act

2. Mineral resources: still more demanding

3. Natural hazards: a safer society

4. Globalization: need for Europe view of the world

5. Unsustainable inequities: development \& governance

6. Information Society: virtual Earth

7. State Reform: time for R\&D, information and innovation

\section{Climate change: need to act}

The imperative necessity of reducing the greenhouse gas emissions will imply the development of alternative energy sources, notably geothermal energy, as well as $\mathrm{CO}_{z}$ sequestration, when fossil fuels will still be used, implying new geological knowledge and expertise concerning more difficult resources, renewed technologies and more severe risk assessments. Besides mitigation, adaptation policies will imply new tools for a prospective coastal management, landslide mitigation, as well as new approaches for soils and groundwater.

\section{Mineral resources: still more demanding The access to development for societies of the third world; notably fast growing BRICS as well as African and Mediterranean countries, increase the pressure on all natural resources including construction materials, industrial minerals, metals, energy, and amendments for agriculture (NPK). This concerns the whole Mendeleev table including - notably for Europe - several emerging metals considered as strategic.}

\section{Natural hazards: a safer society}

Whether due to a real increase of the socioeconomic impact of natural and man-made hazards, to the instantaneous images of disasters diffused by media, or to evolution of the sensitivity of European citizens, the need for a safer society addresses new demands for better knowledge on natural hazards, mapping of risks, as well as tools for mitigation and resilience policies.

\section{Globalization: need for Europe view} of the world

Europe is in a slow construction process in a fast changing world and needs to adjust its strategy and views. Due to the dispersion, at national level, of diplomatic as well as technical capabilities there is a lack of centralized views of the planet, notably in terms of natural resources and risks assessment. In line with US and China capabilities, the need for a shared view of the world based on permanent survey and assessment capabilities is crying out in the EU.

\section{Unsustainable inequities:} development \& governance

While the world population develops, and more countries are entering a path of social and economic development, inequities also develop. We are far from the objectives of eradication of poverty decided by successive world summits. Geological surveys are in a particularly sensitive position to this respect as mineral \& energy resources are frequently condemned as a "malediction" for the producing country, when they should be factors of development. This raises the issue of "good governance", implying the capacity building in concerned countries.

\section{Information Society : virtual Earth}

Information technologies have invaded the scientific world and diffuse material everyday to a wider public, with increased capacities. This provides immense perspectives for geosciences, as 2D, 3D and even 4D solutions can be implemented in order to map, model, understand, manage, predict, debate and inform.

The issue concerns scientific circles, for multidisciplinary applications, as well as policy 
makers, enterprises, education and the public and citizens at large, notably in view of a more democratic integration of environmental, social and economic dimensions of Earth Science applications.

\section{State reform: time for R\&D, information and innovation}

Geological surveys are facing a terrible challenge; as part of the public sector, they face the general revision of public policies, with a generalized tendency for reducing staff and costs. At the same time, the priority is maintained for research and innovation, as well as specialized training that offers new opportunities in sectors which, in the recent past, were not necessarily favored by public policy priorities. This implies better synergies with academic research as well as better coupling with demanding private and public sectors.

Major thematic objectives for Geological Surveys

From the general drivers listed above, we can taking into consideration capabilities and missions of Geological Surveys - deduct the thematic areas to be considered as priorities, define objectives and eventually actions to be implemented.

1. Master and disseminate knowledge on energy resources, storage and management We see that, in a context of increasing demand due to climate change as well as resources shortage, the energy issue is a determining factor.
This concerns directly the interpretation of geological maps and other data (seismic profiles and other geophysical sources, former well logs...) for assessing resources (such as unconventional oil and gas or geothermal), but also engineering issues, such as energy and nuclear wastes storage as well as environment and safety management (notably in the case of $\mathrm{CO}_{2}$ geological storage).

\section{Mineral resources: to know where they are} and how best answer the needs

Competences in Geological Surveys may vary from one country to another, and the long lasting disinterest for mineral resources (for more than 20 years, 1986-2006) has eroded much of the competent human resources which were engaged in the "30 glorieuses" period of postwar growth. But, with new recruitment of staff and newly identified research budgets and contracts, we have to be able to face the new challenge in front of us: discover new mineral resources, to identify feasible exploitation sites and help for defining methods of exploitation answering the needs of social benefit for local population as well as environmental friendly technologies.

\section{Pass from surveillance to active} management of water resources All surveys are involved in the implementation of the EU Water Framework Directive, notably concerning groundwater knowledge and surveillance in terms of quantity and quality. But it will not be possible to just sit on this position. The continuous increase of slow impacts, such as diffuse pollution (notably from agriculture) and climate change demand a more proactive engagement of

Geological Surveys. The groundwater system will be more solicited and therefore more geoscientific input will be needed in order to manage them more efficiently without destroying their functionalities This should be considered on the contrary as an opportunity for restoring better water qualities when optimizing quantitative management.

\section{Provide tools for risk assessment,}

\section{mitigation and resilience}

It becomes more difficult to discriminate between natural and technological risks. The man-made continuous increase of Greenhouse gases is

changing the climate which induces new hazards. Besides this, intense human activity in the most exposed environments (littoral, deltas...) increase technological risks. Geological Surveys must provide all necessary tools for land planning and insurance policies, in view of better integration of prevention, precaution and resilience.

\section{Establish national geological framework} In order to back these 4 sets of targeted needs, and to answer other demands from public policies, private enterprises and citizens, a core activity for Geological Surveys is to establish - having completed geological maps coverage - fully digital 3D framework that can be made available at demand in a tailored format (information "blocks" at the necessary scale). This integrative approach will incorporate actualized mapping (particularly concerning superficial formations) as well as all 
data documenting at depth, such as geophysical coverage, profiles and logs from various drillings, extracted from data banks or newly acquired for this purpose.

\section{Major missions to embrace}

\section{Take responsive place in R\&D}

One of the key tools for public policies at national, regional and EU level will remain and increasingly be R\&D programs handled by public research agencies. Geological Surveys should remain pro-active at all stages of programming from early foresight to evaluation of results, with a strong direct participation. They should consolidate their position in coordinating projects in partnership with academic research organizations - notably universities - as well as other applied public research institutes and private research centers.

\section{Become major partner for innovation} As research public programming previously focused on biology, chemistry, physics or IST geology remains a field particularly open for numerous and various types of innovations.

The key position of the Surveys should be better valued in the future for promoting - in partnership with the demanding sectors - innovations in the field of services, software, technologies, processes and products.

\section{The reference center for all geographic} based information

Mastering information technologies, notably concerning all geographic based information in 3D Geological Surveys should become reference centers at national, regional and EU level. This notably includes the development of referential which guarantee the interoperability and the quality of all data whatever the source in line with the INSPIRE directive.

\section{Properly backing public policies}

The public policies should, at any moment and for any subject concerning geological phenomena or applications involving earth sciences, find in Geological Surveys the necessary tools for decision based on data of incontestable quality and be

recognized as the reference made available to all.

\section{An inevitable international engagement} Climate change, mineral resources, natural and man-made hazards, geology itself do not know boundaries and make it necessary for Geologica Surveys, whatever their geographic sphere of reference, to develop views at larger scales, up to global. Besides the needs to be answered from less developed countries, notably at the initiative of development agencies, the necessity to achieve global perspective and to back the multilateral policies which inevitably will need to be implemented will make it necessary for all European Geological Surveys to increase their activities overseas.

\section{Conclusion:}

"la quadrature du cercle"

As a whole, geological surveys will, in the coming period, have to resolve the difficult challenge to answer strongly increasing demand for a deeper seated scientific expertise in an enlarging perimeter of application, involving still more diversified partnership. Due to lack of skills available in the highly demanded geoscience sector, Surveys will also have to be more involved in teaching and training.

It is clear that such enormous challenges will not be achieved in a reducing perimeter of the concerned public sector - a supplementary reason for sharing a solid foresight among surveys, and with their partners and clients. 
EGS wishes to thank all the contributors to this Report. In particular Claudia Delfini, who was responsible for

the overall coordination, Woody Hunter, Patrick Wall, the Expert Groups Chairpersons and all the authors of the various different sections.

This EuroGeoSurveys Annual Report is a publication of:

EuroGeoSurveys, the Geological Surveys of Europe

36-38, Rue Joseph II - 1000 Brussels (Belgium)

Tel. : +32.2.888.75.53 - Fax: +32.2.503.50.25

info@eurogeosurveys.org
Www.eurogeosurveys.org

www.geology.eu

Design \& production: www.tango-grafix.be 